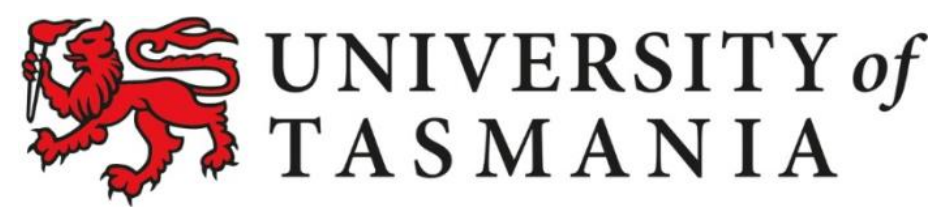

Intersections of Indigenous Knowledge and Place-Based

Education: Possibilities for New Visions of Sustainability Education in Uganda

by

Kevin Lubuulwa Kezabu

B.Ed., M.A Lit.

Submitted in fulfilment

of the requirements of the degree of

Doctor of Philosophy

Faculty of Education

University of Tasmania

Launceston

June 2018 


\section{Declaration of Originality}

This thesis contains no material which has been accepted for a degree or diploma by the University or any other institution, except by way of background information and duly acknowledged in the thesis, and to the best of my knowledge and belief it contains no material previously published or written by another person except where due acknowledgement is made in the text or the thesis, nor does the thesis contain any material that infringes copyright.

Signature:

Kevin Lubuulwa Kezabu

Date:

$13 / 06 / 2018$ 


\section{Authority of Access}

This thesis may be made available for loan. Copying and communication of any part of this thesis is prohibited for two years from the date this statement was signed; after the time, limited copying and communication is permitted in accordance with the Copyright Act 1968.

Signature:

Kevin Lubuulwa Kezabu

Date:

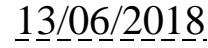




\begin{abstract}
This doctoral research pursued the intersection of Indigenous Knowledge (IK) and place-based education in Ugandan secondary schools. Particular interest was placed on how teachers use place-based education pedagogies to influence their own as well as their learners' reconnection to their communities, cultures and places towards a more sustainable future. Even though the role of community elders ${ }^{1}$ of guardianship and instruction of IK has been weakened by the formal education system (Semali, 1999; Smith \& Sobel, 2010), this research also explored how community elders can contribute to place-based education in their communities. In so doing, this research was guided by three questions:
\end{abstract}

1. How can Indigenous Knowledge, practices and values intersect with place-based education in Ugandan secondary schools?

2. How can teachers use place-based education pedagogies to influence their learners to reconnect to their community/culture and places in Ugandan secondary schools?

3. How can community elders contribute to place-based education in their communities in Uganda?

The impetus for this research stemmed from the issue where Uganda's formal education contributes to the people's disconnection from their communities and from their cultures. This is primarily due to the examination driven curriculum; the foreign

\footnotetext{
${ }^{1}$ These are mostly the older members of the community who are also the guardians of IK in the tribes. Currently, they perform or preside over the cultural ceremonies like traditional marriages, installing heirs, and last funeral rites in their clans.
} 
orientation of the formal education system and the subjugation of IK from the curriculum. For example, Uganda is still using the colonial-inherited education system with English as the medium of instruction and assessment. This has left the Indigenous languages on the peripheries of the formal education curriculum with no importance placed on IK. Researchers (see Gruenewald, 2003; Smith \& Sobel, 2010; Thiele, 2013) have found alienation of the people from their cultures and places as one of the leading causes of the profound lack of care for the environment.

This research employed a Participatory Action Research (PAR) methodology which provided the co-participants (i.e. teachers, elders and community members) with the skills to critically recognize disconnection of the people from their cultures and places because of the colonial formal education system. Since PAR is participatory in nature, it enabled me to work with the co-participants in a collaborative and reciprocal way in and through this research project. In this respect, the co-participants were engaged as full members of the research team and the investigation was based directly on their understanding of their own actions and experiences (Marshall, \& Maclntosh, 2007) in the Ugandan formal education setting. Following the planning, action, observation and reflection cycle of PAR, the co-participants planned and utilized three learning activities to integrate IK into the formal education setting. These included learning about the traditional concept of community service; visiting and learning about the sacred places; and learning about the Indigenous plants and their medicinal values. Data collection methods included group discussions, group interviews, sharing of samples of students' work, sharing of co-participants' diary entries and listening to the community elders' personal and historical narratives.

In the analysis of the PAR cycles of this project, several themes and ideas became apparent including transformative practice, collective responsibility, kinship 
with nature, respect of the elders' voices as voices of the land, diversity and pluralism, and creating a more just and inclusive curriculum. The findings revealed that IK, practices and values were embedded with place-based education in Ugandan secondary schools through the co-participants' involvement with the students in the IK learning activities. In addition, the Ugandan teachers' use of place-based education pedagogies influenced learners to reconnect to their community and cultures. This was evident in the teachers' reports, improved class attendance and improved participation during these place-based lessons. Further, these findings revealed that community elders can contribute in a meaningful way to place-based education in their communities. This was achieved though the sharing of their cultural and historical narratives about sacred places with the teachers and students. In addition, the elders attended participating schools and facilitated the teachers' and students' learning about Indigenous plants around the school grounds.

The study found that collaboration between teachers, teachers and community elders, as well as between the schools and the communities is key for successful implementation of place-based education in the Ugandan educational setting. Finally, for place-based education to be successful in the Ugandan formal education system, teachers' participation in the improvement of their own practice as well as the curriculum is vital. 


\section{Dedication}

To the elders, teachers and mothers of the Land

and to those who genuinely uphold the worth of Indigenous Knowledge 


\section{Acknowledgments}

I am grateful to the following:

The Tasmania Graduate Research Scholarship scheme, University of Tasmania

for making this $\mathrm{PhD}$ possible by generously awarding me a full scholarship.

\section{Dr Jennifer McMahon; Prof David Kember and Dr Allen Hill} the best supervisory team any research student would ever wish for.

Thank you for your patience, kindness, and understanding.

My co-participants;

for your dedication and diligence, all in the heart of Bulungi Bwansi

\section{My family;}

Kizito; for your loving patience and encouragement;

Angella, Priscilla, Rita, Gabriella and Victor;

I could never have made it without your unfailing support.

The Faculty of Education staff, librarians, counsellors, international student advisors and fellow graduate students;

Your varied contribution is unforgettable.

Thank you all! 


\section{Preface}

One of the common features of a Participatory Action Research (PAR) project is that it is cyclical in nature. This thesis is therefore structured to follow the common cycles of PAR which are Planning, Action, Observation and Reflection.

Since the study mainly sought the intersection of Indigenous Knowledge (IK) and place-based education in Uganda secondary schools as a way of making the curriculum more inclusive and just to the local communities, the study was therefore positioned in the critical paradigm. Scotland (2012) affirms that the critical paradigm is concerned with issues of social justice and marginalization. PAR is set in the critical paradigm because it provides the participants with the means to "... deliberately set out to contest and reconstitute irrational, unproductive, unjust, alienating ways of interpreting and describing their world" (Kemmis, 2005, p. 282). PAR was the most appropriate approach to this research project because it provided the co-participants (teachers and community elders) with the opportunity to work together to tackle issues of subjugation of their IK from their education system. In this, the participants were dealing with the improvement of a social practice (i.e. education) which was of major concern to them all.

Carr and Kemmis (1986, p. 165-166) give a general definition of Action Research which is also the umbrella of PAR thus:

It can be argued that three conditions are individually necessary and jointly sufficient for action research to be said to exist: firstly, a project takes as its subject-matter a social practice, regarding it as a form of strategic action susceptible of improvement; secondly, the project proceeds through a spiral of cycles of planning, acting, observing and reflecting, with each of these activities being systematically and selfcritically implemented and interrelated; thirdly, the project involves those responsible for the practice in each of the moment of the activity, 
widening participation on the project gradually to include others affected by the practice, and maintaining collaborative control of the process.

PAR presented opportunities for the participants to come up with mechanisms to improve their curriculum as well as reconnect to their places and cultures through the recursive cycles of planning, action, observation and reflection. In coming up with their own mechanisms of improving practice, the participants took control over the process of the research and thereby gained empowerment through PAR. In this way, the participants' ability to create knowledge and practice in their own interests is restored (McArdle \& Reason, 2008). In addition, through PAR, the co-participants strived to restore their fundamental human right of self-determination that had been taken away from them through the colonial education system which denied IK a place in the education curriculum for decades (Reason, 1998).

Although literature on the application of PAR in African educational settings is very limited, many African and Indigenous scholars advocate for research approaches that are just and inclusive. This is on the backdrop that non-participatory, positivistic research approaches are mainly criticized for monopolizing the development and use of knowledge to the disadvantage of the communities in which the research takes place making such research paradigms exploitative, (Reason, 1998). Wane (2000, p. 55) appeals for a kind of research paradigm that "provides space for the 'other' who has been excluded in the knowledge production", because in most African as well as Indigenous cultures, particularly in East Africa-Kenya Wane's homeland and where her research was carried out, "knowledge is socially constructed" (p. 55). This is in line with the participatory characteristic of PAR, (elucidated in chapter four of this thesis) where the participants are involved in mutual inquiry about issues that affect their own communities (Kemmis \& McTaggart, 2005). Further, Castellano (2000, p.26), an 
Indigenous researcher explains that in Aboriginal societies, "Knowledge is validated through collective analysis and consensus building..." in that through numerous village meetings, issues affecting the community's well-being are discussed and resolved. In addition, Dei (2000) who introduces himself as an "African-Canadian male teaching in a Canadian institution of higher learning (p. xi)" explains that, "African epistemologies perceive knowledge as something that is accumulated by observing and experiencing the social and natural world (p. 79)." These scholars, and many others presented in the discussions of Parts $\mathrm{B}$ and $\mathrm{C}$ of the thesis, highlight the fact that PAR which requires the adoption of a critical stance as well as being characterized by recursive cycles of planning, action, observation and reflection; and upon which the structure of this thesis is perceptively constructed, was the most suitable research paradigm for this study.

While the overall structure of this thesis follows the PAR cycles, the internal structure follows the Kiganda Indigenous ways of knowing as shown in Parts B and C of the thesis. This kind of structuring is particularly important as the study explored issues of decolonization and people who have been beaten down and silenced by a colonial education system. The process enabled the co-participants to gain the confidence to tackle their education curriculum issues in their own way. It also enabled them to critically explore other issues relating to their places. Cajete (1994, p. 144) asserts that "Indigenous people everywhere suffer, in varying degrees, from 'cultural schizophrenia"" because they have to constantly grapple with a foreign education system as well as try to make sense of their worlds in their own Indigenous ways. Many scholars argue that this is very disadvantageous to the mental development of the Indigenous people as well as damaging to their self-identity (Abdi, 2013; Semali 1999; Wa Thiongo, 1994). Scholars argue that IK has the potential to foster empowerment and justice (Semali \& Kincheloe, 2011). In Part B (Action and Observation), the actions 
of the participants are weaved in the spirit of Bulungi Bwansi (for the good of the land). As explained in Chapter Six, this spirit strengthened the bond between the participants and their communities as well as igniting their cultural obligation for the integration of IK into the education curriculum. In Part C (Reflection), the metaphor of the Saagala Agalamidde (I don't want idlers) drumrolls is used to represent my reflections on this research and how it yields to the themes discussed in Chapters 9, 10, and 11 of this section. In addition to the themes that arise in the reflection section, a continuous agency for environmental stewardship as well as reconnection to culture for all the participants is reawakened. This internal structure helps to expose the significant aspects of the study which are IK and place-based education.

In Chapter Two, the lack of African scholars who have conducted research in place-based education in the African educational setting is outlined. Nevertheless, there is a significant closeness between the principles of IK and those of place-based education (Dei, 2000; Semali, 1999). Dei (2000, p.72), defines Indigenousness as "Knowledge consciousness arising locally and in association with long term occupancy of a place." As well, Semali (1999, p. 103) defines the same as "a competency that individuals in a community have acquired and developed over time... and the attitudes of people toward their own lives and the social and physical environment." These definitions depict IK as rooted in the local, and also that it has developed out of the local peoples' long-term, genuine interactions with their natural environments. On the other hand, place-based education is concerned with the integration of the local into the education experiences of the learners. Place-based education has been defined as "learning that is rooted in the local-the unique history, environment, culture, economy, literature, and art of a particular place" (Smith \& Sobel, 2010 p. 328). The main principle of place-based education is taking learning experiences outside the school into 
the local communities and thereby making the students' learning more relevant to the communities where they belong (Gruenewald, 2003a). The fact that the Ugandan people's (Indigenous Africans) education system has been subjugating their IK and imposing on them the Western ways of thinking takes the local out of the education experiences (Abdi, 2005; Semali, 1999; Wane 2000).

The intersection of these two concepts (IK and place-based education) in this study emerge through the three major themes that guide the inner PAR action cycles very prominently depicted in Part B and these were: bringing the community into the classroom; bringing the classroom into the community; and bringing the community into the curriculum. The process of integration of IK into the curriculum was also the way that the participants implemented place-based education in the Ugandan formal education setting. Below is the outline of the overall structure of the thesis.

The 'Planning' section is first and outlines planning on the macro level bringing to the fore the impetus for the study. Next, the 'Action and Observation' section shows how the plan was implemented highlighting the strengths and challenges of PAR. The third section, 'Reflection', takes on the metaphor of the Saagala Agalamidde (I don't want Idlers) drumrolls to reflect on the actions of the co-participants and the effects these actions had on the project. The Saagala Agalamidde drumrolls, according to the elders' historical narratives were used to summon the people to Bulungi Bwansi (for the good of the land) activities in their communities during the precolonial times. Since colonial times, these drums have been silent and so has the communal spirit of Bulungi Bwansi in the region. This metaphor demonstrates how the participants worked together to reawaken the sleeping drums as well as the spirit of Bulungi Bwansi in the participating schools and communities. 
Part A: Planning consists of four chapters, which provide the situational, scholarly and methodological contexts of this research project. Chapter One lays the foundation for my motivation for a $\mathrm{PhD}$ in Environmental Education. In this chapter, I narrate how I develop critical awareness of the environmental situation in my country. Chapter Two clarifies the context of this research by explaining the environmental as well as the educational situations in Uganda. Chapter Three lays the literary background to how the Ugandan people relate to their places. This chapter maps the trend of the people's relationships to their lands and natural environment from the precolonial to the post-colonial times. Chapter Four introduces the methodology utilized in carrying out this research. This chapter also explains the suitability of PAR to the aims of this research and to the Ugandan environmental education context.

Part B: Action and Observation consists of four chapters which describe the actions of the participants and provide the detailed methodological procedure of the research project. This section also contains mine and the participants' observations of the action. In addition, there are also reflections-in-action on the twists and turns in the action. Chapter Five recounts the process of the project in relation to the character of PAR and the uniqueness of the Ugandan education context. This chapter also introduces the pragmatics of the actions that the participants took in their integration of IK into the Ugandan formal education setting. Chapter Six reports the first action that the participants took in their integration of IK in the Ugandan formal education curriculum. This involved the formation of the Bulungi Bwansi clubs in the participating schools in which the participants took students out to the community to carry out community service activities. Chapter Seven reports the second action that the participants took in the integration of IK in the Ugandan formal education curriculum. This involved the participants taking students out to Ssezibwa falls, a sacred place, to learn about sacred 
places and listen to narratives regarding this place. Chapter Eight reports the third action that the participants took in the integration of IK into the Ugandan formal education curriculum. This involved participants taking students out to the school grounds to learn about the Indigenous plants and the plants' medicinal values. Even though they are numbered progressively, these actions took place concurrently.

Part C: Reflection consists of four chapters that present my reflection on the actions that the participants took in their integration of IK in the Ugandan formal education curriculum and their practice of place-based education in the schools. Significantly, this section is presented in the form of a metaphor of the traditional Kiganda Saagala Agalamidde (I don't want Idlers) drumrolls. These historical drumrolls were used during the precolonial times to summon people to community service. This metaphor is appropriate because it reflects the spirit of community altruistic service that highlights the co-participants' motivation for this project, as well as the activities that the co-participants involved their students into. Chapter Nine presents my reflections on the participants' endeavours to bring the community into the classroom as a way of integrating IK into the formal education curriculum. Chapter Ten presents my reflections on the participants' endeavours to bring the classroom into the community as a way of integrating IK into the formal Ugandan education curriculum. Chapter Eleven presents my reflections on the participants' endeavours to bring the community into the curriculum as a way of integrating IK into the formal Ugandan education curriculum. Chapter Twelve presents my concluding thoughts on this research project and projects a picture of the future possibilities of the integration of IK and place-based education in Ugandan schools. 


\section{TABLE OF CONTENTS}

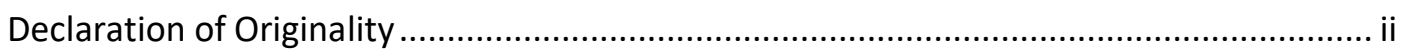

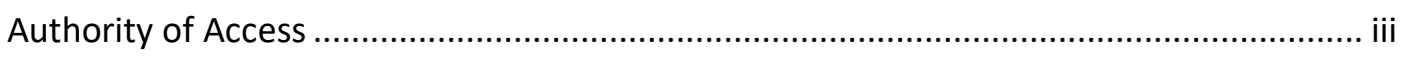

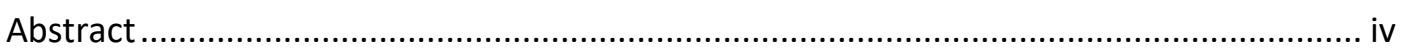

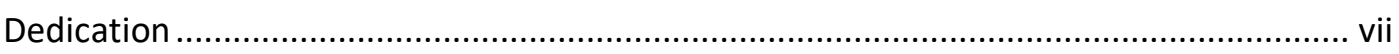

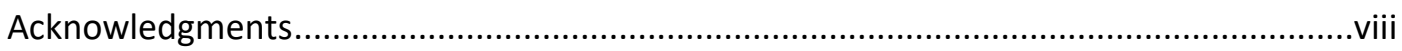

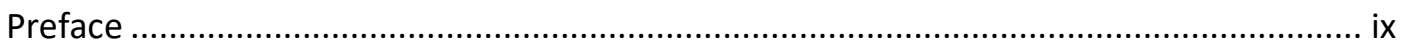

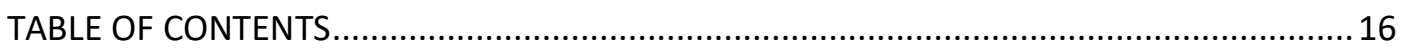

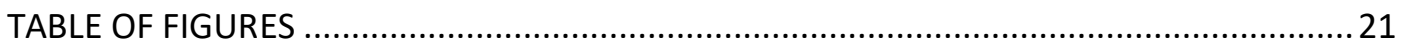

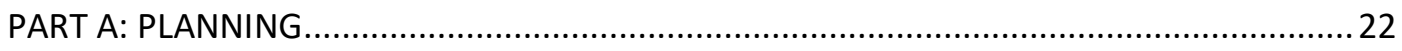

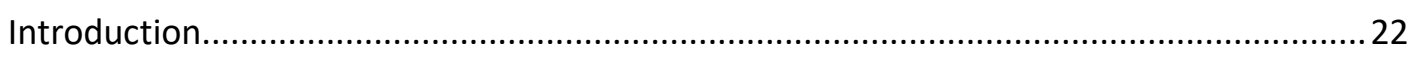

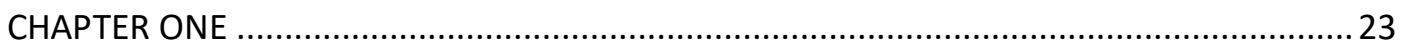

THE JOURNEY TO MY ENVIRONMENTAL CONSCIOUSNESS ...............................................2

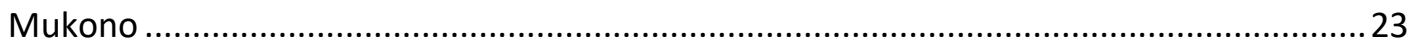

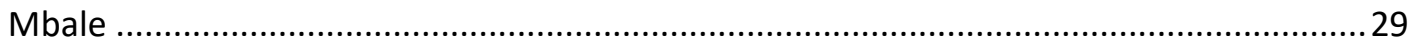

Arua

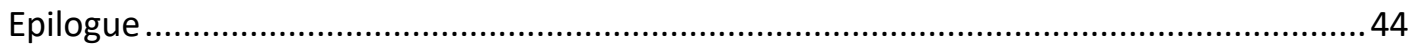

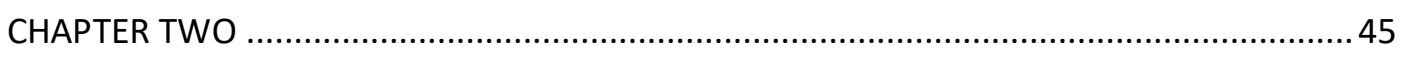

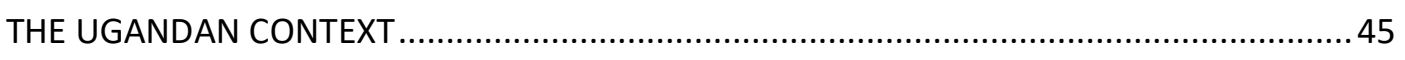

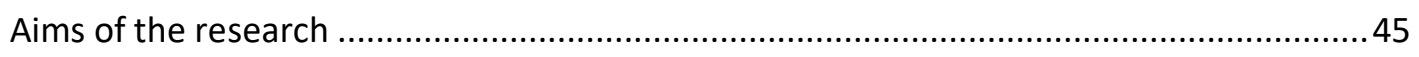

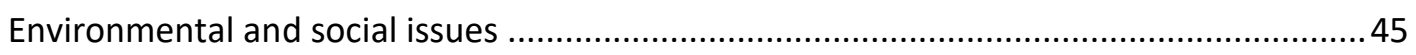

Formal education and disconnection from place .......................................................... 49

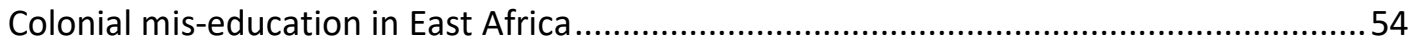

Intersection of place-based education and Indigenous Knowledge..................................59

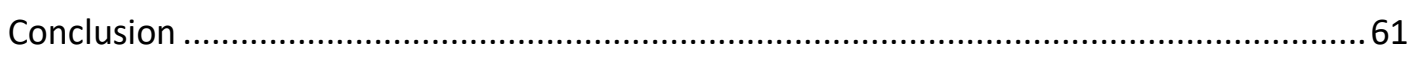

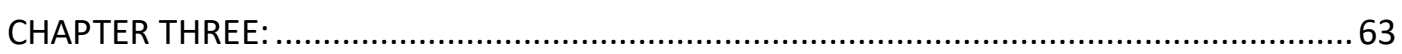

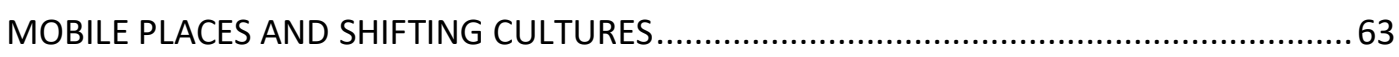


Introduction 63

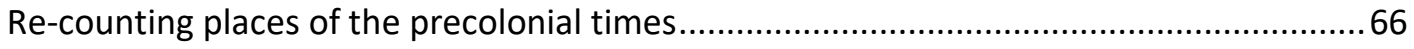

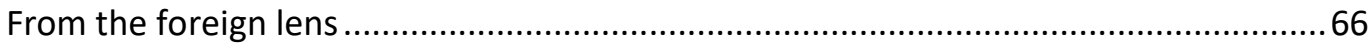

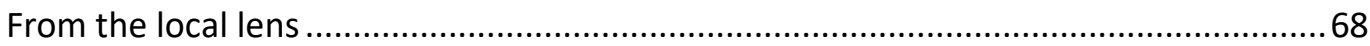

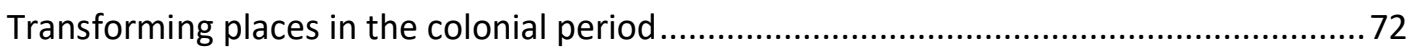

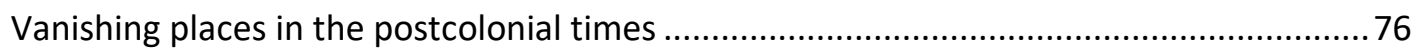

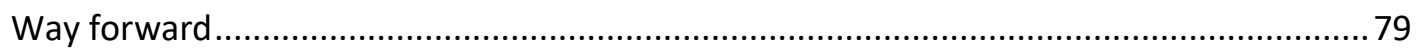

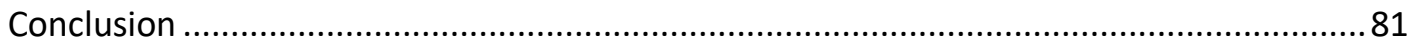

CHAPTER FOUR:

TOWARDS A PARTICIPATORY ACTION RESEARCH INQUIRY .......................................... 82

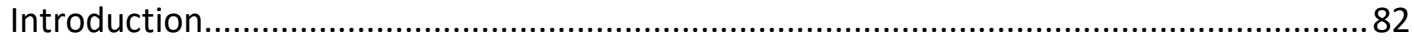

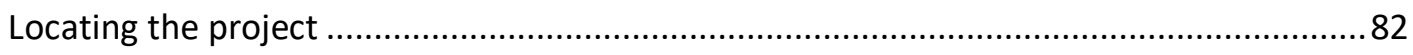

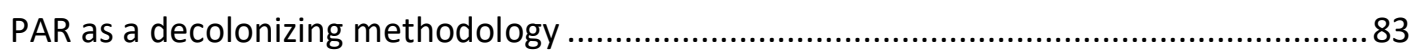

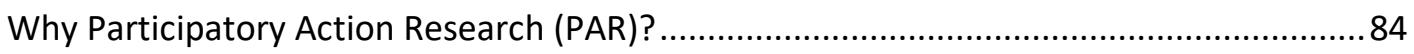

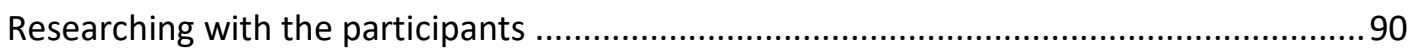

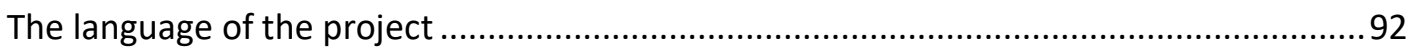

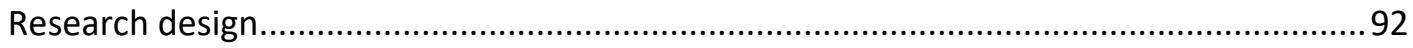

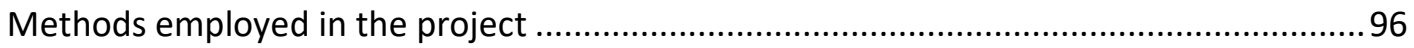

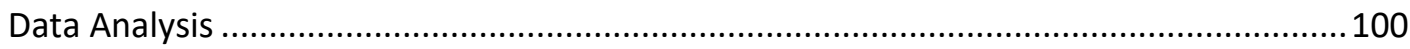

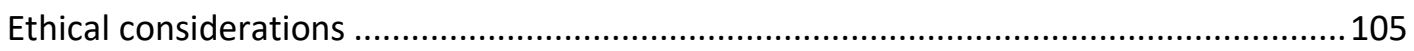

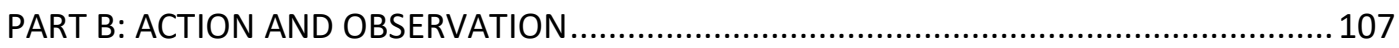

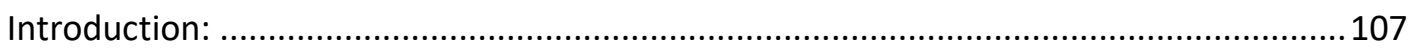

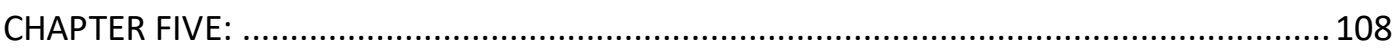

THE MESSINESS OF PARTICIPATORY ACTION RESEARCH …....................................... 108

The background to the enthusiasm of the researcher ...................................................108

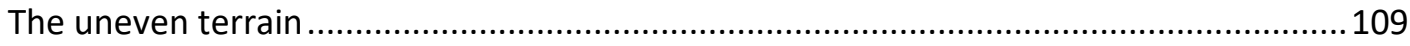

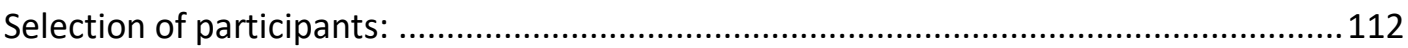


The participant teachers

The participant community elders

The elders' areas of interest in this project

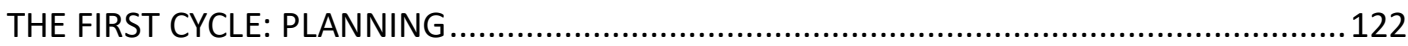

The first Professional Learning Development (PLD) workshop .................................122

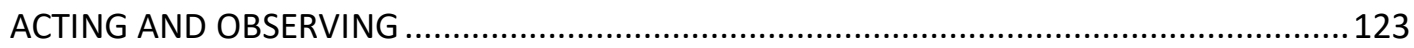

Where is everybody?

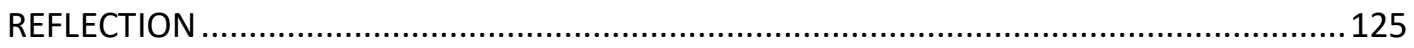

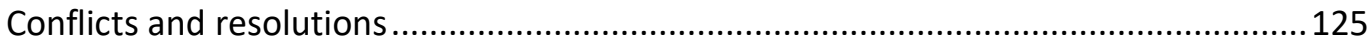

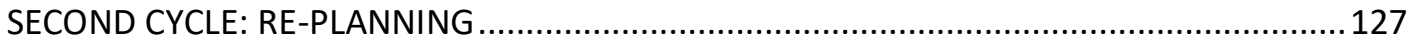

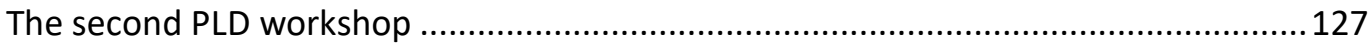

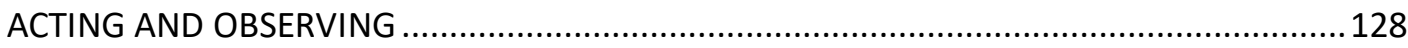

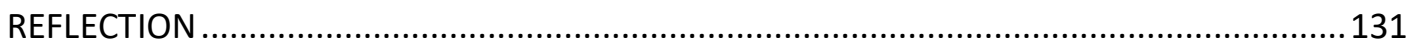

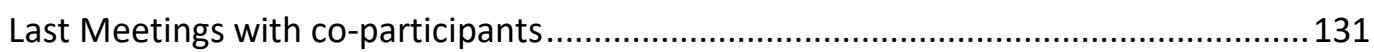

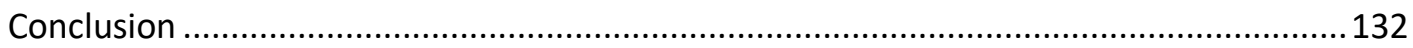

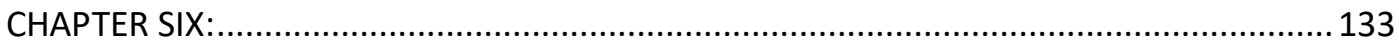

BULUNGI BWANSI AND ELIMINATE CHARCOAL COMMUNITY PROJECT ...........................133

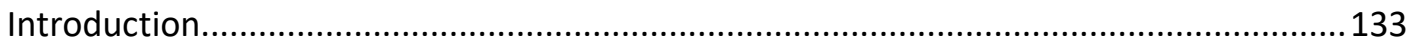

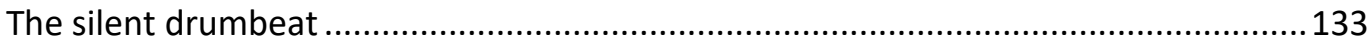

CYCLE ONE- BRINGING THE COMMUNITY INTO THE CLASSROOM ................................134

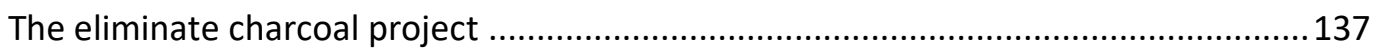

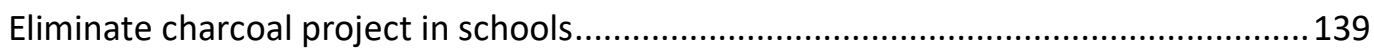

Group reflections on lessons about Bulungi Bwansi through group interviews ...........143

CYCLE TWO: BRINGING THE CLASSROOM INTO THE COMMUNITY...............................147

Bulungi Bwansi/ eliminate charcoal project in the communities ...............................147

Group reflection about the Bulungi Bwansi activities in the community through group

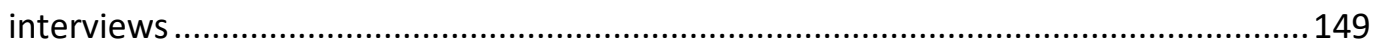

CYCLE THREE: BRINGING THE COMMUNITY INTO THE CURRICULUM AND PEDAGOGY ...152 
Conclusion 156

CHAPTER SEVEN 157

OBUWANGWA NE NNONO /RE-DISCOVERY OF THE SACRED PLACES 157

CYCLE ONE: BRINGING THE COMMUNITY INTO THE CLASSROOM ................................160

CYCLE TWO: BRINGING THE CLASSROOM INTO THE COMMUNITY.................................. 162

Group reflections about excursions through group interview 168

CYCLE THREE: BRINGING THE COMMUNITY INTO THE CURRICULUM AND PEDAGOGICAL

PRACTICE

Conclusion 181

CHAPTER EIGHT 182

OBUWANGWA NE NNONO/RE-DISCOVERY OF THE KIGANDA INDIGENOUS FOODS AND PLANT VALUES

Introduction: 182

CYCLE ONE: BRINGING THE COMMUNITY INTO THE CLASSROOM 184

Group reflection about the lessons on plants through group interviews 190

CYCLE THREE: BRINGING THE COMMUNITY INTO THE CURRICULUM AND PEDAGOGY...199

Conclusion 201

PART C: REFLECTION 202

Introduction 202

CHAPTER NINE 203

THE RE-AWAKENING OF THE SAAGALA AGALAMIDDE DRUMROLLS 203

Conscientization, resistance and transformative practice. 203

Communal solidarity 205

Collective responsibility 208

Conclusion 211

CHAPTER TEN . 212

THE RESOUNDING SAAGALA AGALAMIDDE DRUMROLLS 212

Kinship with nature 212 
A culture of mutuality ......

Elders as voices of the land

Conclusion

CHAPTER ELEVEN

Diversity and pluralism.

Creating a more just and inclusive curriculum

Conclusion

CHAPTER TWELVE

CONCLUSION

Revisiting the aims of this study

Way forward for place-based education in Uganda

Implications for future research

Concluding reflections about the research journey

REFERENCES

Appendix A: Ethics approval.

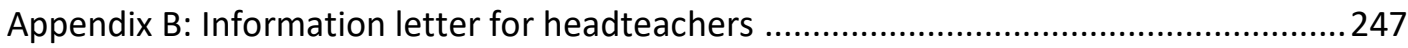

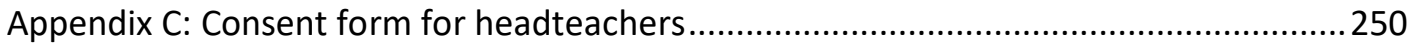

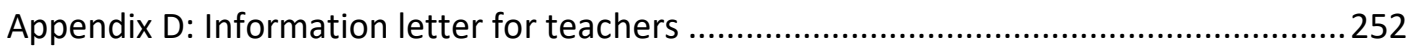

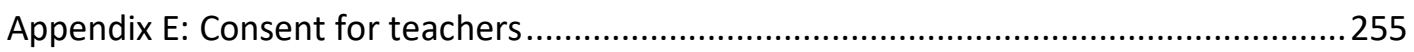

Appendix F: Information letter for community elders in Luganda .................................257

Appendix G: Information letter for community elders in English.................................259

Appendix H: Consent form for community elders in Luganda.......................................262

Appendix I: Consent form for community elders in English .........................................263

Appendix J : Evaluation survey for the first PLD workshop .............................................2. 265

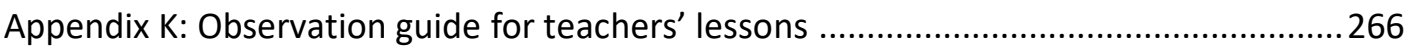


Appendix L: Interview guide for discussions/reflections after IK lessons.

Appendix M: Interview guide for the weekly Nyama Kyoma teachers' meetings ...... 268

Appendix N: Interview guide for first group interview with community elders...... 269

Appendix O: Interview guide for the last group interview with community elders

270

\section{TABLE OF FIGURES}

Figure 1: The phases/stages of the research and the methods that were used as part of each phase.

Figure 2: An overview of the teachers' attitudes towards the first PLD workshop and the project in general as depicted in the survey data.

Figure 3: A snapshot of the action cycle of the project 


\section{PART A: PLANNING}

\section{Introduction}

This section presents the background of this research. The section is made up of four chapters; One, two, three and four which provide the situational, scholarly, and methodological contexts for this doctoral research. In this section, my critical awareness of the environmental situation of my home country leading the motivation for a $\mathrm{PhD}$ in environmental education is shown. Still this section reveals the environmental as well as the educational contexts of Uganda and as such lays the background to the research project. The background to the Ugandan people's relationship to their land is mapped through the precolonial, colonial to the postcolonial periods of the country's history. Lastly, this section explains the relevance of the participatory action research paradigm to this research project. 
CHAPTER ONE:

THE JOURNEY TO MY ENVIRONMENTAL CONSCIOUSNESS

\section{Mukono}

It all started early 2011 with the mysterious death of our neighbour's husband. It was about 7 o'clock in the morning when I heard a scream from next house. I ran to the bedroom to ask if my husband had heard the scream and as I was entering the bedroom, another scream rent the air. My husband was already out of bed.

"What could it be?" We heard a loud bang on the front door and I ran to open it. Our neighbour's eldest daughter entered. This girl was our neighbour's first of four children. She had just completed university and was looking for a job. She had always found comfort in our home with the children.

"What is it? Who is screaming?" my husband asked. Without a reply, she headed straight into the living room and sat without saying so much as a word. Obviously, she was too shaken to speak. As I followed her to the chair, my husband went outside.

I could hear voices outside and knew that people were starting to gather responding to the scream. In Uganda, it is common knowledge that it is quite ineffective to call 999 (the emergence police number) immediately when you get a problem. Police always come too late. The best thing for someone to do is scream very loudly and the people will come to your aid and then you can report to the police afterwards. The people always respond immediately at whatever time one screams.

"Father is dead," she whispered. "They killed him; they killed him." She sobbed. I did not know what to do so I put my arms around her and held her. 
"Who killed him?” I asked.

“The police did!” I was shocked at that revelation. The Uganda police are a very unpopular group of people. Because the ruling party is trying hard to silence the opposition party politicians, the police have acquired huge tanks of tear gas and every day in the media, stories of the opposition politicians being tortured by the police are aired. There are also incidents of accidental spraying of the tear gas in schools and hospitals because the opposition politicians have held a rally next to one of these places. Incidents of accidental shootings of innocent people or children by police, as the police tried to disperse opposition rallies, are also common media reports. So, when this girl accused the police of murdering her father, I was shocked that it could happen to one of us. This was starting to happen very close to home so to speak. However, my neighbour was not a politician so why did the police shoot him? Under what circumstances did this happen? All these questions were swirling around in my head as I comforted the girl.

When I came out of the house, there were many people and I recognised most of them to be close family and friends of my neighbours. Due to the number of people, it was impossible to find the mother of this girl and offer sympathies. It was soon 8 o'clock and I had to leave for work. I asked the girl if she wanted to stay at our place with my children.

At break time, the staff room was abuzz with news of a riot in $\mathrm{Mukono}^{2}$ town and that whoever was planning to go to town should not take the risk. There was tear gas and shootings by the police happening. It seemed that the reason for this riot was

\footnotetext{
${ }^{2}$ Mukono is one of the major towns in Uganda and is also the location of the main campus of the University where I worked. I also lived in this town.
} 
that a timber merchant had been shot dead by the National Forest Authority (NFA) police early that morning and the people were enraged about it. It was at this point that I remembered that my neighbour's husband had been a timber merchant.

This man had five wives and our neighbour was wife number three. I did not know this man very well because he used to only come to our neighbour, his wife, on Friday nights and would always leave early every Saturday morning. We had met once or twice outside the house but I would not really recognise him.

I called home to find out how the children were and what was happening nextdoor. They said that there were police everywhere. Even though the children and the daughter of the man that was killed were all inside the house, they were still feeling the irritation of the teargas. I instructed my eldest daughter to lock the door, to keep all the children inside and for all of them to drink lots of water. I then called my husband to let him know what was happening in Mukono. But he already knew the entire story and said he was on his way back from Kampala ${ }^{3}$.

When my husband reached Mukono, he saw how the anti-riot police had cut off the roads into the town centre due to the riot. Therefore, he came straight to the University to get me. He then told me the details surrounding the death of our neighbour's husband.

Mukono borders on Mabira forest, the biggest natural forest reserve in Uganda. The Ugandan government had recently passed a law against unlawful cutting of trees in the forest. But the timber trade is a very lucrative business. People who deal in timber are doing very well and are employing lots of locals. According to some local people,

\footnotetext{
${ }^{3}$ Kampala is the capital city of Uganda and it was where my husband worked.
} 
it was alleged that the licence for the cutting of trees had been given to a few selective government officials and to some individuals who came from a different part of the country, leaving the locals with no option but to plunder the forest at night illegally as a means of generating an income.

Timber merchants are very shrewd people. They bribe the area police officials on duty and then go to the forest during the night. The National Forest Authority (NFA) has its own police patrol which works closely with the local area police. They do not, however, alert the local area police when they are coming. They abruptly come and then ask the local area police to go with them to the forest. They also have informants from the local communities that tip them off when timber thieves go to the forests at night. The deal that the timber thieves make with the area police officials is in the instance when the NFA police patrol comes unannounced, the local area police can misdirect them allowing the timber thieves enough time to escape.

On the fateful night that my neighbour's husband was murdered, his son was one of three men who illegally entered the forest to cut the timber for the family business. Timber thieves have very fast motor machines to cut the trees. They also have very strong trucks which the locals call 'magulu kkumi' (ten legs) to carry the timber. On their way back after cutting the timber, one of the men got a phone call from the corrupt area police official, that the NFA police patrol were on their way. So, they had to quickly leave. They had no idea what direction the NFA police were coming in so they took a road hoping they would not run into them. Unfortunately, the NFA police found them. When they realised the police were onto them, the son of the man who was murdered rang him for back up. Since the police are aware that the timber thieves are most of the time armed, they have a directive to shoot them. My neighbour's husband went to help his son. He attempted to forcefully drive between the timber truck and the 
police patrol vehicle to interrupt the chase providing the opportunity for the timber thieves (one of which was his son) to escape. By law, the police are not supposed to shoot at a civilian car which is not carrying timber. Our neighbour's husband successfully got between the timber truck which was driven by his son and the police patrol car. When the chase was getting closer to Mukono town, the police must have become frustrated by the husband of our neighbour's obstructing car. So, they started to shoot at him from the back. When they started shooting, he pulled up by the side of the road. However, he had been shot in the head and in the chest and killed. The police never got to the timber truck because it obviously made it out, but my neighbour's husband died at the wheel of his car by the road side.

The industrial area in Mukono town is the place where the timber merchants operate and police cannot get to it. It is full of strong able bodied, young men who at any slight provocation can use anything to attack the police. In the past, these young timber merchants have burnt down police vehicles, killing two policemen. However, the timber community was enraged from the death of the merchant and a riot ensued. They burnt tyres in the middle of the roads, hit any passing cars with stones, and threw bottles at the police. They demanded that the Inspector General of Police must come to Mukono as police had shot a civilian and the responsible policemen must be charged. As a result of this incident, Mukono was in the media limelight for the entire week. The Inspector General of Police never came and the police in question were never arrested. Six years later and the police are still 'investigating' the case.

It was close to $7.00 \mathrm{pm}$ when we finally ventured out of the safety of the University. The town was a mess. There were still burning tyres and huge stones in the middle of the roads and tear gas still filled the air. Shops in the town centre were all closed. The police were everywhere busily trying to clear the roads. Police were also 
arresting 'suspects'. This was worrying as we were afraid that the police would take us as suspects. Hooligans still lined the street throwing stones and bottles. It took several days after the incident before the community calmed down and life returned to normal. Despite the death of our neighbour's husband, his family continued in the timber business plundering the forest in the night and selling the timber during day.

After this incident, my eyes were opened to the plight of the forests in Uganda. I used to travel through Mabira forest on my way to Kamuli, which was my parents' home town. I remember vividly how when the car travelled through the Mabira forest, there was a beautiful long stretch of forest. The air was always cool and clear. I was always entertained by the spectacular sights of monkeys and other animals jumping among the high branches of the trees. But of late, there have been noticeable changes in the forest. The air is no longer as cool as it was five years ago and there are hardly any animals noticeable in the trees. This is mainly because the forest has been badly depleted. When the timber traders raid the forest, they cut the trees indiscriminately and, in the process, the falling trees also damage other trees. Consequently, there is a lot of damage to the forest.

In the August of 2011, it hit the news that the President had decided to sell the Mabira forest to the Indian sugar cane growers who already owned a big sugar plant in the country. The people of Mukono protested with many criticising the move. Many people strongly expressed their displeasure and shock at the sale. For me, personally, I wondered how an educated man could think that the destruction of that forest for profits would be beneficial to the people of Mukono. During this time, I found my heart conflicted between my disapproval of the President's move and the local people who strongly supported the timber merchants whose mission was to cut down as many trees as possible for their illegal timber business. I wondered who was at greater fault. The 
timber thieves on a cutting spree or the frustrated President who would give the forest to Indian sugarcane farmers for an income.

That forest borders the Lake Victoria basin. Because of this, we have the largest natural fresh water lake in the whole of Africa as well as numerous rivers that flow both into and out of the basin. Our Nile, the source of which is in the same region, shares a life with this same forest. The destruction of the forest would lower the water levels of both Lake Victoria and the Nile, impacting not only Uganda but the effects would definitely be felt up to Egypt. Consequently, many local communities that rely directly on the forest for firewood, medicinal plants etc. would be affected. So, would the wildlife and other creatures (i.e. insects, birds and animals) that live in the forest. I found myself wondering if our President had considered the environmental implications of his decision. Sometime after, the parliament successfully refuted the President's selling of the forest. This was a huge relief. However, in early 2012, the President raised the same issue and I realised that it was only going to be a matter of time before the parliament would surrender to the fight and the forest would be destroyed.

\section{Mbale}

Early in 2012, the Department of Languages and Literature at the University where I worked organised a training workshop on teaching methods for tutors to be held at each of the four campuses across the country. As a coordinator for Writing and Study Skills at the University, I was able to participate in these workshops. This University has four campuses across the country. One campus is in Mbale in the Eastern part of the country; one in Arua, in the North-West of the country; one in Kabaale, in the extreme South-West of the country and one in Kampala in the capital city of the 
country. The main campus is in Mukono, in the central region of the country, and this is where I work. I was elated at the opportunity to visit the other campuses.

The department land cruiser came for me at 5:15 one Sunday morning. In the front sat our Head of Department (HOD) who accompanied the driver, Musa. The rest of us; Peace, our new English Language Fellow ${ }^{4}$ (ELF), Jona, a senior colleague and I sat in the back seats. We travelled on a Sunday so we could start the training on Monday morning. As we drove out of Mukono, there was a slight drizzle and our HOD cautioned Musa to drive slowly and to the conditions. In Lugazi, a small town just outside of Mukono, there is a roadside market selling roast sweet bananas, roast chicken, water, Pepsi cola and other soft drinks. Travellers usually grab their breakfast, lunch or dinner at this place. The market is situated alongside the highway and the drivers pull up by the roadside for a few minutes. The sellers run towards the vehicles and display the goods through the car windows for the passengers to purchase.

As we drove by this market, our driver slowed down because there was a taxi ${ }^{5}$ that was just pulling back onto the road after making some purchases. Some sellers were still running after it, obviously still completing transactions. As the taxi was pulling out onto the road, a plastic bottle and a bundle of polythene and other rubbish hit the bonnet of our car before hitting the ground. Obviously, one of the passengers was done with his breakfast and simply disposed of it out of the taxi window. I knew that this was the habitual Ugandan way of waste disposal but it was confronting to see it firsthand.

\footnotetext{
${ }^{4}$ This is a program run by the American Department of Education where they send English Language teachers (the ELFs), to different regions of the world to aid the learning of English and teach about the American culture.

${ }^{5}$ This is the common local public transportation in Uganda. It is very different from the taxis in Australia. These vans carry fourteen passengers for a fee.
} 
I expressed shock when this occurred but Peace said, "this is how it is done here and everywhere for that matter, including Kampala." Then she added, "I hate Kampala because of all the trash. The smell is horrible when it rains. Mukono is much better and fresher." Peace's comment was met with silence.

I ruminated on Kampala for a moment. The waste disposal dilemma of our capital city is terrible. Kampala is highly populated but because there is no proper law enforcement policy and management of waste, heavy rains usually triggered cholera and typhoid outbreaks in the lower parts of the city. In addition, our city was not planned well and as a result, the drainage system is not good. People are almost completely ignorant of proper waste disposal measures and or the benefits of disposing waste properly. This ignorance starts in childhood as school do not properly educate children about waste disposal. This lack of awareness is evident by the amount of litter in classrooms and in most school compounds. The private schools have hired people to do the cleaning instead of training the pupils to take responsibility of their waste. As a result, everyone grows up not knowing how or why to dispose of their waste responsibly.

As part of our commute, we had to drive through Mabira forest to Jinja where we had breakfast at the beautiful Nile Hotel. It overlooks the graceful Nile which runs through the lush vegetation. We found many international tourists there when we arrived obviously enjoying the view and the freshness. At that moment, I realised that is the only place in the country where you could find so many foreigners in such big numbers.

The remainder of the journey took about five hours. We stopped several times so Peace could take pictures of the rural Ugandan landscape and for the first time I was 
able to see my land and people through a set of different eyes. Some of the things that stood out on that trip was a woman riding a bicycle with a baby strapped to her back, a set of decorated huts and the neat maize gardens. I found myself taking pride in the uniqueness of this land and people.

By one o'clock, we were checking into the Mt. Elgon hotel in Mbale town. The hotel derived its name from the looming mountain which is the pride of the place and a great tourist attraction. The hotel was situated on Moni road. I inquired about the meaning of Moni and our HOD narrated that in the sixties, there was a white settler who used to jog every morning along that road. Whenever he passed the local people, he would call out, "Morning! Morning!" And the people, who never understood his language, named the road Moni. The wife of our HOD was waiting for us at the hotel when we arrived. I later learnt that she was the deputy head teacher of Nabumali High school and that she resided on the school premises. This lady invited us to their home at the school at 5:00 pm that evening. We agreed that Musa would come for us at that time as he was staying at a different place.

At five that evening, when we exited the hotel to the parking lot where Musa was waiting, we were greeted with something really special. On the slopes of the mountain, in the distance, the golden setting sun fell on the sparkling falls of a river that disappeared in the vegetation on the mountainside. It was magical. The few times that I have been abroad, I have never encountered a more beautiful sunset like the one we just had the pleasure of witnessing.

Off we went, and of course Musa drove like a mad man since our HOD was not in the car. The school we were going to was located at the foot of Mountain Elgon. But as we started to ascend one of the dusty roads, the sky suddenly became dark and no 
longer serene. In a matter of minutes, we witnessed the true African thunderstorm that Rubadiri ably describes in his famous poem ${ }^{6}$. The road wound through thick vegetation with houses and gardens dotted here and there. In the storm, the trees bent nearly in half towards the direction that the wind furiously took them. I was fearful that a tree or branch might fall on our vehicle or across the road. Musa did not need to be told to slow down. It was automatic given the severe weather conditions.

At one of the last bends before we arrived at the school, we found a huge tree that had been uprooted by the storm lying across the road. Fortunately, Musa knew an alternate route but it required us to back track. When we finally arrived, we went around to the back gate of the school and by this time the storm had passed. Ugandan storms are short but ferocious and never last much longer than 40 minutes.

Our HOD's family was waiting for us at the school and they had prepared lots of delicious local dishes in our honour. It was warm and well-lit inside the house in comparison to the dark, cold weather outside. Peace commented about the severe storm that we had experienced during our commute and the hostess explained how storms were a common occurrence in the area. She explained that as a result, mudslides could occur high up on the mountain slopes. Deep cracks that run from top to the bottom of the mountain first develop. Over time, they lead to mudslides. I remembered vividly the media coverage of the most recent mudslide on this same mountain. It had been reported that a lot of rains coupled with the deforestation on the mountain slopes loosened the soils leading to the disastrous mudslide. The mud ran down the mountain slopes covering entire homes, schools and hospitals which resulted in the deaths of many. Many people were also displaced. Even though the government attempts to

\footnotetext{
${ }^{6}$ An African Thunderstorm
} 
relocate people from areas where land has developed cracks, some refuse to leave their precious homes.

“Could we visit the area where a mudslide has occurred, please?” I asked.

"If we get time while we are here, we can" answered our HOD.

I was so eager to visit the place that had been affected by mudslides that after the sumptuous meal, Peace reminded the HOD whether the following day we could go. Our HOD respected Peace (I think because she is a visitor) and was obliging in her request. I couldn't contain my excitement and since I was sitting next to Peace, I gave her hand a gentle squeeze. She squeezed back.

I worked very hard at the training the next day. I presented my paper, collaborated with the teachers and assisted many teachers and tutors with basic computer skills. The training that day was a great success. At four o'clock, the course ended and our HOD announced that he had located a guide to escort us to the areas and communities prone to mudslides on the mountain slopes. Our HOD decided he would stay with his family and not attend. The guide was a pleasant young man with a Lumasaaba $^{7}$ accent. He advised that our clothes and shoes were unsuitable for the task. We went back to the hotel to change to clothes and shoes more suitable for the mountain trek and then set off. While I did not have the right shoes or clothes for the task, I instead wore comfortable ones.

For the next hour, we drove up a winding mountain road. After an hour or so, our guide stopped the vehicle leaving it at a police post. Then the trek started. Musa refused to leave the car. He preferred to sit on a bench in front of the little mud and

\footnotetext{
${ }^{7}$ The local language of the Bamasaaba, the people that live on the slopes of Mountain Elgon.
} 
wattle police post and talk with the pleasant police woman. The air was humid and the ground was damp. But every plant that grew in the area looked extremely healthy and vibrant. Even though we have the same plants back in Mukono, I was unable to recognise them at first sight because of the difference in size (i.e. larger) and dark green foliage. The size of the flowers surprised me too. Peace was constantly clicking her camera, taking pictures of the thick banana plantations, the birds, the monkeys and the folding mountain slopes.

Even though beauty surrounded us, my mind was on the mudslides and the cracks on the mountain side. Our guide provided us with poles and instructed us to use them as supports as we walked. He walked just a few feet ahead of us and followed a winding path that went through the thick vegetation. We crossed a wooden bridge over a small river that ran down the mountain. It was a somewhat tiresome walk because it was mostly uphill. During our walk, I noticed tree stumps in a maize and bean garden. Our guide explained that the people had to cut down the trees to get enough land to grow their crops. He explained that more and more people were resettling in new different places on the mountain slopes because their former pieces of land had become dangerous.

We then reached the first crack. It looked like a narrow zigzag ditch that ran downhill. Its width must have been about two feet or so. Although narrow, it seemed to be quite deep. Our guide explained that the extent of the crack was something that had occurred over some time and did not just miraculously occur. This could offer some explanation as to why the people ignored the crack until it was too late. Our guide explained that some of the cracks were wider and even deeper than the one we stood in front of. They were very dangerous especially to people who walked after dark. 
We set off on the trek again and the path wound around to a thick banana plantation. Just like any other vegetation in the area, they were also very green and healthy. I noticed that this plantation grew a different type of banana to what we see in Mukono. These bananas were shorter with bigger stems. Although they were thick, they were neatly weeded and pruned.

Out of nowhere, we came across a homestead. There were three grass thatched huts which surrounded a small tin roofed house. The homestead was in the middle of the banana plantation. I also noticed that several banana plants had long poles to support the heavy bunches of bananas that were so large that they almost reached the ground. On the veranda of the house, sat an old woman peeling green bananas for dinner. Our guide called her by name and introduced us in the local language ${ }^{8}$. She was very friendly and invited us in. Our guide politely refused, preferring for us to sit with her outside on the mat. She inquired about where we came from which was relayed through our guide-turned-interpreter. When she learnt that I was a Muganda, she revealed that she spoke Luganda ${ }^{9}$ as she had once lived in Buganda with her late husband. Given we both spoke Luganda, I asked her why she still lives here even though there is a threat of the mud slides.

In answer to my question, she narrated the legend of Mundu and Sera, the father and mother of the Bamasaaba ${ }^{10}$ and how they came to live on the slopes of Masaaba ${ }^{11}$.

\footnotetext{
8 Sometimes 'mother tongue' is used for the same in this dissertation. These are the Indigenous Ugandan languages and most likely the first languages children are exposed to through own family as well as the local community before they go to school. The local language of an area is an elective subject on the Secondary school curriculum in Uganda.

${ }^{9}$ This is the language of the Baganda; the people of Buganda in the Central region of Uganda. Mukono, where this research was carried out, is in Buganda region.

${ }^{10}$ The people of Masaaba.

${ }^{11}$ Masaaba is the original name of Mt. Elgon before the Colonialists 'discovered' and renamed it.
} 
She explained how God gave the mountain to them and their descendants. I had heard this story narrated by students in my oral literature ${ }^{12}$ classes at the University. However, I had never heard this version where it ended with God warning the people to keep the land pure. She said that the mudslides were a punishment to the people who were contaminating the land. I asked what she meant by that and she explained how all her sons, whose huts surrounded her house, had sold off part of their late father's land to foreigners (foreigners to her meant people from different parts of the country). Her sons then left for the big city. She emphasised that the foreigners contaminated the land as they grew strange crops and cut down the trees. She also said that this place was the home of her people, their land and they could not go anywhere else; they would rather die here in Masaaba land. She had no kind words for the government that was forcing them off their land.

In her broken Luganda, she sounded sad and bitter. I was the interpreter for Peace who listened intently to her narrative. I really liked this old woman's stories and would have wished to stay longer with her. The guide listened intently too throwing in a word here and there to clear up any ambiguity. Peace wished to know whether the old lady would allow her to take some pictures which was granted. As Peace was busy taking pictures, my phone rang and it was Musa. "Time to go," he barked into the phone. Anyhow, it was almost dark and I asked our guide if we could go. We bid the old woman goodbye and left. Our guide led us back through a different path to the

\footnotetext{
12 This is an elective subject on the Ugandan secondary school curriculum. It is taught under the department of Languages and Literature and it is taught by teachers of English language and Literature in English.
} 
police post where we found Musa in the driver's seat ready to leave. With a last wave to the policewoman, we drove off as fast as the bumpy roads would allow.

After our second and final day of training, our HOD's lady was happy to take us through Mbale town to buy some souvenirs. Peace wanted to buy some African fabric that she had seen worn by most women in the area. Musa drove the three of us to the town centre. Our guide knew where the best fabrics were sold. In the eighties, Mbale town was known as the cleanest city in the country. I had never been to Mbale before but I remembered them winning that title distinctly as we were taught so in school.

Therefore, when we arrived, I was very saddened by the sight of all the litter in the streets. There were piles of it on the streets with much of it being polythene and empty plastic water bottles. The importation of bottled water is a recent development in the country. So too is the increased use of polythene bags for everything. These two are already a problem in Kampala and the surrounding towns. In Mukono alone, it is very difficult to garden without first digging up hundreds of buried, un-decomposing polythene bags. However, there seems to be no government or council plans for handling these products at the present.

I looked at the litter choking Mbale. No longer was this little town the cleanest in Uganda. Instead, there were pot holed roads, old colonial buildings that were becoming ruins as well as an abandoned coffee factory. At the end of the shopping trip, I bought a beautiful African shirt for my husband, traditional sandals (made from cow skins) for all four of my children; and a beautiful pair of earrings (made from cow horn) for myself. As I talked about them to my husband on phone that night, I eagerly awaited the Arua expedition. 


\section{Arua}

A fortnight after the Mbale training, we set off for Arua for the remainder of our training. We planned to carry out a similar training and workshop for the tutors and teachers of English Language and Literature from the neighbouring schools. We left Mukono at 5:30 in the morning.

This journey took close to 13 hours. Arua is in the west Nile region of the country. So, we had to go through the Murchison Falls National game park. The main road to Arua town did not go through the game park but our HOD took us via there anyhow knowing it would please us. This was my first time to go to a game park. Peace was also excited at the prospect of the adventure. At the entrance to the park, we sought permission from the office and were subsequently all allowed in free of charge.

Ugandans are not charged at the game parks; but foreign tourists must pay a fee before they can enter. As Ugandans, we did not require an escort unlike foreign tourists. The first set of animals we saw were baboons. There were about 20 baboons on the road. Even when the baboons saw the vehicle, they remained on the side of the road and moved just enough to let our vehicle pass. Peace made a mistake of opening the window to take a picture and about five tsetse flies entered the car through the window. We scrambled for newspapers, handkerchiefs and even bags to beat them out. These flies are attracted to the baboons. I was terrified about the possibilities of what we could contract if we were bitten. Peace shared her insect repellent. We sprayed ourselves as well as the four corners of the vehicle.

The game pack is a real wilderness with the animals in their natural setting. Jona explained that in such a setting, it was survival of the fittest. The trees were short and sparse and the long grass was kind of dry and yellow. The next animals that we came 
across was a herd of buffaloes taking a bath in a dirty pool of water. We also saw elephants with streaks of mud over them. I think the elephants had rolled in the mud as a protection against the tsetse flies and ticks. We also saw a herd of impalas. Peace took lots of pictures. As we continued our journey through the park, there was evidence of wild fires. In such a dry place, a wild fire would spread very fast and cause a lot of harm to the animals.

After a few kilometres, we came to a $\mathrm{V}$ junction and a sign pointing to the right indicated Murchison Falls. The Nile ran through this area as it went on to Sudan. We soon heard the thunderous music of the falls before they could be seen. When we got closer, there was a parking lot and in it there were about three other land cruisers parked with the owners already soaking up the scene. We parked and went out and surprisingly, there were no offensive insects around. However, there were also no baboons in the vicinity. On the left of the parking lot, there were a set of beautiful public toilets which was a relief. The falls were spectacular. I removed my shoes to climb the rocks so that I could gain access to some unique points for photograph opportunities. As I immersed myself in the beauty at hand, I reminded myself how many falls in Uganda had been destroyed and turned into electricity power dams. This really saddened me. Bujjagali falls which is now Bujjagali falls dam in Jinja is an example of this. I was lucky enough to visit it a long time ago before it was turned into a power generating dam. It was awesome.

When we set off again, we had to travel at a greater speed so we wouldn't miss the last ferry that crossed the river at 5.00pm. If the last ferry was missed, you would have to wait overnight before crossing 9:00am the next morning. Luckily, we made it just in time. Two cars and almost ten people were on that ferry. While the ferry was in transit, we were told to get out of the car. We were instructed to walk onto the 
platform and hold the rails for protection. Two engines helped to run the ferry and it had a crew of two men. While we were on the deck of the ferry, we saw a group of hippopotamuses in the water. We were also cautioned by one of the crew that there were a few crocodiles in the water so we kept a watch out for them. Just before we arrived at our destination, the ferry had a slight problem because one of the engines failed. But in the end, we landed safely on the other side of the Nile without any incidents or face-to-face encounters with the crocodiles.

As we travelled along the road to Arua town, it became apparent that the most significant trade was charcoal ${ }^{13}$. There were bags and bags of charcoal sold by the roadside. However, the land was almost without any trees and as the miles went by, the landscape was endless dry grasslands with a few short, thorny and scanty trees. It was also evident that bush fires had torn through many places. The dryness of the land coupled with the high charcoal trade was worrying. We crossed the Nile the second time over Pakwarch bridge as we entered the West Nile region. It was nearly nine in the evening when we checked in at our hotel Sunshine in Arua town. It seemed more of a traveller's inn than a hotel but they offered excellent service. I had a long hot shower and went straight to bed and I was too exhausted to even pull down the mosquito net.

The next day was training and it went very well. We used the conference hall at the hotel and the participants were very punctual. The secondary school teachers were very excited as this was the first workshop of its kind in their area. In one of the methodology sessions that Peace chaired, there was a suggestion of making students write from their personal experiences. This is when one of the teachers said that most

\footnotetext{
${ }^{13}$ This is the most affordable and common source of energy for cooking in most urban Ugandan homes. It is made from cutting down and burning of trees.
} 
families had a malnutrition problem and so the students would be able to use their firsthand experiences of living in such dire situations. After the workshop, Peace and I approached this teacher and asked if she would be willing to take us to the place where we could witness firsthand some of these cases of malnutrition.

She suggested that we first visit the main hospital which was only a walkable distance from the hotel where we were staying and the conference venue. The three of us (Peace, the teacher and me) set off for the hospital. We walked for about ten minutes through a surprisingly tidy town to Arua General Hospital. The roads were very good and there was minimal litter on the streets or at least the part of the town I was shown. Our guide, the teacher, introduced us to the nurse on duty and she took us through the paediatric ward. It was heart breaking. Peace was not allowed to take any pictures of just how heart breaking it was. The children, who were mostly between two and six years, were emaciated and looked young for their age. The skin on most of their limbs was very wrinkled and they stared at us through very dull eyes. I observed that most mothers looked strong and healthy but very poor. About 90 percent of the cases in the children's ward were malnutrition cases.

The nurse explained that this area lacked food. This is primarily because the land is very dry and infertile for the growing of crops. The mothers, whose task it was to provide food for the family, walked very long distances in search of food or fertile land to cultivate while the children remained unattended at home. Most men were busy burning charcoal which they sold but in turn spent the money mostly on gambling and alcohol. The depletion of the land was obviously related to the social-economic problems of the people of the area. The nurse also revealed that there was a high occurrence of domestic violence in the area and many women who were subjected to domestic violence occupied the Out Patients Ward. There seemed to be no hope for this 
land to be productive when the trees are continuously cut down and burnt for charcoal. The irony though was that the Nile, with all her luxurious fresh water, ran through this area but the people were dying of hunger seemingly oblivious to the farming possibilities at their disposal.

Back at the hotel, Jona and our HOD were waiting for us when we returned. Over dinner, Peace explained her desire to start an organisation to help the children suffering from malnutrition in the Arua General Hospital. I could understand her reaction because any human who had just experienced what we did would want to do the same thing to help. I was aware that there were many International organisations in many parts of the country trying to help many poor Ugandans. However, I thought that if Ugandans we are taught to manage, respect and handle the environment in a more sustainable way, we could be the food basket of the entire East and Southern region of Africa. We did not need people coming into the country under the guise of coming to help when we had the potential to feed ourselves and many other people. I say 'guise' because we have had many media reports of people coming in the country and doing unspeakable things to the unsuspecting locals ( For instance, among many others, the Turkish man who was arrested for child abuse). When our local people see a foreigner, they immediately think that she/he is the long-awaited saviour and they end up being exploited. But all the same, I was fond of Peace and trusted that her plan was purely humane.

The rest of the workshop was quite uneventful and we went home on the third day. We bought lots of natural honey to take home with us. I bought a 20 litre can. Jona and our HOD bought the same while Peace left with only five litres. Arua may be a dry, hot place but it certainly is the land of pure honey. On the journey home, we did not go through the game park but we still crossed the Nile in two places. We again saw lots of 
charcoal being sold by the roadside in the northern region. When we crossed the Nile the second time to the central part of the country, we saw roast cassava and potatoes in addition to other foodstuffs sold by the roadside. We had now come to the part of the country that was not depleted and could produce food. We parked at one such place and enjoyed the roast cassava. I bought some for my family to crown my coming home.

\section{Epilogue}

My determination to contribute to the cause of Environmental education awareness was cemented when I saw the advertisement of The Best of Both Worlds 2012 Conference in South Africa. As a teacher of Language and a teacher educator, I strongly believed there was a better way that one could assist the Ugandan people and that was to create awareness about the environment and sustainable development. The problem is amorphous but not impossible to overcome. As a teacher educator, I saw many possibilities to propel change in my country. At the conference, I met many people from all over the world and they presented papers on diverse areas of environmental and sustainability education. Some of the papers presented were about successful environmental awareness school/ college projects, while some were on environmental laws in the different countries around the world. It was such a rewarding week and I vowed to pursue my $\mathrm{PhD}$ in Environmental Education. My experiences as mentioned in the aforementioned sections and this conference formed the impetus for my subsequent $\mathrm{PhD}$ research. 


\section{CHAPTER TWO \\ THE UGANDAN CONTEXT}

\section{Aims of the research}

The overall aim of this research was to explore how Indigenous Knowledge (IK) intersects with place-based education in Ugandan secondary schools and how teachers, through the implementation of place-based education pedagogies could influence their learners to reconnect with their communities, cultures and places. Further, given the role of community elders of guardianship and instruction of IK has been weakened by the formal education system, this research inquired into how community elders could contribute to place-based education in their communities through their IK.

These aims are further explicated in this study through the following research questions:

1. How can Indigenous Knowledge, practices and values intersect with place-based education in Ugandan secondary schools?

2. How can teachers use place-based education pedagogies to influence their learners to reconnect to their community/culture and places in Ugandan secondary schools?

3. How can community elders contribute to place-based education in their communities in Uganda?

\section{Environmental and social issues}

Uganda is facing an ever-increasing environmental challenge including depletion of the natural resources (including land, water and minerals), poor management of the remaining natural resources and poor waste management. 
The National Management Environment Authority (NEMA) reports that the area of forested land continues to decline "at an annual rate of 1.85 per cent with tropical forests representing only 4 per cent of Uganda down from 24 per cent 20 years ago" (NEMA, 2010, p. 20). In addition, “97 per cent of Uganda's land area suffers from some form of human induced land degradation" (NEMA, 2010, p. 26).

With one of the fastest growing populations in the world, (37 million people with a national average growth rate of 3.4 per annum) (Natukunda, 2013), of which "97 per cent depend on bio mass for their household energy" (NEMA, 2010, p. 127), Uganda's depletion of the unrenewable natural resources threatens the survival and wellbeing of the human and the non-human life that depend on them. Even though Uganda produces hydroelectric power from the numerous rivers around the country, only 3 per cent of the population can afford it (NEMA, 2010) hence, leaving the biggest percentage of the population to rely solely on the fast dwindling forest resources for their household energy. According to NEMA (2010, p. 127), "the dominant use of biomass for household energy is the single major cause of deforestation in Uganda."

Consequently, Uganda is experiencing a lot environmental disasters in the form of floods, droughts, landslides, wind and hailstorms causing loss of life and property as well as drastically affecting the economy of the country (NEMA, 2010). The Bududa mudslides which occurred in 2010 along the slopes of Mount Elgon in Eastern Uganda destroyed hundreds of lives while thousands of others were displaced by the enormous destruction of property (NEMA, 2010). Sadly, this disaster demonstrates how such occurrences affect mostly the poor people who invariably make up the largest percentage of the population (NEMA, 2010). To illustrate the economic inequalities in the country, NEMA (2010, pp. 13-14) reports that "the wealthiest 20 per cent of the population holds 49 per cent of the total income, while the poorest quintile only 6 per 
cent." This illuminates the prevailing environmental injustice in the country in that the poorest majority of the population remains highly vulnerable to the environmental disasters because they have very limited economic alternatives and heavily depend on the natural environment for their survival.

Diseases and ill health are social issues related to environmental and economic factors in Uganda. NEMA (2010, p. 3) reports that “much of Uganda's disease burden is environmental related." Environmental changes greatly contribute to changes in disease patterns and consequently floods significantly increase the spread of malaria, diarrhoea, cholera, bilharzia, TB and other respiratory diseases (NEMA, 2010). On the other hand, long periods of drought lead to food insecurity and malnutrition leaving the people weak and susceptible to diseases (NEMA, 2010). In addition, "research has linked forest change, particularly deforestation and land fragmentation with the emergent of HIV and Ebola through increased contact between humans and primate carriers" (NEMA, 2010, p. 38). Uganda has recently been attacked by severe outbreaks of deadly viral diseases like Ebola and Marburg which are said to have crossed from wild primates and bats to humans (Kagolo, 2014; Musinguzi, 2012; Namubiru, 2012). Again, the poor majority suffer most because they are either too poor to afford and access proper medication or lack the alternative sources of nutrients (Like fruits and vegetables which are very scarce in drought conditions) required to boost their immunity. Moreover, NEMA (2010, p. 3) highlights that "75 per cent of the overall burden of disease is preventable" through environmental sanitation.

In relation to environmental degradation, cases of crime and violence have increased in the country. Some of these are fuelled by the high levels of poverty as "65 per cent of the population lives on less than US \$2 per day" (NEMA, 2010, p. 13). Other cases of crime and violence are reportedly triggered by the prevailing 
environmental injustice as the largest percentage of the resources are controlled by the few wealthy people while the majority struggle to survive on the margins (NEMA, 2010). As a result, some people resort to desperate measures for their survival (i.e. theft and robbery) hence the increase in crime. The other cause of crime associated with environmental challenges is the total disregard of the environmental policies and laws by some people (Ssempogo, 2009; Tenywa, 2012). This is reflected by NEMA in the 'Worst Case Scenario' by the occurrence of "massive pillage of environmental resources motivated by greed and impunity" (NEMA, 2010, p. 157).

Education has a key role to play in helping people to understand the importance of how sustainable living can lead to a better environmental situation (UNESCO, 2010). Education is essential for the realisation of the Sustainable Development Goals that are at the core of the 2030 agenda for Sustainable Development (Rieckmann, 2017). Education for Sustainable Development (ESD), also known as 'Sustainability Education' aims at empowering learners 'to make informed decisions and responsible actions for environmental integrity, economic viability and a just society for the present and future generations" (Rieckmann, 2017, p. 7). ESD therefore aims to change people's values and practices towards their natural environment through embedding curriculars with the principles that inspire the treatment of fellow humans and the natural environment with care and empathy.

When the UN mandated UNESCO to spearhead the implementation of the Decade for Sustainable Development (2005-2015) at the World Summit for Sustainable Development in 2002, UNESCO consequently developed an international implementation scheme for the decade. The scheme set up a framework for all UNESCO partners, the member countries, to contribute towards the achievement of the ESD goals. As a UNESCO member state, Uganda has shown her commitment to this 
cause by developing her own strategy to achieve the United Nations Decade of Education for Sustainable Development (UNESCO, 2010) by integrating ESD into the education curricular.

However, there is a general lack of confidence in the key role that education can play in terms of educating for sustainability in Uganda. NEMA and other Ugandan environmental bodies' recommendations are focused on the furthering protection of the endangered resources and the development and enforcement of policies and laws (NEMA, 2010; NFA, 2002). Education, which was named as the "key to creating public awareness, and training for moving society sustainably to ensure sustainable development" (UNESCO, 2010, p. 11) is criticised for being theoretical, narrow and insufficient in educating for environmental sustainability (NEMA, 2010; NFA, 2001; UNESCO, 2010).

On the other hand, NEMA and the National Forest Authority (NFA) both recognise the importance of Indigenous and local knowledge systems in understanding and managing the natural resources. While NEMA advocates for the "participation of Indigenous Peoples" (NEMA, 2010, p. 177) in environmental programmes, NFA recommends for the "consideration of the cultural and traditional attributes and institutions" (NFA, 2001, p. 13) in the management of the forest resources. However, IK is disregarded by the formal education system in Uganda mainly due to its conflict with the foreign Ugandan educational background and also the standardized nature of the curriculum.

\section{Formal education and disconnection from place}

Formal education in Uganda was introduced by the Christian missionaries for “Christianising purposes" (Rodney, 1974, p. 241) in the late 1800's and later managed 
by the colonial government until Uganda gained political independence in 1962. Since the schools were founded by the Christian missionaries, attending school meant the denouncing of the Indigenous cultural beliefs (Rodney, 1974). The Ugandan formal education system, which was inherited from the colonial formal education system after independence in 1962, has since had difficulty embedding IK into the mainstream curriculum. However, today, curriculum developers have introduced oral literature and local languages (e.g. Luganda) as optional subjects at secondary school level but these are not prioritised in an education system that undervalues IK in favour of the 'international' Western oriented form of education. Consequently, few schools and fewer students choose to include these optional subjects on their curricular.

The emphasis on standardised assessment has made formal education examination oriented. This has led to the distraction of the people from what really matters (i.e. environment concerns) in community life. The publication of examination results of winners and losers in the national media creates an individualistic tendency in everyone (teachers and learners alike) where each is struggling to be the best (Owor, 2012). Everyone's survival in the formal system depends on students' scores rather than creating an appreciation for the learners and their situations (Tilbury, 1995). Children commence school at the age of three to grasp English, literacy and numeracy skills that are key to achieving the required high scores in the competitive national examinations. The Uganda National Examination Board (UNEB) influences the implementation of the curriculum.

Today, through the national examination scores, students' futures are impacted. Those students who rank high on the examinations get admitted to the 'best' institutions like Makerere University to study popular courses like Medicine and Law. While those who do not achieve appropriate scores get admitted to the 'poor' institutions to study 
the unpopular courses like Education. Those that fail to attain good grades in the examinations end up as drop outs and face a very bleak future of certain unemployment and poverty (Agaba, 2012).

The irony is that whether one achieves or fails to achieve in this competitive education system, neither will be adequately prepared to live and build their communities. The colonial formal education system which Uganda inherited at independence was never meant to equip the people with practical skills for development (Ziltener \& Künzler, 2013) and neither was it meant to build the Ugandans' pride and confidence in their heritage (Rodney, 1974). The values and mentality inherited with that education system distort the meaning of a true education. According to Ziltener and Künzler (2013, p. 303), "education under the colonial government was not primarily meant to improve the minds of the Indigenous population or to open the ways to European universities but to recruit and to train clerks/ officials for the administration." Therefore, it is no wonder that graduates from the current education system are deemed to "lack practical skills, values and ethics to survive and manage resources in a challenging world" (UNESCO, 2010, p. 19).

The alienation of students and teachers from their communities, cultures and places is also due to the long education period that a student must endure. The Ugandan system comprises three years of nursery/ kindergarten, seven years of primary school, six years of secondary school and usually three to five years of university or tertiary education (Ejuu, 2012). At the end of the education tunnel (i.e. after university or training college), students are adults (mostly in their early twenties) who become consumed with professional employment and eventually enter marital relationships. Unfortunately, the same cycle begins for their children. This education cycle traps the population into a placeless space and in the long term, invariably displaces the 
population. We then turn out as Grunewald (2003b, p. 636) describes as, "people who do not understand who, what and where we are, as well as how we might live our lives."

The restriction of the adequate development of the mother tongue by the formal education system further exemplifies the cultural erosion in Uganda. Indigenous cultures and education in East Africa were originally oral in nature with language as both a store and a medium of transmission of cultural values (Wa Thiong'o, 1994). Bowers (2001, p. 58) argues that language is "essential to the self-identity of the cultures' members." Cultural values and instruction were weaved in the rich song, proverb, myth, folk tale and recitation that were a part of everyday discourse. Even though in 2007 the Ugandan government implemented the mother tongue policy which aims at the teaching of the local language in the first three years of primary school in the rural areas ${ }^{14}$, most head teachers refuse to implement it because English is ultimately the language used in national examinations for all students (Altinyelken, 2010). As a result, educators as well as politicians across the country have criticised this policy (Ahabwe, 2014). English as a formal language of instruction was introduced in the 1960's with the dawn of the British 'formal' system of education and has not left much space for the children's proper development of their mother tongues. Ultimately, people grow up with deficient mother tongues and English; lacking to fully develop in either language. This also breeds learning complexities of trying to make sense of knowledge in a foreign language leading to learning frustrations, a meaningless education and a sense of failure in many people (Kyeyune, 2003).

Respect for place and identity was traditionally reinforced during the sacred rites and ceremonies performed in our cultural settings. During these rites, IK, moral

\footnotetext{
${ }^{14}$ This policy applies only to rural schools while urban schools instruct in English from Kindergarten level. This further aggravates the people's resistance against the policy.
} 
values and instructions, are handed down orally from the elders to the candidates thereby acting as cultural didactic opportunities (Lubuulwa, 2012). The time spent at school, however, with the school term running for three months thrice a year makes it virtually impossible for the children and their teachers to take part in their cultural rites and ceremonies. These ceremonies, and the way they are performed impress upon all participants the "pride in identity", (Wattchow \& Brown, 2011, p. 22) but most importantly the duty of belonging to the clan, tribe, family, and land thereby unquestionable stewardship of their places. In addition, ceremonies reinforced the place of the elders in society as stewards of wisdom to be passed onto the next generation orally during communal gatherings (Lubuulwa, 2012). Due to the formal education system, most young people are either at school (teaching or learning), or working in the cities, and no longer have the time or the sense of duty to take part in these sacred rites and ceremonies.

Uganda is endowed with a rich natural ${ }^{15}$ beauty and there is no excuse for the education system to restrict children's learning experiences to abstraction. At best, education must be able to 'inspire in learners an appreciation of beauty and wonder' (Gruenewald and Smith, 2014, p. xx), for them to develop a lasting love and commitment to the service of their communities. It is no wonder that Ugandans are ready to sell their sacred heritage when there is market for it. In many government documents, 'our heritage' is closely followed by 'tourism' (NEMA, 2004, 2010; NFA, 2001, p. 10). The education system has for decades been training Ugandans to make money out of anything; even the most sacred of things that would never be touched by

\footnotetext{
15 Uganda is also known as 'The Pearl of Africa' because of her exceptional beauty.
} 
our forefathers. Therefore, educators must use place-based education to "reclaim the hearts" (Gruenewald, 2003a, p. 7) of Ugandans.

Currently, the Ugandan formal education system is using the colonial traditional transmissive pedagogies where the teachers cover standard content by lecturing to the learners expecting them to reproduce the same knowledge in the exams (Altinyelken, 2010). Sustainability education requires students to go beyond the structured classrooms so they are prepared to take up the challenges of today and the future, for instance the prevailing environmental issues (Vartiainen, 2013). Place-based pedagogy makes learning relevant to the students thereby enriching the education experience of both the teachers and the learners (Gruenewald, 2008). Tilbury (1995) emphasises relevance in environmental education for sustainability. She argues that increasing the students' understanding of themselves and the world around them helps them to "recognise the totality of the surroundings and links between lifestyles and the use of nature" (p. 199). This can be attained through place-based education pedagogies.

\section{Colonial mis-education in East Africa}

Historically, colonialism in Africa is responsible for many far-reaching effects like the construction of national boundaries; the education systems and many other things resulting in the present political, economic and social set up of those countries. Colonialism is a form of temporally to extended domination by one group of people over another resulting in a universal history of intergroup subjugation, oppression and exploitation (Ziltener \& Künzler, 2013). East Africa is politically made up of five countries which include: Uganda, Kenya, Tanzania, Rwanda and Burundi. But many people share the same languages and cultures across the political borders of these countries. 
Like many other African countries, these countries were under colonial domination for a significant period. Uganda was colonised by Britain from 1890 to 1962 (72 years); Kenya by Portugal and Britain from 1647 to 1963 (315 years); Tanzania by Portugal, Britain and Germany from 1624 to 1963 (339 years), Rwanda by Germany and Belgium from 1899 till 1961 (62 years) and Burundi by Germany and Belgium from 1897 to 1962 (65 years) (Ziltener \& Künzler, 2013). These are the years of colonial domination, but in most cases the period of contact and influence of the European capitalist culture had started much earlier. Education was a scheme that the colonial countries put in place to gain control of their colonies for easier administration and longer exploitation. Consequently, they progressively imposed a Western, foreign type of education on the colonised populations to replace the traditional religious and educational practices in these areas (Labé, Dembélé, Sirois, Motivans, \& Bruneforth, 2013).

Indigenous education was in nature place-based and relevant to the cultural setting of the people. According to Rodney (1974, p. 239), a relevant education system is one that "grows out of the environment; the learning process being directly related to the pattern of work in the society". The African Indigenous education system was relevant in that it had structures that ensured that an individual was equipped and transformed to benefit himself and the community (Rodney, 1974).

Formal instruction was given during the rites of passage (i.e. circumcision, marriage, and installing an heir) that people went through to mark their development through life stages for instance from boyhood to manhood. Preparing the youths for these very important stages of their lives, elders instructed the candidates on their future roles and how to live responsibly in their respective communities (Lubuulwa, 2012). The Indigenous education system was "practical and produced an individual who was 
mentally, physically, and spiritually fit to live sustainably in his community" (Rodney, 1974, p. 239). This kind of education where there is an emphasis on one's role and pride in the community has almost been completely obliterated. In this regard, Omotoso (2010, p. 226) argues that in most African societies today, "traditional rites and customs have lost their living content." In most colonial literature, to be educated is to be 'Europeanised' and unlearn all traditional ways of life and languages. In the process, the role of the elders in the education of the young has been gradually eliminated (Semali, 1999).

It is also evident that colonial governments deliberately set out to replace traditional education systems with their own kind of education systems (Labé et al., 2013; Omotoso, 2010; Rodney, 1974; Ziltener \& Künzler, 2013). Colonial formal education systems were aimed at recruiting and training lower carder officials (office messengers, clerks, cleaners) for administration purposes (Ziltener \& Künzler, 2013) and to deliberately confuse and mystify the colonised people (Rodney, 1974). What was introduced was not developmental education. Rodney (1974, p. 241) explained how it was "education for subordination, exploitation, creation of mental confusion, and the development of underdevelopment". In the beginning of the colonial era, this colonial mis-education was given to the privileged few who were mainly sons of kings, and chiefs and this created a mentality in the rest of the populations that it was a great opportunity for one to acquire this kind of education. This is because those who were initially part of this type of education got to enjoy privileges in the colonial administrative structures (Omotoso, 2010; Rodney, 1974).

This same education system and the colonial schools trained our ministers, kings and presidents who are today's policy makers. Since they were trained in the British colonial education system, they lack the relevant values to live sustainably in 
their local communities. Colonial educational systems deliberately destroyed the ethical values in society. Ziltener (2013, p. 302) argues that the colonial education system is "a kind of perverted logic that turns to the past of the oppressed people and distorts, disfigures and destroys it." This was the intent of the colonial powers. Without pride and confidence in a people's history, there would never be real independence.

In most of the literature, you find that colonialism in Africa is closely linked with religion; in East Africa, it is mainly Christianity. In some instances, you find that missionaries made contact with the Indigenous Peoples just before colonialism. However, for the colonialists to succeed in their domination and control of the people, they worked closely with the missionaries. The missionaries in their work stressed humility, docility and acceptance so that the oppressed people looked to God alone and passively accepted their forced labour on the coffee, or sugar plantations (Rodney, 1974). The missionaries introduced many schools for their Christianising purposes in East Africa and these were eventually used for the colonial educational schemes. Some of these schools are; in Uganda, King's College Buddo; in Kenya, Alliance High School; and in Tanzania, Tabora Secondary School (Rodney, 1974).

Many young people converted to Christianity so that they could access education in the missionary schools (Labé et al., 2013; Ziltener \& Künzler, 2013). Missionaries also did a fair bit of work alienating the Africans from their cultures by preaching against the African ancestral beliefs. The African ancestral beliefs were denounced as pagan and equated to witchcraft and magic (Rodney, 1974). Converts got baptised and acquired 'Christian-European' names to symbolise the new self. The hatred for self and for anything African was ensured by stressing the negative things 
about the African social life like polygamy, the polytheistic ${ }^{16}$ beliefs, beliefs in ancestral spirits, and the use of traditional medicinal plants. Many young people renounced the authority of the elders/culture and converted to Christianity. In 1886 in Buganda, over 30 of Kabaka's subjects were sentenced to death because they refused to renounce Christianity. These people who lost their lives are Uganda's martyrs and are commemorated yearly in addition to complimenting the Ugandan religious education curriculum. The thousands that died under the yoke of forced labour, slavery and eviction are unknown.

The worst element in the package of colonial mis-education was capitalist individualism. This individualism completely replaced the social solidarity that was the backbone of most African Indigenous cultures (Omotoso, 2010; Rodney, 1974). Labour in the pre-colonial times was meant to serve the community. Land and other resources were used communally and therefore were protected for and by the community. Collective labour, responsibility, and achievement were the norm. This cultivated sustainable living in peoples' ways of life. The theme of which is reflected in the figures of speech of the neglected and dying Indigenous languages (Semali, 1999). With the colonial system of formal education, individual achievement is the ultimate goal. It completely destabilised the traditional communal way of living. According to Rodney (1974, p. 255), "the formal school system and the informal value system of colonialism destroyed social solidarity and promoted the worst form of alienated individualism without social responsibility."

\footnotetext{
${ }^{16}$ Traditionally, the Baganda have many Gods (Ba lubaale) for the different aspects of their world. For instance, Muwanga is the God of creation, Musisi is the God of rain and of the winds; Kibuuka was the God of war or defence etc.... The Christian missionaries discouraged this belief and the Christian converts were called to believe in the one and only God of Christianity.
} 
This is the education system Uganda as well as East Africa inherited in the 1960 's after their political independence and it is the same system prevailing today. Teachers are graduates of this alienating system and are instructing their students in the same way they were instructed thus continuing a recycling of Christian values, oppression and disconnection to their land and values.

\section{Intersection of place-based education and Indigenous Knowledge}

In the previous section, we get to see that literature on colonial education reveals that colonial education, which Uganda inherited at independence, did not foster a people's sense of pride in identity due to the aims and intentions of colonialism (Labé et al., 2013; Omotoso, 2010; Rodney, 1974). Moreover, this is not made any easier by the Ugandan examination oriented curriculum which centres on students' test scores. All this reveals that the formal Ugandan education is not doing enough to nurture students' and teachers' connection to place and community.

Even though there seems to be no African scholarship in the field of place-based education in the African educational setting, insights from indigenous scholars working in a range of global contexts have tended to confirm that there is a significant closeness between the principles of IK and those of place-based education. Dei (2000, p.72), defines Indigenousness as "Knowledge consciousness arising locally and in association with long term occupancy of a place." Semali $(1999$, p. 103) defines the same as "a competency that individuals in a community have acquired and developed over time... and the attitudes of people toward their own lives and the social and physical environment." These definitions depict IK as rooted in the local, and also that it has been developed over a long period of long time. On the other hand, place-based education has been defined as "Learning that is rooted in the local-the unique history, environment, culture, economy, literature, and art of a particular place" (Smith \& Sobel, 
2010 p. 328). The main principle of place-based education is taking learning experiences outside the school into the local communities and thereby making the students' learning more relevant (Gruenewald, 2003a). Gruenewald and Smith (2014, p. xvi) explains that place-based education is "a community-based effort to reconnect the process of education, enculturation, and human development to the wellbeing of community life". The intersection of IK and place-based education is one way that Ugandan teachers, through their pedagogies, can help not only themselves but also their students to "know enough about their community's members and feel enough attachment to its places that they are proud of their own human and geographical roots" (Smith \& Sobel, 2010, p. 525). They can then cultivate the commitment to caring and protecting those places.

Place-based education stresses the concept of immersing students in the local phenomena. Place-based education aims to making learning meaningful and relevant as it draws on the local phenomena as a source of the learners' experiences (Gruenewald 2008). IK is largely what the Ugandan students are immersed in outside school. But in a formal education system that ignores IK, learning becomes meaningless and frustratingly complicated. As Semali (1999, p. 106) reveals:

Many opportunities are lost when prior knowledge of indigenous ways of knowing things are ignored by teachers. Opportunities to teach language skills by describing native plants in the students' gardens or recounting the local history of local heroes and heroines, can enhance connections between what is learned in the classrooms and what the student already knows outside the classroom.

Indigenous forms of learning have similar principles as place-based education. Indigenous learning is practical and directly related to the pattern of life of the community. The young acquire knowledge, skills and values through the exemplars of the elders and also in form of instruction at the required stages of growth of an 
individual (Rodney, 1974). Moreover, just like in the principles of place-based education, this learning takes place in their own local settings. On the same point, Maurial (1999, p. 65) elucidates, "homes, rivers, gardens, forests are the settings of indigenous education by which indigenous knowledge is learned in a dialogical relationship with nature". It is highly evident that the intersection of IK and place-based education can improve teachers' practice.

Many times, research and literature recognises that any education system needs to be relevant to meet the needs of a community. Presently, Uganda's formal education system is not achieving its aim and this is reflected in the leading environmental bodies in the country (NEMA and NFA) calling for IK to be utilised in order to save the country's fast dwindling natural resources. It is evident from the wanton plunder of the resources that the social solidarity has been destroyed. It is therefore essential for Ugandan educators to consider the intersection of IK and place-based pedagogies in the Ugandan classroom in order to mend the connection between the people and their places. Dialogue between Indigenous educators (i.e. elders) and formal educators (i.e. Ugandan teachers) needs to re-commence so that they can, together, critically evaluate the education system (Semali, 1999). This is a way to move forward to ensure education is relevant to the Ugandan community and most importantly, to reconnect both the teachers and the students to their communities.

\section{Conclusion}

This chapter gives background to contextual information important to this study by explaining the Ugandan education context. The chapter outlined the environmental challenges that Uganda is grappling with and their effects on the poor majority. Finally, the chapter highlights the importance of place-based education in addressing the Ugandan education challenges. 
The next chapter outlines the theoretical context of this research project. It traces the development of the Indigenous problems through critical place inquiry and postcolonial theory. This chapter also provides suggestions for moving forward for the Indigenous people through re-embracing their Indigenous cultures. 


\section{CHAPTER THREE:}

\section{MOBILE PLACES AND SHIFTING CULTURES}

\section{Introduction}

The aim of this chapter is to examine Indigenous Peoples' relationship with and interpretation of places through the pre-colonial, colonial and post-colonial periods. Literature shows that the Indigenous Peoples' perception of place changed through their contact and interaction with the colonialists and imperialists (Cajete, 1994; Mills, 2009; Smith, 2013). In addition, according to research, the Indigenous Peoples' perception of themselves changed and is still changing because of their changing landscapes due to colonial/imperial and presently, neo-colonial influence (Fanon, Farrington, \& Sartre, 1963; Memmi, 2013; Rodney, 1974; Wa Thiong'o, 1994). Further, researchers like Ashcroft, Griffiths, and Tiffin (2013), Memmi (2013) and Mills (2009) argue that the rest of the world's perception of the Indigenous Peoples was and still is heavily influenced by how the explorers, missionaries, cartographers, settlers and journalists portrayed the Indigenous Peoples' lands in both literature and in maps.

I have used the Tuck and McKenzie (2015) definition of place as, "the setting for social rootedness and landscape continuity" (p. 20). Since many Indigenous Peoples construe 'places' and 'lands' in the same way, I have also used both terms interchangeably. I have used the terms 'landscape' and 'portrait' to show peoples' responses to places. However, I have also used 'place' (i.e. as a verb) to describe how dominant cultures situate Indigenous Peoples and as a result how the Indigenous Peoples situate themselves in the global arena. In this case, I have used 'place' interchangeably with 'mental landscape'. The term 'mental landscape' has been used to describe the Indigenous Peoples' perceptions of themselves in relation to their land and the dominant global cultures. This notion is in response to Mills' (2005); and Tuck 
and McKenzie's (2015) descriptions of how people develop particular views of themselves or of others in relation to their places/landscapes. Mills (2005) discusses the development of the mental landscape of different people in relation to their places by showing how the Indigenous Peoples in relation to their human counterparts are always associated (stereotypes) with the wilderness or simplicity. In relation to this, Tuck and McKenzie (2015) discuss the metaphorizing of the body in relation to place whereby a Black American woman views her raped /abused body in the same way her homeland/place has been raped/disrespected.

It is also important to note that I am aware of the vast differences among the Indigenous Peoples around the world and that as I write of them, I do not mean to lump them all together. However, the term 'Indigenous Peoples' is used to describe those different groups of people around the world who have lived in their local places for millennia, but who have also been afflicted with either colonialism or imperialism and have experienced that burden with ongoing consequences. 'Indigenous Peoples', according to Smith, $(2013$, p. 7), "is a term that internationalises the experiences, the issues and the struggles of some of the world's colonised peoples." Smith (2013) further elucidates that 'the final ' $\mathrm{s}$ ' in 'Indigenous Peoples' is used as a way of recognising that there are real differences between different Indigenous Peoples." Today, many of them are experiencing neo-colonialism, which is viewed as the new form of colonialism but has the same damaging effects on the people, communities and places.

This chapter focuses mainly on the Indigenous Peoples' perceptions of place to bring to light the relationship of the Baganda (where the study was undertaken) with their place and to put in context the motivation for this study. There will also be some discussions of the non-Indigenous Peoples' perception of the Indigenous Peoples' landscapes. 
To explicate the nature of places and their relationship with the inhabitants, this study is grounded in critical place inquiry. The critical paradigm is concerned with issues of social justice and marginalisation (Scotland, 2012). In an era where places are viewed in terms of "occupying, exploiting and profiting" (Gruenewald, 2003b, p. 629), critical place inquiry acknowledges places to be living entities that deserve to be treated with respect and care. Gruenewald (2003b, p. 624) affirms that "a theory of place that is concerned with the quality of the human-world relationships must first acknowledged that places themselves have something to say." Gruenewald emphasises the need for humans to listen to their places thereby underlining the dialogical obligation between humans and the natural environment. Gruenewald (2003b) accentuates that critical place inquiry calls for attentiveness to places.

With globalisation and technological advancement, people, places and cultures are continuously changing. Critical place inquiry, according to Tuck and McKenzie (2015, p. 19) "understands places as themselves mobile, shifting over time and space and through interaction with flows of people, other species, and social practices." Nakagawa and Payne (2015, p. 152) highlight this continuous movement by describing places as "fluid" and the people as "highly mobile". Tuck and McKenzie (2015) also highlight that places change physically and/or geographically. Like in the instance of tectonic plates moving, or historically like in the case of African slaves being moved to the different parts of the world. Thus, critical place inquiry recognises that amidst the fluidity of places, the cultures of the people are also changing. However, critical place inquiry also highlights the resistance of the people in these places to the different changes taking place around or within themselves because of this fluidity (Tuck \& McKenzie, 2015). 
Much as people who inhabit places are responsible for the changing of the places they inhabit, places are also known to change people in profound ways. Freire (2005, p. 109) argues that 'people, 'as beings in a situation', find themselves rooted in temporal-spatial conditions which mark them and which they also mark." Gruenewald (2003b, p. 621) emphasises that, "places make us: As occupants of particular places with particular attributes, our identity and our possibilities are shaped." In this, critical place inquiry is also concerned with how people change or make places; and how places change or make the inhabitants.

Post-colonial theory is important here because it explores how colonialism has played a significant role in the development of certain types of race and classed behaviours in relation to viewing, knowing and experiencing place (Hall, Dei, \& Rosenberg, 2000; Mills, 2009; Shizha, 2005). Further, post-colonial theory engages with "the analysis of cultural forms which mediate, challenge and reflect upon the relations of domination and subordination between nations, races or cultures-andcontinue to be apparent in the present era of neo-colonialism" (Moore-Gilbert \& Moore-Gilbert, 1997, p. 12). Moreover, literature shows that colonialism does not only affect the physical landscape of the people but also the epistemological or mental landscape of both the colonised and the coloniser (Kayira, 2015; Mills, 2009).

\section{Re-counting places of the precolonial times}

\section{From the foreign lens}

The precolonial African landscape and that of other Indigenous Peoples around the world is heavily represented in literature from Western-coloniser-explorer perspectives (Mills, 2009; Ntuli, 2002; Smith, 2013). Early accounts of the precolonial Indigenous African landscape illustrated the continent as a jungle; and its inhabitants 
uncivilised savages (Ntuli, 2002). Still, Indigenous Peoples' lands elsewhere like in Australia were described as empty and uninhabited - terra nullius (Mills, 2009). Early maps showed interior Africa as populated by "savages, cannibals or monsters"; and moreover, Indigenous lands on the maps were represented by drawings of "sub-human, wild-men" (Ashcroft et al., 2013, p. 40).

The above perception is contested by post-colonial critics and scholars on grounds that the early explorers, cartographers and missionaries had to portray the Indigenous landscape in that way to justify their dominance and inhuman practices in those places (Hall et al., 2000; Smith, 2013). Mills (2009, p. 822) reveals that "politically, it is seen that the myth of cannibalism was used by whites in Australia as a means of casting Aborigines as inhuman and contesting their claims for land." Mills (2009), however, shows that Indigenous Peoples could have used the cannibalism narrative as a way of distancing and controlling the colonisers. In this regard, Mills (2009) warns against the usual consideration of Indigenous Peoples as merely passive victims but that they were also living actors of their history.

It can also be argued that the early missionaries, cartographers and explorers' descriptions of the Indigenous landscapes as jungles inhabited by primitive cannibals or just empty spaces was based not only on their own understanding of the concept of place but also an ignorance of the Indigenous Peoples' episteme and relationship with the places. Tuan (2013, p. 63) affirms that, "Visitor and native focus on very different aspects of the environment. A visitor's perception is often a matter of using his eyes to compose pictures- well as the native-has a complex attitude derived from his complete immersion in the totality of his environment." In this case, where the Indigenous Peoples thought of their land as spiritual, sacred and apart of themselves, the early travellers who did not understand this way of thinking, saw nothing or something else. 
In addition, to many explorers, the places that they went to meant exploitation of resources (human, scientific and minerals) for themselves and for their countries back home; however, they were mindful of the dangers that they would encounter in those unkown places. McClay and McAllister (2014, p. 157) give us an insight into the Western perception of place from which the early explorers perceived of the Indigenous places that they went to; "Places were apprehended in terms of passability and possibility." The authors illustrate that to the early explorers, the places that they went to meant either danger in terms of whether they would survive or find their way through or whether they would find resources to exploit in those places.

It is also possible that the early explorers' and missionaries' accounts of the places were because of their confusion and fear that is felt when one gets to a new and distant place and is overwhelmed by lack of understanding of the place. McClay and McAllister (2014) equate the feeling to the same one a person who lives in a small town feels when they find themselves in a vast city like New York. The vast landscapes, mountains and valleys in addition to different kinds of people that spoke different languages might have been disconcerting for the early travellers. Traveller's tales have featured giant sea monsters wrecking ships just like the recounts of savages devouring missionaries. In these tales both the sea and the distant lands are depicted as differentfrom-the-normal places and therefore pose different-from the-normal challenges.

\section{From the local lens}

Often Indigenous Peoples have been portrayed as a people who are incoherent or lacked the independence to voice their own stories (Kayira, 2015; Mills, 2009). In her discussions of the gendered other in colonial literature, Spivak (1988, p. 91) describes Indigenous women as "historically muted subjects." She, however, notes that 
today Indigenous Peoples have "learnt to speak" to counter the hegemonic views in colonial literature.

Indigenous scholars explain how the Indigenous Peoples perceive the land as an elevated living entity (Cajete, 1994; Holmes, 2000; Wa Thiong'o, 1994). They viewed their land or the earth as a mother and because of this status, the Indigenous Peoples strived to live in harmony with fellow human beings and with their non-human relatives. In many precolonial African communities, land and the resources were utilised communally. Wangoola (2000, p. 265) explains that for the Indigenous Peoples, "The earth is not for them to conquer and subdue, but their mother to live with in harmony and reverence." In many Indigenous cultures, spirituality in relation to land is a common occurrence (Cajete, 1994; Castellano, 2000; Dei, 2000; Hall et al., 2000; Wa Thiong'o, 1994).

Indigenous Peoples perceive of the land as their primary provider and source of life. This kind of relationship is not the same as a place from which they can exploit resources but one that takes care of them. Holmes (2000, pp. 44-45) reports of one of her participants, “Importantly, Tutu Ohi'a describes land and rivers as subjects who act to 'feed us' and 'give us water'." In this sense, the land cares for the people like a parent would to their children. There is evidence in literature that many Indigenous cultures accorded deep respect to their places. For example, in some Ugandan Indigenous cultures, Wangoola (2000, p. 265) explains that "the earth is the only abode in perpetuity for the living, for the dead, and for those yet unborn." Indigenous Peoples in Uganda, before Christianity and Islam, never looked to another place to go to after death like heaven or hell. This is the reason, in many Indigenous cultures, a lot of rituals had to be performed when it was felt that the Earth had been wronged or in response to any changes in the seasons (Cajete, 1994; Wane, 2000). 
Further, many scholars show that Indigenous Peoples have familial ties with the land and with their non-human inhabitants the animals and plants. In Buganda, the clans are strongly tied to animals. People are grouped and named according to these clans. Wangoola (2000, p. 266) explains that, "members of a clan whose totem is the buffalo do not eat this animal, nor do they sit on its skin or wear buffalo leather or do harm to the beast." This is the norm among the Indigenous Peoples of Uganda. In addition, the Kiganda ${ }^{17}$ way of life is highly based on their clan ties. In Buganda, the members of one clan are brothers and sisters and strictly do not marry from within the clan thereby safeguarding the people from problems related to intermarriages. Apart from protecting animals and plants, this norm cultivates the value of humility and respect for fellow humans which is healthy for their land.

The precolonial landscape is also depicted to have had challenges that impacted on the people and their environment. In the instance of precolonial East Africa, Wa Thiong'o (1994, p. 36) elaborates, "The cruelty of nature: there were droughts and floods, threatening devastation and death... the cruelty of human beings, enemies come to take away a community's wealth in goats and cattle." The people confronted these challenges as a community. They performed rituals for the propitiation of Mother Earth and worked together to defend the community against the enemies.

The mutual relationship and interdependence of human beings and nature is expressed in many Indigenous people's ecosophy. According to Cajete, (1994, p. 197), "ecosophy" is the term that describes "the integration of environmental knowledge with physical, social, mythological, psychological and spiritual life characteristic of

\footnotetext{
${ }^{17}$ That of Baganda (the people) or Buganda (the region). In Luganda, $K i$ is a prefix added on Ganda to mean 'that of' Baganda or Buganda. Baganda are the people; Buganda is their region; Luganda is their language and Uganda is the Country.
} 
Indigenous societies." In some of the Indigenous societies of Africa, this ecosophy is expressed through philosophies like Ubuntu in Southern Africa (Abdi, 2013; Kayira, 2015); Mpaambo in Busoga Eastern Uganda (Wangoola, 2000); and Bulungi Bwansi in Buganda Central Uganda (explained in chapter six). In these philosophies, the Indigenous Peoples understand and go by the fact that the individual well-being is derived from the well-being of the community. Most importantly, the well-being of the land (Obuwangwa for the Baganda), and that of the people is also intricately woven together. This is the Indigenous Peoples' understanding of the land (which is the same as earth for many Indigenous Peoples). This ecosophy is expressed throughout their oratures, art forms and languages. Hall et al. (2000, p. 6) explain:

For millennia, many indigenous cultures were guided by a world view based on the following: seeing the individual as part of nature; respecting and reviving the wisdom of elders; considering the living, the dead, and future generations; sharing responsibility, and resources within the community; and embracing spiritual values, traditions and practices reflecting connections to a higher order, to the culture, and to the earth.

This philosophy was affirmed in their practice and in the education of the young. Indigenous practices involved the spiritual as well as the practical aspects of life. Everyday activities like hunting, or cultivating the land had rites associated with them (Cajete, 1994; Lubuulwa, 2012; Wa Thiong'o, 1994). The education of the young was based on the keen observation and involvement in the daily activities of the communities and through folk stories and other forms of community oratures (Cajete, 1994; Wa Thiong'o, 1994).

This section explains the pre-colonial landscape from both the perspectives of the Non-Indigenous and the Indigenous scholars. The next section will explore the Indigenous Peoples' perception of their places in the colonial/ imperial times. 


\section{Transforming places in the colonial period}

Colonialism ushered in permanent changes to the Indigenous lands and the way the Indigenous Peoples view their lands. The land was demarcated and colonial borders were established. According to Michalopoulos and Papaioannou (2016, p. 2), "Europeans did not take into account local political and geographic conditions while designing the borders." Groups of people who were already established with own systems of governance found themselves in two different countries, with a border drawn right across their lands. Nyerere (1964, p. 41) says, "those unfortunate tribes who now find themselves divided by the present boundaries find it very awkward ...Their cousins on the other side of the border will be foreigners." In Uganda and her neighbours Kenya, Tanzania, Sudan and Congo, many people that once belonged to the same tribal family are now citizens of two different countries. Until very recently with the emergence of the East African Federation, people would require a series of documentation to visit their relatives across the border.

In addition to the colonial boundaries, imperialists in Africa renamed places and discarded the original names of these places. Places were named after the Imperialists' own places in their homelands or after certain important personalities back home. Some examples are Lake Victoria which originally was Nalubaale and Lake Albert which was Rwitanzige. Unfortunately, the original names of these places had significant meanings and carried historical narratives about the places. Names like Victoria and Albert meant absolutely nothing to the Indigenous Peoples. To the people of the land, Nalubaale meant 'Mother of the gods' and this emphasised the sense that she was living; she was powerful and she was sacred. And this is because for millennia, these people have lived with this water body, observed her characteristics and developed a great respect for her contribution to their lives. From their organic interaction with the 
lake, they called her Nalubaale and thus established norms for management of the lake and her resources. With the loss of her name to imperialism, Nalubaale lost her living attributes; dignity, power, and most importantly, sacredness. She is now only a shadow of the original 'Mother of gods'. Mills (2009, p. 186) explains, "colonialism and exploration were at their very heart founded on laying claim to land, settling and naming land and hence depriving others of it." The renaming of places, like the case of Lake Victoria among the Baganda, transformed the way the people interacted with their places.

Some of the colonial and imperial marks on the places run deeper than transforming the attitudes of the people towards places. Some places were disfigured by the introduction of invasive species of flora and fauna without prior research to ascertain the repercussions of such introductions to these places. In Uganda, the introduction of the voracious Nile Perch into Lake Victoria has led to the extinction of more than three quarters of the original Indigenous fauna of the lake (Goldschmidt, Witte, \& Wanink, 1993; Ogutu-Ohwayo, 1990; Welcomme, 1988). This is not only upsetting the ecological set-up of the world's largest tropical lake, but it is also affecting millions of Indigenous Peoples whose lives directly depend on the lake's fauna. Also, this predatory fish was introduced for trivial reasons (i.e. sport fishing and more fish stock) which till now is referred to as a grave mistake (Goldschmidt et al., 1993; Pringle, 2005).

The colonialists' and imperialists' disrespect for the Indigenous places as depicted from the way they carelessly and without deeper understanding altered these places has caused these places and the communities irreparable damage. Sadly, after the political independence of the numerous former colonies, the Indigenous communities have got to deal with how to live in these altered and disfigured places. 
This is not made any easier with yet the transformation of the Indigenous Peoples themselves.

In addition to the transformation of the land, colonialism and imperialism altered the people that lived in these places. This alteration is mostly conceptual. The alteration of the Indigenous Peoples was done through education (Abdi, 2013; Hall, 2000; Semali, 1999). Fanon et al., (1963, p. 7) highlights that "the European elite undertook to manufacture a native elite. They picked out promising adolescents; they branded them, as with a red-hot iron, with the principles of Western culture." What constituted the curricular in the colonial schools did not represent the Indigenous ways of life and thinking. In addition, the language of instruction was the colonisers' language. Memmi (2013, p. 105) rightly elaborates about the schooling of the colonised:

The memory which is assigned to him is certainly not that of his people. The history which is taught to him is not his own. ... everything seems to have taken place out of his country. He and his land are nonentities. The books talk to him of a world which in no way reminds him of his own..."

This kind of miseducation alters the Indigenous Peoples so much so that they lose their self-esteem and consequently their self-identity. The loss of identity for the Indigenous Peoples is aggravated by the fact that the world in a global context regards the Indigenous Peoples inferior (Fanon et al., 1963; Memmi, 2013; Wa Thiong'o, 1994). In the same vein, when the Indigenous Peoples view themselves from this dominant Eurocentric global context (largely brought to them through their own education systems), they tend to learn to believe in the notion of being inferior to their human counterparts. This negative shift of their mental landscape is responsible for a lack of self-worth and a lack of interest to pursue their human dignity (Wa Thiong'o, 1994). Memmi (2013, p. 87) argues, “constantly confronted with this image of himself, set 
forth and imposed on all institutions and in every human contact, how could the colonized help reacting to this portrait?" The continuous degradation of self-worth and pride in identity makes it hard for many Indigenous communities to tackle or resist neocolonialism hence leading to the prevailing failure to manage their places.

The inferior position of the Indigenous Peoples is also confirmed in the constant denial of the importance and worth of their IK in the academy. Here is a good example of that denial:

I think it is evident that tribal cultures possessed an ecological innocence of sorts because they did not have the possibilities or the knowledge given to us. We, in contrast, must choose between biophobia and biophilia because science and technology have given us the power to destroy so completely as well as the knowledge to understand the consequences of doing so. (Orr, 2004, p. 798)

Even though Orr might have been satirising the use of technology in the 'developed' nations, it is evident that IK is simply dismissed as a disability or an inability on the part of the Indigenous Peoples. It is true that today several scholars acknowledge the value of IK, but many still will not only dismiss IK in the academy but will also not acknowledge its contribution to the fields like Agricultural science, human medicine, Literature and Art. This global lack of acknowledgement of its value has led to the Indigenous people themselves to not have the confidence to include their own IK into their formal education curricular. In Uganda, for instance, IK is not considered important enough to be included in the formal education curriculum.

The mental transformation is what makes it hard for Indigenous Peoples to achieve liberation and heal their lands. Abdi (2005, p. 33) affirms:

It has been possible to see people all over the world achieving physical liberation from European colonizers but the meta-corporeal effects of the 
case will remain intergenerational and will shape the mental dispositions and as importantly, the self and group confidence of the colonised.

Worse still, the Indigenous elite is described as struggling to look and act like the coloniser (Fanon et al., 1963; Memmi, 2013; Wa Thiong'o, 1994). This exemplifies how most Indigenous people today are frustrated about their identities or worse, they do not understand who they really are. As a result, they are depicted to be continually in pursuit of an identity which globally (and through their formal education curricular) is showed off to be the dominant, accepted one - the coloniser's identity. Scholars have explained how this state of mind (of confused identity) is not healthy enough to take a stand against colonialism and its effects (Fanon et al., 1963; Memmi, 2013). Unless people understand who they really are, they will never be able to appreciate either themselves or their places. Moreover, it is only when people appreciate their places that they will strive to protect them.

\section{Vanishing places in the postcolonial times}

With the dawn of independence in the 1960s, many African nations reorganised themselves into 'Independent Nations' basing on the demarcations of their lands by the imperialists. In Uganda, for instance, more than thirty groups of people were locked together as one country although each of the groups possessed a language and culture different from the rest of the other groups. In the precolonial times, each of these groups were an independent entity, politically and culturally different from the rest.

During the imperialist rule, Buganda Kingdom was semi-autonomous with her Kabaka on the throne and the Lukiiko ${ }^{18}$ (an assemblage of elders representing the clans) in charge of making governance decisions. This was such an organised group of people

\footnotetext{
18 The Buganda system of governance has a group of elders representing the clans in Buganda. This group of elders helped the Kabaka in governance. The Kabaka never makes administrative decisions in isolation.
} 
that they managed to retain considerable control over their land during the imperialist rule. However, when the 'nation' of Uganda was born (Uganda was derived from Buganda ${ }^{19}$ ), Buganda was disorganised; the Kabaka exiled; his people killed and his palace burnt down (Mutesa, 1967). The Kabaka was later murdered in exile. Since then, Uganda has experienced several very devastating wars.

The land was no longer the same after independence with the vanishing of the Indigenous systems of governance, and the tribal boundaries. This was all the groups of people in the country. Nepotism, a form of corruption, is one of the leading challenges in Uganda's politics and resources management today. In trying to unite all the tribes in one Uganda, after independence, the land has been riddled by deep divisions, wounds, and scars of all the wars that stemmed from tribal politics. Divisions based on tribal politics have been highly favourable for neo-colonialism to flourish ( Nyerere, 1964).

Post-colonial Africa is depicted as a land of misery. The media and other sources show, daily, children suffering from hunger and disease. The land is ridden by war, disease, poverty, hunger, and corruption. Abagi (2005, p. 301) explains, "once a continent with riches and beauty and people full of optimism and hope, the African continent is on the brink of economic disintegration, permanent famine, political chaos, institutional and social confusion." To the outsider as well as the young Africans, this confirms the portrait that was initially painted by the explorers, missionaries and the imperialists.

\footnotetext{
${ }^{19}$ The name Buganda is related to oluganda which is an equivalent of 'blood relation'. Luganda is the language spoken and yet it is the noun for 'familial relationship'. Other words that derive from Buganda are; okuganza (creating relationships, love); obuganzi (having lots of love for someone); enyanda (blood relatives). Buganda therefore means deep connections with others and with the place.
} 
African scholars have attributed this state of their land to the kind of education given to the people. Nyerere $(1967$, p. 2$)$ warns, "whenever education fails... society falters in its progress or there is social unrest as people find that their education has prepared them for a future which is not open to them." The language of instruction has greatly contribution to the disconnect from place in many African states. Memmi (2013, p. 107) argues, "the entire bureaucracy, the entire court system, all industry hears and uses the colonizers language. Likewise, highway markings, railroad station signs, street signs and receipts make the colonized like a foreigner in his own country." Subjugation of one's language amounts to loss of self-identity, culture and can also lead to hatred for self, for one's community and place (Wa Thiong'o, 1994).

The free movement of people, as a result of globalisation, results to the free movement of cultures and ways of knowing. Today, this has resulted into the changing of our places in significant ways. According to Abdi (2010, p. 4) globalisation is the "unhindered movement of peoples, good and services across regional, national and continental boundaries." Technology, through the internet and social media has enhanced globalisation (Abdi, 2010; McClay \& McAllister, 2014). McClay and McAllister (2014, p. 140) assert, "for some, placelessness has become the essential feature of the modern condition." This is especially true for people whose jobs take them to different countries all the time; people who want to start a different life in a different place like the immigrants; or people whose work is internet based. For such people, places vanish.

In this case, the physical and geographical places do not matter. People start making virtual places. This is what McClay and McAllister (2014) call cultural cosmopolitanism. These scholars argue that cultural cosmopolitanism, "is a consequence of globalisation whereby, through mass media and ease of travel, cultural 
particularities are dissolved into a universal culture" (p. 147). In this culture, people share the same beliefs and practices. McClay and McAllister (2014) describe this as a situation where people of different backgrounds, regardless of where they come from, accept to survive together wherever it is convenient. However, he also warns that one aspect of this increasingly globalised culture is the fact that the dominant culture is privileged.

Perhaps one of the direct effects of globalisation for most African lands is the loss of skilled labour to countries that are known to be 'rich' today (Akokpari, 2000). Many young African men and women have decided to abandon the motherland and migrate to other countries taking not only labour but skills, capital, and development. Globalisation therefore makes Indigenous Africa poorer and more vulnerable to exploitation. As such, some places continue to be exploited while some become more better off. Critical place inquiry calls for an understanding of how social practice (i.e. economic migrations) can help in the making of places either exploitative or otherwise (Tuck \& McKenzie, 2015). In this regard, it is noteworthy that action in the opposite direction of the norm can help to put things in either a conflicting or a harmonious order.

\section{Way forward}

For the Indigenous places, globalisation and cosmopolitanism are highly problematic because the Eurocentric culture is privileged (McClay \& McAllister, 2014). In this situation, the Indigenous Peoples' ways of knowing and doing are silenced. McClay and McAllister (2014, p. 126) argue "that to be cosmopolitan means setting oneself against certain local beliefs and morals..." in other words, it is to abandon localised attachments to place. But for the Indigenous Peoples, within the fabric of the dominant global culture lies subjugation, exploitation and neo-colonialism. 
Even for the dominant cultures, the continual neglect of attachment to place, especially because of the assumption that placelessness or globalisation is a modern condition, is dangerous. According to Gruenewald (2003b, p. 628), such a notion "releases people from their responsibility as place makers and - legitimises the ideology that is embedded in the places we take for granted." Moreover, whether it be globalisation or fluidity, "we live our lives in places and our relationship to them colours who we are" (Gruenewald, 2003b, p. 624).

To heal both ourselves and the places we inhabit requires a place-based education, also called place-conscious education or pedagogy of place for the people (Gruenewald, 2003a; Smith, 2013). Place-based education helps to connect schools to the communities as well as allowing the students and teachers to recognise the opportunities in their local places. In addition, place-based education brings to their awareness their interdependence with their natural environment and moreover helps them to understand and appreciate diversity within their communities (Smith \& Sobel, 2010).

In his analysis of place-based education, Gruenewald (2003a) calls for decolonisation and reinhabitation. He emphasises that the two terms are interdependent. "If reinhabitation involves learning to live well socially and ecologically in places that have been disrupted and injured, decolonisation involves learning to recognise disruption and injury and to address their causes" (p. 9). Many scholars advocate for decolonisation as a means of liberating Indigenous Peoples from situations and mindsets that limit them from achieving their full human potential (Engel-Di Mauro and Carroll, 2014; Nakagawa \& Payne, 2015; Wa Thiong'o, 1994). 
Around the world, Indigenous voices are reawakening. Many African scholars "are engaging in post-colonial counter-hegemonic approaches to decentre the dominant discourses" (Kayira, 2015, p. 106). There are many projects now involving IK in the classrooms. This means that the voices have moved on from just talking to participatory action. A lot of literature highlights the importance of IK for its land and social ethical values (Calderon, 2014; Smith \& Sobel, 2010; Thiele, 2013; UNESCO, 1992). In decentering of the dominant views by Indigenous scholars around the world, there is hope that both the Indigenous and the Non-Indigenous Peoples will come to genuinely appreciate, embrace and put in practice the wise counsel of IK.

\section{Conclusion}

This chapter has explained the literature on place. It ends by showing how the concepts of decolonisation and reinhabitation can be used to counter the effects of colonisation and loss of identity.

The next chapter discusses the method of inquiry that was used for this research project. Through a detailed discussion of the characteristics of PAR, this chapter shows how PAR has been used in this research as a decolonising methodology. The chapter ends with a discussion of the methods that were used for the collection of the data for this research. 


\section{CHAPTER FOUR: \\ TOWARDS A PARTICIPATORY ACTION RESEARCH INQUIRY}

\section{Introduction}

The previous chapters have detailed contextual and theoretical literature relevant to this study. This chapter will discuss methodological considerations and the research design which were used for the empirical aspects of this study.

\section{Locating the project}

This research project was intended to improve the co-participants' (i.e. teachers and elders) practice and confidence in their culture through creating space for their IK in the formal education system. Chapter two revealed the dichotomy between formal education and the people's way of life through the subjugation of IK. Literature (Elliott, 1991; Kemmis \& McTaggart, 2005) shows that PAR is effective in emancipatory projects (e.g. projects that require social change) because of its potential to build the confidence of participants through genuine collaboration. For the co-participants, this project was a decolonising journey. Decolonisation according to Nakagawa and Payne (2015, p. 154) is "the process to emancipate human subjectivities from socio culturally objectified constraints of place, which function as obstacles for individuals to achieve our 'full' potentials as human beings." In this project, the co-participants also sought to regain 'full' potential as contributors to the well-being of their communities in directly addressing both sustainability issues and connection to place.

As an empowerment methodology, PAR was employed in this project because it provided authentic collaboration between the participants and the researchers. The participants actively took part in the research project evolving with its progress (Johns, 2008; Swadener \& Mutua, 2008). At the same time, PAR as a decolonising 
methodology is framed in relationship which Swadener and Mutua (2008, p. 36) claim to "transcend individual action and require working with collectives or alliances." In this PAR project, the co-participants worked together as a team in all the IK activities in the schools and in communities. The participants planned the activities (like visiting the sacred places and taking students out for Bulungi Bwansi community service) together and collectively learned from the same activities. In so doing, their motives were driven for the good of their common heritage, Buganda. As a PAR project, this is a continuous learning process because the alliance of the co- participants continues even after the research project in a way that the teachers still meet and together, plan their place-based teaching activities.

In relation to critical place inquiry, PAR is a highly relevant research paradigm because it not only involves collective participation but also the "efforts of real people in real places" and to this end, PAR can "yield real and useful knowledge about place and places" (Tuck \& McKenzie, 2015, p. 89). Similarly, Kemmis (2008, p. 125) argues that PAR is critical in a sense that the participants examine how "particular perspectives, social structures and practices 'conspire' to produce untoward effects, with the aim of finding ways to change things so these consequences can be avoided." Therefore, PAR can effectively be used in critical place inquiry studies, like this one, since it deals with social action that is in response to critical place inquiry issues like neo-colonialism, subjugation of IK and environmental degradation (Tuck \& McKenzie, 2015).

\section{PAR as a decolonizing methodology}

Historically, PAR was successfully applied in situations that required democratic change (Johns, 2008; Titchen, 2015). In the history of PAR, Kurt Lewin's principles of Action Research were applied to the improvement of workers' output and 
motivation in a coal mining industry in Britain after the second world war (Bradbury, Mirvis, Neilsen, \& Pasmore, 2008). The philosophical root of PAR is traceable to Marx and Freire, both of whose philosophies envisioned social change through emancipatory action of the marginalised poor in their communities (Rahman, Reason, \& Bradbury, 2008). Also, the emancipatory nature of PAR as a method of inquiry is evident in that PAR validates its findings through dialogical consensus of the co-participants, contrary to the positivist paradigm that requires externally determined standards of data verification (Rahman et al., 2008). Habermas (1996, p. 361) also describes this process as a 'space' where "persons acting communicatively encounter each other - with their cooperatively negotiated interpretations."

Much as PAR is shown to have such potential in empowering participants, we need to be aware of its down side as regards to some scholars. Swadener and Mutua (2008) warn scholars engaging in decolonising research to be constantly mindful of the fact that the research process or the outcomes might instead reify the hegemonic power structures thereby creating marginalisation. PAR, which sits in the critical paradigm, is criticised for stereotyping co-participants by labelling them as a marginalised group (Scotland, 2012). In projects involving Indigenous people and IK, PAR could potentially pose a real danger of reinforcing the essentialist notions of indigeneity as prehistoric, static, unchanging and thereby romanticising the Indigenous (Kincheloe \& Steinberg, 2008).

\section{Why Participatory Action Research (PAR)?}

PAR was particularly suitable for this project because this project involved the co-participants reconnecting with their Indigenous ways, and together, forging means of integrating them into the formal education curriculum for the benefit of their community. Kemmis and McTaggart (2005, p. 296) explain, 
Participatory action research is one of mutual inquiry aimed at reaching intersubjective agreement, mutual understanding of a situation, unforced consensus about what to do, and a sense that what people achieve together will be legitimate not only for themselves but also for every reasonable person.

PAR was relevant for this study due its five essential characteristics as discussed by Stevenson and Robottom (2013). In this way, it is suitable for "a research agenda and a process that is controlled by those individuals or groups who are engaging an issue of their practice" (p. 470). These aforementioned characteristics have also been discussed by Mills (2007) and Noffke and Stevenson (1995).

The first characteristic of PAR involves practitioners or researchers where they research their own practice. In this project, the co-participants were education practitioners in their community. The participants involved were secondary school teachers; the student researcher who is also a teacher had taught for eight years in the same community; and community elders who are culturally and traditionally responsible for educating the young. The elders were responsible for working with the teachers to bring IK into the formal education setting. All of them were working towards a worthwhile change in the education system of their country.

The second characteristic of PAR is action oriented. The PAR practitioners take immediate action to combat a collective concern. According to Stevenson and Robottom (2013, p. 470), this is usually done "in cycles that integrated action and reflection." In this project, the collective concern was the fact that the formal education system did not do much in the integration of the IK of the people into their formal education curriculum. In this project, the co-participants attended Professional Learning Development (PLD) workshops to plan on how to bring IK into the formal education setting. Following on their plan, the co-participants observed classes where the elders taught about IK. They also attended group interviews to discuss and reflect 
upon the ideas generated in the elders' IK classrooms. The co-participants then attended group meetings to revise the plans and implement the knowledge gained in the curriculum.

The third characteristic of PAR involved a systematic process of recursive cycles of action and reflection that is responsive to evolving understandings and circumstances. This cyclical nature of PAR required researchers to engage in a continuous cycle of "plan, act, observe, and reflect" (Noffke \& Stevenson, 1995, p. 5). However, this cyclical nature, originally Lewin's cycle of Action Research, is not static (Mills, 2007; Noffke \& Stevenson, 1995). It is expected to be emergent depending on the circumstances of the study. Again, according to Noffke and Stevenson (1995, p. 4), this reflects the educators" "continual need of revision in their thoughts and actions." In light of this study, the participants would be required to make decisions on the next course of action depending on emerging factors. For instance, when the teachers found that their allocated 80 minutes' class time was not enough for the two-hour IK lessons, all the participants agreed to instead carry out the IK lessons during the time periods scheduled for extra-curricular activities. In this way, they collaboratively sorted and adapted their plans because of the circumstances.

The fourth characteristic is concerned with practical issues. According to Stevenson (2013, p. 470), PAR is "concerned with practical issues associated with human actions and social situations." Practitioners deal with the issues they encounter in their daily practice. Daily, teachers were faced with issues of teaching content that was completely irrelevant to the lives of their students. The elders were concerned that they were living in a world which completely ignored them and their vast IK that could indeed be beneficial to the lives of the people in their communities. Thus, both the 
teachers and the elders were concerned with practical issues about the education system in their community.

The fifth characteristic is that the intentions, process, and outcomes of PAR are publicly shared. In the project, issues of professional responsibility and trust were collectively addressed to ensure the smooth running of the project. There were many occurrences when the co-participants met to discuss the research process and the IK findings coming to a democratic agreement of the best ways to integrate IK into the education system. During group discussions, teachers shared diary entries and samples of students' work. They also met to discuss the topics and teaching methods to use in the integration of the IK into the curriculum.

Participation, in addition to collaboration in PAR makes the project political in a sense that the participants collaboratively recognize injustice and then go further to practically address it. McArdle and Reason (2008, p. 6) contend:

PAR is explicitly political, aiming to restore to the oppressed peoples the ability to create knowledge and practice in their own interests. PAR practitioners emphasize emergent processes of collaboration and dialogue that empower, motivate, increase self-esteem and develop a community solidarity.

In this project, the co-participants built a strong alliance of teachers and community elders and together negotiated ways of addressing the injustice of the education system that subjugates their IK. The support they gained from the collective to tackle their social problems suits the political imperative of PAR (Kemmis \& McTaggart, 2005).

In so doing, participation in this research provides the opportunity for the coparticipants to be empowered as they make decisions on their own practice, gaining control of their own lives. Reason (1998, p. 3) highlights empowerment benefits saying, "PAR affirms the fundamental human right of persons to contribute to decisions which 
affect them. Human persons are centres of consciousness within the cosmos, agents with emerging capacities for self-awareness and self-direction." The continuous discussions about the knowledge gained and what was important in IK, coupled with the numerous group discussions on how to bring IK into the curriculum empowered the co-participants into making practical improvements to their own practice and community. This is also part of the decolonisation process. From my own teaching experience in Uganda, lack of control of own practice makes professional teachers in Uganda lose confidence in themselves and their capabilities.

The teachers' freedom of thinking is controlled by the rote teaching methods enforced through the rigorous examination driven curriculum. Hence, teachers are driven to teach students for the sole purpose of passing the UNEB examinations. PAR as a method of inquiry can emancipate teachers from this thinking. This is achieved through the teachers' own initiative to first of understand the importance of their IK and then creating the space for it in the curriculum. By the end of the project, all the participant teachers were confidently planning lessons with IK activities although this content is not going to be examined by UNEB. PAR has an emancipatory advantage. Reason (1996, p. 81) explains:

The emphasis of participatory research is that the purpose of the research is the development of knowledge that can be applied to emancipatory purposes, and that the process of the research should in itself be an education for freedom, an education for the community and the individual in the experience of creating one's knowledge.

Even though freedom of thought in their practice and in their creative capability cannot be gained overnight, the co-participants embarked on a deliberate course to pursue it. Nyerere (1964, p. 43) explains, "people can only free themselves, no one can prevent them from trying to win their freedom, and no one else can do it for them." This pursuit must be done constantly and deliberately with perseverance. Freire (2005, 
p. 45) adds, "freedom is acquired by conquest, and not by gift. It must be pursued constantly and responsibly." The reflexivity of PAR with its emphasis on collaboration was advantageous for this pursuit.

This project benefited from the ecological benefit of PAR in that through their actions, the co-participants involved their communities and their natural environment. Reason (1998, p. 3) contends that "human persons are communal beings, born deeply immersed in community and evolving within community." This was exemplified during the Bulungi Bwansi activities when the co-participants worked with community members to save their disappearing trees. They also listened to the elder's historical narratives about Ssezibwa while his thundering voice affirmed his sacred legacy in Buganda. Finally, they re-connected with the land by interacting with the Indigenous plants and having conversations about them. Reason (1998, p. 13) explains that participation "affirms that human persons are a part of the cosmos, we evolved with it and are part of its creative force."

Lastly, this research paradigm was suitable because participation is a fundamental value in the Kiganda society as reflected in the historical narratives of the Saagala Agalamidde drumrolls and the spirit of Bulungi Bwansi. In the historical narratives, when the people of Buganda heard the drumrolls, they took on the social responsibility to go for Bulungi Bwansi - for the good of the land. Usually this involved digging or cleaning water wells, clearing the roads and many other social responsibilities. Participation is deeply embedded in the cultural ways of the people of this region. 


\section{Researching with the participants}

The relationship between researcher and participants is a significant issue in decolonising research projects as well as in PAR. Collaboration in PAR is important. Working together for the benefit of the common good requires good and strong relationship between the co-participants (Abdi, 2013; Kemmis \& McTaggart, 2005; Kindon, Pain, \& Kesby, 2007). Researchers have recorded the problematic position of Indigenous scholars or native intellectuals in doing research within Indigenous communities (Abdi, 2013; Kincheloe \& Steinberg, 2008; Smith, 2013), in particular, the mistrust that the local people might have for the Indigenous scholars which can inherently impact the research process.

The area of Buganda and specifically Mukono where this research was conducted, is a very important place for all the participants. Specifically, Mukono is the area where when I first qualified as a secondary school teacher I subsequently worked for a period of eight years before moving on to work at a local university in the same locale for another eight years. Some of the teachers with whom I worked on the project had been colleagues when I was a teacher in the same schools; one had been my former student in my early years of teaching in the area. Mukono has been my home for 20 years. As such, I was aware of the cultural norms of the people; the language, the culture and what teachers in that area of Uganda experience in their daily service. The most significant binding factor in the relationship between the co-participants was that all the teachers and elders on this project were Baganda. Only two people, myself and a community participant, were not Baganda by birth. However, both of us were Baganda ${ }^{20}$ by marriage. Our children are also Baganda. Buganda is home to all the co-

\footnotetext{
${ }^{20}$ We were married to Baganda men and culturally we now belong and adhere to the customs of the tribe. Our children belong to their fathers' clans in Buganda.
} 
participants in the project and therefore the cultural wellbeing of Buganda held great significance for us all.

Power was of primary concern to me in and through the research and therefore I wanted to ensure that the relationships that I held with co-participants were not problematic. The teachers and I were at the same level of 'teacher-learners'. An example of this was in the Nyama Kyoma meetings. In these meetings, I did a lot of listening while guiding the participants' discussions to ensure they did not stray too far from the interview guide. However, the teachers were the experts in the curriculum here. They were the Luganda and oral literature teachers and knew their subjects well enough to suggest where to insert what IK aspects. The elders were much respected in and through this research project. We all called the lady elders Ssenga, a respectful title for the paternal aunt, while we also called the male elder Mzee Taata since he was (culturally) a father figure to all of us. One of the teachers was Mzee Taata's daughter but he also called me Muwala (daughter) because he was from the same clan as my husband. This is a cultural way of acknowledging relationships in the community. The elders called the teachers Musomesa, which is a respectful title for Teacher. The coparticipants' relationship was based on mutual respect which also reflected our roles (teachers and elders) in the community rather than on this particular research project. We were a team of experts in our own unique and different ways. There did not appear to be any power imbalances but rather a mutually respectful community of practice. There was deep respect for the elders but this does not mean that the elders exercised any power over the rest of the participants involved in the study as there were instances when the elders were learners as well. This highlights the collegial respect among the co-participants. 


\section{The language of the project}

Language played a significant role in the success of this research project. The language we used in this research project was Luganda. Luganda is the local language of the area and it is also the subject that most participant teachers taught in the schools. Only one teacher taught oral literature but even then, it was the oral literature of Buganda. By using Luganda, there was no communication barriers between the coparticipants and moreover the Kiganda IK concepts were implemented without the burden of translation. The elders, who hardly spoke any English could freely communicate with the co-participants and students in Luganda. Learning about the IK of Buganda in Luganda with community elders of the same area made this a placebased educational experience.

\section{Research design}

Since PAR is participatory in nature, I worked with several co-participants in the research project. The co-participants included; three elders, two community members who facilitated the IK learning activities, five teachers and me as the student researcher. Together, we actively contributed to the integration of IK into the education system through our different roles in the community. Marshall, and Maclntosh (2007, p. 373) urge that "researching with people means that they are engaged as full persons and the exploration is based directly on their understanding of their own actions and experience, rather than filtered through an outsider's perspective." The participants could participate in the project in equal ways and in so doing, made sound decisions about the procedure of the project. The project was undertaken in two phases. Phase one involved the initial selection of the participants. In this phase, I sought to obtain consent from the head teachers so that I could work with their schools and teachers. 
After gaining their consent, I could seek the consent of the teachers. The teachers helped me to get in touch with the elders where subsequent consent was gained.

Phase two involved the PAR cycles of planning, action and reflection. This phase started with a PLD workshop which centred on developing 'conscientization' 21 within the participants. The workshop also assisted planning various elements for the action stage which was scheduled to occur at the beginning of second term. Participants were also requested to give their consent for them to take part in the next stage of the project. Consent was sought at this stage because after the workshop presentations, I felt that the participant teachers had gained a greater understanding of what the study entailed and therefore were able to make informed decisions. Specifically, consent was sought through an anonymous survey implemented at the end of the workshop.

In phase two, the action element occurred. Specifically, the action phase involved three activities that included, Bulungi Bwansi and the eliminate charcoal program; rediscovery of our sacred places; and the exploration of the Indigenous plants. Each of the activities centred on three themes: bringing the community into the classroom; bringing the classroom into the community; and bringing the community into the curriculum. Also, in this phase, reflection on action through meetings occurred. Because of these reflections, we re-planned how best to bring IK into the formal education setting. After replanning, we launched back into the action phase centring on the three revolving themes. As such the PAR cycles were continuous.

It is important to note that less details of the project are given in this particular chapter because an important feature of PAR is the way activity design is modified following reflection in action. Advance plans were a key element of confirmation of

\footnotetext{
${ }^{21}$ Conscientization centres on acquiring a critical understanding of the social issues in society.
} 
candidature $^{22}$ and ethics approval. However, as discussed in chapter five, these had to be modified at an early stage to be consistent with the activities which participants were willing and able to undertake.

Figure 1: The phases/ stages of the research and the methods that were used as part of each phase

${ }^{22}$ Confirmation of candidature is a requirement of all University of Tasmania PhD, ED. D and MA candidates in their first 12 months ( 6 months for the MA) in which the University assesses the academic development, performance, and suitability of the candidates' projects. 


\section{PHASE ONE: SELECTION OF PARTICIPANTS}

- Sought head teachers' consent Through:

- Sought teachers' consent $\checkmark$ Individual interviews

- Sought elders' consent $\checkmark$ Group interviews/discussions

- Invited elders for initial group interview $\checkmark$ Personal and Historical narratives

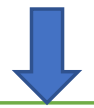

PHASE TWO: PLANNING - First PLD Workshop

- I presented a paper on PBE

- Elders presented on areas of expertise

- Teachers and elders drew plan for action

- Administered survey to participants

\section{Through: $\checkmark$ Group interviews/discussions \\ $\checkmark$ Personal/historical narratives \\ $\checkmark$ Teacher survey}

\section{ACTION\& OBSERVATION-IK activities in schools}
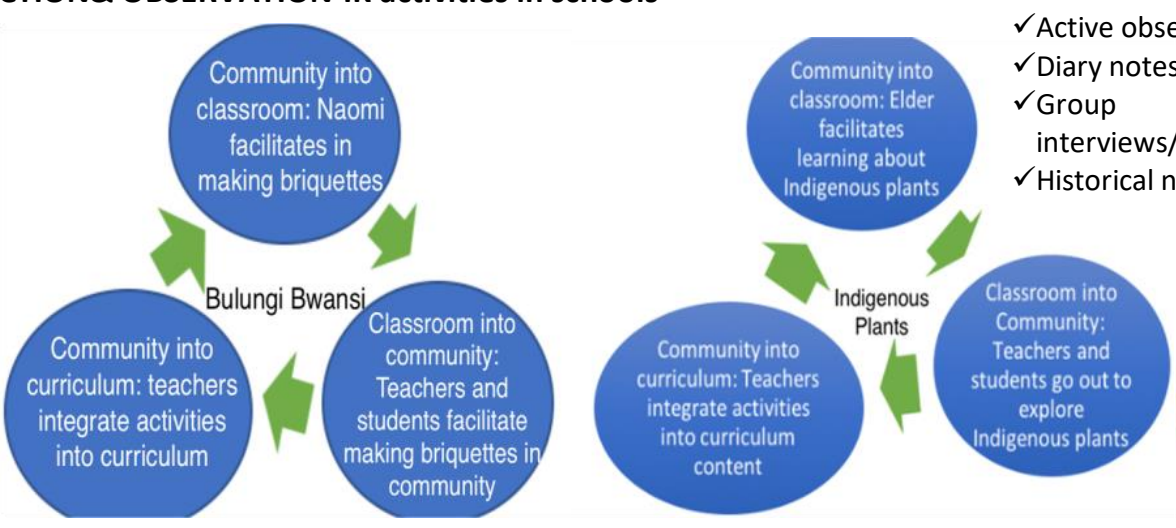

Through:

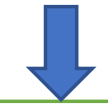

\section{REFLECTION-Participant Meetings}

- Co-participant meetings at end of activity

- Weekly Nyama Kyoma teachers' meetings

\section{Through:}

Group interviews/discussions

$\checkmark$ Sharing diary notes

$\checkmark$ Sharing samples of students' work and teachers' lesson plans

\section{RE-PLANNING- Second PLD Workshop}

- Revision of actions

- Naomi facilitates new area/activity

- Addressed project challenges

Through: $\checkmark$ Group interviews/discussions

$\checkmark$ Personal narratives

$\checkmark$ Sharing diary notes

$\checkmark$ Sharing samples of students' work and teachers' lesson plans 


\section{Methods employed in the project}

The methods employed in this research project were in line with the empowering goals of PAR. McArdle and Reason (2008, p. 6) explain that PAR aims to "restore to the oppressed peoples the ability to create knowledge and practice in their own interests." For this reason, we used dialogue-rich methods that empower, motivate, increase self-esteem and develop a community solidarity (McArdle \& Reason, 2008). Therefore, we used group discussions, group interviews, active observation, personal and historical narratives, individual interviews and diary notes. A survey was used at the end of the first PLD workshop, in the selection of participant teachers to take part in the action part of the second phase.

\section{Individual interviews}

Individual interviews were used mostly in the selection of participants at the beginning of the study in phase one. This method was used as a way of involving potential participants in a "deliberate informed conversation" (Klein, 2012, p. 21). This was done to find out whether they would be interested in getting involved in the project. The other reason for the implementation of these individual interviews was to build a rapport with the people who could potentially be part of the team. I designed a short interview guide with five short open-ended questions to guide me during these individual interviews. However, I allowed for flexibility in case the person wished to speak about his or her relationship to the land and culture in a deeper and more involved way. I also encouraged the person to ask me any questions. The elders asked questions about my clan, my clan totem, my husband's clan totem, my husband's clan, the names of my parents, the names of my husband's parents and the like. It was only after I had answered their questions, that they made up their mind about whether to join the project. These interviews subsequently took place at a location of convenience for the 
interviewees. These personal interviews were not audio recorded but I took notes with prior permission sought.

\section{Group interviews/discussions}

Group interviews/discussions were conducted during the reflection meetings. In PAR, group interviews and discussions are important because each participant can be able to "collect new kinds of evidence about practices, understandings and the conditions for practice in their settings" (Kemmis, McTaggart \& Nixon, 2014. p. 3102). In light of this, group interviews were a point of reflection for all the participants about the project and also about their own individual practices. The group interviews/discussions were also very useful in helping the co-participants to make sense of their knowledge. These group interviews/discussions revealed a lot of information on IK and Indigenous education in our culture. According to (Creswell, 2009), these interviews can provide historical information on issues. An interview guide was purposely designed to guide us through the most relevant areas. However, the co-participants were involved in asking each other questions to validate information or to seek clarification about cultural aspects of the activities that we had been involved in with the elders. These group interviews were also audio recorded and these recordings were replayed for the group whenever we needed to refer to something that we had done earlier; validate the information; or compare different cultural concepts that needed explanation.

\section{Personal narratives/historical narratives}

The personal narratives were stories that laid background to these participants' significance to the project. Usually the participants narrated about their family history and what makes them true Baganda. Through these narratives, we learnt about attachment to place; the dissatisfaction with the present cultural disintegration and 
therefore, the reason for one's participation in the project. In the same vein, the historical narratives were used by the participant elders to reconnect us to our culture and with the land. Smith (2013, p. 145) explains how "the story and the story teller both serve to connect the past with the future, one generation with the other, the land with the people and the people with the story." These narratives were audio recorded with the permission of the narrators and co-participants.

\section{The teacher survey}

The teacher survey was administered after the first PLD workshop. The main purpose of the survey was to assist in the selection of the participants, particularly those who were willing to move onto the next stage of the project. After the first PLD, the survey provided me with information regarding how many participants were willing to continue with the project after hearing about what the project entailed. The survey also provided insight into what the teachers thought about the PLD workshop. This was important because in the Ugandan education system, it is a new phenomenon to involve community elders. Engaging with the teachers' responses about the elders' presentations provided me with the teachers' initial thoughts regarding how they felt about working with the elders in the formal education setting. The survey was anonymous so that the participants' responses were not biased.

\section{Active observation}

Active observation was carried out by all the co-participants in the study. During the IK learning activities, the participants were involved actively in the ongoing actions. "Observation enables researchers to record important details that become the basis for formulating descriptions from which stakeholding groups produce their accounts" (Stringer, p. 133). During these observations, the co-researchers made diary notes which they later shared with the rest of the co-researchers and discussed about 
during the group meetings. I designed an observation guide that was utilised by all the participants so that we are guided on the things in line with the aims of our research for us to take note of during these activities. Active observation also enabled the coparticipants to gain a practical learning experience during these activities.

\section{Diary notes}

Diary notes were used by the participants to note significant information during IK activities, class observations, or during reflection group meetings. In PAR, diary notes "become a rich source for exploring different participants' different perspectives on what happens." (Kemmis et al., 2014, p. 3112). At the beginning of the study, every member received a diary. Everyone was encouraged to make entries against a date and place and give some detail about the incident. These were also used when the coparticipants were planning lessons around the areas of IK that they had been involved in. Participants shared their diary notes during the meetings; however, this was not mandatory. Only willing participants shared their diary notes.

\section{Samples of students' work and teachers' lesson plans}

Samples of students' work and teachers' lesson plans were used by the teachers in their integration of IK into the curriculum. During the teachers' weekly meetings, participant teachers shared samples of their students' work as a way of initiating discussions with co-participants about how to integrate IK into their curriculum. They also shared lesson plans as a strategy to collaboratively learn how to integrate IK into their pedagogy. In PAR, document analysis is important as the documents might contain relevant information or evidence that is related to the issues being explored in the research (Kemmis et al., 2014). Like the diaries, there was no pressure regarding what was shared in this exercise. Only willing participants shared these documents and the discussions that ensued resulted in improving and enriching their practice. 


\section{Data Analysis}

In this research, data analysis took place synchronously with the data collection. As a PAR project, the participants were involved as co-researchers and therefore their interpretations, analysis and decisions were important, and resulted into significant changes in the various phases of the research project. Ezzy (2002, p. 61) elucidates that "integrating data collection and data analysis allows the analysis to be shaped by the participants in a more fundamental way." The integration of data collection and analysis further situates this PAR project within critical place inquiry in that the co-researchers are not just providing the data for the research but are further engaging in a critical reflection of their lives in relation to their places and vocations. Tuck and McKenzie (2015, p. 19) affirm that critical place inquiry "entails understanding places as both influencing social practices as well as being performed and reshaped through practices and movements of individuals and collectives." Given that these co-researchers knew well their education as well as cultural contexts, their collective analysis led to not only relevant but also real pedagogical changes for the Ugandan teachers.

In this study, the co-researchers' interpretations of their integration of IK into the school settings grew and evolved throughout the different phases of the research. Data analysis in qualitative research, and especially in action research, has been described as an interpretive process (Ezzy, 2002; Stringer, 2014). As the co-researchers reflected on how the different IK activities were being utilised in the reconnection of the students and teachers to their places, they found that they had to continually adjust on how to carry out these activities in order to effectively integrate IK into the formal educational setting. This furthers exposes the theoretical underpinnings of critical place inquiry that emphasises the shifting nature of places through the social interaction of the people and their practices (Tuck \& McKenzie, 2015). In this case as the co- 
researchers engaged in rediscovering their cultures through the IK learning activities, the way they engaged with their professions changed them into a new kind of professionals who are able to actively work towards a worthwhile change in their professions and places.

During the frequent group discussions that were part of the reflection phases in this research, the co-researchers made decisions on the areas of IK that they wanted to be brought into the classroom settings and how best to do this. Through this analytical process, they would discover their own voices (i.e. voices that had been silenced by the unfair conditions of the education system) to take control of their professions and lives. This reflects on the PAR grounding in critical place inquiry as it deals with issues of social justice (Tuck \& McKenzie, 2015). When the teachers decided not to bring into their schools the IK about Obuwangwa due to its conflicting nature with Christianity, the elder responsible for this area decided to merge with another IK area in which she used her vast knowledge about the land to teach about the sacred places. The decisions that the co-researchers continually made for them to improve their practice were all based on their knowledge and understanding of their cultural as well as educational terrains. Consequently, this was key to the ongoing analysis of the data in this PAR project.

From the IK activities, themes emerged that were in line with the language and culture of the co-researchers. The participatory nature of PAR was very much in line with the IK concept of Bulungi Bwansi, which calls for responsibility and altruistic service to the one's land. Stringer (2014) clarifies that in PAR, analysis is grounded in the participants' terms, concepts and meaning. The co-researchers' dedication to the improvement of their practice through the integration of IK into their curriculum was driven by this concept of Bulungi Bwansi. The co-researchers met regularly to discuss 
progress, attend and observe one another's classes to get ideas from one another, as well as share teaching materials; all in spirit of Bulungi Bwansi. The knowledge and understanding of their cultural context was key in the interpretation of the data which was integral to the data analysis in this research project.

The continual collaboration with the participants after the data collection was instrumental to the development of my deeper interpretation of the data. This was integral to the further analysis of the data which led to the emergence of the detailed cultural themes that underlay the discussion and structure in the last section (Part C) of the thesis. Throughout the process of translation and transcription of the data, I continually engaged in telephone conversations with the participants in the interpretation of various synonymous Luganda terms and concepts (i.e. Ensi and Eggwanga in relation to land, country and earth) which the elders had used in their IK lessons. This process is all explained in chapter five. The collaborative interpretation further helped to bring into the thesis the participants' analytical understandings of their culture thereby contributing to the PAR principles of collaboration and participation. In addition, the continuous analytical conversations highlight the critical place inquiry paradigm as it brings into perspective how the co-researchers continually strive to understand, conceptualise and even practice their places during and beyond the research project (Tuck \& McKenzie, 2015).

The integration of the data collection and analysis in this PAR research further enabled the growth of the three major themes that not only guided the process of data collection but also allowed for the co-participants constant reflexivity about their actions. These themes depict the continuous critical analysis of the co-participants' own actions of integrating IK into the curriculum and thus making porous the walls between the schools and the community, which is one of the primary principles of 
place-based education (Gruenewald, 2003a). The three major themes that guided the inner PAR action cycles depicted in Part B were: bringing the community into the classroom; bringing the classroom into the community; and bringing the community into the curriculum.

The collaborative approach that took place in this project, where the participants continuously discussed and reflected on the ongoing action led to emergence of these themes. Stringer (2014, p. 137) explains that, "the interpretive activity exposes the conceptual structures and pragmatic working theories that people use to explain their conduct." In this project the participants' activities which followed the pattern of always marrying school with community helped in the identification of these themes as key experiences of the co-researchers in the research project. Moreover, Freire (2005) affirms that whenever education is dialogic in nature, it leads to thematic investigation. These themes (bringing community into the classroom; bringing classroom into the community and bringing the community into curriculum) represent the perspectives and experiences of the participants as they repeatedly and collaboratively worked out ways of bringing their IK into the curriculum. These themes are born out of the continuous process of the participants' reflexivity and making sense of their actions in this project.

The theme bringing the community into the classroom came out of the actions of the co-researchers when they strived to ensure that in our research project, the schools opened up for the community (i.e. community elders) to come in and instruct on the different aspects of IK. In all the three IK activities which included instructing students in community service, learning about sacred places and learning about the Indigenous plants (as detailed in Chapters 6, 7, and 8), opportunities were availed for the participant elders and/ or community members to come into the classrooms to 
facilitate in the selected IK topics. Stern, Townsend, Rauch, and Schuster, (2014, p. 856) argue that, "PAR is about developing a realization that local people are knowledgeable and that they, together with researchers, can work towards analyses and solutions." As is also characteristic of PAR, all these activities were followed up with critical reflection of the co-researchers in form of group discussions (as is detailed in Part B of the thesis) where they collaboratively analyzed their actions of bringing the communities into the school settings and made recommendations on how to improve their actions.

In addition, the theme bringing the classroom into the community was born out of the co-researchers' actions of creating opportunities for the classrooms to go out into the communities, interact with the community members, and learn about their IK outside the walls of the classrooms and under the instruction of the community elders. In all the three IK activities that the participants involved their students into (as described in Chapters 6, 7, and 8), there were opportunities availed for the classrooms to be taken out into the communities. Freire (2005, p. 95) contends that "Only dialogue, which requires critical thinking, is also capable of generating critical thinking." After every each one of these lessons, the co-researchers were involved in collaborative critical reflection events in form of group discussions. During these meetings, the coresearchers, together, deliberated upon and analyzed their actions and as a result, made recommendations for the next actions.

Lastly, the theme bringing the community into the curriculum was molded from the actions of the teachers' weekly meetings (Nyama Kyoma as detailed in Part B) during which the participant teachers met to discuss how they could bring the IK that they had acquired throughout the weekly activities into the curriculum. In these meetings, the teachers dialogically evaluated the actions of the entire week through 
sharing teaching materials (on IK), diary notes (made during the elders IK lessons) and exchanged and analyzed students' work samples (on the IK activities). These meetings were a great opportunity for the participants to rectify or/ ratify each other's interpretations and as a result developed richer understandings on which they based to bring the different aspects of IK into their curriculum (Freire, 2005). This highlights the data analysis process that is enmeshed in the actions of the participants in this project.

These analytical themes were very instrumental in guiding the inner action cycles of PAR in all the co-participants' actions of integration of IK into the classroom as well as implementing of place-based education in their education system. As such, these themes are relevant to the study in that they highlight the primary aim of placebased education which is making permeable the barriers between school and community, thereby making school relevant to the community (Duenkel \& Pratt, 2013; Smith \& Sobel, 2010). As the plans of the co-researchers in this project evolved, it became evident that these themes clearly highlighted the pattern of the PAR actions as well as the analysis of the data in this project.

\section{Ethical considerations}

The approval to conduct this research was granted by the University of Tasmania Higher Research Ethics Committee. The participants read information letters and signed consent forms prior to their participation. In addition to giving the participants information sheets and consent forms, the participants were informed regarding how long the research was going to take and the kind of commitment that would be required. There were translations of the information letter and consent form into Luganda for the participants who were not familiar with English. I met the participants individually and talked with them about the research in detail so that they 
could make informed decisions. The participants were also made aware that participation was voluntary and that they could leave the project, at any time, if they felt constrained and/or stressed.

The participants' consent for audio recording was explicitly sought. They were also informed that direct quotations from the interviews, discussions and narratives would be used in any subsequent research publications. They also were given an opportunity to access their information before it was used. Participants had the right to refuse their information being used in the research. To assure confidentiality of the participants, all names have been replaced with pseudonyms.

There were no issues of researcher safety. This study was conducted in accordance with section 4.8 of the national statement. As a Ugandan, I have lived in the area for over 20 years and taught in secondary schools in the same area for over eight years. I am proficient in the local language of the area and well versed with the cultural context of that region. 


\section{PART B: ACTION AND OBSERVATION}

\section{Introduction:}

This section consists of four chapters that provide the detailed methodological procedure of the research project. The section also relays the observations of the all the co-participants throughout the inner circles of the actions as carried out in this PAR project. The details of the research design including the shifting nature of PAR, which I refer to as the messiness of PAR, are explained in chapter five. The details of each of the actions in addition to the inner cycles of the PAR are elucidated in chapters six, seven and eight. 


\section{CHAPTER FIVE:}

\section{THE MESSINESS OF PARTICIPATORY ACTION RESEARCH}

\section{The background to the enthusiasm of the researcher}

I was very enthusiastic about the project from the start. A primary reason was that I felt that the project held so much promise for the Ugandan education system and I looked forward to sharing it with the teachers and the rest of the participants from the communities in the Mukono district. Having been a teacher, I knew how frustrating it was to work in the Ugandan education system (e.g. teachers constantly pressured to ensure that students' scores were high). As I continued to reflect on the Ugandan education system and the inconceivable disconnection from place it caused to both teacher and student through the constant race for test scores, I became more and more convinced that a place-based education strategy may remedy our social and environmental problems in the country. In the subjugation of our IK and languages, our educational system is unjust to Ugandans (and has been for a long time), thus responsibility ultimately falls on the teachers.

Teaching in Uganda means dedicating your career to your students' passing of the Uganda National Examinations Board (UNEB) exams. You are continuously drilling, marking and coercing your students, so that they excel in the UNEB exams. Your time is spent either in the classroom or in your students' workbooks, marking. Students learn by rote as teachers teach to the text. Students' enjoyment of their learning is of no importance; passing the exams and scoring highly is what matters. Teachers are tasked to find ${ }^{23}$ ways of ensuring students pass their examinations.

\footnotetext{
${ }^{23}$ In many cases, this is a desperate battle that ends up in devising means of cheating for the students and/or training students to cheat.
} 
To help teachers achieve success, there is the timetable (showing the timeperiods of the subjects or activities and the responsible teachers) in addition the Director of Studies (DOS) (to ensure that the time-table is followed) and the UNEB syllabus. In this kind of educational environment, everyone concerned with the education system is a loser for various reasons. The teacher is denied the freedom to reflect deeply upon his or her values (and practice) well as the learner is denied the freedom to enjoy their education experience (McNiff, 1993). The result is a vicious circle of disconnection.

On the three-day journey from Launceston where I was undertaking my $\mathrm{PhD}$ studies back to Entebbe, I continuously reflected on my project and on the pragmatics of the methodology and the Ugandan education terrain that I knew so well. I continued to read various examples of Participatory Action Research (PAR) projects and as a result I felt more confident in its possibilities to empower and transform the Ugandan teachers (i.e. the ability to develop the confidence in their capacity to make decisions about their own practice) and eventually the education system.

\section{The uneven terrain}

I was prepared to be flexible when things did not go according to plan which often occurs in PAR (Duenkel \& Pratt, 2013), thus I was equipped with a plan B. As a result, I was prepared for the surprise that I would not be working collaboratively with the local university to meet and select my participants as had been earlier planned. Therefore, I immediately set out to implement plan B where I went to the local schools to meet with the head teachers, seeking their consent to select teacher participants from there.

I contacted a former friend and colleague who is also an examiner with UNEB to get his advice about the schools in Mukono that offered Luganda in their curriculum 
as a means of narrowing down the search and saving time. As Luganda is an optional subject, not every school has it on their curriculum. However, I was confident that most schools had oral literature because it was offered under the Department of English. After listening about my project, my friend suggested the names of the schools that offered Luganda in each sub-county ${ }^{24}$ in Mukono and in addition, encouraged me to let the head teachers know that he recommended their schools for the project. As an examiner, he was quite respected in the secondary school circles.

One of the major hurdles that I had to overcome was the weather. It is during the first school term of the year (Around the months of February, March and early April) that we experience the rainy season in the region. The research project had to be done during the first and second terms because the third school term is when students sit for the UNEB examinations and it would be difficult to gain the head teachers' consent to work with the teachers during this term. The intense rain did not make my journey to the schools easy. It rained hard for the whole week from morning to evening making it impossible to travel to the schools. The following week, the rain abated, however, there was still rain for several hours every day. The roads to these places were impassable. They were muddy and no cars would travel on them. For this reason, I had to hire a boda boda ${ }^{25}$ cyclist that I trusted and was able to maneuverer through the roads to the schools. I realised that a sound knowledge of the terrain and the people was an advantage in overcoming challenges that arose during the research project.

\footnotetext{
${ }^{24}$ Uganda is divided into 111 districts; which are further divided into counties. The counties are further subdivided into sub-counties. Mukono district, the district of my research, forms only one county which is Mukono county. Mukono county is divided into thirteen sub-counties.

${ }^{25}$ Boda boda is a local name for the motorbike used in the same way as a taxi. Although they are generally considered unsafe, they are the best and sometimes only means to get to hard-to-reach places.
} 
After listening to an overview of my project, the head teachers of the schools referred me to the Director of Studies (DOS) who had the final say over whether the project had any academic relevance to the students or not. I knew from experience that the DOS had the power to refuse me from proceeding any further. I did a lot of explanation about the project as well as offering copies of the information letters which outlined the relevance of the project for both the students and the teachers in Buganda. It was no easy task to convince them on a relatively new idea, that being place-based education and that the current schooling set-up is condescending to their IK. Realising how precarious my position was in this negotiation, I strategically mentioned my UNEB examiner friend who recommended their school for the project. This helped immensely, primarily because the UNEB drives the curriculum.

The lengthy information sheets and consent forms were problematic for the people to read in one go to make their decisions about whether they were willing to join the project. While some head teachers and DOS signed the consent forms after scanning through them, others required me to return to the schools several times before consent forms were signed. This is because the potential participants had not yet had the time to read the documents in full. Most of the teachers' consent forms were received during the first PLD. The elders' consent forms were returned during the first group meeting which was held at Patron hotel. The signing of the consent forms had very little to do with the genuine consent of the participants to work with me on this project. The participant elders' consent was gained through extensive conversations with me. As a result of these conversations, they trusted the person I was and saw sense in what I said. What I soon was to realise was that the participant teachers' signed consent forms did not in any way mean they had consented to participate as I later discovered. This point will be expanded on later in the chapter. 


\section{Selection of participants:}

\section{The participant teachers}

Selection of the participants was not as straight forward as I had expected. I had planned to work with 12 teachers as well as six elders from approximately six schools in the six sub-counties in Mukono district. It was essential to find people that would be enthusiastic about the project because that would determine its success. In previous PAR studies, people already work together in a certain field before they carry out PAR. Therefore, they know one another well and their challenges are shared and felt by all of them (Elliott, 1991). With this knowledge in mind, I realised that the participants in this PAR needed to obtain what (Freire, 2005) refers to as consientização (conscientization) for them to appreciate and develop dedication to the project and eventually benefit from it. For this reason, it was essential to recruit participants who would work with me throughout the many cycles of the PAR project and beyond.

It became apparent early on that the teachers did not fully understand the consequences of their disconnection from their culture and place. This is because their cultural values had always been subjugated by the formal education system. The teachers from whom I had to select participants to work with were not free minded individuals, but people who were dominated by their education system. This was the primary reason why the selection and retaining of participants to the end of the project was not straight forward.

When the DOS introduced me to the teachers, I did not feel confident that they would want to participate. I knew that I had to gain the teachers' trust and consent when the DOS or headmaster was not present. So, I set out to establish connections with them by seeking individual meetings with them away from the school environment. It was 
only after I had spoken with each of them in person, that I was able to gain their consent. When I had visited the 12 schools and received the consent of six teachers with the promise of about 10 others, I started to prepare for the first PLD workshop.

\section{The participant community elders}

Two of the teachers, one of which was a former student of mine, introduced me to two elders. The two elders introduced me to two other elders. I planned with them to meet for a focus group discussion about their role in the community and how they could contribute to the project. One of the elders did not turn up. So, I ended up with three elders in total. One was a male and two were female.

One of the elders advised that one of the most important areas rich in IK in Mukono was Ssezibwa falls. He encouraged me to visit Ssezibwa and invite the old lady, who is also the diviner ${ }^{26}$, to join us. Unfortunately, the lady turned me down. She clearly expressed her mistrust of me and 'people like' me. Smith (2013) acknowledges mistrust by the Indigenous Peoples as one of the challenges faced by Indigenous scholars. I was confused and hurt by the rejection. After that rejection, I resolved to encourage the building of a strong relationship with my participants as well as amongst them all. I was also grateful for the participants who had consented.

A young tourist guide (in his mid-thirties) who is very knowledgeable about Ssezibwa agreed to join in the project. This is one of the things that occurred that was not planned initially. Two of my participants were neither elders nor teachers. They were members of the community, who were in unique positions to enrich the project.

\footnotetext{
${ }^{26}$ This diviner is considered the mediator between the people and the Spirits of Ssezibwa. When people come to Ssezibwa with problems, they talk to her and she advises what they can do (in relation to Ssezibwa) to overcome their troubles.
} 
At this point, I invited this young tourist guide, $\mathrm{Kintu}^{27}$ to work with us. He had a degree in Tourism and Travel from Makerere University and he worked as a tourist guide at Ssezibwa. He was a Muganda ${ }^{28}$ and had a genuine respect for the place.

In our first group interview, three elders as well as Kintu attended. In the group discussion, the elders were very enthusiastic at the prospect of working with the teachers. They discussed about their disappearing role in the education of the young people and the disconnection of the young from their cultures and from Buganda, their motherland. They shared personal narratives about growing up in Buganda. They also chose specific aspects of IK that they wished to teach at the schools.

The initial plan was that each of the six schools would have a community elder assigned to them. Instead, the elders suggested that they would attend all the schools and educate about areas of interest and expertise. I was impressed with their enthusiasm. However, it was challenging to see my well thought out plans change into something different at this stage. I realised that this is when 'my plan' shifted to 'our plan'. Being flexible was an adjustment. Before fully realising the reality of working with the participants, I constantly struggled with how I was going to organise them. How was I going to organise their transportation and schedules? I recall my conversation with one head master who I explained that when the teachers agreed to work with me, the next step would be to attend a PLD workshop. His retort was "At whose cost?" It was not only the interest that mattered but there were also other logistical issues (i.e. financial, political, religious etc.) to consider. I continuously

\footnotetext{
27 Pseudonym

${ }^{28}$ This was very important because the project was in Buganda and all the elders and teachers were Baganda. We spoke Luganda most of the time and there was no stress of English.
} 
wrestled with what I deemed to be looming difficulties and how I was going to manage them. This soon changed.

\section{The elders' areas of interest in this project}

The elders played a vital role in the implementation of place-based education in the schools and in the reconnection of both the teachers and the learners to their cultures and communities. They did this by sharing their IK. Teachers organised with elders to attend school and facilitate an IK session in a certain area depending on their planning.

My role at this stage was mainly coordination and organisation. The teachers would call me and tell me which elder they would like to have and their preferred time and I would then need to check in with the elders as to whether that was convenient. Sometimes the teachers would get in touch directly with the elders and the elders would then get in touch with me for the transportation arrangements. Two teachers took it upon themselves to sort out the transportation issues when it required organising buses. I caught up with everyone's progress during the meetings with the teachers. To understand what it was that we did, it is essential for me to explain the elders' IK areas at this stage.

\section{Bulungi Bwansi (For the good of the land)}

Mzee Taata was the elder whose area of expertise was Bulungi Bwansi. Mzee Taata said that he is the advisor on matters of Bulungi Bwansi (in Kyaggwe region) in Buganda kingdom. Bulungi Bwansi, which directly translates into 'for the good of the land,' is a traditional practise in Buganda that was very popular before colonialism but got discarded like many other Indigenous values by the disrupting tendencies of colonialism and the capitalist traits of today (Labé et al., 2013). Bulungi Bwansi by its name means working together, without expecting any kind of payment, for the good of 
the place and community. According to Mzee Taata, Bulungi Bwansi started a long time ago. But it became popular during the reign of Ssekabaka ${ }^{29}$ Ttembo in the year 1404 . Ssekabaka Ttembo also started the drum, 'Saagala agalamidde’ (I don't want idlers) which was sounded to summon the people for Bulungi Bwansi activities like cleaning up their wells, clearing roads etc. When he addressed the teachers about Bulungi Bwansi in schools during the first PLD, Mzee Taata said:

Bulungi Bwansi is a value of togetherness. It is togetherness in joy, in pain and all other kinds of situations that may befall a community. Bulungi Bwansi is a wide concept. It is also applicable when one takes pity on fellow men and creatures. A person who has the heart for Bulungi Bwansi helps others. There is love in Bulungi Bwansi and there is also discipline. A person who has the heart for Bulungi Bwansi has humility. He takes the responsibility to do what is required of him or her. In Bulungi Bwansi one must be open in what they are doing. There is self-sacrifice in Bulungi Bwansi...

I want to remind you that Ssaabasajja ${ }^{30}$ encouraged the people of Buganda to sow the heart of love and service to Buganda in all the people especially in the young. This will permit the Buganda of tomorrow to progress on firm pillars like those that our ancestors prepared for us. However, we cannot sow in the young that which we do not know... (May 2015)

Through his work with the teachers, the Bulungi Bwansi clubs were born. Teachers and students were involved in dynamic activities in the surrounding communities, as will be expanded on shortly. With his expert knowledge of the social values in Buganda, Mzee Taata helped the teachers and students see the good in selfless service, a value that underscores Bulungi Bwansi. He helped in the reconnection of both the teachers and the learners to the community and vice versa. And even now, these clubs are going on and Mzee Taata is doing what he likes best,

\footnotetext{
${ }^{29}$ Ssekabaka is the title given to a king that died and Kabaka is the title for the living king of Buganda. The current Kabaka is Ronald Muwenda Mutebi the second.

30 This is another title for the Kabaka. Someone might say, "Ssaabasajja, Kabaka Mutebi said..."
} 
teaching about Bulungi Bwansi in schools because of his dedication to Buganda ${ }^{31}$. He is doing it in the heart of Bulungi Bwansi.

\section{Naomi and the eliminate-charcoal community project}

I met Naomi very unexpectedly through her guardian, an elderly nun, on a minibus to Kireka, a suburb of Kampala. Naomi is an innovative young woman who started making briquettes when she felt that she could no longer afford to buy charcoal anymore daily to cook for her three children. In my interview with her, she revealed that she was a trained teacher but she had never got employed ${ }^{32}$ because the government put a hold on the recruitment of teachers. Her husband was employed but money had always been a problem. So, she started using soil, cow dung and saw dust to make briquettes for cooking. She explains:

I got this idea from my childhood when we used to go to the wilderness to tend to the cattle. My brothers and I used to roast very tasty potatoes, cassava and yams in a mound of cow dung and soil that we built. That mound would keep the fire for at least three days and we would use the same mound for that long. So, from my knowledge of how we used to do that, I felt I could make balls out of the same materials that would work the same way in the charcoal stove instead of the charcoal. I experimented until I came up with these products. By the way, I remember my grandmother using stones in the hot ashes to keep our food hot and the food was hot for a long time. This is not really a new thing. It is a matter of remembering or asking how our grandmothers used to do it. (May 2015)

When these briquettes worked for her, Naomi started making enough to sell to her neighbours. Eventually, she put up a roadside stall and word spread in the neighbourhood about her products. That is when the police arrested her over selling

\footnotetext{
${ }^{31} \mathrm{He}$ made sure that he reports his actions to Buganda offices in Mmengo by taking the lists of students' and teachers' attendance in these activities back to Mmengo. By this I thought that he was also dedicated in the reassurance of the Kingdom that Bulungi Bwansi is taking root in the young.

32 High levels of unemployment for trained teachers is the major cause of exploitation and disrespect for these people by the government and their leaders. It has also made education a very unpopular course in universities.
} 
stuff illegally and in the wrong area too. When I met her guardian in the minibus that afternoon, she was on the way to Kira police station to bail Naomi out. Together we went to the police station and got Naomi out. Naomi and I had become fast friends since then.

Naomi joined our project in the second phase by first attending the second PLD workshop. At this workshop, she demonstrated to the members how she makes briquettes and how they work. She had three types of briquettes, the ones that worked for a short while (i.e. about two hours). There were also ones that worked for up to eight hours and the lighters. She said she was continually trying out different ways to improve them. It was agreed that she would work with Mzee Taata in the Bulungi Bwansi clubs. One of the vibrant things about our project came to be the EliminateCharcoal community project. It is still alive and according to Naomi's emails more schools are getting involved and as a result they are engaging with the communities in Bulungi Bwansi.

\section{Indigenous plants and values}

The elder whose area of expertise was the Indigenous plants and their values was Ssenga Namu ${ }^{33}$. Ssenga Namu works with the Nnaabagereka ${ }^{34}$ of Buganda in the program Ekisaakaate. Her major concern is that people no longer understand the use of many plants and therefore are destroying them. When talking to the teachers in the first PLD, she said:

Once upon a time, if you can recall at all, they (the plants) used to be very much a part of our daily lives but now the modern foods and medicines have replaced them. Most of these plants and foods are around us although we no longer see them. Just like cows cannot thrive

\footnotetext{
${ }^{33}$ Ssenga is a title of respect for the female elders. It also means paternal Aunt. Namu is a pseudonym.

${ }^{34}$ This is the title of the Queen of Buganda. The current Queen is Sylvia Nagginda.
} 
on cooked potatoes, the same applies to us with imported food stuffs. Our foods boost our immunity faster and much better. We have enough fertile land to grow our own basic foods and vegetables. Today many people have forgotten, and do not know or recognise many of our Indigenous foods and fruits. This is the reason they are destroying the plants. (May 2015)

Ssenga Namu played a vital role in educating us on the plants and their medicinal and food values. She worked with the teachers by taking the classes around the school grounds identifying plants and their values. This elder unpacked plant information from medicinal to food values. She was a moving and breathing botanical dictionary of Indigenous plants. She took us all (i.e. the teachers and students) on discovery journeys that ended up in students' notebooks and teachers' diaries. During the teachers' weekly meetings, teachers reported about students' class projects of collecting Indigenous plant information following Ssenga Namu's informative sessions.

\section{Obuwangwa n'ennono in Buganda}

Ssenga Naki was the elder whose area of expertise was obuwangwa n'ennono ${ }^{35}$. Ssenga Naki is a very dedicated person to the Kingdom of Buganda as was her father according to her personal narrative. She also works with the Nnaabagereka in the Ekisaakaate program. She is the one that recruited Ssenga Namu to our project. Ssenga Naki's major concern is the division or conflict between obuwangwa and religion. The concept of obuwangwa goes beyond culture according to Ssenga Naki. It includes the physical land, the people, their language, food, dress etc. She explains the difference between the permanence of obuwangwa and transience of the obulombolombo (i.e. the beliefs) in her address to the teachers. She emphasised that failure to understand the

\footnotetext{
35 I could not get a suitable English translation or equivalent for these words. Many online sources call it 'culture' but Ssenga Naki's definition is much bigger than just culture as explained in chapter ten.
} 
difference between the two has made people to fear and even hate their buwangwa. In her address to the teachers during the first PLD she said:

Our nation ${ }^{36}$ is lagging because we have separated obuwangwa from development and this tension/friction between the two makes development quite impossible. The same tension/friction has been created between religion and obuwangwa. When religion came, it never understood our buwangwa and so the missionaries labelled obuwangwa Satan. So, when they are preaching they will discourage the people from thinking about their buwangwa. This friction confuses many people...

We are very much unaware of our wealth in obuwangwa. For instance, recently, our hill of Namubiru was sold to some Japanese company and they are right now blasting the stones. In selling that hill, we have lost more than we can ever explain to our grandchildren. Do you know that the hill Namubiru shelters large water wells underground? Do you know that many people come to tour and spend time at that hill like they do at Ssezibwa? At Namubiru there were many trees and herbs that are medicinal. Such places like Namubiru are sacred and cannot just be sold off. That is the wealth of our children and grandchildren from their obuwangwa...

It is sad that today when one hears the word obuwangwa, especially you the educated people, you just conclude that the talk is going to be on $b a$ lubaale (the ancestral gods) and related issues. Do you realise how this ignorance keeps us behind? You the educated sign contracts with outsiders and sell our buwangwa because you do not fully understand its timeless value. The mistakes you are making will haunt and affect us and the future generations. (May 2015)

Ssenga Naki's area of expertise was very delicate/sensitive to balance with the teachers' religious/school pressures. Not a single teacher invited her to their classes to facilitate about obuwangwa. She therefore merged with the other elders and worked in the Bulungi Bwansi activities and the Ssezibwa program. She was very dedicated in all activities and moreover very knowledgeable about the historical events at Ssezibwa.

\footnotetext{
36 'Ensi' directly translates to 'earth' but the context in this speech is closer to 'nation', which is the same as 'Eggwanga.' In my transcription, I struggled to decide whether the word translates, or is closer in meaning to land, earth, nation or country! They are all synonymous in Luganda.
} 
Both teachers and students enjoyed her historical narratives ${ }^{37}$ about Ssezibwa and the Buganda Kings. On top of working with teachers, she worked well with the fellow elders and this allowed us to have enough resourceful elders to work with.

\section{Ssezibwa falls and conservation}

Kintu's area of expertise was Ssezibwa ${ }^{38}$ falls. As tourist guide in Ssezibwa, Kintu accepted to work with us because he loved his work and he came to believe that if students came to know about Ssezibwa, it would be good for the place. When I first interviewed him about Ssezibwa, he said that students rarely ever came to Ssezibwa. He said that people thought that this was more of a spiritual and tourist place than an educational one. He said the people who came there were tourists and the local people who needed to pray for different issues in their lives like having children, getting rich etc. However, Kintu noted that Ssezibwa is a place of conservation amidst destruction. During the first PLD, Kintu explained to the participants:

Critical to a historical understanding of the environment is the definition of God. Respect and fear of the inexplicable has had an influence on the relationship between humans and nature. Ssezibwa is sacred through the belief that it was a twin born river; a belief that has protected it from human exploitation and destruction. ( $8^{\text {th }}$ May 2015)

Kintu's role in the project was positive. He never came to the schools but he was always there to meet us in Ssezibwa when we took the students. He worked well with the teachers and myself to organise tours when the place was not congested with tourists so that he had time to dedicate for our classes. During these learning moments, he was a learner like all of us when Ssenga Naki narrated the historical stories about Ssezibwa. Out of the formal school setting, in Ssezibwa, he made it possible for our

\footnotetext{
${ }^{37}$ I recorded five historical narratives of the late Kings (Ssekabaka) and Ssezibwa and in one of them; she showed us a tree that she says was planted by Ssekabaka Mwanga at the place. Ssekabaka Mwanga ordered for the death of the Christian converts (Uganda martyrs) in 1885. 38 In Ssenga Naki's narratives, she tells the story of how this river was born.
} 
re-connection to our buwangwa, our culture and places. Our project opened Ssezibwa for students' exploration and reconnection to place.

\section{THE FIRST CYCLE: PLANNING}

\section{The first Professional Learning Development (PLD) workshop}

We agreed to hold the first PLD workshop in the first week of the first term school holidays when the teachers were free. 24 teachers represented 11 schools. Since it was hard to predict who of the members would remain throughout the entire project, this was a promising turn up and it seemed prudent to go on with all of them. Three elders plus Kintu attended the first PLD workshop.

In order for me to make clear the background context of our project, I presented a paper on the relevance of place-based education and IK in Ugandan schools and on the possibilities of PAR in improving practice. The elders discussed about their areas of IK expertise and Kintu gave a PowerPoint presentation about Ssezibwa.

The teachers divided into discussion groups with an elder assigned to each group and together they planned how to integrate IK and place-based education in the formal education system. From each group, a representative described a plan about how they planned to integrate IK into the curriculum. We shared materials about the presentations and a contact list with every member was shared. We agreed to start Bulungi Bwansi clubs in the schools at the start of second term.

In the group discussions, teachers tried hard to align the elders' IK areas of interest with the content of their teaching syllabi. This was not easy. During the group discussions, as I checked on the audio recordings during the different group discussions; teachers mostly argued about which topic to integrate with what area of 
IK. I noticed that teachers were struggling with this because for them everything had to be taught in line with the UNEB examinable syllabus.

At the end of the workshop, I carried out a survey of what members thought of the workshop and to find out who wanted to take part in the next phase of the project. All 24 teachers and the four elders agreed to take part in the next phase of the project.

\section{ACTING AND OBSERVING}

\section{Where is everybody?}

During the school holidays, I worked on the observation guides, interview guides and prepared all the necessary things that we would need for the observation and successful participation. I stayed in touch with some teachers and elders. Some teachers during this time went quiet. However, some remained in touch and would call and give suggestions of how they thought the next phase would proceed especially in relation to their school programs. These calls were encouraging and reassuring because I started to feel that I was part of a group and that we were working on this together.

Soon it was time to start our class observations. However, it soon became apparent that many of the participant teachers were no longer with me. When I called them on their personal mobile phones, some gave excuses that they were busy with beginning of term exams and needed more time. Some of them said they just realised they were in Christian/church founded schools and it was not a good idea to bring in the elders or IK. But some just kept quiet and never answered my calls or returned them. Where were they? I faltered because after the first PLD workshop, I was confident of their interest to be part of the project. All of them, through the anonymous survey, had accepted to take part in the next stage. The survey also revealed the teachers' attitudes towards the presentations. This also exposed their concern for the disconnection from 
place and therefore expressed the fact that they wished to take part in the project. As I went through the survey comments I became even more confused by their withdrawal.

\section{Figure 2: An overview of the teachers' attitudes towards the first PLD workshop and the project in general as depicted in the survey data}

\begin{tabular}{|c|c|c|c|}
\hline $\begin{array}{c}\text { Last three } \\
\text { Survey Questions }\end{array}$ & Respondent one & Respondent two & Respondent three \\
\hline $\begin{array}{l}\quad \text { Explain which } \\
\text { presentation } \\
\text { impacted on your } \\
\text { professional } \\
\text { development. }\end{array}$ & $\begin{array}{l}\text { The presenter on } \\
\text { ecological literacy. This is } \\
\text { because I have learnt that I } \\
\text { can use cheap things to live } \\
\text { a good life. }\end{array}$ & $\begin{array}{l}\text { The presentation } \\
\text { about Ssezibwa falls } \\
\text { and how we can } \\
\text { conserve the } \\
\text { environment using } \\
\text { nature and culture }\end{array}$ & $\begin{array}{l}\text { The elder's presentation } \\
\text { about culture. She } \\
\text { challenged me on issues of } \\
\text { culture that I least attached } \\
\text { importance. Such aspects I } \\
\text { realised would go a long } \\
\text { way in helping me marry } \\
\text { culture and formal } \\
\text { education. }\end{array}$ \\
\hline $\begin{array}{l}\quad \text { What worked } \\
\text { well for you in the } \\
\text { workshop? Explain } \\
\text { why? }\end{array}$ & $\begin{array}{l}\text { The knowledge I have } \\
\text { got through the different } \\
\text { presenters because I } \\
\text { know it is going to have a } \\
\text { big impact on my learners. }\end{array}$ & $\begin{array}{l}\quad \text { Environmental } \\
\text { conservation and } \\
\text { culture because we } \\
\text { need to conserve our } \\
\text { environment }\end{array}$ & $\begin{array}{l}\text { The use of the } \\
\text { Indigenous language } \\
\text { Luganda. It gave us an } \\
\text { opportunity for self- } \\
\text { expression without the } \\
\text { hindrances and inhibitions. }\end{array}$ \\
\hline $\begin{array}{l}\text { Please advise on } \\
\text { any shortcomings } \\
\text { that you feel need to } \\
\text { be improved in the } \\
\text { next workshop. }\end{array}$ & $\begin{array}{l}\text { Sensitisation/publicising } \\
\text { such workshops so that } \\
\text { many teachers can attend. }\end{array}$ & $\begin{array}{l}\text { More schools and } \\
\text { institutions should be } \\
\text { invited to attend. }\end{array}$ & $\begin{array}{l}\text { Time for discussion } \\
\text { groups has not been } \\
\text { enough to allow the } \\
\text { participants to explore the } \\
\text { concepts and applicability } \\
\text { of the same. }\end{array}$ \\
\hline
\end{tabular}

Only five teachers out of the 24 remained and they represented only four out of the 11 schools that attended the initial workshop and had signed consent forms to participate in the project. Of the five teachers that remained, only one taught oral literature while the other four taught Luganda. My initial plan was to have 12 teachers; six who taught Luganda and six who taught oral literature. 
However, the three elders plus Kintu were enthusiastically in touch with the remaining teachers, ready to start implementing the plans in the remaining few schools. I distributed the observation guides to the remaining participant teachers and explained the guiding questions to them. We then launched into action. This was how we began the action phase of the project.

\section{REFLECTION}

\section{Conflicts and resolutions}

It was important to meet as often as possible with the participants to reflect and learn from one another and to resolve any issues that might have arisen for the participants (Stringer, 2014). It was a learning process for everyone. It was also great to collaborate to manage the conflicts that arose. At the end of the first week of IK activities and lesson observations, we decided to meet in Mukono town for Nyama Kyoma (roast beef or pork). The teachers suggested the venue for the meeting, the day and the time of the meeting. It worked for all of us and it was particularly convenient for the teachers.

Nyama Kyoma directly translates to 'roast beef on pokes'. The roast beef, sometimes pork (depends on choice), is served hot on long skewers with a plate of spiced cassava ${ }^{39}$ and avocado. In Uganda, this kind of social gathering is informal. It is usually for friends and colleagues to relax and have a good time together.

The first issue that was raised was the missing teachers and schools. Members were concerned about why some members were missing and how we would help them to return to the project. I quoted one of the surveys I received after the first PLD in

\footnotetext{
${ }^{39}$ This is a common root vegetable and a food crop in the area.
} 
which some members had wished more schools and institutions had taken part in the workshop. I also mentioned that some of the teachers were not comfortable with IK because they were serving in Christian schools while others said they were too busy with school programs and could not commit any further. One of the teachers revealed that her colleague couldn't come for the first PLD because she was busy preparing students for the coming UNEB examinations. Another teacher suggested that we invite the teachers again but this time as members of the Luganda Teachers' Association ${ }^{40}$ (LTA) and try to impress upon them the importance of getting involved in this project.

The other issue that arose was the issue of time. One of the teachers revealed that she was having problems planning for the lessons that involved the elders in a 40minute time frame and that she had observed the same constraint in another teacher's class that she had observed. This constraint occurred when the lesson required outdoor activities like plant exploration. Teachers of Luganda revealed that Luganda was allocated with 40 minute lessons twice weekly. These time slots were not long enough for our project as we needed more time.

Everyone agreed that the classroom situation was very challenging regarding the lesson time frame and planning. One of the teachers suggested that we organise our lessons with the elders during the extracurricular activities time because it is only compulsory subjects, like English language and Mathematics, which can be allocated more time. This was well received by everyone. We agreed that this would allow us ample time to get out into the community for the IK learning activities like Bulungi Bwansi and the Ssezibwa falls activities. The teachers decided that the field work activities would inform their classroom activities. It was agreed that depending on the

\footnotetext{
${ }^{40}$ It so happened that this same teacher was heading the LTA association in Kyaggwe region and he had some influence over the teachers of Luganda in the area.
} 
lesson, if a teacher negotiated successfully with another staff member for lesson time, they could swap lessons and then invite the elders to come to the school and have a lesson within the school compound. The co-participants realised that flexibility was key. Moving from the constraints of the 40-minute lessons would give us the time and resources that was needed. The teachers agreed that it was important to work well with other staff members and to make other staff members aware of what we were trying to do.

Lastly, a date was set for the next PLD and it was to be the coming Saturday. We planned that during that time we would all reflect, improve and re-plan. All participants (i.e. elders and teachers) who had attended the first PLD workshop were to be invited to this next workshop.

\section{SECOND CYCLE: RE-PLANNING}

\section{The second PLD workshop}

The second PLD workshop was more of a reflection and re-planning meeting than the first workshop. We held it at a venue suggested by the teachers. During this PLD workshop, one of the schools represented was totally new. This new teacher was invited by one of the participant teachers. As he had not attended the first PLD, I had to explain to him about the project and give him the materials we shared in the initial PLD. Unfortunately, none of the teachers that had dropped out returned to the study.

Naomi demonstrated the briquettes to the participants during the second PLD workshop and members agreed that she worked with the elder for Bulungi Bwansi. This is how Naomi's project became the most resounding Bulungi Bwansi activity among the participating schools. 
We agreed to continue meeting every Wednesday evening for Nyama Kyoma to reflect and together come up with the best way of implementing IK into the curriculum. During the Nyama Kyoma meetings, participants shared diary entries about significant observations as well as samples of students' work.

After the second PLD, we met every Wednesday at $7.00 \mathrm{pm}$ for an hour at the Princess Gardens ${ }^{41}$ in their conference room. Each one of us ordered Nyama Kyoma and a drink. While the hosts prepared our orders, we had a group discussion guided by an interview guide. These meetings were possible because all the teachers lived in Mukono town. We did not meet with the elders for Nyama Kyoma because none of them lived in the town centre. But as it turned out, it was good to meet just as teachers so that we could brainstorm on how to implement IK into the curriculum and the teacher's pedagogy.

\section{ACTING AND OBSERVING}

At this stage of the project, we engaged in the planned IK activities facilitated by the elders and we also did a lot of active observations of the same. We got involved in the Bulungi Bwansi activities that involved making Briquettes, we visited Ssezibwa falls, and we also went out to learn about the plants in all the participating schools. There were lesson observations in every one of these activities. These were guided by an observation guide. These lessons went on concurrently with the different elders visiting different participating schools. Also, teachers were attending different participating schools for lesson observations. I think that this was a real breakthrough for the teachers because previously, rather than working together, teachers of different

\footnotetext{
${ }^{41}$ Princess Gardens is a social gathering place between a café and bar. At Princess Gardens is a conference hall with an overhead projector and a laptop.
} 
schools would compete against each other to see who had the greatest number of students pass the UNEB examinations.

After every lesson, there was a group interview held involving the teachers and the elders. These were guided by the interview schedules/guides. All the interviews were audio recorded so that we could go back and listen to what we had decided upon in an earlier meeting. This helped to guide our decisions and progress.

During the group interviews, we discussed the different highlights of the lesson. This was a great way of capturing what the elders thought was important in an IK activity. These discussions also helped to equip the elders with the teachers' expectations for the lesson. I noticed that the elders usually took on the teacher's suggestions and included aspects that had previously been missing. This way, the elder was trained in handling IK for formal class situations.

In this acting and implementation of the second PLD plans, a new cycle emerged; bringing the community into the classroom; bringing the classroom into the community; and eventually bringing the community into the curriculum and pedagogy. These themes are relevant to the study in that they highlight the primary aim of placebased education which is making permeable the barriers between school and community, thereby making school relevant to her community (Duenkel \& Pratt, 2013; Smith \& Sobel, 2010). In addition, as the plans of the co-researchers in this project evolved, it became evident that these themes clearly highlighted the pattern of the actions in our project. As the figure below demonstrates, our actions revolved around the same themes and consequently our analyses arose from the same pattern.

Figure 3: A snapshot of the action cycle of the project 
Bringing the community into the classroom

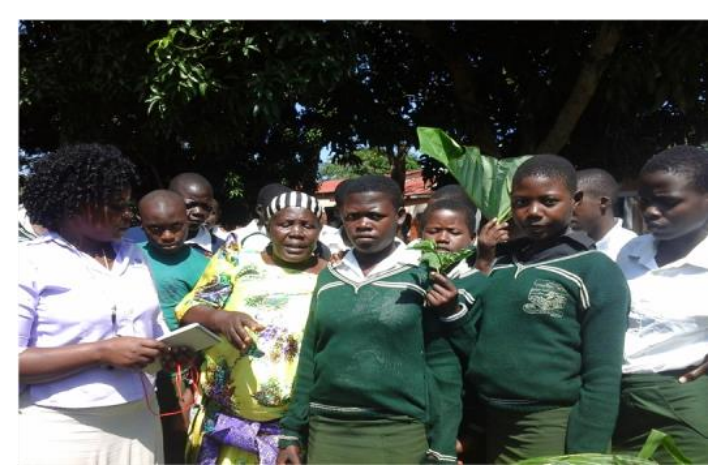

(Ssenga Namu teaching about plants)

Elders came into the formal education settings to contribute towards Bulungi Bwansi, Ssezibwa, and Indigenous plant values

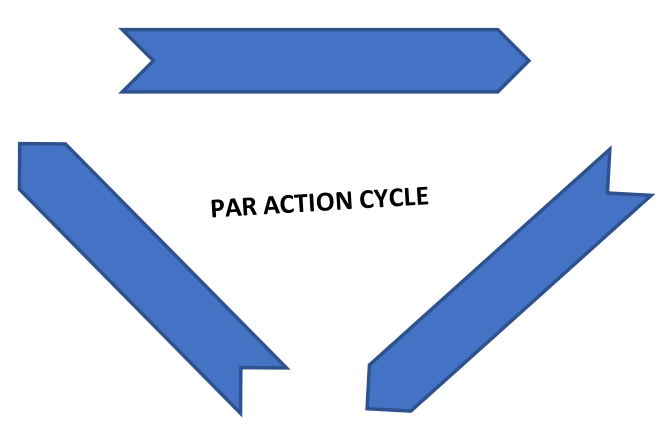

Bringing the community into the curriculum

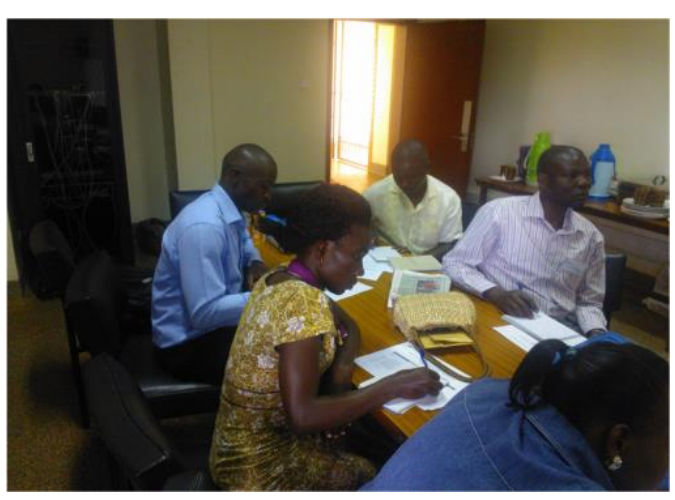

(Teachers'weekly meetings)

Teachers integrate the acquired IK into the curriculum. They designed lessons basing on the IK learning activities that had been facilitated by the elders to enhance their students' learning.

\section{Bringing the classroom into the community}

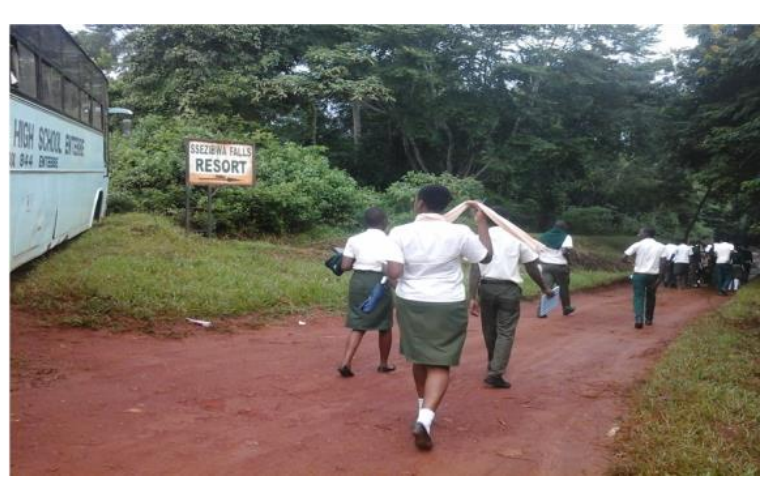

(Students get off bus at Ssezibwa)

Students were taken out into the community settings to carry out Bulun $B$ wansi activities, to experience and learn about Ssezibwa and to carry own research about plants and the values. 


\section{REFLECTION}

\section{Last Meetings with co-participants}

My return to Tasmania did not mark the end of things for the research project. Teachers continued meeting weekly (over Nyama Kyoma) for their group reflections. They had planned lessons and expeditions with the elders for the rest of the second term. However, I needed to meet the elders to carry out our last group discussion and specially to find out how they felt about their new roles of working with teachers in the formal education settings. I had already explained at the start of the project that we would be meeting, so it was a matter of organising a time with them. They chose to have it at Mmengo Bulange ${ }^{42}$. To them, this place represented their heritage and culture as Baganda. I was happy to go there. Naomi came too. Unfortunately, because it was a weekend, Kintu could not make it because he was at work in Ssezibwa. It was a very interesting meeting in which we all reflected on our journey in this project. Everyone revealed how happy they were with it and vowed to continue working with the teachers. Naomi was happy in her new role as a facilitator in the Eliminate Charcoal Project. She said she'd found a way of using her innovative talent. She said:

Before meeting Kevina, I did not know that my skills would help save our environment. I had started to think it was a bad thing that was putting me against the law. I am glad that now I have found a way of using it for a bigger purpose. I am looking forward to working with the teachers and I hope that one day, it will be a big project for the whole country. Thank you all for working with me. Naomi. (July 2015)

The next day was Sunday and I planned with Kintu to meet in Ssezibwa and have a last interview. During that interview with him, it rained hard the whole time! I also met with the teachers for Nyama Kyoma for one last meeting on the last Wednesday of my stay in Uganda. It was not very different from the usual meetings except that there was an item on the schedule to say goodbye. They all said that they would continue their work with the elders and the two

\footnotetext{
42 Mmengo Bulange is the administrative headquarters of the Buganda Kingdom.
} 
facilitators, Naomi and Kintu to enhance their practice and their students' connection to place. I also helped the teachers to open email addresses that evening and we updated the contact list by adding country codes. This was to ensure that international collaboration between us could be continued. The bond between us was created through working together on this project and it remains.

\section{Conclusion}

This chapter has outlined how the research design was structured and the relationship between the different cycles of the research project which include, planning, action and reflection. It also explained the nature of a PAR project in the sense that PAR keeps shifting and therefore the co-participants require dedication to the cause of their action and flexibility.

The next chapter will discuss in detail one of the three actions, Bulungi Bwansi, that the participants used to integrate IK into their curriculum and to reconnect students to their culture. In this chapter, there is detailed description of the cycles that emerged within the PAR action (i.e. bringing the community into the classroom; bringing the classroom into the community; and bringing the community into the curriculum and pedagogy). In the next chapter, there is also a detailed discussion regarding how the co-participants worked together to bring the IK into individual topics of their teaching syllabus. 


\section{CHAPTER SIX:}

\section{BULUNGI BWANSI AND ELIMINATE CHARCOAL COMMUNITY PROJECT}

\section{Introduction}

\section{The silent drumbeat}

Bulungi Bwansi is a traditional Kiganda practice that has slowly been forgotten in society not unlike most traditional ways of knowing. Traditionally, Bulungi Bwansi was a respected practice. Members of a community quickly responded to the drumbeat of 'Saagala Agalamidde' which was the signal for Bulungi Bwansi. The concept was extended to acts of human kindness in the community where members carried out deeds 'for the good of the land' (i.e. provision of food and shelter for strangers). Bulungi Bwansi encompassed communal activities like digging or cleaning of wells, mending roads or even when there was trouble and the community required to respond in a certain way. The elder, Mzee Taata, told the teachers during the first PLD workshop:

Bulungi Bwansi started a long time ago. But to become very popular it was during the reign of Ssekabaka Ttembo in the year 1404. Ssekabaka Ttembo brought a lot of development to Buganda during his reign. He was very organised because he encouraged people to work together. Ssekabaka Ttembo started the drumbeat 'Saagala agalamidde' (I don't want idlers) which was sounded to call people for Bulungi Bwansi. Saagala agalamidde meant that there was no place for idleness. When people heard that drumbeat, they rose and went to work to improve their lives. (May 2015)

Today, the Saagala Agalamidde drumbeat is silent and it seems unlikely that it will ever sound again because the largest number of the population hardly recall its significance. In Buganda, Bulungi Bwansi represents the value of communal responsibility and care for what belonged to the community. Every person took the responsibility for the good of the entire community and in this way, the community took care of the individuals. With the death of Bulungi Bwansi, the cords that bound the people to their communities disintegrated. 
Subsequently, abuse and misuse of community land resources, (i.e. by the very people who should be taking care of them), escalated. The need for agency is evident in Mzee Taata's address to the teachers in the first PLD when he is introducing Bulungi Bwansi. He emphasises the need for the "heart of Bulungi Bwansi" in the people. Most importantly for our project, he recognises that the teachers are in a better position to bring about this change. He said:

Bulungi Bwansi starts with us; we are Bulungi Bwansi, you and me. We must bring that heart of Bulungi Bwansi back in us today in this Mutebi ${ }^{43}$ era. This heart used to protect us and what we have and bring us together. We should be a model to the rest; we must teach others the benefit of working together for the good of the community. We must support each other. You the teachers must be the amplifiers/speakers to broadcast this message for a change to happen today. We used to be very dignified people here in Buganda. That is why this country bears our name Uganda. We have to revive our legacy... ( $8^{\text {th }}$ May 2015)

The Buganda cultural government has started the Bulungi Bwansi awareness campaign where the people of Buganda remember the value of Bulungi Bwansi. Buganda government dedicated a day, October 08 to commemorate this practice. On this day, the Kabaka addresses his people, the Baganda. The people carry out acts of kindness like visiting the sick or giving to the poor. However, the real practice of Bulungi Bwansi, like its drumbeat, is no more.

\section{CYCLE ONE- BRINGING THE COMMUNITY INTO THE CLASSROOM}

\section{The debates: beginning of the clubs}

Even though this project was designed to improve practice and it centred on teachers and community elders, I believe it is essential to present an assemblage of revelations from my observations and audio recordings. This in turn may reveal the perceptions of students about their lives and education and further assist us to understand the impact of the teachers and the

\footnotetext{
${ }^{43}$ The Kabaka of Buganda is Mutebi. So, this period in Buganda is commonly called the 'Mutebi era' (Omulembe Omutebi).
} 
elders in their introduction of IK and place-based education to the students in this formal education system.

To introduce the concept of Bulungi Bwansi, the teachers organised provocative class debates and invited Mzee Taata, one of the participant elders, to talk to the students and the teachers about Bulungi Bwansi. Another participant teacher from another school and myself attended these classes but we did not actively participate in these debates.

The topics of these debates were predominantly concerned with fundamental issues in the contemporary society. Some of the topics were "Is Indigenous Knowledge relevant?" and "Wealth is here (Africa); not in the West (Europe)." Debates are usually used as a learning activity in language classes to develop speaking and critical thinking skills. A topic is given to the students beforehand to allow them to research the two opposing sides of the argument in preparation for the debate. Students then choose their preference of argument. The class then selects a chairperson, timekeeper and secretary for the debate. The teacher's role is more of a facilitator during this part of the lesson because the activity is student centred.

In the first school, the participant teacher invited the elder and myself to the oral literature lesson. In this class, the topic for debate was, "Cleaning at school should be done by porters". 'Porters' is a term used to describe hired workers. This debate was conducted by senior two students who are the equivalent of Grade 8 in the Tasmanian education system (i.e. approximately 14 -15 years old). One girl said,

Students should not do cleaning at school because it might lead to students being mistreated by the teachers and it is also tiresome. It can make us tired when we are supposed to be studying. (May 2015)

One boy on the opposition side said, 
We come from different families and some rich parents do not want their children to do any work at home, so if we clean up here at school, we can all learn the skills so that we can also help at home. (May 2015)

And yet another girl hotly defended the motion by saying:

When we get home, we do a lot of work and we never get time to revise our books, that is why here at school we should not do anymore work but concentrate on our studies, the porters should do all the cleaning. (May 2015)

It is noteworthy that for students, school is a place to concentrate on studies; and when they get home, they require time to revise so that they can pass the examinations. Work is usually divorced from the school/learning context. These debates presented good settings for the elder to introduce the concept of Bulungi Bwansi.

This lesson started with a heated and yet humorous debate where students expressed their beliefs about hired labour in education. Since this was an oral literature lesson, the debate was handled in English but Mzee Taata addressed students in Luganda. The elder could understand some English and so he was able to follow the debate proceedings quite well. He asked the teacher to explain some of the proceedings that he did not understand very well. It is important to note that the students and the teacher shared the same first language, Luganda, with the elder.

After the debate, the teacher invited Mzee Taata to talk about the concept of Bulungi

\section{Bwansi.}

Have you ever heard of Bulungi Bwansi? (Murmurs of yes and no). This is doing something without expecting any form of payment. It is just as you hear the name 'for the good of the land'. It is communal; it happens in good times and in bad times. Even if most of the time, people come together in Bulungi Bwansi out of their own initiative, sometimes they are forced to do what is right for them, for their own good. Just like the chairperson ${ }^{44}$ in Rwengo who had to force the people to clean their places and dig

\footnotetext{
${ }^{44} \mathrm{He}$ was a community leader who beat up his people because they did not have toilet facilities and there was "children's" poo in the area. He beat up every able-bodied man whose house did not have a toilet/latrine facility and there was an outcry about him in the media.
} 
latrines; that too was Bulungi Bwansi. When you feel for the others in your community and you do something about it, then you have the heart of Bulungi Bwansi. (May 2015)

The elder explained to the students the history of Bulungi Bwansi and what it means to have the heart of Bulungi Bwansi. At the end of that lesson, the first Bulungi Bwansi club was formed. In this club, Mzee Taata was chosen by consensus to be the patron of the club and three students were elected to take on the roles of chairperson, secretary and treasurer. These four elected members helped in the organisation of the club activities. Activities included the making of briquettes; going to local communities to educate the people about how to make and or sell the briquettes and to talk about the dangers of cutting trees for charcoal burning.

In all the participating schools, teachers did the club registrations and formalisations. These debates were held for all the participating schools to introduce Bulungi Bwansi to the students just before the formation of the Bulungi Bwansi clubs. All the participating schools formed the Bulungi Bwansi clubs and these clubs are existent up to now.

\section{The eliminate charcoal project}

In the previous chapter, I outlined how I came to meet Naomi. In this research project, Naomi was the person that enriched the Bulungi Bwansi club activities. Naomi represents the common Ugandan woman fighting the odds to survive. She is an unemployed teacher who cannot afford the daily charcoal to cook a meal for her family. She puts to use the wisdom she acquired when she was growing up in her village in Mbale (Eastern Uganda) and comes up with a solution that would not only help her cook for her young family but also to bring in a little family income. She uses litter, soil and cow dung to make briquettes for cooking in the charcoal stove. Naomi says she keeps on experimenting with the available materials and so far, she has come up with three different types of products. She told the teachers in the second PLD workshop: 
Let us imagine a situation when there is no more charcoal, when all the trees have been cut and there is nothing else to use, won't we eat? Therefore, I think that we need to use what we have (soil, cow dung and rubbish) to come up with some sort of charcoal to cook food with. I have come up with three different kinds of briquettes and they all work in different ways. I have the ordinary briquettes that work with for a short time; I have also the reusable ones which are heat retainers and one can even use them for three days and I have the lighters which help to light the charcoal stove. The briquettes can be made by anyone just like when we used to collect firewood, no one used to buy firewood; at least not like today. (June 2015)

When Naomi joined our project, she came to appreciate Bulungi Bwansi. She did not know about the concept of Bulungi Bwansi since she comes from a different cultural background and her intentions for her innovations were different. In this, I mean the main aim of her innovation was to earn some income. Bulungi Bwansi aims for service to community without expectation of any payment. After the second PLD workshop, it was agreed by the participants that she work with Mzee Taata in the Bulungi Bwansi project. That part of Bulungi Bwansi was named the "Eliminate charcoal project" since its purpose was help in saving the trees by coming up with an innovative and yet affordable alternative to charcoal. What made this activity more appealing as a Bulungi Bwansi activity is that the communities were empowered with the skills to make their own briquettes. This saved the people from having to spend money on charcoal and equipped them with a way of making money if they chose to do that.

In this activity, Naomi used to meet the participant teachers and their students in the Bulungi Bwansi clubs at their respective schools. Naomi would then train the teachers, students, and elders to make the briquettes. Afterwards, Naomi and the club members (in addition to the teachers, elders and myself) were equipped to go out to the communities and carry out the training to members of the community. In the community, the student club members got involved in the selling of Naomi's already made briquettes. This way, Naomi could in turn make some money for her family. 


\section{Eliminate charcoal project in schools}

In the first school training, the Bulungi Bwansi club consisted of 28 student members as well as two elders, Naomi, and myself, the researcher. Two members of the school administration joined us in the football field where we worked. Since it was a club activity, it was scheduled for weekends in all the participating schools; for this school, it was a Sunday afternoon. The planning of the schedule was done during the weekly Nyama Kyoma teachers' meetings.

Naomi brought a bucketful of sticky soil which weighed approximately 50 kilograms, a sack (a bag made from sisal) of cow dung weighing approximately 10 kilograms, a sack of char (burnt mixture) made from all sorts of rubbish, and a smaller bag of charcoal dust. She also brought several mingling sticks (these look like wooden spoons), and a five-litre can of cool cassava porridge (made from cassava flour). The participating teacher in the school organised water, and several empty plastic buckets. He also organised Naomi's transportation of the materials to the school.

The training started with the singing of the first verse and the chorus of the Buganda anthem. We always sung this part of the anthem in the participating schools at the start of the IK learning activities with the students. This is an anthem of the Baganda as an ethnic group of people in Uganda. It is sung on cultural functions that have been held in Buganda by people that respect the values of the region. Singing this anthem at the start of the IK activities at the schools was a suggestion of the elders because they argued that it was one way of reconnecting the young people to their culture and their homeland.

Since this anthem is sung in Luganda, there is no formal English translation available. The below representation is my translation/interpretation in consultation with the participant teachers. I consulted the participant teachers by phone to seek their opinion about the closest 
English translations of the words to best represent the meaning. This anthem has six stanzas but we used to sing the first one plus the chorus.

Verse 1: Okuva edda n'edda elyo lyonna

Lino eggwanga Buganda

Twamanyibwa eggwanga lyonna

Okwetoolola ensi zonna

Chorus: Twesiimye nnyo, twesiimye nnyo

Kulwa Buganda yaffe

Ekitiibwa kya Buganda kyaava dda

Naffe tukikuumenga
From time immemorial

This land is Buganda

We were renown in the whole country

Surrounding the entire world

We are fortunate, we are fortunate

For our Buganda

The glory of Buganda is timeless

Even us we must keep it up

Mzee Taata opened the meeting by reminding everyone about the importance of Bulungi

Bwansi. He said:

People must first recognise the problem in the community to determine the right solution for that problem. Our major problem today is the changing weather patterns. We get no rain for months and when it comes, it floods, making it hard for us farmers to grow any food. We hear that it is because of the indiscriminate cutting of trees for charcoal burning. We need a solution for charcoal. Charcoal is expensive and yet toxic for our land. We need to eliminate charcoal by introducing other means of cooking. Back in time, a true Muganda did not wait for the government to do for them Bulungi Bwansi but struggled to keep himself and his community in a good life. We are privileged today to have this kind lady (Naomi) to show us, in the heart of Bulungi Bwansi, how we can save our land. (June 2015)

We then divided up into groups and each group was given an empty bucket along with a mingling stick. Naomi stood in the middle with all the materials in clearly marked containers, lined up near her. She showed us how to mix the different materials step-by-step. Each group had a person who was mixing. The other members of the group were either helping to bring the materials or assisting with the quantities. Every now and then, the participants and the students asked Naomi questions about the procedure. We all learned how to make briquettes with the materials that Naomi brought. 
Naomi instructed in Luganda:

We are going to make two kinds of briquettes but they both take three to five days of good sunshine to dry. Now, in the interest of time, I will have some of you make the short-term briquettes and the others can make the reusable ones. The process is the same but differ in the amount of the ingredients, as we shall see.

There were eight groups. Four groups made the reusable briquettes and the other four made the short-term briquettes. Naomi called the short-term ones the 'real' briquettes because they burnt for a shorter time (about three to four hours) just like charcoal.

The first step is for all of us to take two cups of the sticky soil from the big bucket and put it in your buckets. As you can see, the soil has already been soaked overnight. Mix it up with the mingling sticks until it is a smooth paste.

Student: What kind of soil is this? I have never seen soil this sticky before.

Naomi: This is anthill soil. It is sticky because it has been soaked for a long time.

Elder: Does it have to be anthill soil?

Naomi: No, you can also use the clay soil in swamps, the same that is used to make bricks but I chose anthill soil because it is easier to get where I live. However, you cannot use sandy or loam soils. We need soil that can stick ${ }^{45}$.

Next step, for those who are making the reusable briquettes, add one mug of char and continue to mix. For those who are making the 'real' briquettes, add three cups of char. The char should be more because they are supposed to burn more quickly than the reusable briquettes. The more soil put in the mixture, the more heat is retained and the longer the briquettes can burn.

Teacher: What is in the char?

Naomi: That is a good question. Char is rubbish that I burnt in a drum. I burn it carefully to keeping it carbonated because if, like charcoal, if it is over burnt, I will remain with only ash and it will not make briquettes. That is why I use a drum to burn it. You can also burn it in a saucepan with a cover but you must ensure that it burns carefully not to turn to ashes.

Student: What kind of rubbish is this?

\footnotetext{
45 Naomi emphasised this because she needed soil with a sticky texture. The elder explained later that Anthill soil is what people used for making earthenware (i.e. cooking pots, cups, plates) because it holds together for a long time.
} 
Naomi: Any rubbish can work. You can see some banana peels (we could tell by the shape that there were banana peels in there), but there are all sorts including food left overs and fruit peelings. But you do not use, glass, metal or plastic. This is why you must be careful to sort your rubbish before putting it in the drum.

Next step, we add either cow dung or cassava porridge. They both do the same job. I brought both because some people do not want to touch cow dung. Use whichever is best for you. But remember that the more cassava porridge or cow dung you put into the briquettes, the smokier they will burn and that is not nice. For the porridge, you can use about half a cup and for cow dung you may use about three quarters of a cup. Keep up the mingling and make sure it is smooth.

Elder: I think cow dung is better because when it burns, it deters mosquitoes.

Student: I would like to use porridge; I hate the smell of cow dung.

Naomi: Yes, you are right, it does not smell nice in this state; however, dried briquettes give off a good scent when burning.

Next step, we shape the briquettes. You can use your hands to roll round small chunks of the mixture. Or if you want a particular shape, you can use a metallic cup to make the shapes. Put the shapes on a flat and smooth mat to dry. Here are a couple of cups to try out. We have two marked mats over there for the different briquettes. We need to separate them.

The advantage of the briquettes is that anyone, even the poorest person can get to make them and cook for their families. The other advantage, as the elder has already pointed out, is that we get to save our trees. Any more questions?

Teacher: This is not a question, Naomi, but a comment. Thank you very much for your heart of Bulungi Bwansi, I just wish to tell you that the other advantage of the briquette is that you get to burn and use your rubbish instead of disposing it in the most terrible way. I am looking forward to making my own briquettes and telling people about them.

Naomi: Thank you Musomesa (teacher). I have brought some dried ones, readyto-use briquettes that I made. You can buy them cheaply for only $1000^{46}$ Ugandan shillings a pack... (Bulungi Bwansi activity, June 2015)

This training was undertaken for the four Bulungi Bwansi clubs in the four participant schools. Since these trainings occurred on weekends, non-members of the Bulungi Bwansi clubs who were either teaching staff or students of the participating schools and were interested in

${ }^{46}$ Equivalent to 0.35 Australian Dollars 
observing, were also welcome to attend. We referred to them as onlookers but sometimes they would become active observers. I believe that they learnt a lot from their observations.

Throughout all the briquettes making lessons/ trainings, it was evident that the elders, teachers and students were very eager to learn everything about the making of the briquettes. This was a practical way of learning; a kind of learning that was not common in the Ugandan formal education curriculum. I noticed a lot of note taking by both the teachers and the students. A lot of questions were asked about the process; the materials; and the how the products worked. In this way, everyone was eager to learn this new skill that was passed on through the Bulungi Bwansi clubs. To experience the effectiveness of the product, the participants bought some of Naomi's dried briquettes. Some people carried home their own made but still wet briquettes planning to dry them at home and use them. Their findings on the effectiveness of the briquettes were part of the teachers' weekly meeting discussions.

\section{Group reflections on lessons about Bulungi Bwansi through group interviews}

After the training sessions at the schools, I met with the teachers, the elders and Naomi for group interviews/ discussions about the trainings. These interviews were audio recorded with the permission of the co-participants. In addition to my data collection, these interviews were a way of reflecting on the project and evaluating our Bulungi Bwansi activity of making briquettes. They also served the purpose of guiding us to the next step in the project. For instance, we discussed about which community venue we would hold the community briquette making trainings and what permissions we were required to seek regarding the teachers and students, and the venue for the training. In addition, during these interviews/discussions, the participants discussed freely about what it meant for them to be part of this project and individual challenges regarding the project (i.e. the challenge of time for the IK lessons). These interviews were guided by an interview schedule. 


\section{Reflection on IK lessons}

In these interviews, the participants described what they did during the trainings at the school. This section was guided by discussion of the question, tell us what you did in your class today. When describing the activity of making briquettes with the students in the schools as part of a learning experience, the participants revealed what it meant for them to save our environment. In the first school, the participant teacher said:

In this activity, we got trained in the making of briquettes to use in the cooking. We learnt how to make them from the most common things around us like banana peelings, potato peelings and soil. Now we can finally do something to save our trees. If every one that attended this training can take the skill to their homes, we can lessen the amount of charcoal we use and as a result, we can save out trees. (June 2015)

One of the participant elders, after participating in the training in the first school said:

Elder: Thank you for this skill. The other day in our village, we were shocked to realise that we no longer have Ekifabakazi! Do you know that in the whole of Nama, there isn't a single one left just because of the Charcoal burners? It is one of those trees you just cannot afford not to have in the village.

Teacher: Why is it so special?

Elder: Ha, just think of its name, women kill it. From its leaves to its roots, it is all different medicines for pregnancy and childbirth related issues. Since time immemorial, women have relied on this tree's medicinal qualities. I recently had to travel to Bugerere ${ }^{47}$ to get a few pieces of its bark for my son's wife. (June 2015)

In the discussions, participants related the activity mostly to the advantages it would give to the prevention of the cutting down of the trees. The participants in all the four schools expressed their dissatisfaction at the rate of deforestation in their areas. There was genuine concern about the rate at which the trees were indiscriminately cut down for charcoal burning. The teachers expressed how the training would help them in raising awareness about environmental degradation.

\footnotetext{
${ }^{47}$ Bugerere is a two-hour taxi ride from Nama.
} 


\section{What went well in these lessons:}

These group interviews were opportunities to reflect together about the success of the project. In addressing the question of what went well, the teachers referred to the conduct of the classes and other pragmatics that indicated how the activity was a success for the class. A participant teacher in the third school said:

What well in this training was the fact that the students were very well behaved. We spent an hour in the football field ${ }^{48}$ and yet not one of them ran off to the latrine or somewhere else... (June 2015)

The practical nature of the training usually resulted in cooperative students and manageable classes. I also noticed the fact that the teachers and their students worked in the same groups and collaborated as a team. This was one way of connection of people in the same community. The driving nature of the curriculum in Uganda hardly leaves much room for connections between the teachers and their learners. The working together of teachers, students and elders, as members of the same cause of Bulungi Bwansi, was one of the highlights of these lessons.

\section{Challenges encountered in the implementation of place-based pedagogy in the}

\section{classrooms}

The participants discussed the challenges they faced in the facilitation of the trainings in the participation schools. In the discussion of the challenges, the participants discussed and suggested ways of working around the challenges. They supported one another and as such learnt from the discussions. In addition to the weather, one of the issues that the participants talked about was the issue of transportation of the materials. This was because the materials

\footnotetext{
${ }^{48}$ Due to the messiness of the process of making of the Briquettes, we used to hold the training outside, in this case it was in the football field.
} 
were heavy and required at least two able bodied men to move on and off the truck. This is what Naomi, the facilitator, said after the training at the second school:

I really appreciate working with you, this program encourages me to work even harder to make sure that I make the best products. However, I find that the materials are heavy to load on the vehicle. They are not only hard to load but also to unload once we get to the school. What can we do about this issue? I am happy that you have organised for the truck to come for me. However, the driver is an old man and cannot help in the loading or the unloading of the materials. (June 2015)

In the previous training, Naomi brought the materials she had prepared for the training of the participants. In a way, all the participants had not really thought of learning how to prepare their own materials for making the briquettes. As a result, Naomi was starting to feel the strain of preparing that much materials which was not only cumbersome (i.e. for instance digging up the soil, having to collect all the cow dung...) but also draining to load onto the truck.

\section{How we overcame this challenge}

These meetings were a great way to address the challenges that were affecting the participants in the project. In reply to Naomi, one of the participant teachers answered:

I think we can now start to prepare our own materials at the schools. This will give all of us the practice and extend our learning to become self-reliant. In any case, there is no way we can confidently say that we have learnt how to make the briquettes when we cannot prepare the materials! I suggest we address this issue in the Nyama Kyoma meetings so that all teachers are aware that the Bulungi Bwansi club members start to prepare the materials at the school. (June 2015)

This was how the teachers started to organise their students, the members of the Bulungi Bwansi clubs, to prepare their own materials for the trainings both on the school compounds and in the community. All the materials we used in the community trainings were prepared by the Bulungi Bwansi club members of the participating schools. This gave the participants more practice and as a result more confidence in the skill of making of briquettes from scratch. 


\section{How these trainings have been received by others:}

Since these activities were new in the formal education setting in Uganda, it was important to check on the attitudes of the administrators and other members of staff towards the project. In all the discussions, the teachers showed that the other members of staff liked the activities and some of them requested to take part in them. One of the teachers in the first school said:

Many of the staff members think this is a very smart project. Our DOS also came today to the football-field to observe. This shows that he likes it and the fact that it is taking place on the weekends does not make him feel like we are using the time for the classes to train students in making of the briquettes. I believe that many people that have taken notice in what we are doing are impressed and even like the idea. (June 2015)

In all the participating schools, the teachers reported that they did not meet any administrative resistance to the IK activities, including the Bulungi Bwansi clubs. Instead, some members of the school communities wanted to join in the activities. In the next section, I discussed how the participant teachers could organise for the Bulungi Bwansi club activity of making of the briquettes to get into the communities.

\section{CYCLE TWO: BRINGING THE CLASSROOM INTO THE COMMUNITY}

\section{Bulungi Bwansi/ eliminate charcoal project in the communities}

In Uganda, formal education is highly examination oriented. Students must acquire certain grades in prescribed content areas. The struggle to teach and complete the examination syllabus makes it difficult for the teachers to create any opportunities for students' interaction with the wider community and therefore it is very difficult for students to ever get an opportunity to learn from the community (Gruenewald \& Smith, 2014). Moreover, this results in the failure of the learners to see how their learning fits into their real lives. On the same note, Randle (1989, p. 68) states, "it is only via organic links between community and school based 
learning that children and students can contextualise their learning." Place-based education emphasises the local as the centre of the students' learning experience.

In this project, Bulungi Bwansi was used to reconnect students and the teachers to their local communities by taking their club activities to the communities. Through the same Bulungi Bwansi club activities, the participants and the students acquired and shared the skills needed to regenerate and sustain their communities (Gruenewald, 2008).

After Naomi trained the club members and the participants in the schools, the teachers mobilised the local communities for the people to be trained in the making of briquettes. Due to time constraints and key participants' changing schedules, we trained at three out of the five communities we had planned to visit while I was there. Two women's groups and one youth group were trained during the time that I worked with them. Each of the training venues were within (10 to 15 minutes) walking distance from the participating schools. The students walked to the training grounds with their teachers. I am aware that the other communities did the training after I had left and during the third term. To date, more schools in Mukono have introduced Bulungi Bwansi clubs and Naomi is still working with the teachers. As explained earlier, Naomi gets to have her products sold during these activities. This is how she gets to make some money, otherwise, her work with the teachers is voluntary.

In Uganda, it is common for people with a common interest to come together to form groups in which they carry out some self-help projects like communal loan and saving schemes, agricultural projects like group tomato growing and so on. In one of the school communities, we trained a women's group called Twekeembe Women's group. This women's group gathered at a mosque and the training took place in the local mosque grounds, which is shared by a Moslem primary school. This group consisted of 17 women. We had two teachers, two elders, Naomi the trainer, myself and a group of 24 students who were also the Bulungi Bwansi club 
members. There were also several onlookers. The participant teacher, through the school administration, had sought the permission of the head of the mosque to hold this training at the mosque. The local council of the area was also made aware of the training for security reasons.

Even if Naomi led the training, the students took active roles in this activity, explaining the ingredients, helping with the mixing and discussing why we must save the trees. We carried charcoal stoves and samples of dried briquettes to the communities. We trained and demonstrated how the briquettes worked. The students also helped in the selling of Naomi's different types of briquettes, explaining to the members of the public how these worked and how they are made.

It was through these community activities that the students were introduced to the practical possibility of becoming change agents ${ }^{49}$ in their own communities. They also learned new skills and discovered their potential for public speaking through undertaking these activities. The teachers discovered another side of education as their students were provided with richer learning opportunities as they engaged in the practical activities of the clubs. During one group interview, the teachers revealed their surprise that the students whom they thought were non-achievers in class work were more involved and became the greatest contributors in the Bulungi Bwansi club activities.

\section{Group reflection about the Bulungi Bwansi activities in the community through group interviews}

After the Bulungi Bwansi training activities in the communities, the co-participants held their reflection group interviews/discussions at the school of the main participant teacher. Through these group reflections, the co-participants got to validate the success of the activities

\footnotetext{
${ }^{49}$ In these activities, students talked about the dangers of deforestation. In this, they were advocating for a change of heart in the community. As a result, they were being moulded into agents of change for their communities.
} 
and learn from the each other's analyses. The participants also got to forge ways of handling any challenges that they were experiencing in the implementation of the actions.

The discussions on the Bulungi Bwansi activities in the communities showed that all the participant teachers agreed that students can achieve even without scoring highly in the exams. This was exemplified through the excellent way that the students performed out in the community. In these interviews/discussions, it became evident that teachers were transforming their practices (i.e. they indicated a different perspective on student achievement). They started to realise that judgment of the students' performance should not only be based on class work but also in practical tasks like public speaking, explanation of issues to people, learning skills like the making of briquettes, and demonstration of their learned skills to community members. The teachers argued that the confidence with which the students perform practical tasks should contribute to the judgement the teachers or the education system makes about the student.

\section{Reflection on IK lessons}

This section was guided by the question, could you please tell us what you did in the class today? Through the recounts of the events by the co-participants, I managed to discern what the participants thought about the activities that they were involved in. A teacher in the second participating school said:

Today we went out to the community mosque to train the members of a Women's group how to make briquettes. The students were involved in explaining the importance of briquettes and what to use while making them. This was good for the students because they gained confidence in speaking in front of members of the community. (July 2015)

The participants then discussed their highlights of the activities and the reasons as to why they thought those moments were important. In this way, the co-participants learnt from one another particularly in how to judge a successful IK learning activity.

\section{What went well in the Bulungi Bwansi community training activity?}


In the discussions about what the participants thought went well in these activities, they talked about the behaviour of the students. Interestingly, they also talked about how the community responded to the students' interaction with them in the Bulungi Bwansi activities. A teacher in the third school said, "In this lesson, I liked the fact that my students were very involved. I believe that we shall get more students next year because our students represented the school very well today in the community" (July 2015). In many Ugandan schools, student numbers are determined by how the community perceives the school. In most cases, the school performance in the UNEB exams determines the community's perception of the school which invariably contributes to the high school enrolment. In some cases, parents have been known to enrol their children in schools that perform well in games and other extracurricular activities. In this comment, the teacher reveals the fact that the students' confident actions and ideas about deforestation made a positive impact on the community about their school.

The elders also contributed to the discussion of what went well in these activities. The elders' contributions revealed the social rather than the academic perception of students' achievements. The elder in the second school Bulungi Bwansi community activities said, "The students behaved very well and they did not mind "soiling" themselves at all. They showed the right example to the youth on the village. We had quite a crowd today because we were at the mosque" (July 2015). This elder's insight revealed how the educated do not do jobs that 'soil' them. In other words, the education system trains people to be served rather than to serve. When the students go out into the community and make the briquettes from sticky soil and cow dung, the elders and other community members (i.e. the parents) are impressed. This social perception of 'the educated' goes a long way in justifying the fact that the Ugandan education system does a lot of miseducation of the people. This is one of those perceptions that our project tried to change with the participants and in the communities. 


\section{How students reacted to place-based pedagogy; what changes in students' learning did the participant teachers notice}

This discussion question is mostly targeting the participant teachers. The teachers discussed the behavioural change that they noticed in their students' participation in this new learning environment, the Bulungi Bwansi community activity. A teacher in the first school said:

There are a lot of changes. I noticed that some of the poorest students in my class were the most active. This gives me hope that they can be something in future. It is not all about examination marks. Even a student who never says anything in the class was talking, explaining to the people the advantages of the briquettes... (July 2015)

A teacher in the third school said:

I have noticed that the students are more willing to work in the community than they do when it comes to working at the school. For me, this shows an interest in learning. Many students do not even raise their hands up in class; even when they know the answer. But the energy that I have seen in the village is very different. The students showed that they liked what they were doing. (July 2015)

Therefore, it became apparent that the greatest teachers' transformation involved the ideas about poor and good students. There is a default judgement placed on students in Uganda based on their test scores. This neglects many other significant factors like the mode of teaching and the language of instruction. Many times, teachers commented on the 'poor' students' ability to demonstrate in these place-based lessons; previously, a thing that the teachers thought would never be possible. Most importantly, the participants agreed that the Bulungi Bwansi community project served to reconnect the students and their teachers to their communities and places.

\section{CYCLE THREE: BRINGING THE COMMUNITY INTO THE CURRICULUM AND}

\section{PEDAGOGY}

The teachers discussed how to integrate the knowledge and skills acquired from the Bulungi Bwansi activities into the curriculum and into their pedagogical practice. As outlined in the previous chapter, the participant teachers met every Wednesday for Nyama Kyoma for one 
hour. This place provided a non-formal atmosphere in which the teachers worked under nonjudgemental conditions, supporting one another and building knowledge together. In these meetings, the teachers shared their diaries entries, lesson plans and some samples of students' writing to show how they were integrating Bulungi Bwansi activities into the curriculum. These were sessions where the teachers collaborated, shared materials and sought for a way forward in their practice as well as in the curriculum.

During the Nyama Kyoma meetings, teachers agreed on how IK concepts could be best integrated into the curriculum. It was agreed amongst them about which topics would be most suited to integrate certain place-based concepts. The most appropriate teaching methods were also discussed.

The teachers used the local language syllabus, which is also used by the Uganda National Examinations Board (UNEB). These are the topics that the teachers of Luganda worked with regarding Bulungi Bwansi and the Eliminate Charcoal project.

Topic one: Writing Indigenous language: sub-topics; the sound system and punctuation.

In this topic, the teachers agreed to centre on sounding out and building vocabulary surrounding the activities of briquette making and other activities of the Bulungi Bwansi clubs. The teachers also agreed this was an opportunity for students to practice using different punctuation (i.e. the comma and the quotation marks) in the discussions about the Bulungi Bwansi activities.

Regarding the teaching methods for these topics, the teachers agreed on debates, role play and drama. The teachers also discussed ways of developing students' confidence in public speaking in Luganda. They argued that the students needed confidence in the language 
especially since the community regards Luganda as a language for those that did not attend school. The teachers agreed to involve students in activities of public speaking as a way of boosting their confidence and pride in the language.

Topic two: Parts of speech: sub-topics; nouns, pronouns, the verb, adverb, adjectives, conjunctions, prepositions and interjections

In this topic, the teachers focused on the students' use of the different word groups in writings about Bulungi Bwansi activities. The participant teachers suggested ways of using the Bulungi Bwansi activities as a way of developing students' writing. For these topics, the teachers suggested making use of group work, word games, class discussions and peer review of anonymous short paragraphs.

Topic four: Extended vocabulary: sub-topics; people and places, colour, education, and the weather

The teachers discussed how they could use the concepts like deforestation, charcoal burning and briquette making to support students' writing skills around the above areas. For instance, one of the teachers highlighted how there had been a change in weather patterns due to the rampart deforestation.

The teachers suggested the following teaching methods for this topic which included, class discussion, group research in the above areas, speech writing and dialogue writing. One teacher shared a sample of student writing describing the vegetation during the recent droughts that had hit Mukono. Students' samples such as this provided the teachers with insight into their students' learning. As a result, teachers devised ways of making clear the relationships between Bulungi Bwansi and saving of the environment. 
Topic five: Family, clan and tribe system: sub-topics; cultural values and norms, the family, socio-economic activities, and leisure

The teachers suggested that students are supported to internalise the cultural values by carrying out research in their families, clans and communities. The teachers suggested that students would have to link historical and cultural narratives of their families to the concept of Bulungi Bwansi. The elder had explained, during the teachers and students' sessions at the schools, that in Buganda all the clans (i.e. to which all students and teachers belonged) had specific duties that they used to carry out in the palace and in the kingdom. For instance, in the palace some clans were responsible for the constructions and repairs, well as others were for ensuring that the Kabaka was in a good relationship with his subjects. In groups, the students were encouraged to collect oral histories, songs, proverbs and myths associated showing their clans' historical duties in the Buganda kingdom. These oral artefacts were then presented to the classroom. Group work is emphasised in most of the topics because it helped to build community solidarity; a concept which is disregarded by the individualistic tendencies of the exam oriented education system.

The teachers suggested the following teaching methods for teaching about family, clan and tribe system: group research, group presentation, role play, class discussions, and dialogue. The teachers encouraged each other to find out different innovative ways to teach about these topics and then to discuss with the rest of the co-participants in the next Nyama Kyoma meeting.

\section{Topic seven: Translation, composition, comprehension and summary writing}

The teachers discussed various ways of how to integrate into their students' writing the knowledge of briquette making as a measure of saving the environment and the Bulungi Bwansi concept. In this regard, teachers suggested that in composition writing, for instance, they could support the students in writing about making of briquettes; the dangers of cutting down trees or 
how one can save the trees through making and using of briquettes. One of the teachers shared samples of her students' letters (In the sub-topic of letter writing) to different people in the local governments about the dangers of charcoal burning and requesting to train communities in briquette making. The co-participants suggested that the following would be the methods of teaching this topic: group discussions, role play, dialogue and debates.

\section{In oral literature: the teacher used the following subtopics: oral narratives, proverbs and} songs

Even though there was only one teacher of oral literature, the discussions helped and guided her to develop teaching strategies about the integration of IK into her teaching. She integrated the concept of Bulungi Bwansi into the different topics of oral literature for instance the folktales and songs. During the Nyama Kyoma meetings, the teachers also shared samples of their lesson plans. Some of them planned to visit and observe each other's lessons to see how they addressed some of these topics first-hand in their teaching. In this way, the teachers worked together to improve their practice and to bring place-based education and IK into the curriculum.

\section{Conclusion}

This chapter has provided a detailed description of Bulungi Bwansi and how the coparticipants used this activity to integrate IK into the formal education setting. In the next chapter, the second action phase that the co-participants utilised when integrating IK into formal education in Ugandan secondary schools will be outlined. This was the re-discovery of the sacred places. Like the previous chapter, this chapter gives a detailed account of the cycles of the PAR action and shows the co-participants' reactions to their work through their group discussions. The chapter concludes with a detailed discussion of how the teachers' integrated IK into the curriculum and their pedagogy. 


\section{CHAPTER SEVEN}

\section{OBUWANGWA NE NNONO /RE-DISCOVERY OF THE SACRED PLACES (SSEZIBWA}

\section{FALLS/ SPIRITUALITY AND CONSERVATION)}

The Baganda have a strong connection with their natural environment, which is strongly evident in their language but also in their subjugated IK. Many Indigenous Peoples hold nature to be sacred and their spiritual ecology is metaphorically expressed through myths, rituals and beliefs (Cajete, 1994). The relationship of the Baganda with the natural environment is so intricate that the individual, the clan and the entire tribe is understood in relation to the animals, birds, plants and physical features in their natural environment.

Every Muganda belongs to one of the 54 clans that make up the tribe of Buganda and every clan has its totem, which is either an Indigenous ${ }^{50}$ land or water animal, a type of Indigenous fish, bird or plant. Members of the different clans are identified through the unique clan naming systems. Clan names are connected to the sacred places of the clan origins or to their totems. To date, even with the disruptive wave of religion and colonial formal education that I discuss in the second chapter, the Baganda's self-identity is fundamentally tied to their clan totems by which they are named and to which they are deeply related.

Obuwangwa is a Kiganda term that translates to 'creation' and yet ennono ${ }^{51}$ roughly ${ }^{52}$ translates to 'norms'. These words represent the Kiganda ecosophy in that they depict the way the Baganda perceive of nature and their world. According to one of the elders, Ssenga Naki, "Obuwangwa is that which was created at the beginning and given to the different peoples on earth. It is those things that define the places in which they are found..." And ennono is "the

\footnotetext{
50 Invasive species that were introduced by the colonialists are not part of the totems.

${ }^{51}$ If preceded by any determiners like 'our' or 'the', the word ennono loses the prefix ' $e$ ' but the meaning remains the same as that of ennono.

52 'Roughly' is an approximation as it is quite difficult to translate the term to the exact meaning in English. I consulted with the teachers in Uganda about the English translations of these terms.
} 
law that governs obuwangwa..." The word obuwangwa represents not only the physical features that mark places on earth but also the people in those places. Its morphology shows the holistic interconnectedness of the people with their natural environment through its etymological relationship with words like Muwanga (The god of creation who features in many Kiganda prayers and rituals); Eggwanga (a nation or a people, singular for nations, like the Baganda); and Amawanga (the different nations on Earth). All the words stem from oku-wanga, which translates 'to create'. Indeed, the term obuwangwa portrays the deep connection of the people of Buganda to their natural environment. Ennono, according to Ssenga Naki:

This is the law that governs obuwangwa. As a result, we should keep questioning ourselves. What does our nnono say about this? In the event of making a mistake, the nnono reminds us of the right path. For instance, if two people wish to get married, we will consult the nnono regarding their clans; what does it permit? Are they of the same clan? If they are, then the nnono does not permit that marriage. Is one of them of the other's mother's clan? Then the nnono does not permit it either. Ennono is the guiding principle in most things we do. Today religion is weakening this; or can I say in addition to education? (May 2015)

In the same way, the nnono is supposed to guide the people's interaction with their environment. There are things that people are not meant to do, for instance, hunt and kill their clan totems. The totems are blood relatives in the same way that people who share the same totem are brothers and sisters. There is a strong belief in Buganda and in many other cultures in Uganda that injuring of one's totem or even failure to protect it could lead to calamities. In the same vein, there is a strong belief that one's totem would never hurt them for instance when one's totem is a leopard, they are sure that it would never hurt them. The elders' concern was that when religion and education subjugates the people's IK, the young generation stops taking the nnono as seriously as they should and most times the young people are unaware of the existence of ennono in the event of making of sensitive decisions. There is therefore no cultural guiding principle in the decisions that these ignorant young people are making. 
River Ssezibwa, just like many other unique features of the Buganda landscape, is part of obuwangwa. Ssezibwa is sacred because of the shared myth among the Baganda that he was born of a woman. The Baganda like many Indigenous Peoples around the world explain the relationship within themselves and their natural environment in form of myths. In Buganda, there are many shared myths that explain the sacredness of places and things in our natural environment and as a result help to maintain the essential relationships of the people and Mother Earth. According to Cajete (1994, p. 52):

The function of myth is as diverse and complex as human life and cultures. The myths that we live by, glue our communities together through shared metaphors of identity and purpose. Myths help to balance individual psychologies and connect them to the greater whole of the tribe, natural environment, and global community.

The people of Buganda strongly believe that Ssezibwa is a twin born river. Upstream, the river divides in two distributaries; Ssezibwa, which is believed to be the male twin and Mubeeya, which is the female. In Buganda, twins are considered sacred children and they are also revered. If they are not treated with respect, twins are believed to curse clan members by bringing sickness, bareness and even death. So, at their birth, and in life, twins are pacified with many rituals and ceremonies. And this is reflected in the respect and reverence given to Ssezibwa. Today, this tribal myth has shielded the river and the surroundings from the exploitation that has devastated many places in Buganda. Cajete (1994, p. 63) argues, "tribal myths are filled with metaphors, symbols, images and creative linguistic and visual forms that are emotionally effective for members of a tribe."

The spiritual ecology surrounding Ssezibwa is expressed through the shared belief in its healing powers. Ssezibwa is mythically a place of abundance. This is because the mother of Ssezibwa gave birth to twin rivers. So, if someone is badly in need of anything, they come to Ssezibwa to pray for their needs. The people that come to Ssezibwa, according to Kintu, comprise of childless couples; people who need a good harvest, businessmen and women who 
need a better profit and the like. On visiting Ssezibwa, one cannot fail to notice as people go to the river bank to take a drink of the cool flowing waters or lay a gift at the huge rocks. The elder explained that the gifts are presented in thankfulness of a wish that was granted. As a result, there are numerous clay pots of gifts at the base of the huge rocks.

Places like Ssezibwa are highly respected even by the most money driven individuals of the community such as the charcoal burners. There is an unwritten nnono (respected by everyone in the region) as explained by Ssenga and confirmed by Kintu, that nothing that lives around Ssezibwa is killed. This includes the animals, snakes and birds that make this place their habitat. As a result, Ssezibwa is a tourist hotspot because there are thousands of bird species in the surroundings. The trees growing around Ssezibwa are never cut. Many medicinal trees that have disappeared elsewhere in the region due to charcoal burning can be found here. Moreover, Kintu explained that the medicinal plants can be used free of charge. Myths like Ssezibwa bring the Baganda together and explain our dependence to the natural world. They also underscore the significance of maintaining respectful relationships with our places.

\section{CYCLE ONE: BRINGING THE COMMUNITY INTO THE CLASSROOM}

Ssezibwa to be included as a part of this research project was a suggestion made by the participating elders during the first focus group interview. Their suggestion was given in response to the last question on the interview guide, which stated, "now that you have a chance to work with the formal educators, what strategies can you use to reclaim the hearts of today's young generation towards Buganda and the Kiganda norms?" One of the elders suggested that visiting and learning about sacred places in Buganda would help the young people understand their buwangwa and ennono since they tend to be very ignorant about this important part of their culture. Ssezibwa was chosen because it is the nearest sacred place within Mukono. 
According to the elders, one of the biggest problems of the young generation is the ignorance about their cultures and the elders believed that this was brought about by both education and religion. In the discussion about the issue, one of the elders commented about formal education, "Our disease today is ignorance... Formal education has done us a great dishonour. This is because those who have acquired this education are deaf to that which they are supposed to hear, because they now only hear English" (May 2015). On religion, Ssenga Naki, one of the elders, discussed:

This religion, which came to save us, did us a great wrong by abusing our buwangwa ${ }^{53}$ and dressing it in the picture of Satan. If you meet any religious leader and ask them to explain to you the meaning of Satan, by the way Satan is black, they will not be clear about it. Satan was dressed in the concept of our buwangwa. Every time one speaks of obuwangwa, the people will think of Satan. So, you end up without a way of speaking about it at all. (May 2015)

In this way, the elders expressed their disappointment of both formal education and religion in the way that not only separated IK from the people but also inherently labelling the culture and everything about it as evil. For the co-participants, Ssezibwa was one of the cultural places that would inspire respect and awe. In addition, learning about Ssezibwa would be an opportunity for both the teachers and the students to regain some of their lost IK. The participant teachers decided that Kintu, the tourist guide at Ssezibwa, worked with Ssenga Naki whose area of interest was obuwangwa.

Just like how the diviner was not ready to work with scholars like me or journalists, the participant teachers were not prepared to invite Ssenga Naki (an elder) to come to their schools or classes to teach students about obuwangwa. This exemplifies the divide between IK and formal education in the schools. These teachers were understandably afraid for their jobs because of the prevailing conflict between religion, culture and the highly exam oriented

\footnotetext{
${ }^{53}$ If preceded by any determiners like 'our' or 'the', the word buwangwa loses the prefix 'o' but the meaning remains the same as that of obuwangwa.
} 
curriculum $^{54}$. Having been a secondary school teacher in Uganda for over eight years, I understand these teachers' fears. And moreover, since many schools (both public and private) are established on religious foundations, it makes it even harder for teachers to introduce IK into a formal education setting. It was only after the first PLD workshop when many schools pulled out of the project despite several head teachers and teachers signing the consent forms, that those fears and the need to tread cautiously became even more apparent.

With the remaining few teachers, we agreed to not have any talks within the classrooms or school grounds about obuwangwa; however, the teachers would bring their students to Ssezibwa as part of learning tours under the extracurricular activities. This way we integrated IK and place-based education into the formal education by bringing the classroom into the community and then bringing the community into the curriculum.

\section{CYCLE TWO: BRINGING THE CLASSROOM INTO THE COMMUNITY}

In our project, students, teachers and elders visited Ssezibwa to foster a reconnection to places and to culture. In visiting Ssezibwa, the reconnection was furthered made through guided tours around the place and learning about the sacred Ssezibwa. This was done by listening to historical narratives, which also included some influential historical figures in Buganda. Ssenga Naki, the leading elder narrated these stories as we sat under the huge tree that was planted by Ssekabaka Mwanga; one of the historical Kings of Buganda. This is how we organised the Ssezibwa trips.

During our weekly Nyama Kyoma meetings with teachers, members suggested the days that would work for them to take the students out for the Ssezibwa program. They also stated the number of students that they would be taking out and if transport was needed. For the Ssezibwa program, four schools initially participated, however many schools continue to visit

\footnotetext{
${ }^{54}$ It is hard for teachers to teach outside the examinable syllabus or contrary to their schools' principles.
} 
Ssezibwa. The teachers continue to work with Kintu because of the connection that was established with him during the project.

Transport issues were resolved by sharing of the buses. For instance, teachers worked together to organise the transportation of students from two different schools to Ssezibwa on the same day in one big bus. This was because one of the schools owned a big bus while the other did not. This sharing of the bus resolved the transport problems and lessened the time constraint issues allowing the two groups to visit on the same day. As part of the preparation, Kintu would inform us via telephone correspondence which of the days had fewer tourists/visitors to minimise students' distractions during these visits. We would also ensure that we went there when he was available so that it did not interfere with his job. These factors were key considerations for the teachers when they planned the excursions to Ssezibwa.

When we got to Ssezibwa, Kintu took us on a guided tour. The co-participants carried diaries providing them with the opportunity to make notes. The points of interest that they had noted during these excursions would later be shared in the teachers' weekly meetings. They were also referred to in their lesson planning. I also carried a tape recorder to audio record these sessions so they could be referred during the weekly teacher meetings.

At the start of every excursion, Ssenga always explained the meaning of the name Ssezibwa to those who attended. In Buganda, names tell a lot about places and people. Even Kintu, who was the tourist guide was unaware of how the name Ssezibwa came about. He explained during his last interview that listening to Ssenga Naki's narratives provided him with IK that he was unaware of which inherently made him a more informed tourist guide at Ssezibwa.

“Okay, now how many of us here know the meaning of Ssezibwa?” Ssenga Naki would start her classes. The students gave a range of answers to Ssenga's questions. During the first 
excursion, one student said it might have been because the river was named after the village. After correcting the student that the village was Kayanja, Ssenga asked whether the students learned about the river at their school. The students said that they had not learned about Ssezibwa at school. The teachers explained how the students only learned about the Nile because it is considered important in the world Geography. The teachers explained that Ssezibwa is not referred to on the syllabus. Ssenga Naki explained:

Ok, I will now tell you. The name Ssezibwa comes from the word sizibwa (I cannot be blocked). The river flows through places that would easily slow down any river but Ssezibwa says, "Sizibwa!" The real name is Sizibwa but with time and with so many people from different areas of Uganda settling in Mukono, the pronunciation has changed to Ssezibwa. You will find that the very old people in Buganda still pronounce it 'Sizibwa'. (May 2015)

Ssenga Naki's first oral narrative was about the birth of Ssezibwa. She engaged her audience by asking them provocative questions thereby keeping them motivated and active listeners. She started:

This is the story of Ssezibwa's birth. Long time ago, there lived a man and his wife. This man was called Nsubuga Ssebwaato and the woman was called Nakangu Tebateesa. They lived in Ngogwe sub-county, which is today called Buikwe district. After some time, Nakangu Tebateesa became pregnant. In those days, there were no hospitals to have babies in but if one needed to have a baby, they would go to an old woman who did the job of delivering babies. However, the couple lived in an isolated spot and they did not have anyone that would help with the delivery of the baby. One evening, Nakangu started to have her labour pains. She immediately told her husband who decided to take her back to her mother's home where she would get some help. On the way through the dark, thick forest, Nakangu Tebateesa went into labour.

But instead of a human baby, she birthed two pools of water that started flowing in different directions. The first born was the strong one and he was the male child, Wasswa Ssezibwa and the next to come was a weak small girl named Nakato Mubeeya. (May 2015)

Usually at the end of the narrative, Ssenga Naki discussed some of the key cultural aspects in the narratives. This helped to reinforce the key points in the IK lesson. It also helped 
to highlight the important points for the teachers to note in their diaries for their lesson planning afterwards. Ssenga Naki used the question and answer approach for this discussion.

As mentioned earlier, in Buganda, twins are very important children and so when a couple has twins, they acquire certain prestigious cultural names and so do the twins. Ssenga Naki discussed with her listeners the cultural names of the twins as well as the parents of the twins. In all the discussions, students showed that they knew the names of the twins and readily mentioned that Wasswa, was the name given to the eldest twin boy and Kato was given to the youngest one. While Babirye was given to the eldest twin girl and Nakato for the youngest one. Ssenga Naki then discussed the names/ titles given to the parents of the twins. Her listeners expressed knowledge of the cultural names of the parents of the twins as Nnalongo for the mother and Ssalongo for the father. Ssenga Naki concluded the narrative, "That is how the mother of Ssezibwa, Nakangu Tebateesa, became Nnalongo Nakangu Tebateesa and the father Nsubuga Ssebwaato became Ssalongo Nsubuga Ssebwaato” (May 2015).

This provides insight into why Ssezibwa is Wasswa and his younger twin sister Mubeeya is Nakato. In addition, the distinctive cultural role of the parents of twins which also exemplifies the importance of Nnalongo Kkubo, one of the guardian spirits at Ssezibwa, is explained. Through these prestigious titles, Ssenga showed us one of the most important cultural reasons for respecting Ssezibwa.

During these discussions, we encountered examples of the prevailing loss of identity and change of culture through religion. This is seen when Ssenga Naki asked if there were any twins among the listeners of the day and whether the twins had the cultural twin names. During the first excursion, two students said they were twins. Of the two girls, only one had the cultural twin name given to her at birth. The other one said that she was never given a cultural twin name because her family was 'saved'. This is the term for staunch Christians. The 'saved' 
Christians were usually opposed to the Indigenous cultural norms such as the rites performed for the twins where they are given the cultural names. When Ssenga asked the student to mention her name, the student mentioned a male name. She explained that she used her father's surname. Ssenga explained why this is not the norm in the Kiganda culture. She explained that in Buganda, girls or women do not take men's names, instead they are given clan names that link them to their fathers' clans. To demonstrate her point, Ssenga identified the clan of the student by her father's name which is the Mmamba (lungfish) clan. The co-participants then discussed how it was difficult for students from religious families to learn about their cultural norms and places. A religious home, in addition to the education system that only favours Western thinking, makes it hard for such students to get any exposure to their cultural norms. Therefore, bringing the classes to places like Ssezibwa and having the elders facilitate bridged a significant gap between schools and communities as well as between formal education and IK.

In addition to these conversations about cultural names, Ssenga reassured some of her listeners' uncertainty about their IK during the excursions. An example of this was during the second excursion to Ssezibwa, a student asked whether it was true that people 'worshiped' this place. 'Worship' in the Ugandan formal school setting is a conflicting term. In the formal education setting, worshiping of God by the Christians and Allah for the Muslims is the norm. This question seemed to question the legitimacy of the excursion. It was almost as though the student was asking if it was okay to come to a place that was 'worshiped'. There were also quite a few other conflicting questions or comments during these excursions.

In addressing issues of conflict like this one, Ssenga Naki emphasised the cultural and tribal importance of Ssezibwa and other sacred places. The spiritual aspect in relation to the values of the land and life were of most significance according to Ssenga Naki. This is how she handled that question: 
Ssezibwa is very important because it is our buwangwa. Our great ancestors believed and taught us to believe that we can get anything we need (i.e. from our buwangwa) in peace only when we are upright. For one to be upright, they should not be guilty of abuse of obuwangwa here or anywhere else. Human beings are part of obuwangwa and should not be abused. The spirit that guards this place is called Nnalongo Kkubo and if you are an upright person, you can receive what you need. Our people have always believed and that is why you see all those gifts under that rock. If people did not get what they wished for, they would not have returned with thanks... (May 2015)

In addition to the story of the birth of Ssezibwa, Ssenga Naki narrated some other important historical narratives relating to Ssezibwa. The historical narratives connected the myth of the sacredness of river Ssezibwa to the real world. One of the stories involved one of the historical Ssekabaka of Buganda. This Ssekabaka is renown in the colonial history for having persecuted the Uganda Martyrs and this is what is taught about him in the formal education curriculum. Ssenga's narrative gave us a different side to this historical figure describing him as a generous leader of his people. She narrated:

Nnalongo Kkubo is the spirit that guards Ssezibwa and she is the one that grants the people's prayers of healing or wealth at Ssezibwa. Among the people who came to ask for blessings was Ssekabaka ${ }^{55}$ Bassamula Mwanga II. This Ssekabaka was the son of Muteesa I and his mother was Baagalayazze of the yyonge (otter) clan. You should remember that this is the same Ssekabaka who ordered the execution of the educated ${ }^{56}$ (Ugandan Martyrs). He ordered the digging of Kabaka's Lake in Ndeeba. He was the first Kabaka to rebel against the British invasion. He was exiled in 1899 to the Islands of Sserere (Seychelles) where he died in 1903.

Ssekabaka Bassamula Mwanga II used to come to Ssezibwa to ask for blessings and he also used Ssezibwa as a place to carry out official duties in Kyaggwe region. The day he planted that tree, my father told me, the Kabaka had come to install a new county chief of Kyaggwe, and to also reward one of his trusted men with land in Kyaggwe region. He planted this tree that you see here to commemorate that occasion. (May 2015)

\footnotetext{
55 This is a title of a deceased King of Buganda.

${ }^{56}$ Ssenga Naki's words were the educated, because as was discussed later, at that time Christianity and education were synonymous as the missionaries taught the converts how to read and write.
} 
The listeners asked questions for clarification while Ssenga wisely elaborated on the moral lessons in the narratives. The teachers made notes in their diaries about what Ssenga said and what they would use in their discussions during the Nyama Kyoma meetings. Ssenga also clarified the differences between the term Ssekabaka and Kabaka. She used both terms in reference to the Kings of Buganda in the narratives. Ssenga also explained the reason as to why during the narration, she mentioned the mother of Ssekabaka Mwanga's clan and yet that of the Ssekabaka was not mentioned. Ssenga's explanations were useful in educating us about the cultural ways in Buganda including the aspect of governance in Buganda. These concepts do not appear anywhere in the formal education curriculum; concepts that would help to change the historical image of our recorded colonial history. Ssenga Naki said:

Kabaka is the title of the living Kabaka. When a Kabaka dies, the title changes to Ssekabaka. In Buganda, the Kabaka does not belong to the father's clan like it is with everyone but he instead belongs to his mother's clan. When I mentioned the clan of the mother, it also means that that was the clan of the Kabaka. This nnono explains why the Kabaka can marry from any clan in Buganda, apart from his mother's. It helps in ensuring that every clan can have a chance of bearing a Kabaka. (May 2015)

For all three excursions to Ssezibwa, there was a lot of IK that the elders shared with the co-participants and the students. The teachers made notes in dairies for later reference. Students also made notes in their books according to their teachers' instructions.

\section{Group reflections about excursions through group interview}

After every excursion to Ssezibwa, I facilitated a group interview/discussion which was guided by an interview guide. These group interviews/discussions provided an opportunity for the co-participants to reflect together on their learning experiences from the Ssezibwa excursion. Reflection on the action in PAR is vital for the construction of new meanings (Kindon, Pain, \& Kesby, 2007). Three group interviews in total were held following the three group excursions to Ssezibwa. 
This shift of activities between action and reflection in the research process is a characteristic of PAR (Kindon et al., 2007). Both the participant teachers and elder/s participated in these group interviews and subsequent reflections. These group discussions also presented us with opportunities to further strengthen the teachers, elders and researcher relationships (Duenkel \& Pratt, 2013). This is significant as the elders had a unique opportunity to listen to what the teachers thought about the project and about working with them (i.e. elders). In contrast, the teachers came to understand what the elders thought about working with them and with their students. Most importantly, working together initiated the process of making "more porous the walls between the classrooms and the communities" as greater understandings of our shared experiences are constructed (Smith \& Sobel, 2010, p. 261). These group interviews laid the foundation that was important for the future collaborations of the two groups to sustain beyond the project.

\section{Reflection on IK lessons}

The participants reflected on the IK lessons that took place during the excursions. The interview question that facilitated the critical reflection about the IK lessons was "Tell us what you did in your class today". According to (Duenkel \& Pratt, 2013, p. 128), "self-reflection and critical reflection are used to challenge biases and assumptions and create new understanding". After the second excursion, a teacher said:

Today we went to Ssezibwa falls to learn about our buwangwa. We learnt about many things regarding our culture. We learnt about the spirit of Ssezibwa and how we can peacefully get what we pray for if we are good people. We also learnt about the cultural naming of twins and their parents. My students have benefited from Ssenga's stories about one of the great Ssekabaka of Buganda in addition to why Ssezibwa is respected in Buganda. I had never known that Ssekabaka Mwanga ever did anything good in Buganda apart from ordering the execution of the Uganda martyrs. It was a great lesson for my students and for me. (May 2015)

Some teachers' reflections, like this one, showed a new trend in their practice and in the educational experience of their students. What happened in the field that day with the students 
and the elder was something new but also good in the Ugandan formal educational setting. This was something that held great meaning for all of us and for our shared identity as Baganda.

\section{What went well in these lessons?}

All the participants responded in some way to this question. They mostly expressed their satisfaction about the students' conduct during the excursions. Ugandan classes are always quite big in size even for optional subjects like Luganda. In every class, we had more than 50 students. In Uganda, big classes usually have discipline issues, however, both the participant teachers and the elder expressed their satisfaction with the students' engagement, discipline and general conduct during the excursions. After the first excursion, a teacher said:

What went well for me was that the students were very interested. None of them had ever been to Ssezibwa but they showed interest in the place as we went around. They asked the guide a lot of questions about the river, trees, birds and many other things. They also showed great interest in the stories that Ssenga Naki narrated and were thoroughly engaged. I also liked the attention they gave to Ssenga because for me, that showed that they respected her and what she taught us. Yes, I think everything went well at Ssezibwa today.

The elder said:

I was very impressed with the discipline and respect these young people showed me. I know that school children are very disrespectful to elders but after working with them on this project, I have changed my mind. I have gained the courage of working with young Baganda once again. It is important for young people to learn to respect elders because that is when they can gain the knowledge passed onto them. (May 2015)

In all the group discussions after the Ssezibwa excursions, the participant teachers commented on their students' interest in the river, the animals, colourful birds but most importantly the historical narratives that the elder told. The teachers recognised the connection that was made with place and the learning opportunities that the students gained through these excursions. This realisation might be one of the reasons that the teachers' interest in Ssezibwa as an IK learning environment persists. 


\section{Challenges encountered in implementing place-based pedagogy in the classes}

With the demands of the exam driven curriculum, any teacher in Uganda would find it a challenge to get involved, let alone think about a program that would require one to involve students into anything else rather than academic related work. In addition, since we were doing PAR for the first time, we all experienced several challenges in our different ways and it was informative to hear what everyone was going through so that we could collaboratively find solutions. A teacher, after the third excursion, said:

The greatest challenge, for me, in implementing place-based education in my classes is the awareness that all these learning activities will not be part of the UNEB assessments. For example, about Ssezibwa, we have learnt many things that can benefit both our students and us as teachers. But when UNEB does not test something, many teachers and other people will not take it very seriously. (May 2015)

Even though teachers discussed in the Nyama Kyoma meetings how to integrate what they had learnt into their teaching, some teachers still struggled with it. Since it was the nature of the project to work things out in a collaborative manner, we put this on the list of issues to be discussed and addressed at the next Nyama Kyoma meeting.

\section{Strategies to overcome these challenges}

During these group interviews, the co-participant teachers came up with strategies to overcome the challenges that were brought up by some of the members that were experiencing these challenges. Usually a lot of discussions centred on finding practical ways to address some of these challenges (i.e. finding time for the lessons, sharing of lesson plans and invitations to observe classes). I think that these suggestions showed that the teachers knew exactly what they wanted for their students. The teachers also showed that they knew the direction that they wanted their teaching to take as shown in one of the participant teachers' suggestions:

It is indeed hard when you must target students' passing exams because many times we spend a lot of time going through past papers with the students instead 
of teaching them about real things that would help them in life. However, I think as teachers of Luganda, if we come up with ways of integrating IK into the curriculum, we will be the example to the rest. What we are learning now is the real-life situation and you will not find this in the UNEB syllabus or the past papers. We need to keep looking for new ways of how to bring our cultural values into our teaching... (May 2015)

Even if some participants expressed challenges of integrating IK into their pedagogy, it was also evident that others knew that it was through innovative teaching strategies (i.e. using the weekends for the extra time), that they could indeed integrate IK into the curriculum. It was evident that UNEB was one of the teachers' main challenges regarding integrating IK into the curriculum and yet this same UNEB represents the examination centeredness of the curriculum. In relation to the above teacher's challenge, Ssenga Naki answered:

Thinking about the lives of the individual people is very important. These visits to Ssezibwa have shown me that nothing about our ways of life is taught to our children. We are Baganda. Nothing is going to change this. We need to teach our children our nnono ${ }^{57}$ so that they know why certain places should never be destroyed. This is the same with the medicinal plants. This knowledge is important for everyone. We need to stop teaching only what makes our children deaf and blind to their nnono and obuwangwa... (May 2015)

These discussions helped to educate the participant elders on the dilemma of the education system and how all the stakeholders should work together for a better community. These discussions helped to highlight the need for both the elders and the teachers to collaborate in finding new ways of bringing IK into the classroom. This in turn would bridge the gap between formal education and IK.

\footnotetext{
${ }^{57}$ As explained earlier in this chapter, ennono roughly translates to 'norms'.
} 


\section{Students' reactions to place-based pedagogy and changes that the participating teachers have noticed in their students' learning}

The participating teachers indicated, through the group discussions and diary notes that they shared with the rest of the members, that the students enjoyed this way of learning more than their usual mode of learning. After the first excursion, a teacher revealed:

Mostly my students have liked place-based education. Since it is based on their surroundings and not in the textbooks, it is easy for them to relate to. This makes learning easy and enjoyable. Attendance has greatly improved. Usually students do not want to come to class but in these lessons, you find that I have a full classroom ... (May 2015)

Another teacher, after the third excursion said:

I have two students who are challenged academically. They lacked discipline as well and could never stay in class for the entire 40-minute lesson. But during the excursions, they are not the same students any more. One of them was appointed a Bulungi Bwansi leader, very good at organising others during the Bulungi Bwansi activities. His lack of discipline has disappeared and he is now more involved in the class discussions. The other student is leading in the class projects and he is also very vocal in the class. They are completely different students and all the teachers are just amazed at this change. (May 2015)

In these discussions, teachers did not only discuss the success of this new teaching strategy but they validated the changes that were happening in their students' attitudes towards learning due to the place-based pedagogy. In this way, the teachers were gaining confidence in this pedagogical approach.

\section{Instances when students' prior knowledge of their Indigenous Knowledge and experiences are supported by place-based pedagogy}

The participant teachers confirmed that students have some knowledge about their IK during the excursions and in their interaction with the elders. The teachers also noted that students from very religious backgrounds and highly educated families lacked the knowledge 
or were reserved towards participating in the discussions relating to their culture. After the second excursion, a teacher said:

Yes, there are instances when you realise that the students are not entirely ignorant about their culture. For instance, some students revealed during our Ssezibwa tour that their relatives went to the river for healing. Also, many students knew the special names given to the twins and the parents of the twins according to our culture. So even though they do not know a lot of things, like the history of their place, they know some beliefs and practices because these are still practiced in their homes. On the other hand, students that come from very religious families (like the ones that are saved) and those that come from highly educated ones, lack tribal knowledge and are usually reserved from talking about their cultural beliefs and practices.

In confirmation, the elder said:

Yes, I observed the same thing. Some students showed great understanding of the way twins are treated in Buganda. I was a bit shocked though, that some girls are using their fathers' names instead of their clan names. In Buganda, women do not take on male names. I was also shocked to learn that some parents deliberately do not allow their children to know about their cultures because of religion. I think that is wrong because my father was a religious man but he was a true Muganda. However, it is good that many students are willing to learn about their cultures and I could see this through the questions they were asking the whole time. (May 2015)

In this way, the students' level of insight into their IK was assessed and the coparticipants reached a conclusion of what to work towards in helping to improve their students' knowledge of IK and reconnection to their cultures.

\section{How well place-based pedagogy met students' needs}

All participants agreed that place-based education is very beneficial for the students and for the participants themselves. In most discussions recorded, the teachers expressed the fact that the information that they learnt in these IK activities was very necessary for them and that they wished they had learnt it as part of their formal education. A teacher after the first excursion said: 
I believe that students learn about their cultures, which is not given to them at home or school. They have also learnt to appreciate their community and places. For instance, at this excursion, we learnt of some good things about Ssezibwa, the uniqueness of the place and some good information about Ssekabaka Mwanga. From more exposure to such information, the students will love to belong to their tribes and cultures, which is a good thing. (May 2015)

The elder after the first excursion said:

Even as elders we have learnt a lot from this kind of education and working together with everyone else. We have a proverb in Buganda that says, "Agalya awamu ge galuma ennyama" (when teeth eat together, they can bite the meat.) When the teeth work together, they are successful even when encountered with tough meat. So, working together will indeed lead to our success in educating our children. (May 2015)

As the elders emphasised the value of working together to educate about IK and culture, the teachers talked about the how their teaching helped to reconnect the students to their cultures. They also talked of the love for one's culture which is one of the challenges of globalisation.

\section{How the teachers found working with the elders}

Reflecting on working together was advantageous in terms of building the bond between the teachers and the community elders. As discussed in the second chapter, Ugandan formal education does not currently provide opportunities for relationships between the schools and the community or the teachers and the elders to be built. A teacher after the second excursion said:

It is very good. I think that teachers and schools should make use of the elders in their communities because these elders are very knowledgeable. We have missed this for a long time. What I have liked best about working with the elders is that they are ready to share their knowledge with us. Even when some teachers did not want to come or simply pulled out, the elders stayed with us and continued to work with us. One elder has already told me that when this project concludes, he is still happy to contribute. So, I am thankful for all their time and effort in teaching us all these things about our culture. (May 2015)

The elder after the second excursion replied: 
That is right. Anytime that you want to work with me, on anything, just call my number. Not many teachers or students want to ask us anything, so when we get someone who wants to learn something about our culture, we see some hope for the young generation and for Buganda. (May 2015)

\section{How the rest of the school community thought about place-based education}

I thought that it was important to find out whether the school community was supportive of the project. In Uganda, it is very easy for teachers to become victims of their own practice when the administration goes against them (i.e. in instances when the DOS or head teacher thinks that the teacher is putting the students' test scores at risk). It was therefore important for all of us to talk about whether the school administrations of the participant schools were cooperative with the participant teachers regarding place-based education or not. During our discussions, it was evident that all the participant teachers thought that their school administrations were happy about the project. This indicated that there were more opportunities for place-based education in many of the schools in Uganda. A teacher, after the third excursion, revealed:

My DOS is happy if the lesson plans have got the UNEB curriculum content. I just make sure that I show how the IK activities would benefit the students' achievement of their learning objectives. I think it was good putting most of the activities at the end of the day or during the extracurricular time. This gives time for the other teachers and sometimes administrators to attend the sessions too. The lady who teaches Christian Religious Education (CRE) is not very keen on Ssezibwa but she liked the medicinal plant lesson. She followed our class around and took a lot of notes. She said that her grandmother had taught her some of the medicinal plants that she already knew. Otherwise some of the teachers I have talked to are really interested but feel left out. Our geography teacher said he should have been invited to be part of this project because he witnessed the making of the briquettes session and he felt that he would really need to use that information for his geography lessons. He has attended a few of our Bulungi Bwansi activities as well. (May 2015)

This information helped to strengthen the co-participant teachers' confidence in the integration of IK into their teaching and curriculum. It also helped to reveal to the co-participants 
the significance of their work to other members of the school community hence strengthening their confidence in their practice.

\section{How the participants felt about the research project}

All the participants expressed that they benefitted from the project. The teachers indicated that they had gained better ways of teaching, thereby improving their practice. In this they indicated that working with elders and using IK concepts (i.e. the historical narratives of Ssezibwa) in their teaching improved their teaching practice. The elders revealed that they had gained new skills and the opportunities in working with school teachers in school settings. The elders indicated that working with the teachers (i.e. during the excursions to Ssezibwa) showed them how to pass on their IK to the young people of today.

\section{CYCLE THREE: BRINGING THE COMMUNITY INTO THE CURRICULUM AND PEDAGOGICAL PRACTICE}

During the Nyama Kyoma meetings in Mukono, the co-participant teachers and I discussed how to integrate the acquired IK into the curriculum. We considered the descriptions of Ssezibwa that were acquired from the guided tours, as well as Ssenga Naki's narratives about Ssezibwa. We also used other IK products relating to Ssezibwa acquired through our interaction with Ssezibwa. Examples of these included: our observation of the people that came to seek for blessings; the gifts that were laid at the rocks; and flora and fauna of the place. To enrich the discussions, teachers shared notes from their diaries about the excursions and the group interviews held after the excursions. In addition, some teachers brought and shared some samples of their students' work.

During these Nyama Kyoma meetings, teachers collaboratively explored various ways of enriching their students' learning experiences by smoothly integrating place-based education like the one acquired through the Ssezibwa excursions, into their teaching practice. About the 
Ssezibwa excursions and classes, the participating teachers came up with various ways, as explained below, of how to integrate IK into the curriculum.

\section{Topic one: Writing Indigenous Language: sub-topics; the sound system and punctuation.}

In this topic, the teachers centred on building vocabulary from things like the falls, caves, rocks, trees, birds, animals and many other things found and observed around Ssezibwa. The teachers planned lessons about building the local language vocabulary during the learning about and sounding out of the Indigenous names of trees, birds and other creatures. Correct identification of these things (e.g. trees, birds, animals) and pronunciation of their names in Luganda was emphasised. The teachers suggested the following methods to teach this topic: class discussion, dialogue, role play and word games

\section{Topic two: Parts of speech: sub-topics; nouns, pronouns, the verb, adverb, adjectives,} conjunctions, prepositions and interjections

In this second topic, the teachers suggested and discussed different ways of teaching the word categories using the knowledge acquired in the excursions to Ssezibwa. The participant teachers also suggested engaging students in class discussions about students' experiences during the excursions as a strategy in the teaching about the different parts of speech in Luganda. Through the discussions, the students would practice constructing sentences using the different word groups (i.e. nouns, verbs). The other teaching methods suggested for teaching the parts of speech were the use of word games and puzzles. (i.e. quizzes).

\section{Topic three: Complex Numerals}

For this topic, the participant teachers agreed to leave it to the individual teachers to come up with ways of using the IK acquired in the Ssezibwa excursions in their teaching and then share with the rest of the members later in the coming Nyama Kyoma meeting. 


\section{Topic four: Extended vocabulary: sub-topics; people and places, colour, education, and} the weather

In this topic, the teachers discussed the kind of people who visit Ssezibwa in the present day compared to the people that visited the place in the past. This was inspired by the fact that during our excursions, we noticed tourists and the local people, yet according to Ssenga Naki's historical narratives, the Kabaka of Buganda used to come to this place for official and cultural reasons. Today, Ssezibwa is both a tourist hotspot as well as a cultural place. Yet in pre-colonial times it was a cultural and administrative place.

The teachers also discussed how they could use the reported changes in the weather patterns in Mukono (and how these affect Ssezibwa) in their teaching about extended vocabulary in the local language. When we visited Ssezibwa, it was during the rainy season and the water falls thundered because of the increased volume of water. Kintu explained how during the dry season, the water levels are usually very low and the falls do not thunder as much. Teachers suggested class discussions and as some of the teaching methods they would use in the teaching of this topic.

\section{Topic five: Family, clan and tribe system}

The teachers discussed how to integrate the cultural values of Ssezibwa as a sacred place into their teaching. They also wanted to highlight its importance in the lives of the Baganda and the other people that live in and around Mukono. The themes that were suggested by the teachers were as follows: many young people like Kintu gained employment because Ssezibwa is a growing tourist resort. In addition, people come to Ssezibwa for spiritual inspiration and healing. Birds, animals and plants were identified as totems for the different clans in Buganda, and moreover, the neighbouring vast sugarcane and banana plantations were economic activities in 
the area. In this regard, teachers discussed how to integrate concepts of healthy river basins for agricultural purposes. The teachers suggested using the following teaching methods:

- Student debates (i.e. Is Ssezibwa more important to us as a source of income?)

- Group discussions (i.e. about the benefits of cultural sacred places)

- $\quad$ Quizzes $^{58}$ (i.e. clan versus the plants, animals, and birds at Ssezibwa)

\section{Topic Six: Dictionary usage}

For this topic, the participant teachers agreed to research about ways of teaching dictionary usage by using the terms acquired during the Ssezibwa excursions. The teachers would then share their results with the rest of the team of the participant teachers in the coming Nyama Kyoma meeting.

\section{Topic seven: Translation, composition, comprehension and summary writing}

The teachers discussed how to integrate Ssenga Naki's oral narratives into the students' composition writing. For instance, one teacher shared a student's composition about how Ssezibwa healed a woman's infertility. The teachers also discussed how to integrate the cultural values of Ssezibwa as a sacred place into the teaching of functional writing like letter writing, speech writing and writing of statements. Teachers suggested the following methods for topic seven:

- Student debates (Is Ssezibwa falls more beneficial to the people of Mukono as it is or should it be turned into a hydroelectric power dam?)

- Group writing projects (i.e. Groups of students translate a piece of writing about Ssezibwa, given by the teacher, from English to Luganda)

\footnotetext{
58 Quizzes are enjoyable word games that can be used in teaching language as well as improving memory.
} 
- Role-play (i.e. students to write short scripts showing the role of Ssezibwa and staging plays in their classes)

\section{Oral literature: the teacher used the following subtopics: oral narratives, proverbs and songs}

The teacher for oral literature used the story of the birth of Ssezibwa to teach about folk narratives in Buganda. The teachers' discussions on how to integrate IK into the curriculum were an ongoing process that was undertaken together in a collaborative manner. There were continuous consultations and encouragement that occurred, with an importance placed on the need to try out different ways of bringing IK into the formal classroom. They also visited each other's classrooms to observe how they each went about it. As well as these consultations, collaborations and peer observation sessions, the teachers also brought samples of their students' work to the Nyama Kyoma meetings to share.

\section{Conclusion}

This chapter has provided a detailed recount of the action component of the rediscovery of the sacred places. The chapter also shows how the elder educates the teachers and students, through historical narratives, about their cultural values. The chapter also explicates how the participant teachers planned to integrate this IK into their pedagogy.

The next chapter will outline the third and last action component that the co-participants utilised in the integration of IK into the formal education curriculum of the region. This chapter, entitled 'Rediscovery of Indigenous plants', details how the knowledge about Indigenous plants is used to reconnect students and teachers to their cultures. The last section shows how the teachers used the same activity to bring place-based education into the curriculum. 


\section{CHAPTER EIGHT}

\section{OBUWANGWA NE NNONO/RE-DISCOVERY OF THE KIGANDA INDIGENOUS FOODS AND PLANT VALUES}

\section{Introduction:}

This chapter outlines the third and final activity that the co-participants carried out throughout the implementation of place-based education in the participating schools in Mukono district. During the entire research period, the three activities (Bulungi Bwansi, Ssezibwa and the Indigenous plants) were carried out concurrently. This was done by the participant elders splitting up and attending separate schools. In addition, the participant elders followed a schedule drawn up by the co-participants during the teachers' weekly meetings.

The Kiganda Indigenous food and plant values activity involved the exploration of Indigenous plants and their importance in the lives of the people of Buganda. In this activity, the leading elder was Ssenga Namu. In the first group meeting with the elders, she chose Indigenous plants as her specific area of interest and expertise. Ssenga Namu is a retired teacher but when she participated in this action research project, she was working with the Nnaabagereka ${ }^{59}$ of Buganda in the Ekisaakaate initiative where she taught cultural values to young girls.

The area of Indigenous plants was integral to this project because plants are essential to the survival of the people of Buganda. Plants are used as medicine for both physical and spiritual health issues as well as being used for food; shelter; fuel and other cultural functions. According to Cajete (1994, p. 101), "plants have always played an intimate role in the life and survival of the Indigenous people around the world." Even though the Ugandan formal education system and Christianity continuously devalue the cultural knowledge and use of plants for medicinal

\footnotetext{
59 The title for the 'Queen' of Buganda; HRH Sylvia Nagginda of the Omusu clan.
} 
purposes, many people in the society still rely on them for their survival in a variety of different ways.

As explained in the second chapter, the biggest challenge that many Ugandans face today is an ignorance towards the environment. Ignorance of the environment is associated with the subjugation of IK by the formal education systems (NEMA, 2010; Semali, 1999). IK which is also known as Indigenous literacy or folk knowledge, encompasses traditional knowledge and understanding of the Indigenous plants and their values. The same is described by Kahn and Kahn (2010) as "traditional ecological knowledges" (TEK). This is the knowledge or wisdom that people acquire through their interaction with their environment over a long period of time (Hall et al., 2000). Orr (1992, p. 86) warns, "the fact that this kind of intimate knowledge of our landscape is rapidly disappearing can only impoverish our mental landscape..." In Buganda, this knowledge is also disappearing fast and so is our biodiversity.

For many Indigenous cultures, Indigenous literacy is closely associated with ecological literacy (Prakash, 1999; Semali, 1999). Yet Semali (1999, p.103) describes Indigenous literacy as, "a competency that individuals in a community have acquired and developed over timepart experience, part custom, religion, customary law and attitudes of people towards their own lives and physical environment." Within the context of the Western world, Orr (1992) explains how ecological literacy has been challenged by the indoor education experiences of the learners. In East Africa, ecological literacy is challenged by the fact that IK is considered 'inferior' while the education associated with Western thought is perceived superior and "the better of the two" (Semali, 1999, p. 96). The 'inferior' knowledge, which is also the knowledge of the place or indigenous literacy is ignored and uprooted from the education system. The result is a lack of ecological literacy in a place where people still directly rely on the same natural environment for their daily survival. 
As part of Indigenous education, IK was imparted to the younger generation through several ways including mythology, ritual, experience and observation (Cajete, 1994; Wa Thiong'o, 1994). Today, young people rarely get the opportunity to observe or be involved in tribal rituals thereby missing out on this important part of education. The forums for distributing this information are even rarer as the young people continue to be distanced from the elders in their communities due to the subjugation of the IK and the changing lifestyle of the people.

In the next section, a detailed section relating to how Ssenga Namu, one of participant elders, worked with the teachers to pass on her knowledge of the Indigenous plants to the young in the formal education settings. This action was done through the cycles of bringing the community in the classroom; the classroom into the community; and the community into the curriculum and pedagogy.

\section{CYCLE ONE: BRINGING THE COMMUNITY INTO THE CLASSROOM}

The participant teachers agreed that the activity of rediscovering the Kiganda Indigenous plants would take place at the school-grounds and/or the surrounding areas near the schools (i.e. the banana plantations). The teachers were to organise a triple block lessons (i.e. approximately two hours). This would ensure there was enough time for all activities. On arrival at the schools, the participant teachers met the elder, myself, and in two cases another participant teacher from another participating school at the staff room of their school. The teachers then briefed us about the class for the day. For instance, information was shared about the number of students that would be in the class; which area of the school grounds we were going to be using; and where group interviews could be conducted at the completion of the activity.

After the briefings, the teachers led us to the classes where we sang the Buganda Anthem, Ekitiibwa kya Buganda. As explained in chapter six, we sang this anthem every time 
we went for the IK activities in the schools. The facilitating elder, the participant teachers, and myself (the researcher), were introduced to the class by the teacher. The participant teachers, whose classes we went to observe explained the importance of our visit to the students and then called upon the facilitating elder to speak to the class. This was the start of the elder's lessons on the Indigenous plants in the participating schools. The elder introduced her lessons by speaking about the importance of plants in Buganda. In the first school, she started her lesson by saying:

I greet you my friends! Today I am here to talk about plants. When Muwanga created this earth, he made plants to sustain the life of all the creatures. Our ancestors taught us to look after our land that was full of these important plants. Many people today do not know much about the importance of plants. This is why the plants are being destroyed. Our people are cutting down every tree including fruit trees, and medicinal ones for charcoal burning. We are here today to remember the importance of our plants. We will look at the plants that can be used for food, medicine and our spiritual nourishment. I am aware that some of you are saved and might not be free to enjoy this lesson. You are free not to listen to any part that you do not want to. As we move along, you are welcome to ask any questions that you might have about these plants. (June 2015)

At the completion of the elder's introduction, the co-participants and the class followed the teacher to the part of the school-grounds that was planned for the lesson. Once there, Ssenga Namu pointed out which plants were medicinal and told us their names and how they were used. She warned us of plants that have similar features but do not have the same medicinal properties. For instance, in the second school we visited she said:

Who knows this plant? (Some hands were raised and there was animated discussion of the plant and its description). Now this little plant is called obukwanso kwanso. This plant grows mainly in wetlands but it used to mainly grow at the water places (wells, springs and rivers) where we used to fetch water when we were young. Today it is rarely seen; perhaps because wetlands are getting destroyed or maybe because these days we no longer have the wells? You will notice that this plant looks like akayukiyuki but it is much smaller in size and its fruit is purple and sweet. The ones for the kayukiyuki are black. Its little wild fruits would make us delay at the well and we would get beatings for it! Children that eat these fruits do not get severe coughs and colds that children suffer from today. When you develop a cold, boil the leaves 
in a pot and cover your head with a blanket over the steaming pot, and just let the mucus flow. This is a very good remedy for fevers and nasal congestion. (July 2015)

Most of the medicinal plants that Ssenga Namu explained were at the same time fruit trees or utilised as food in Buganda. Cajete (1994, p. 105) explains how, "for Indigenous people around the world, the food they depended on for life was also their medicine." As the coparticipants and the students walked around the school grounds, Ssenga pointed out the different fruit trees and explained their medicinal values. From the reaction of the group, they were unaware of the medicinal values of the common fruit trees. In most cases, when the food value of the tree was its fruit, the medicinal function was either the leaves, the bark or the plant's roots. She made specific reference to the use of the pawpaw during the first school lesson:

\begin{abstract}
You all know the pawpaw? Many people do not eat pawpaw. They think it is for dogs, not so? (Murmurs) I have a friend who cut down all the pawpaw trees on his land because he said they were useless since one could not even make charcoal out of their stems. On the contrary, pawpaw is a good fruit for you. Can you imagine a cool slice of pawpaw on a hot afternoon after working in the sun? (Murmurs) Pawpaw is also good in preventing constipation. Pawpaw leaves, when lightly roasted, keep food fresh overnight. If you wrap fresh meat in pawpaw leaves, the meat will be fresh until the next day. Pawpaw leaves also help in making the meat get ready quickly. If you put a piece of pawpaw leaf in the meat as you cook, the meat will soften in no time and you will save on charcoal or firewood. Or you could just put a drop of pawpaw sap on the meat as you roast it as the effect is the same. The same effect will be achieved with pineapple juice. (June 2015)
\end{abstract}

Ssenga Namu also talked about many foods that people no longer take seriously in Buganda. These foods used to be heavily relied on in the past. She also commented on the traditional preparation of some of the foods in relation to how people cook today. The elder stressed that the contemporary trend of food preparation in Buganda is not good for the people. She expanded on this point by talking about the bitter Indigenous leafy vegetable, locally known as nakati as well as yams during the third school visit:

This is nakati. When visitors come to Buganda and taste our food, they always remember nakati! These vegetables are good when steamed on top of the bananas. You really do not need to fry them in cooking oil as many people do nowadays 
because that spoils them for you. These vegetables greatly improve your health when you cook them the right way. Over there are the yams (pointing), the leaves can be steamed and eaten in the same way as the leafy vegetables and of course you all know how to cook yams. People these days no longer like to grow yams. Yams are very reliable in all sorts of weather conditions, you are always certain of a harvest because they can withstand long droughts. Chicken, pigs and cattle enjoy the leaves as well. (July 2015)

During these explorations with the elder, some students brought plants for identification and to discuss their functions in everyday life. In one of the participating schools, one student asked the elder for the function of a certain plant. After getting the elder's clarification, he disclosed another function of the same plant that he had learnt from his grandmother. The elder explained that many of the plants have multiple medicinal functions. It was also clarified how in one community, a plant can be utilised for one function and yet in another, the same plant can be used for a different purpose. The elder highlighted the need for people from different regions to communicate with each other so that community knowledge banks are expanded.

Some of the functions of the plants that we (co-participants and students) explored were how they can bestow spiritual wellbeing on individuals and heal inner selves. These were ebbombo, olweeza and namirembe ${ }^{60}$. Ssenga said that these plants could be used in many ways. For example, one of the many function of the ebbombo plant is that it can be used is for bathing newborn babies. The newborn is bathed in the plant for the first week of their lives. However, Ssenga clarified that these plants work best when used together. In the third school we visited, the elder explained about the use of these plants in the following way:

I hope many of you have used ebbombo. This is the ebbombo. It makes our bodies clean. When you have that strong teenage smell, this is what you need to use. Simply get a bunch of ebbombo leaves, avoid including these clinging little things on the stem. Then take the leaves only and use them as a sponge to scrub under your armpits and other smelly parts of your bodies. You will not smell again. How many have used it in this way, eh? (Some hands of both teachers and students rise). Yes, it really works well. Ebbombo is also very good in ensuring spiritual nourishment and

60 The botanical and English name/s for these plants could not be found. 
development in people. It must be used in the baths of newborn babies here in Buganda for centuries to ensure good health and peace of mind. For this purpose, you have got to mix, ebbombo with olweeza and namirembe. The baby is bathed in this mixture for at least the first five days of its life. It clears the babies' skins as well. Whenever you feel depressed for no apparent reason, you need to take a bath in this mixture. It is very likely that you could be having a spiritual problem. Simply crush a handful of leaves from each of the plants (i.e. ebbombo, olweeza and namirembe) in a basinful of water until the water turns a dark green shade and bathe. This will definitely restore you to your normal self. (July 2015)

Many of the listeners knew about ebbombo. The teacher in the first school we visited revealed that she knew that ebbombo was very effective for healing stubborn coughs. She said that you need to chew at least two leaves twice a day and the cough will go. The only trouble with using this plant for healing coughs, according to this teacher, was that its leaves were extremely bitter and therefore hard for children to chew.

Ssenga Namu also explained the benefits of bananas. She explained how banana is a staple food in Buganda as they have grown and used bananas for many generations. Ssenga Naki talked about the use of the different species of banana in the banana plantations surrounding the schools that we visited. She mentioned about four species that are used for emmere (food). There were (I could not find any English translations for these Indigenous species), Nakitembe, Musakala, Nakabululu, and Mpologoma. In Buganda, the term 'food' refers to the main course served. Anything else that is served as part of the meal has a different name. The elder also explained that for the Baganda, what is considered as the most important 'food' is the banana. She explained in the fourth school:

In Buganda, you cannot serve a respectable meal without banana. If I came to visit your home and you cooked something else that did not contain banana, however tasty, I will go back home and tell my people that I did not eat any food at your home. At formal gatherings like funerals and weddings, banana is the food served to the guests. Banana has always been our food. It is very sad that today banana is becoming more and more difficult to grow in Buganda. (She spoke very sadly.) (June 2015) 
The elder's explanation clarifies the cultural significance of bananas to the Baganda. This also distinguishes Baganda from the different tribes throughout the country whose important foods include potatoes and/or millet. The cultural significance of the banana helped to show the participants their shared connection to Buganda and how the different crops in the region have different uses.

Ssenga Namu pointed out the different species of bananas that are used in the preparation of the local beer, which is an important social practice of the people. The local beer is used for leisure purposes, and for ceremonial functions. In addition, she showed us the three species which are served as snacks, (bogoya, kivuuvu and ndiizi $)^{61}$. These species are eaten only when they ripe. Not all species were represented in one single plantation of the three we visited.

Ssenga Namu also informed the participants about the historical importance of the bananas in the Buganda pre-colonial administration. Ssenga stressed that it was imperative for every Muganda to have a well looked after banana plantation. She said that during the time of the reign of the $\mathrm{Kabaka}^{62}$, chiefs went around the villages checking to see whether everyone had a banana plantation. Every family had to have a banana plantation or they would be breaking a law that had been passed at the time. By having a banana plantation, people did not starve or resort to theft in times of drought or floods or any bad situations. Ssenga also showed us how the banana stems were to be properly stripped during harvesting. As well as this, she also showed us how the plantations were to be pruned, mulched and weeded. In the third school that we visited, the students and teachers got to participate the traditional pruning in the school banana plantations with Ssenga Namu.

\footnotetext{
61 There was no English translation for the different Indigenous banana species.

62 The Kabaka reigned during the pre-colonial and partly the early colonial times. After independence in 1962, the Kabaka was stripped of his kingdom and the Ugandan state was formed. The Kingdom of Buganda became a cultural institution without any powers to enforce any laws.
} 
In Buganda, bananas are also used in the cultural rites and ceremonies. Cajete (1994, p. 101) explains how there are many examples throughout the world where "Indigenous Peoples have represented their understanding of health and wholeness in metaphoric, symbolic and ceremonial ways." Ssenga Namu highlights the importance of bananas in the performance of the rites concerning the birth of twins and the cultural birth check for the legitimacy of children during the funeral rites.

Throughout the classes that we had with Ssenga Namu on the topic of Indigenous plants, it was evident that both the teachers and students gained a lot of traditional ecological knowledge (TEK). This was evident during the group reflection meetings where the teachers discussed how they would incorporate this knowledge into their teaching. During these classes, both teachers and students sought for explanations about the different plants and their functions to the people of Buganda. In addition, some students and teachers shared knowledge about the different functions of some of the plants that Ssenga talked about. In these lessons, the learners utilised their Indigenous literacies and this transformed the classrooms into "interactive environment of knowledge production" which engaged the teachers, the students and the community elder (Semali, 1999, p. 107).

\section{Group reflection about the lessons on plants through group interviews}

In this activity, as well as during the entire project, participants were involved in continuous reflection, which occurred at different levels of the cycles of the research project. Goodnough (2008, p. 433) argues that participants of PAR project should keep "engaging in continuous cycles of reflection, dialogue, action and learning as they developed and implement their inquiry projects." As explained in the previous chapter, after every lesson involving placebased education at the participant schools, we met for a group interview with the participant teachers, the elder, and the researcher. 
The group interviews involved a lot of discussions which were guided by the interview schedule. During these group interviews, dialogue centred on what worked well and what could have been improved in the participants' implementation of place-based education. In this way, the participants were being collaborative as well as critical about this process. Further, the participant teachers discussed new concepts and theories that grew out of this experience in relation to their practice (Kemmis \& McTaggart, 2005). All group interviews were held at the schools immediately after the actual IK lessons were carried out.

\section{Reflection on IK lessons}

Using the key question on the interview guide; "Tell us what you did in the class today", the participants described what they did during the lessons. Through such dialogue, participants came to understand the nature of IK relevant to their communities (Goodnough, 2008). The participants described their own learning experiences in these lessons. Both teachers and elders appreciated the critical importance of the knowledge of the Indigenous plants which could be utilised in the present day. In the first school that we visited, a teacher revealed:

Today we learnt about the different uses of our plants. We discovered a lot of good uses for plants that we were never took time aware of. Many of my students and I were happy to learn more about the other functions for plants. For example, Ssenga Namu explained the importance of avocado leaves and the avocado seed, the pumpkin seeds, mango leaves pawpaw leaves and many more. We also learnt the many different of plants that we were unaware of. For me, this lesson has opened a whole new way of teaching Luganda which is enjoyable. I now have a great interest in the plants in my surroundings. (June 2015)

In these recounts, the participants showed that they were developing a sense of place that they did not have before. They were now looking at their place as an important entity that is directly related to their wellbeing. Such revelations indicated that the teachers recognised how place-based education could reconnect them and their students to their places and cultures. 
Some participants' reflections about this lesson were more centred on the environmental aspect of the activity. The participant teacher in the third school said:

In this lesson, we saw that every plant around us can give us more than we can imagine. We learnt that every plant has a reason as to why it was created; from a big tree like the ekifabakazi to the climbing weeds like ebbombo. Ssenga Namu gave us a lot of information about the plants. We also realised that the charcoal burners brought about the scarcity of many important medicinal trees like the ekifabakazi that Ssenga talked about. For me, this lesson showed me that we still have a lot to learn about our plants, which we can do from the elders living with us in the community. (July 2015)

The teachers' description of what happened in these classes highlighted their growing ecological literacy as well as their awareness about the importance of the natural environment to humans. Teachers started to look at the vegetation with more respect which they would later emphasise in their pedagogy. Most importantly, their descriptions showed that these teachers' practice of place-based pedagogy was becoming better. These participant teachers indicated that they did not only learn to value their local plants but gained lot of information about their natural environment. The established relationship with the elders ensured the future prospect of continued interaction between the teachers and elders thereby providing opportunity to improve the teachers' IK.

\section{What went well in these lessons?}

The participants discussed what went well during these outdoor lessons. These reflections provided insight for both the teachers and elders on what to consider for place-based education. The teachers acknowledged the increased students' interest in their learning because it was grounded in their surroundings and moreover by people who lived with them (i.e. the elders). The participant teacher in the second school said:

For me, what went well in this lesson was the students' interest. When Ssenga Namu talked about the use of the avocado seed and leaves, I realised a growing interest as well as extensive note taking. For the first time, everyone was looking at the different features of these plants as Ssenga Namu explained about them. When the bell sounded 
for end of lesson, students still lingered behind to speak in person with Ssenga. I think this lesson really went well. (July 2015)

In relation to the students' interest in learning about their culture, after the plant lesson in the fourth school, the elder said:

I was impressed with the seriousness that some students brought into this lesson. I did not see any unserious conduct. Two girls wanted to know in confidence which plants were most effective for "visiting the bush' ${ }^{6}$ ! I realised that we still have real Baganda women in Buganda. And because of this, I pledge my commitment to work with the teachers anytime they want me to come to the schools. Before this project, no one ever came to ask me anything. But now, I realise that some people still care to learn about their land and I will pass the information to them. (June 2015)

In working out what went well for both the elders and the teachers, the teachers gained insight about their culture and how to enrich their students' learning experiences through their IK. The teachers also appreciated IK in reconnection of both themselves and the learners to their cultures. As a result, the co-participants were able to effectively plan the next class activities since group reflection fosters group learning (Goodnough, 2008).

\section{Challenges encountered in implementing place-based pedagogy in the classes}

During the group interviews, the participants also reflected on the challenges that they encountered in the lessons about Indigenous plants. There were many times when the participants experienced challenges in implementing the plans of the project. Goodnough (2008, p. 452) affirms, "messiness and uncertainty are inherent and often necessary in PAR".

This is what the teacher at the first school experienced:

My biggest challenge for this lesson has been mostly the unpredictable weather. I have had to reschedule this lesson twice due to heavy rains and last week it started to rain just when Ssenga arrived. Since I had to swap lessons with another teacher, it became tricky to get another triple lesson once I had lost that one due to the weather. So, for me, the greatest challenge in carrying out this lesson was the rain

\footnotetext{
63 This is an expression for a valued rite of passage for girls to womanhood in Buganda. It is a disappearing rite in today's younger generation as not many girls still go through with it.
} 
(i.e. weather). Otherwise, this is a necessary way of teaching about our environment and I will continue trying to come up with ways to make it possible to have such lessons with the help of the elders. (June 2015)

Apart from the weather, one of the participant teachers had been confronted by a parent concerned about her son getting involved in ungodly activities such as traditional medicinal plants. This was raised at three different group interviews highlighting one of the challenges of IK. Many people related IK to evil. One of the teachers in the second school reported:

Some of our students come from very religious families. There is a feeling that what we are learning is not good for their faith. A parent who was very concerned about medicinal plants research that the students carried out confronted me about the issue. (July 2015)

This confusion is one of the challenges that place-based educators in Uganda are likely to face. This highlights the need for continuous group discussions and reflections to remain as they are very important in terms of coming up with a common strategy of creating a change in the social attitudes of the communities.

\section{Strategies to overcome these challenges}

PAR is hardly a neat research paradigm. The co-participants in this project engaged with challenges all the time. As such, all members were aware that when we met for the group interviews, there would be reflection on ways of overcoming these challenges and even turning them into learning opportunities. In this respect, Goodnough (2008, p. 452) explains that "those who engage in PAR need time to grapple with new ideas, to make sense of an emergent process and to construct shared meaning with PAR communities of practice." Strategies to overcome the challenges were a key part of the conversation.

When asked how he was dealing with the challenge of the unpredictable weather, the teacher in the first school said: 
You see we have a proverb that states, Ekijja omanyi kinyaga bitono (What comes when one is aware, takes a few things.) In this case, I am sure that we can equip ourselves with alternative plans in case our initial plans fail. For instance, the issue of time has been discussed with the rest of the team during the Nyama Kyoma meetings and we have come up with strategies like swapping lessons and using weekends and extracurricular time for some of these lessons. This weather makes it hard for both teachers and students in the school. By the way, when it rains continuously like this, everything starts to revolve around the weather. (June 2015)

The participants agreed that prior preparation for such lessons would contribute to their success. Whenever a lesson on IK failed to happen, the responsible teachers agreed that they would meet with colleagues to find out how best to overcome the challenge. One of the strengths of this project was the spirit of working together and learning from one another.

About the issue of parents questioning the kind of education their children were getting, a teacher in the second school suggested:

How about involving the Parents Teachers Association (PTA) in future? I mean if during one of the PTA meetings (we have them twice a year), one of the teachers presented some of the achievements of this project and requested the parents to support their children in related projects. I think this could really help. In any case, if a parent is totally against her child's involvement, there is nothing one can do, except support the child through it all as well as respect the parent's wish. It is hard to change people all of a sudden. Yes, because... you see, people have been taught that their culture is evil since they were young. How can they change these thoughts suddenly? We need to think about that too. (July 2015)

It so happened that the elder, Ssenga Namu was a representative on the PTA in the same school. So, we agreed that we needed to involve the parents and therefore the other participant teachers needed to discuss this proposal as well. All the participating teachers resolved to talk with their school administrations about parental support and involvement at their next school PTA meeting. During this conversation, the co-participants explored the fact that changing people's poor attitudes towards their culture is not something one can quickly fix. Attitudes and beliefs take time to change and place-based educators should be aware of such challenges and plan for them. 


\section{Students' reactions to place-based pedagogy}

For all the participating schools, the participant teachers informed us that their students showed great improvement in class participation; completion of assignment tasks; and increased interest in the learning about Indigenous plants. According to one of the teachers, this occurred primarily because students found the activities relevant and moreover, they directly related to their lives. One of the teachers in the second school said:

I have noticed that some of my students who never said anything in class were freely interacting with the elder. There is this girl who was continuously discussing some of the plant uses that she knew and asking questions about other plants. This girl is always very quiet in my class and I used to think she was just afraid of class work. Today she was a different student. (July 2015)

A teacher from the third school said:

I realised that this is one of the few lessons where all the students want to participate joyously. When Ssenga showed us how to prune the banana plants, all the students were struggling to take a turn at trying out the methods she showed us. The students were very attentive as Ssenga explained the process. All the students tried out the Kiganda pruning methods and I am sure they will get busy practicing the Kiganda pruning style once they get home.

The co-participants discussed the nature of the IK activities. They acknowledged the fact that most of these activities (i.e. pruning banana plants) were grounded in the students' local experiences. This made learning not only easy but enjoyable for the students. In this regard, the co-participants validated the exploration of Indigenous plants as an effective way of place-based pedagogy.

\section{Instances when students' prior knowledge of their Indigenous Knowledge and experiences are supported by place-based pedagogy}

The participants agreed that the students had some knowledge of the Indigenous plants in their environment. Students freely discussed the functions of some of the plants that Ssenga 
Namu talked about and they also discussed other plants that performed the same functions as the ones that the elder talked about. A teacher in the third school said:

They (students) will try out what we learnt today because they had knowledge about the plants already for different functions. For instance, when Ssenga talked about the use of the pawpaw leaves in the cooking, many students got excited. Everyone is familiar with pawpaw, just like the mangoes and avocado. These students' prior knowledge of the trees will make using the same plants for the different purposes more interesting and the information hard to forget. (July 2015)

\section{How well place-based pedagogy met students' needs}

During the exploration of the Indigenous plants with Ssenga Namu, the teachers indicated that this was a very necessary lesson in the lives of the students and the teachers themselves. During the group interviews at the different participating schools, the teachers agreed that learning about the Kiganda plants was beneficial to both the students and teachers themselves because of the values in the plants. The teachers in the fourth school said:

The knowledge about these local plants is very important for both the students and for us the teachers. The students needed this information to learn how to utilise the natural resources. The best example I can give is the use of ebbombo which can be used to eliminate that awful odour that many students suffer with. It is very difficult to get deodorants and perfumes in this village. I hope that students will start using this plant by the end of the day and the other plants as well. (July 2015)

A teacher from the first school also said:

This knowledge is very important for our students' needs and as a result might be used for solving some of the problems affecting our community. This district is notorious for charcoal burning. Some students have parents whose only source of income is charcoal burning. People are cutting down trees indiscriminately for the charcoal. Such lessons can change the attitudes of these students towards caring more for their environment. (June 2015)

It is hard for many Ugandan parents to easily afford medicines (i.e. medicines for influenza, coughs, skin diseases etc.). It is even more difficult to acquire things like deodorants. The coparticipants agreed that the knowledge about Indigenous plants would be very helpful to solve 
many local problems of both the students and teachers as well as cultivating a heart of care for the environment.

\section{How the teachers found working with the elders.}

Throughout the project, all the participating teachers found working with elders beneficial. The participant elders said they appreciated working with the teachers. One teacher in the third school said:

I find working with the elders valuable. It is a pity we have lost so much time. There is a lot they can teach us that we cannot find in textbooks. We need to work with them as much as we can. I am concerned about the time and energy they spend with us. They need to feel appreciated and be encouraged to continue doing what they are doing now. I wish the Ministry could hire community elders as consultants for us teachers. That way, they can be paid for their work. (July 2015)

The question of the elders' remuneration was raised in the teachers' Nyama Kyoma meeting and it was agreed that the teachers would bring this issue to their school administrations for future considerations. This was important particularly as the teachers felt that they needed to continue working with the elders beyond this research project. There was a consensus to try and lobby for an income for the elders in all the four participating schools. The idea was mainly supported by one of the teachers who also happened to be a deputy head teacher in one of the participating schools. A teacher in the first school we visited said:

I have learnt a lot from the elders in this lesson. When my mother died, I stayed with my Aunt who was an herbalist. She was my father's eldest sister. Many people used to come to her for help when they were sick. I used to go with her to the bush to dig up some of these medicines and as a result I learnt a lot from her. But after my father remarried and took me away from her, I never had time to learn from her anymore until she died. However, I still remember what she taught me. I also continue to use some of the medicinal plants. Working with the elders in this lesson reminds me about the plants values which my late aunt taught me. I will try out many ways of getting my students interested in learning about these plants because they can save lives. I am also thankful that Ssenga Namu has agreed to come and conduct the same lesson with another class that I teach. (June 2015) 
After these activities took place in the participant schools, the participant teachers started to plan with the elders to come again to their classes to meet with other students to learn about the Indigenous plants and plant values. This highlights the improvement in these teachers' practice and it was a sign that the wall between the school and the community was dissolving.

\section{How other school community members received place-based education}

The co-participants agreed that the other members of the school community were in favour of this new way of teaching. On several occasions, we had non-participant staff members join us in the study about the Indigenous plants. Two teachers in the third school had also joined us for the traditional pruning of the bananas with Ssenga Namu. This was evidence that the teachers of other subjects had an interest in the integration of IK into formal education. It might take time to change the entire education system but the response to IK in the participating schools indicated a promise that it will eventually happen.

\section{How the participants felt about the research project}

The co-participants revealed that they gained a lot of knowledge and skills from learning about the Indigenous plants with Ssenga Namu. These teachers revealed that the knowledge and skills they gained in learning about Indigenous plants was vital for their survival. All the participant teachers agreed that this learning activity was necessary for the students for them to lead better lives in their communities in Buganda. As a result, the teachers agreed that they would continue to involve their students in learning about the Indigenous plants with the community elders. The elder agreed to continue working with the teachers.

\section{CYCLE THREE: BRINGING THE COMMUNITY INTO THE CURRICULUM AND PEDAGOGY}

It was during the Nyama Kyoma on Wednesday evening, that the participant teachers and I discussed the integration of the knowledge about the Kiganda plants into the curriculum. 
During this meeting, the teachers shared what they had done so far regarding the integration of this IK into their teaching. Some teachers shared diary entries which outlined what they thought was the important aspects of the IK activities in the elder's lesson. Also, samples of their students' work that demonstrated how the teachers were integrating the knowledge about the Indigenous plants into their teaching were shared. In this meeting, the teachers worked together to bring that knowledge into the subject topics. In addition, the teachers also discussed the teaching methods that they would employ in teaching of these topics.

For the teaching about the Indigenous plants and their values, the teachers resolved to use this IK gained in the teaching of mainly two topics; topic six which is dictionary usage and topic seven which is composition writing. However, the teachers agreed that in case any of the teachers wanted to use this IK in teaching of the subject topics, they would share their methods with the rest of the participant teachers during the next Nyama Kyoma meetings.

\section{Topic Six: Dictionary Usage}

In this topic, the teachers agreed that students learn dictionary skills by compiling lists of the Indigenous plants and how the local people can use the plants. The teachers suggested that this be a class project for the term because it would be carried out in stages. The first stage would involve students carrying out research at home with their grandparents, parents or just community elders. In this, students would ask these elders about the Indigenous plants and their values. The students would construct lists of Indigenous plants and their functions in addition to the ones that Ssenga Naki taught them. The second phase would involve all the students bringing together their individual lists to be joined into a single class list showing the plants in alphabetical order. The third and last stage would involve the editing and proofreading of the whole class dictionaries of the Kiganda Indigenous plants and functions in the community. The teachers and some students would work with Ssenga Namu to edit the final copies of the 
documents. Finally, the finished product would be sent off to be typed, bound and after which, kept in the school libraries of the participant schools for community reference. The teachers were excited about the prospect of compiling the first copies of the Kiganda plant dictionaries for their local communities' benefit.

\section{Topic seven: Translation, composition, comprehension and summary writing}

The participant teachers discussed how they would integrate the knowledge about the Indigenous plants into the students' composition and functional writing. The teachers suggested that students would practice writing compositions explaining about how certain plants can help to cure certain conditions (i.e. the ebbombo and the body odour). The teachers also suggested that students practice letter writing about the use of the Kiganda plants advocating for herbal medicine. For instance, the teachers suggested that students would practice writing letters to the Ministry of health suggesting more research into the use of herbal medicine made from the Indigenous plants.

\section{Conclusion}

In this chapter, a recount is provided about the last action component undertaken with the participants who integrated IK and place-based education into Ugandan schools. This chapter details the exploration of the Indigenous plants and concludes with a detailed account of what the co-participants did in the research project. 


\section{PART C: REFLECTION}

\section{Introduction}

This section represents my critical reflection on the action presented in the section above. In this section, there are chapters Nine, Ten, Eleven and Twelve. I use the metaphor of the Saagala Agalamidde (I don't want idlers) drums to discuss the themes that arise in this reflection. The Saagala Agalamidde drumrolls are explained in chapter six as these were used to summon the people to Bulungi Bwansi activities in their communities during the precolonial times. These drums were silenced by colonialism. The metaphor demonstrates how in this PAR project the participants worked together to reawaken the silent drums as well as the spirit of Bulungi Bwansi in the participant schools and communities.

In using this metaphor, I show the fact that this research is grounded in the critical place inquiry by portraying the coresearchers' recognition of the injustices caused by colonialism (i.e. represented by the silencing of the drums) and their resistance to those injustices by their deliberate actions to reawaken the drums (Tuck \& McKenzie, 2015). In addition, this metaphor

is foretelling that our IK is still alive and that given the right conditions it will awaken and thrive in the communities and in the land. 


\section{CHAPTER NINE}

\section{THE RE-A WAKENING OF THE SAAGALA AGALAMIDDE DRUMROLLS}

In this chapter, I reflect on the actions of the co-participants as they endeavoured to bring the community into the classroom as a way of integrating IK into the formal education curriculum. The metaphor of reawakening of the drums portrays the starting of a deliberate, and yet powerful agency of a decolonizing education. In the action chapters, we see how the elders and the teachers work hard to strategically acquire a space for IK in the formal education arena which has for decades privileged the dominant, colonial-inherited education system. In this chapter of Saagala Agalamidde, the main ideas that arise are conscientization, resistance and transformative practice; communal solidarity; and collective responsibility.

\section{Conscientization, resistance and transformative practice}

This study was the start of the journey for the participants as a people of this area to critically deliberate on their IK in relation to their education system. Conscientization is a Freirean term that refers to the development of critical social consciousness in which dialogue and analysis serve as the foundation for reflection and action (Grande, 2008). Although the coparticipants show some awareness of the subjugation of their IK by the formal education system, it is clear, through the group discussions, narratives, and observations, that it was only through this project that they came to critically evaluate the effects of this subjugation on the individual and on their communities. It was also during this project that they decided to come up with means of countering this challenge. Freire (2005, p. 51) explains:

Functionally, oppression is domesticating. To no longer be prey to its force, one must emerge from it and turn upon it. This can be done only by means of the praxis: reflection and action upon the world in order to transform it. 
As a result, through continuous group reflection and dialogue, the co-participants came up with suggestions on how to overcome this challenge. While the participant elders suggested the IK activities that they could all immerse the students into to bring IK into the classrooms, the teachers sought ways of integrating what they learnt from the same IK activities into the curriculum as well as their pedagogy.

In a way, the participants' bringing of IK activities into the classroom, was an act of resistance to the dominant education system and practices in the post-colonial Uganda. Hall et al. (2000, p. 4) explains that "the process of teaching (and learning about) their histories and cultures is, for many Indigenous Peoples, an act of political resistance to colonialized and imposed ways of knowing." In this act of resistance, their quest for self-determination is evident. Self-determination means that individuals are free to determine their own goals and make sense of the world in their own culturally generated ways (Bishop, Berryman, Cavanagh, \& Teddy, 2009). When the elders came to the schools to facilitate the IK lessons like the learning about the Indigenous plants, the co-participants worked towards culturally enriching their lives and those of their students with the knowledge and values that had been taken away from them by the dominant education system. One of the elders said as she introduced her topic:

I am going to speak about the foods/plants that are commonly dismissed by people today because they are local and therefore have been taken off the menu. Once upon a time, if you can recall at all, they used to be very much a part of our daily lives and food but now the modern food has replaced them. Most of these plants and foods are around us although we no longer see them at all. (May 2015)

From the group discussions that were held after these activities, the co-participants realized how since the lives of people in Buganda still depend heavily on the knowledge of their natural environment, it was vital for this information to be taught in schools. According to Bishop et al. (2009), self-determination means that the people gain control of their lives in such a way that they get to take responsibility for their affairs and plan for their future. Indigenous 
plant knowledge and values is something that the formal education does not consider important even though the Ugandan people still directly depend on their natural environment for food, medicine and in many other ways as discussed in chapter two. The resolve to bring into their pedagogy this kind of knowledge is not only self-determining but also transformative practice for the co-participants in this study. Transformative practice is possible when the coparticipants demonstrate the ability to make autonomous decisions about collective action. (Stern, Townsend, Rauch, \& Schuster, 2014). In addition, Kincheloe (2003, p. 309-310) highlights how "empowerment involves teachers providing themselves with the skills and resources that enable them to reflect on educational practice." This is what is reflected in this project when the co-participants bring the different IK aspects in their classes and in the curriculum. This initiative symbolizes the reawakening of the Saagala Agalamidde drumrolls in that the co-participants started to take control and shape their own education practice and curriculum according to the current and future needs of their communities.

\section{Communal solidarity}

In this study, the action of bringing the community into the classroom was the start of the rebuilding of the solidarity between the co-participants and the school community. One of the fundamental African Indigenous values which is not catered for in the present formal education curriculum is communal solidarity (Dei, 2000). This project created an environment where the co-participants built strong relationships with each other, with their learners, and with the communities in which they worked. Gruenewald and Smith (2014, p. xvi) argue that "the phenomenon of 'placelessness' is associated with alienation from others and a lack of participation in the social and political life of communities." Working with elders to facilitate in the IK activities did not only help in bridging a generation gap created by the formal education but it also helped in the creation of a special bond between the elders and the teachers; 
the elders and the students; and between the teachers and the students. These are the relationships that are not nurtured in the present formal education system.

In addition, the participants built solidarity in their common cultural heritage. Every time, at a start of an activity in the school, the elders requested that we sing the Buganda anthem, Ekitiibwa kya Buganda (The Glory of Buganda). At all the schools, just before the IK activities, this important cultural anthem reminded the participants of the magnificence and permanence of their identity.

Verse 1: Okuva edda n'edda elyo lyonna

Lino eggwanga Buganda

Twamanyibwa eggwanga lyonna

Okwetoolola ensi zonna

Chorus: Twesiimye nnyo, twesiimye nnyo

Kulwa Buganda yaffe

Ekitiibwa kya Buganda kyaava dda

Naffe tukikuumenga
From time immemorial

This land is Buganda

We were renown in the whole country

Surrounding the entire world

We are fortunate, we are fortunate

For our Buganda

The glory of Buganda is timeless

Even us we must keep it up

In these solemn words, a solidarity based on building and restoring the participants' cultural identity was formed. This is something that the formal education system destroys in its subjugation of IK and privileging English over the Indigenous languages in education. Wa Thiong'o (1994, p. 11) sums up the cultural disharmony as a result of privileging English in colonial formal education when he said: "And then I went to school, a colonial school, and this harmony was broken. The language of my education was no longer the language of my culture."

The fact that the elders came to the schools to work with the teachers highlights communal solidarity against what scholars have termed as epistemicide; "the destruction of the knowledge of a given social group" (Knijnik, 1999, p. 1055). As discussed earlier, the elders' role in the traditional Buganda society was to teach the young people how to live their lives and 
be a part of their communities. The elders held respectable positions in the communities then. But with the coming of the colonial formal education, the elders were rendered useless because IK was not considered important anymore. Ironically, the formal education system makes society to disregard elders as ignorant and thereby breaking up the traditional societal structure. Castellano (2000, p. 25) highlights how as a result of the colonial formal education, "intergenerational transmission of ancient knowledge has been disrupted, and the damage has not been limited to the loss of what once was known; the process of knowledge creation has also been disrupted." In this project, the participant elders and teachers united in counteracting of the knowledge destruction. The teachers, elders, students and the community members formed a learning community to bridge the knowledge gaps created by the formal education system.

In this project, the language of communication was Luganda. As discussed in chapter two, the formal language and language of instruction in Uganda is English. However, using English in the formal environment takes away the freedom of expression, enjoyment and originality from the learning/teaching experience of both the students and the teachers. In addition, Grande (2008, p. 234) warns, “whole nations get trans or (dis) figured when articulated through Western frames of knowing”. English as a language is embedded with white cultural assumptions about non-white cultures and therefore frames them as inferior and primitive (Semali \& Kincheloe, 1999). In the project, we found that English not only divided the people of the same community by creating a barrier in communication, it also damages the people's understanding of their cultures by failure to represent many local concepts in the learning activities. When, in one of the schools we visited for Bulungi Bwansi, students in the oral literature class debated in English, the elder had to continuously get clarification from the teacher about what the students meant. This removed the authenticity, enjoyment and freedom of expression from the learning activity. Throughout the group discussions, it is evident that 
using Luganda in this project brought us all close to one another, to our culture and to our places.

In the first PLD workshop, one of the teachers commented that what he liked best about the workshop was the fact that we used Luganda as the language of communication. To the question, "what worked well for you in the workshop and why do you say so?" He wrote, "The use of the Indigenous language Luganda. It gave us an opportunity for self-expression without the hindrances and inhibitions." Wa Thiong'o (1994, p. 4) argues that, "the choice of language and the use to which language is put is central to a people's definition of themselves in relation to their natural and social environment, indeed in relation to the entire universe." Using Luganda in all the learning and teaching activities in this project was very instrumental in enhancing the solidarity of all the participants; in the liberation of our communication (tongues) and in the liberation of the flow of ideas.

\section{Collective responsibility}

This project provided a platform on which the participants contributed to the rebuilding of the value of collective responsibility in the schools and amongst themselves. One of the most important value in many Indigenous African cultures is that of collective responsibility (Dei, 2000). The competitive nature of the colonial formal education system tends to enhance an individualistic, self-centred way of life as explained by one of the most revered African leaders and educators. Nyerere (1967, p. 1) explains that the purpose of education in any society is "to prepare the young for their future membership of the society and their active participation in its maintenance or development." Colonial education is not transmitting the right values and knowledge of our society to our young Indigenous African people for future membership to their communities. Nyerere (1967, p. 2) highlights that colonial formal education, "emphasized and encouraged the individualistic instincts of mankind instead of his cooperative instincts." In this, Nyerere (1967, p. 2) further explicates that the colonial education which we are giving to 
the our young, "induced attitudes of human inequality, and in practice underpinned the domination of the weak by the strong." In the Bulungi Bwansi concept in this project, the coparticipants encouraged selfless service, discipline and respect. In Buganda, as explained by the elders and as observed in all the activities, collective responsibility is at the heart of the concept of Bulungi Bwansi. This is explicated by the elder when he said:

Bulungi Bwansi starts with us; we are Bulungi Bwansi, you and me. We must bring that heart of Bulungi Bwansi back in us today in this Mutebi ${ }^{64}$ era. This heart used to protect us, bring us together and what we have. We must be a model to the rest; we must teach others the benefit of working together for the good of the community. (May 2015)

In the actions of forming the Bulungi Bwansi clubs in the participating schools, the elders were not only reawakening an important cultural value in the co-participants but they were also embedding collective responsibility in the educational experiences of the students. Bulungi Bwansi clubs were formed to go out to the community to carry out good deeds without the members expecting any form of payment but with the understanding that they were doing it all 'for the good of the land'. The students advocated for environmental responsibility by making the briquettes to reduce deforestation. Not only was it advantageous to the students to learn the practical skills, but the entire community reaped and will continue to reap a lot of benefits by the opportunities of the introduction of the Bulungi Bwansi clubs in schools. According to Smith \& Sobel (2010, p. 237):

Creating opportunities that allow children to become change agents in their own communities is likely to inspire a taste for such involvement and encourage the formation of social capital and a sense of common identity so essential to the maintenance of a democratic society.

In these actions, the students together with their teachers were practically learning to be responsible members of their communities by participating in their communities' maintenance

\footnotetext{
${ }^{64}$ The reining Kabaka of Buganda is Mutebi. So, this period in Buganda is commonly called Omulembe Omutebi (Mutebi era).
} 
and development which is in line with Nyerere's vision for education. The same value of community responsibility and service is elucidated by Smith and Sobel (2010).

This project does not only provide the co-participants with a platform to create knowledge together but most importantly it gives them a space in which to establish a common vision for what constitutes educational excellence (Bishop et al., 2009). The teachers worked hard in planning the IK activities of bringing the elders into the school settings. In this, they continuously came up with new and better ways of developing a place-based pedagogy. One teacher commented in a group discussion:

In this lesson, we saw that every plant around us can give us more than we can imagine. We learnt that every plant has a reason as to why it was created; from a big tree like the kifabakazi to the climbing plants like ebbombo. Ssenga Namu gave us a lot of information about the plants in addition to the little knowledge we had about them already. We also realised that the charcoal burners brought about the scarcity of many important medicinal trees like the ekifabakazi that Ssenga talked about. For me this lesson showed me that we still have a lot to learn about our plants, which we can do from the elders living with us in the community. (July 2015)

In addition, the teachers frequently visited each other's classes for observations and held continuous group discussions about the best way of making porous the walls between the community and classroom (Gruenewald, 2003a). As a result, the teachers refined their practice to make relevant to the students the value of their IK and their communities.

In their collaboration, the co-participants take on a responsibility to ensure that the education of the young people of Buganda is culturally relevant and that it also helps to address the impacts of colonialism. One of the participant teachers commented in the group discussion:

My students have benefited a lot when they listened to Ssenga's stories about one of the great Ssekabaka of Buganda in addition to why Ssezibwa is respected in Buganda. I had never known that Ssekabaka Mwanga ever did anything good in Buganda apart from ordering the execution of the Uganda martyrs. It was a great lesson for my students and for me. (May 2015) 
In the elders' narratives about Bulungi Bwansi, the students and teachers get to learn the historical and cultural relevance of collective responsibility thereby countering the capitalist traits in the dominant colonial education system (Abdi \& Cleghorn, 2005). Throughout the project, the co-participants display a strong commitment and dedication to developing a culturally relevant pedagogy; a mission that was possible due to their collective responsibility.

\section{Conclusion}

In this chapter, the bringing of the community (in form of elders and their IK) into the classroom marked the start of the process of self-definition for the co-participants, the students, and the community members in Buganda. This was also the beginning of the bridging of the divide between the classroom and the community. Further, bringing the community into the classroom in this project demonstrated a great potential for place-based education in the schools and the assurance of teachers getting more involved in decolonizing education practice. Indeed, bringing the community in the classrooms marked the reawakening of the Saagala Agalamidde drumrolls. 


\section{CHAPTER TEN}

\section{THE RESOUNDING SAAGALA AGALAMIDDE DRUMROLLS}

In this chapter, The Resounding Saagala Agalamidde drumrolls, I discuss the themes that emerge in the reflection on the actions related with bringing the classrooms into the community. The resounding drums represent how the co-participants' intersection of IK in the formal education setting helps in the reconnection of the teachers and students to their communities, cultures and places. As discussed in chapter 6, these drums are a call to the people to respond to the community's need. In this chapter, the drums are resounding, actively urging the co-participants on to revive the values of kinship with nature, mutual reciprocity, and respect of the elders' voices as voices of the land. These are values that we badly need in our society today and yet they have been locked out of the curriculum by our Westernized formal education system. In this chapter I reflect on the resounding drums and the reaction of the people to the call.

\section{Kinship with nature}

One of the major ideas identified in this study was educating about co-participants' Indigenous relationship with nature. Many Indigenous Peoples around the world share the view that nature is sacred and that human beings are intricately part of the natural environment (Cajete, 1994; Semali \& Kincheloe, 1999; Wane, 2000). Mosha (1999, p. 213) affirms humanity's relationship to their nonhuman counterparts, "humanity and all other beings form one large family which must continually act and relate as one entity." In his description of the meaning of Indigenous, Cajete (1994) explicates the Indigenous people's relationship to their places and to their environments. Cajete (1994, p. 86) explains: "Indigenous means being so completely identified with a place that you reflect its very entrails, its soul" and hence confirming the strong relationship and bond that the people had with their natural environment. 
In one of the group discussions with the elder who facilitated about the sacred places and obuwangwa, we learn that the Indigenous culture of the Baganda consider the people to be part of obuwangwa. She explained:

Obuwangwa is that which was created at the beginning and given to the different peoples on Earth. It is those things that define the places in which they are found. For instance, the hill, Namubiru, will only be found in Ggomba and in the same way, you will only get Ssezibwa in Kyaggwe and not in Ggomba.

Obuwangwa is a very wide concept if we are to explain it in detail. The first thing that is obuwangwa is this land that we are standing on followed by the people who are meant to live on the land. Language is obuwangwa; food is obuwangwa because even though we eat lots of different foods from the market, we have types of foods that were specifically created for us as Baganda... (May 2016)

In the elder's IK facilitation, she also emphasized the sacredness of nature. This is especially seen in the elder's narratives about Ssezibwa where the river is portrayed as a living, spiritual entity. In one of the narratives, we learn that Ssezibwa was born to a human couple and that anyone with a pure heart can get whatever they want when they ask of the Spirit of the river. According to the elder, proper understanding of the concept of obuwangwa is crucial in the appropriate reconnection to our places. In the group discussion that followed one of the excursions to Ssezibwa, the elder stressed the importance of a culturally relevant education which engages students deeply with places and their significance to social, cultural and ecological connectedness:

These visits to Ssezibwa have shown me that nothing about our ways of life is taught to our children. We are Baganda. Nothing is going to change this. We need to teach our children our nnono so that they know why certain places should never be destroyed. This is the same with the medicinal plants. This knowledge is important for everyone. We need to stop teaching only what makes our children deaf and blind to their nnono and obuwangwa... (May 2015)

In her narratives, this elder emphasizes respect of these places and what they stand for. The historical narratives that the students and teachers listen to by the river show how the 
Ssekabaka (King) of Buganda respected these places and the fact that to date, some people still strongly believe in the power of these places. This validates the deep respect that must be accorded to these places. She explains:

Ssezibwa is very important because it is our buwangwa that our great ancestors believed and taught us to believe that we can get anything we need in peace only when we are upright. For one to be upright, they should not be guilty of abuse of obuwangwa here or anywhere else. Human beings are part of obuwangwa and should not be abused. The spirit that guards this place is called Nnalongo Kkubo and if you are an upright person, you can receive what you need... (May 2015)

Relating to nature in a deeper and spiritual way is one of the things that our formal education has left out of the curriculum by the subjugation of our IK. In bringing the classrooms to these sacred places, both the students and the teachers got to not only learn about, but also to experience the sacredness/spirituality of these places. This same experience is echoed by Cajete (1994) when he says:

When one views the world as a sacred place, a place that reflects a living process and way of being that goes beyond the human sense of experience, one deals with nature in a very different way. It becomes a life-and breath-charged experience. (p. 87)

On the same note, relating deeply to our environment can help to counter the present environmental issues we are experiencing in Uganda. Semali and Kincheloe (1999) explain how IK can counter Western Science's destruction of the earth "because of its tendency to focus on relationships of human beings to both one another and to their ecosystem" (p. 16). In visiting and learning about these sacred places through the facilitation of the community elders, the teachers and their students got to reconnect to their culture and places in a culturally meaningful way. This was a meaningful way of learning about the Kiganda IK.

\section{A culture of mutuality}

One of the themes that stand out in bringing of the classrooms into the community is the traditional value of mutuality. Mutuality according to Cajete (1994, p. 25) is the "reciprocal 
relationships between one's social group and the natural world." When the participant teachers, through the Bulungi Bwansi activities, create opportunities for students to educate about the environment in their communities and to also train community members in making of the briquettes, the students were inherently learning that they are a part of these same communities and that the wellbeing of the communities is tied to their own wellbeing. This value of mutuality counters the alienation of the people from their communities when the education that they are given distances them from the life in their communities and their natural world. Wane (2000, p. 55) echoes this alienation when she writes, "I was not taught about my culture or the things my parents learned from their parents in school; yet I was taught about the American Revolution...I realized that my formal education had somehow divorced me from my roots." The formal education system creates individuals who are 'aliens' in their local communities and as a result these people neglect their local areas for either the urban or other places. This is the making of a placeless population.

Creating learning opportunities for the students in their local places builds a sense of place based on pride and understanding of their communities. No one can love or care about what they do not know. But when students are given the opportunities to understand and share in the participation of building of their communities, then they will look differently upon these communities. In bringing the students to the community, the co-participants in this project were "creating patterns of connectedness and mutuality that are the foundation of community wellbeing." ( Gruenewald \& Smith, 2014, p. xvi)

In addition, the co-participants' bringing of students to the bushes and plantations to explore the Indigenous plant values and to Ssezibwa was a way of raising their own and their students' sense of mutual dependence with their natural environment. Many indigenous cultures indicate a recognition of Earth as a provider and a giver of life and therefore the duty of the humans to respect and honour that relationship. Holmes (2000, p. 44) portrays this in one of her 
Hawaiian respondents' memoirs, "Take care of the land. You know the land feeds us. And the rivers give us water." In this, the Earth is shown as tenderly caring for humanity and therefore the people's obligation to take care of her. On the other hand, Cajete (1994, p. 100) describes the Indians' ethical belief about taking from the Earth, "Every time you pull a plant from the earth, she feels that pull, and you must always make the proper offering of tobacco and prayer". In this case, one must always be conscious of the well-being of the Earth as we take from her. This mutual reciprocity forms one of the strong basis of Indigenous education. In the excursions, and through the discussions with the participant elders we all learnt how the Earth cares, provides and protects us. We learned about plants that provide us with food, medicines for many diseases, spiritual cleansing and healing and we also learned about how to care of some of the plants in the traditional way. In all our interactions with the elders, what was clear was that when we do not treat our Earth well, we are the losers. Here is one of such discussions after a training of how to save the trees through making of the briquettes.

Elder: Thank you for this skill. The other day in our village, we were shocked to realise that we no longer have Ekifabakazi! (name of a tree) Do you know that in the whole of Nama (name of a sub-county in Mukono), there isn't a single one left just because of the charcoal burners? It is one of those trees you just cannot afford not to have in the village.

Teacher: Why is it so special?

Elder: Ha, just think of its name, women kill it. From its leaves to its roots, it is all different medicines for pregnancy and childbirth related issues. Since time immemorial, women have relied on this tree's medicinal qualities. (June 2015)

It is important to note here that well as the elder can recognize the loss, the teacher has no idea what we have lost in the destruction of this very important tree. When our education system tends towards competitive personal achievement, people are naturally inclined to regard nature only as a resource mine in no way connected with their personal well-being (Smith \& Sobel, 2010). In this project, when the classrooms are brought into the community, the participants' and students' sense of environmental stewardship is cultivated. The need to 
recognize the harm that human activities have caused to Earth, at the local level, is necessary for people to develop a heart of care for our only life-giving planet.

\section{Elders as voices of the land}

In working with the elders on this project, one of the ideas that stands out is the underutilization of their vast IK. From our interaction with the elders, through discussions, observations and listening to their personal and historical narratives, the elders demonstrated vast knowledge of the IK which is not only vital for the well-being of the community but also of the land. Castellano (2000), emphasises the importance of the learning that elders can promote and warns of the real danger that IK may not be passed on to new generations.

The young people no longer have daily access to experiential learning on the land; they have decreasing levels of fluency in aboriginal languages that would keep them in communication with the elders; and they spend much of their time in educational institutions that socialize them into dependency on the written word. There is a real danger that the elders who still retain traditional and spiritual knowledge, and who know the context in which empirical observations must be evaluated, will join their ancestors without passing on what they know (p. 32).

Our formal education system contributes to a widening gap between the youth and elders in our communities through the subjugation of our IK (Nyerere, 1967; Semali, 1999). Since our cultures are mostly oral and the elders passed this knowledge to the young through word of mouth and observation, the colonial education systems, simply do not favour the passing on of this knowledge and this is one of the principle threats to the survival of IK in many African Indigenous cultures.

As noted already the elders in our research project showed that they were the link to our Indigenous environmental knowledge. The knowledge and skills that the elders passed on to the participants was not written but authentic and practical knowledge and if embraced by the people, would help them to survive and live well in their places and in their communities. Kincheloe and Steinberg (2008) expresses this loss of knowledge in education, "we find it 
pedagogically tragic that various indigenous knowledges of how action affects reality in particular locales have been dismissed from academic curricular" (p. 136). In our study, all the participants expressed the fact that working with the elders was most beneficial for their practice. One of the teachers said,

I find working with the elders valuable. It is a pity we have lost so much time. There is a lot they can teach us that we cannot find in textbooks. We need to invite them and work together as much as we can. (July 2015)

In addition, one of the community members said that he feels that working with the elders made him a better tourist guide at the sacred place that we visited. At the end of the study, both the teachers and the elders showed that they would continue their collaboration. If many teachers in Uganda gain the confidence to work with community elders in the co-creation of their curricular, as is done in this project, there is a good chance that the current generations of Ugandans would gain a lot of knowledge and values about their land and cultures.

From working with the elders in this project the teachers' creativity and innovation was highly charged. One of the projects that the teachers started was to work with the students to document the indigenous plants and the plant values with the guidance of the elders, so that the booklets are put in the school libraries of the participating schools. This is just one of the ways that the present generations of Ugandans can help to save their IK. However, it is sad to note that some of the IK can only be passed on to the young generations through song and ritual and moreover through the contexts in which they are performed like circumcision, hunting or planting (Cajete, 1994; Wa Thiong'o, 1994; Wane, 2000). As long as IK continues to be separated from the mainstream curricular and our Indigenous languages ignored and left to die, IK will continue to appear on the radar of endangered knowledges and so will our landscapes.

This project, however, demonstrates that the participant elders depict a readiness to work with the teachers in formal education settings to pass on their IK to the youths. Scholars 
have mentioned about the conservative nature of elders in adjusting to change (Castellano, 2000; Wane, 2000). However, in this study, the participant elders show a considerable enthusiasm to learn new skills of passing on their IK to the young generation. As Castellano (2000) elucidates, there could be reasons as to why some elders are unwilling to pass on their IK to others and researchers need to be mindful of such. However, in some cases, like in this project, the elders had to be encouraged, with good reasons for sharing of their IK. Moreover, the researchers or teachers need to follow the appropriate cultural protocol to gain the elders' consent (Wane, 2000). Elders must be shown the available platforms to pass on the IK to the younger generations because they are already aware that this is their duty. As reflected in Holmes (2000, p. 50) appeal, "we will all need to listen to indigenous elders, and through them, hear the voice of the land."

\section{Conclusion}

In this chapter, the drums are resounding as the co-participants transport their classrooms into the communities. I discussed the themes that come up as both the schools and the communities are brought together in the reawakened spirit of Bulungi Bwansi. Still, I demonstrate how, in this project, bringing the classroom to the community influenced the learners and the teachers to reconnect to their cultures and communities. Lastly, I discussed the advantages of this cycle to the teachers and the challenges that still face the passing on of IK to the young generations of the Indigenous Africans, especially the Baganda, in the present era. 


\section{CHAPTER ELEVEN}

\section{SUSTAINABILITY OF THE DRUMROLLS}

In Chapter eleven, Sustainability of the drum rolls, I discuss the themes that emerge in reflection on the actions related with the cycle of bringing the community into the curriculum and teachers' pedagogy. In this chapter, the possibility of the sustainability of the drumrolls is reflected in the values of diversity and pluralism and creating a more just and inclusive curriculum. The sustainability of the drumrolls provides an insight into the prospects of placebased education in the Ugandan education setting.

\section{Diversity and pluralism}

Bringing the community into the curriculum helped in enhancing the co-participants' critical reflection on their roles as educators. Teachers in Uganda have always been trained to perceive the Western scientific ways of knowledge production as the only legitimate ways of viewing the world. As such, the students are taught to see and interpret knowledge from only the Western perspective. In addition, the bulk of the curriculum content is majorly Western oriented. For instance, what they know about the history of their places is majorly influenced by what was recorded of the places by the Western explorers and missionaries. A good example in Buganda is the history about Ssekabaka Mwanga II who is recorded to have killed his subjects, (today known as the Uganda Martyrs), because they converted to Christianity. It is the only version of history taught in the Ugandan formal education curriculum about this historical King. In this record, Ssekabaka Mwanga is portrayed as a savage King who ordered the death of the innocent Martyrs. The formal education curriculum does not show or reflect to the learners the internal administrative struggles in the Kingdom at the time when a new wave of religion and colonialism swept in. 
As a result, only the painful parts of their history (i.e. the parts that make them want to distance themselves from their cultures) are taught to the students in schools. Meanwhile, the other side of the history, (i.e. the one that can enhance connection to culture and place), is locked in the untold oral narratives of the elders. It is through the lens of the Christian missionaries, early explorers and colonialists that the co-participants and fellow Ugandans viewed their world.

In learning about our IK in this study, the participants are exposed to the fact that the dominant lens is not the only way of interpreting the world. The elders showed us another side of our history; another lens to view our world and in the case of Ssekabaka Mwanga, that he was a leader who appreciated and rewarded his subjects. Semali and Kincheloe (1999, p. 33) argue that, "an understanding of indigenous ways of seeing as a subjugated knowledge alerts us to the fact that there are different ways of seeing the world." When teachers realize that this is not only an unjust way of seeing their world but also not the only one, they begin to take IK seriously and find means of bringing it into the curriculum. Kincheloe and Steinberg (2008, p. 139) figuratively explain this change of view as, "the single photograph of Cartesian thinking is replaced by the multiple angles of the holographic photograph."

The teachers came up with meaningful strategies of engaging their students in exploring other ways of interpreting their world beside what they are taught in the UNEB curriculum. An example of this 'multilogicality' (Kincheloe \& Steinberg, 2008) is when teachers and students are involved in researching and compiling lists of the Indigenous plants and their functions. In this way students start re-valuing not only their IK but the fact that there are multiple ways of making sense of the world and their IK is one of them. It also becomes clear to the coparticipants, that our IK is directly connected to our survival and well-being. The revelation of the interconnectedness of their well-being with their subjugated IK only made the coparticipants more determined in ensuring the sustainability of the drumrolls. This same 
revelation of the value of their IK is also evident in the group discussion following one of the IK lessons about the Indigenous plants. The participant teacher explains how well the placebased pedagogy suited the students: "The knowledge about these local plants is very important for both the students and for us the teachers. The students needed this information to learn how to utilise the natural resources" (July 2015). Before this project, these teachers did not see these plants in this value laden perspective. That is why they never realised the danger that these plants were in because of the charcoal burners' activities. They saw these trees mainly as either sources of fuel or sources of income for the charcoal burners. However, with this project, another very important perspective of viewing these plants is revealed to them and as well as to the students. In their integration of IK into the curriculum, the participant teachers became more analytical and creative in their exploration of other ways of seeing their world.

\section{Creating a more just and inclusive curriculum}

The process of bringing the community into the curriculum brought to the attention of the participants the political nature of knowledge production (Kincheloe \& Steinberg, 2008; Semali \& Kincheloe, 1999). Many Ugandan teachers today still take it for granted that the current formal education curriculum is genuine and the best means of transporting values to the young generation in our society. But when in this project, the co-participants are exposed to the nature of their IK, they realized that their formal education curriculum privileged only one way of knowing, which is the Western way. They learnt that knowledge production is a highly political process which is embedded with power struggles; "a power to control representation of whose knowledge was 'civilized' and whose was 'primitive"” (Semali \& Kincheloe, 1999, p. 36). In this, the dominant ways of knowledge production are employed as "rationales for cultural dominance and unequal power relations" (p. 35). Semali and Kincheloe (1999, p. 36) further explains that, "power refers not simply to the control of financial, institutional, political, ideological, and communications resources, but also the control of representations of reality." 
For instance, in this project, the teachers realise that the students who indicate that they are academically challenged in the classroom thrive under place-based education. As the teachers learn to let the students take control of their own learning through the Bulungi Bwansi community activities, they soon realise that these same students who are perceived as 'challenged' are instead brilliant, promising, young people. In the group discussion that follows the IK activity, one participant teacher reveals:

I have two students who are challenged academically. They lacked discipline as well ... But during the excursions, they are not the same students any more. One of them was appointed a Bulungi Bwansi leader, very good at organising others during the Bulungi Bwansi activities. (May 2015)

As the participant teachers gain insight into the dynamics at play in knowledge production and legitimization, they start to consider making room for their own subjugated knowledge systems in the formal education curriculum with an informed background of their history. Kincheloe and Steinberg (2008, p. 146) further elucidates:

The oppressive forces that shape us have formed the identities of both the powerful and the exploited. Without an analysis of this process, we will never understand why students succeed or fail in school; we will be forever blind to the tacit ideological forces that construct such perceptions have on their school experiences.

Throughout the project, the teachers learnt to recognize subjugation and cultural domination and as such strived to come up with ways to create a "just, critical, practical, anti-colonial and transformative" curriculum (Kincheloe \& Steinberg, 2008, p. 155). In this study, one of the ways that the teachers did this was to develop students' confidence and pride in their mother tongue, Luganda. For the African Indigenous Peoples, "Language is both a repository as well as the carrier of culture, — but more importantly a way of connecting to the world that surrounds us" (Abdi, 2013, p. 74). The co-participants planned lessons with learning activities that gave students opportunities of public speaking, holding formal conversation with the community members, class debates and class discussion; while all the time encouraging proper 
pronunciation and intonation of words in Luganda. In addition, the teachers took students out to Ssezibwa where they listened to traditional narratives about the sacred river narrated in Luganda by the community elder. As such the teachers make the language of the learners also the language of instruction. This presents a possibility of a just and inclusive curriculum.

The co-participants also strive for a just and inclusive curriculum when they bring the knowledge about the indigenous plants and plant values into the curriculum. Plant knowledge is very important for the survival of the people of Buganda as it is with many Indigenous groups around the world. Subjugation of IK by the formal education system is therefore a form of injustice to the people of those places. This is because a lack of the Indigenous plant knowledge will make the population less likely to appreciate and manage their environment in the same way their forefathers did. This is a form of epistemicide caused by their own formal education system which is unfair to the communities that continue to occupy these places. In creating a space for their IK in the formal education curriculum, the co-participants were striving to create a just and more inclusive curriculum for the children of Buganda. One of the participant teachers affirms this during the group discussion when he said; "This is a necessary way of teaching about our environment and I will continue trying to come up with ways to make it possible to have such lessons with the help of the elders." (June 2015)

\section{Conclusion}

This chapter demonstrates the sustainability of the Saagala Agalamidde drumrolls in the participant schools and communities. This chapter also outlines the possibility that what the participants started in this project will have the desired effect in the schools and the communities in Buganda. 


\section{CHAPTER TWELVE}

\section{CONCLUSION}

\section{Revisiting the aims of this study}

The aims of this doctoral research were guided by the following research questions:

- How can Indigenous Knowledge, practices and values intersect with place-based education in Ugandan secondary schools?

- How can teachers use place-based education pedagogies to influence their learners to reconnect to their community/culture and places in Ugandan secondary schools?

- How can community elders contribute to place-based education in their communities in Uganda?

This study sought to explore how IK practices and values can intersect with place-based education in Ugandan secondary schools. To achieve this aim, I worked with five participant teachers, three community elders and two community members in the planning and implementation of three IK learning activities. The participant teachers further used these learning activities to implement place-based education in their schools. The participant elders together with the two community members aided the teachers and their students through the following IK activities:

- Bulungi Bwansi community projects where they learnt and facilitated the making of briquettes from local materials to conserve their trees

- Visiting and learning about the sacred places (e.g. Ssezibwa)

- Exploring and learning about the traditional Indigenous plants and their medicinal values

The co-participants organized group reflections in two different ways for them to promote the intersection of IK, practices and values with place-based education. 
These were group reflections after the IK activities and the weekly Nyama Kyoma meetings. The group reflections focused on the participant teachers meeting with the elders for group interviews/discussions which occurred after every IK learning activity. During these sessions, all the co-participants (elders and teachers) reflected on how they could better enhance their IK learning experience in the formal education setting. The other group reflection was the Nyama Kyoma meetings. These meetings involved all the participant teachers from the four participating schools meeting every Wednesday evening to plan as a team about how best to integrate the IK into the curriculum. During these meetings, teachers shared samples of students' work and some of their field diary entries. They also planned classroom observations where they attended each other's classes. It was through these approaches that IK, practices and values intersected with place-based education in these Ugandan secondary schools.

This study also sought to identify how teachers can use place-based education pedagogies to influence their learners to reconnect to their community, culture and places in Ugandan secondary schools. In undertaking this research, several points in regarding this aim were discovered. First, the teachers revealed through the group interviews, discussions and diary notes, that the students enjoyed working on the community engagement activities (e.g. Community training in making of the briquettes). Several participant teachers revealed that the students were more interactive with the community elders and community members than they were usually willing to do with the teachers and peers in the classroom situation. In addition, the teachers revealed that the students were more committed in terms of class attendance than they were in the 'ordinary' classroom situation.

Further, the teachers revealed that the students performed better in the community engagement learning activities as compared to the daily classroom work. The teachers finally revealed that students' discipline greatly improved during the community engagement activities; for instance, a teacher gave an example of his two students whose discipline issues 
disappeared with these IK lessons that they were appointed in leadership positions. The teachers displayed samples of their students' projects of these activities which revealed deep knowledge of IK (e.g. student composition writings showing how certain Indigenous plants were utilized for medicinal purposes). Secondly, students in the four participating schools formed the Bulungi Bwansi clubs in which they carried out community service projects for the communities surrounding their schools. The aim of these activities was to develop students' understanding and love for community service. In this way, the teachers used place-based pedagogy to reconnect students to their communities, cultures and places. These clubs are still ongoing even though the research project is complete which was communicated by the participant teachers who remain in touch. Further, additional schools have also joined the club.

Lastly, this study sought to find out how community elders could contribute to placebased education in their communities in Uganda. First, the elders facilitated in the learning about the sacred places by travelling with the teachers and students to the sacred places, sharing with them the cultural and historical narratives about these places. The elders also facilitated the teachers' and students' learning about the Indigenous plants and plant values found around the participating school grounds. In this case, the elders attended the schools where both the participant teachers and students were situated. The elders also took part in group interviews with the teachers where they discussed on how to better implement place-based education in the formal school setting. This highlights how the community elders contributed to place-based education in their communities.

\section{Way forward for place-based education in Uganda}

As outlined in chapter two, the Ugandan formal education system is highly examination driven. The whole teaching and learning experience focuses on test scores with schools investing resources (i.e. time and money) into teaching the UNEB syllabus and students' revision of past papers. This kind of environment is not easy for educators to implement a place- 
based pedagogy. In their reflection on such an education system, Smith and Sobel (2010, p. 486) argue, "without the ability to demonstrate or at minimum promise improvements in performance on standardized examinations of student learning, even the most attractive instructional or curricular proposals will be discarded."

In this project, our most common challenge was to find the time within the normal school day to integrate our IK learning experiences. This is a common challenge that the teachers of Luganda and oral literature face in their practice. These specific subjects are given less time in comparison to subjects like English and mathematics because of the poor attitude of the curriculum bodies towards the Indigenous cultures. In this project, we had to find time to involve students in the community participation learning activities with the elders. The teachers decided to use the time for extra-curricular activities and in some cases, weekends for these activities. Since flexibility is one of the qualities of PAR, the co-participants were good at finding solutions to the challenges that occurred. The readiness to adapt to change was motivated by an understanding of the fact that these participants were doing something worthwhile for the future of their community and their students.

The participant teachers acknowledged the value of place-based pedagogy during the project. This was exemplified in the numerous group discussions which followed the activities. In these discussions, the teachers revealed that the students showed enjoyment of the lessons by the fact that they were keener to attend all IK lessons in addition to the increased level of participation in the same activities. Further, the students who had been considered underachievers in the classwork were thriving in these activities because, according to the teachers, they started to freely engage with the elders in the IK discussions and some of them became leaders in the same IK activities. Smith and Sobel (2010, p. 493) explain, "Learning experiences that push past textbooks and worksheets to inquiry and application also tend to be more inclusive of a broader range of students, many of whom remain marginalized for academic 
or behavioural reasons in conventional classrooms." The Ugandan education system tends to marginalize students who are not performers in academic work. Such students are made to feel that they are incompetent in life by repeatedly failing in the monthly tests in addition to having their poor results displayed at the front of the classroom. This continuous humiliation could lead to these students' lack of self-esteem and self-confidence. Through a place-based education approach, the participant teachers soon realized that it is not only test scores that can determine students' achievement. Rather, these teachers learned that students are gifted in many other areas when given a chance to discover their potential. This realization helped the teachers to carefully integrate the local into the students' learning experiences, to give all students a chance to realise their self-worth.

Further, place-based education assisted the students to not only gain self-confidence but also to build a sense of belonging that is born out of a feeling of being appreciated by one's community. When schools fail to build a sense of self-worth in the students through the failure messages communicated by the test-scores, the students never get a chance to fully feel loved and appreciated and as a result can feel more detached from their places. Smith and Sobel (2010, p. 522) explain, "rather than being embarrassed about coming from a small rural town or innercity neighbourhood, students come to see that there is value in what they had formally disregarded." This attachment to place is built from the students' sense of appreciation through their contribution to the community's development. In this project, the teachers revealed how the students put in energy and zeal in comparison to what they put in their class work. This is reflected in one of the participant teacher's comment, "But the energy that I have seen in the village is very different. The students showed that they liked what they were doing" (July 2015).

The project was a learning journey for all the co-participants, but it also planted a seed of change in all the co-participants for the improvement of the Ugandan secondary education curriculum. As the teachers appreciate working with the elders in their practice of a place-based 
pedagogy, they develop an approach that provides students with an opportunity to enjoy their educational experience. This highlights the start of a journey of place-based education for the participants and the schools in the area. In my last Nyama Kyoma meeting with the participants, they revealed that they intended to continue their collaboration with each other and that the Nyama Kyoma meetings were going to continue. In addition, the Bulungi Bwansi clubs that were started in all the participant schools for the community service were a long-term project for the students, teachers and the elders. This project generated the start of many other projects including recording the Indigenous plants in the area. This highlights their ongoing commitment to place based education.

In their weekly meetings, the teachers discussed how their gained knowledge would influence the educational and school policy. This reveals how the teachers had become researchers of their own practice, gaining a deeper understanding of the value dimensions within their education system (Kincheloe, 2003). Thus, they had a clear view of their educational purpose as opposed to educators who were simply satisfied with implementing educational policies handed to them from the top (i.e. Ministry of Education). For instance, they had discovered the value of IK and the relevance of community elders in the formal education context. With their gained critical research skills and understandings, the participant teachers could influence and critically reflect on educational policies. For example, the teachers planned to involve their school administrations in putting in place a way of remunerating the community elders for their work with the teachers. Further, they strategized how they would get parents involved in supporting the integration of IK in the curriculum.

While there were significant issues that the co-participants encountered in the integration of IK into the curriculum, they also demonstrated strategies in how these could be overcome. In this, the co-participants discovered that through participation and collaboration, they could work out the way forward for place-based education in their schools. For instance, 
when one of the teachers encountered resistance from a parent for teaching about the Indigenous plants, the co-participants discussed this issue during the Nyama Kyoma and decided that they would each raise it with parents in parent/teacher meetings. In this way, they planned to invite the parents to participate as a way of raising the parents' awareness and support. This exemplifies how these teachers were empowered by their understanding of PAR process. The vision of the co-participants is to slowly and democratically change their school policies and eventually the education policies of their country. Kincheloe (2003) argues that teachers as researchers cannot avoid being political to effect change in the education system and in society.

For all the co-participants, the drumrolls have reawakened and they are rolling. The sound of Saagala agalamidde is a significant call (due to its royal genesis as is explained in Chapter 6) and for this reason cannot easily be ignored. This is because the people still have something in them that respects their heritage.

\section{Implications for future research}

This research demonstrated how teachers can work with the community elders in the integration of IK, practices and values into the formal education setting in Ugandan secondary schools. I have explained (in chapter two) how the Ugandan formal education system disregards IK from the formal education curriculum. George (1999, p. 494) argues that "IK has the potential of impacting on the teaching/learning situation in significant ways." Although scholars in Southern Africa (Anderson et al., 2015) have started to research into the integration of IK in environmental education, no research has so far been done in this area in Uganda. Since the scope of my research was in Ugandan secondary schools only, it would be worthy for more research to be carried out in the intersection of IK and place-based education for sustainability education in Ugandan primary and higher education settings. 
Further, this research has revealed the success of PAR in equipping Ugandan teachers with the knowledge and skills to critically evaluate and then improve their own practice. Through the genuine collaboration in this PAR project, the participant teachers gained the skills to became researchers. Through this project, the participant teachers evolved from mere "deliverers of pre-packaged and homogenised information" (Kincheloe, 2003, p. 40) to researcher practitioners who are continually ensuring that their practice is of quality and that the curriculum suits their students' unique needs. I observed that the participant teachers were more in control of their practice and as a result were happier professionals than they had been at the beginning of the project. In the Ugandan education setting no research has been published yet using PAR as a method of inquiry and especially in motivating teachers or even in environmental education. It would be worthy to carry out further research in the utilisation of PAR in teacher motivation and retention in Ugandan schools.

In addition, my research was carried out in Buganda which is in the Central part of Uganda. Uganda is made up of more than 30 ethnic groups of people living in the different parts of the country. It would be worthy to carry out PAR in the intersection of IK and place-based education in other parts of the country since, as shown in my introductory narrative, these places are equally experiencing environmental education issues and yet they are all sharing the same formal education system that subjugates IK.

Lastly, the research revealed that the participant community elders were willing to work with the teachers in the implementation of place-based education in the formal education settings. And moreover, this research shows that the elders were very knowledgeable in the Kiganda IK which they passed on to the teachers and students in the different participating secondary schools in Buganda. Scholars argue for the involvement of community elders in the reconnection of students with their communities and places in place-based education research projects (Semali, 1999; Smith \& Sobel, 2010). There has not been any research in Uganda 
where elders are brought into the formal education setting to facilitate in place-based education. More research would be valuable to be carried out on how elders can be involved in place-based education in primary schools in Uganda as well as in other parts of the country.

\section{Concluding reflections about the research journey}

As is shown in my narrative in chapter one, this research was out of the shocking revelation of the Ugandan people's lack of awareness of the true state of the environment, both in my hometown of Mukono and around the country as witnessed during my travels. As a teacher of language, I believed that, through research, I could contribute to the education of the people about their environmental responsibility. In my pursuit, I did not anticipate that this would also be my learning journey especially about my culture and homeland. Like all the participants had revealed about this project through the group interviews, I too emerged from this research project much more connected to my culture and to my homeland. Everything I learned, from the elders' narratives to my fellow teachers' discussions, showed me the extent of my own disconnection from my culture and place and as a result helped me to understand how to mend the disconnection.

My father worked as veterinary doctor and therefore our family was always on the move to the different areas around the country where he was frequently transferred to work. This meant that all of us children had to attend boarding school. My brothers attended boys' boarding schools well as my sisters and I attended girls' boarding schools whenever each one of us turned five. We only saw our parents during visitation days (two days in the three-months term) and during the two-weeks holidays wherever Dad had been transferred. During the three-weeks Christmas holidays, we lived with our maternal grandparents in Western Uganda where we helped to tend to cattle, sheep and goats in the plains overlooking Mountain Rwenzori. This was the only unchanging home I knew in my early years of growing up. Like many other Ugandan children, boarding school was where I learnt everything else (i.e. the Bible, 
Shakespeare, the French revolution...) but nothing about who I was meant to be or the importance of my language, culture, or tribe.

Consequently, I grew up a stranger to my own culture. Since there was no proper opportunity in developing connections with my culture, I did not strive to embrace it. I felt burdened whenever there were events like introduction ceremonies or last funeral rites in our clan. I even avoided attending some of those events whenever I could come up with an excuse. The best part of my Indigenous literacy was acquired while we lived and worked with grandmother during the Christmas holidays; through her instruction, folktales, wise proverbs and songs.

There are times in my adult life when my IK inadequacy has been embarrassing. This was especially during my own traditional marriage ceremony and when I had my first baby. These were the times when the older women in the tribe got impatient with me for not being able to carry out certain cultural tasks that I was expected to know by virtue of my age. The awareness of my incompetence made me want to distance myself further from my culture and tribe. Even though I had been a studious student at school, my formal education was totally irrelevant and unhelpful in these cultural matters because these (i.e. IK and formal education) are two different worlds. Moreover, as a mother, I constantly struggled with which way I should raise my children. In my discussions with the co-participants in this project, I found that we all faced the same challenges. This research journey, for me, has made me understand the genesis of mine and many other Ugandan people's disconnect from culture and place; the effects of this disconnection and how we can deal with it for the benefit of the young generations. I believe that because of this project, I have become a better teacher and member of the tribe.

In addition to my re-connection to culture and place, I also learned, through the PAR cycles of this project, the power of working as a team with the other co-participants. As a 
secondary school teacher, I am aware of the situation of teachers as "passive recipients of the dictates of the experts" (Kincheloe, 2003, p. 34). This is one of the reasons why teaching tends to be a disempowering profession in Uganda. In this research journey, I learned the value of teachers collaboratively carrying out research on their own practice and gaining the independence that arises from doing something that they understand. This research project was as much a decolonising journey for me as it was for everybody else on the team. 


\section{REFERENCES}

Abagi, O. (2005). The role of the school in Africa in the twenty-first century: Coping with forces of change. In A. A. Abdi \& A. Cleghorn (Eds.), Issues of African Education: Sociological Perspectives (pp. 297-315). New York: Palgrave.

Abdi, A. A. (2005). African philosophies of education: Counter-colonial criticisms. In A. A. Abdi \& A. Cleghorn (Eds.), Issues of African Education: Sociological perspectives (pp. 25-41). New York: Palgrave.

Abdi, A. A. (2010). Globalization, culture and development: Perspectives on Africa. Journal of Alternative Perspectives in the Social Sciences, 2(1), 1-26.

Abdi, A. A. (2013). Decolonizing educational and social development platforms in Africa. African and Asian studies, 12(1), 64-82.

Abdi, A. A., \& Cleghorn, A. (2005). Sociology of education: Theoretical and conceptual perspectives. In A. A. Abdi \& A. Cleghorn (Eds.), Issues of African education: Sociological perspectives (pp. 3-24). New York: Palgrave.

Agaba, J. (2012). Calculating cut off points-University Guide. New Vision. Retrieved from http://www.newvision.co.ug/news/629669-calculating-cut-off-points-universityguide.html

Ahabwe, V. (2014). The mother tongue teaching policy in Uganda. Retrieved from http://www.britishcouncil.ug/the-mother-tongue-teaching-policy-in-uganda

Akokpari, J. K. (2000). Globalisation and migration in Africa. African Sociological Review/Revue Africaine de Sociologie, 4(2), 72-92.

Altinyelken, H. K. (2010). Curriculum change in Uganda: Teacher perspectives on the new thematic curriculum. International Journal of Educational Development, 30(2), 151161.

Anderson, V., McKenzie, M., Allan, S., Hill, T., McLean, S., Kayira, J.,...\& Butcher, K. (2015). Participatory action research as pedagogy: Investigating social and ecological justice learning within a teacher education program. Teaching Education, 26(2), 179195.

Ashcroft, B., Griffiths, G., \& Tiffin, H. (2013). Post-colonial studies: The key concepts. New York: Routledge.

Bishop, R., Berryman, M., Cavanagh, T., \& Teddy, L. (2009). Te kotahitanga: Addressing educational disparities facing Māori students in New Zealand. Teaching and teacher education, 25(5), 734-742.

Bowers, C. A. (2001). Educating for eco-justice and community. Athens: University of Georgia Press. 
Bradbury, H., Mirvis, P., Neilsen, E., \& Pasmore, W. (2008). Action research at work: Creating the future following the path from Lewin. In P. Reason \& H. Bradbury (Eds.), The sage handbook of action research: Participative inquiry and practice, (pp.77-92.). London: Sage.

Calderon, D. (2014). Speaking back to manifest destinies: A land education-based approach to critical curriculum inquiry. Environmental Education Research, 20(1), 24-36.

Cajete, G. (1994). Look to the mountain : An ecology of indigenous education. Durango, CO: Kivaki Press.

Carr, W., \& Kemmis, S. (1986). Becoming critical: Education, knowledge, and action research. Brighton, Susssex: Falmer Press.

Castellano, M. B. (2000). Updating Aboriginal traditions of knowledge. In G. J. S Dei, B. L. Hall, \& D. G. Rosenberg (Eds.), Indigenous knowledges in global contexts: Multiple readings of our world (pp. 21-36). Toronto: University of Toronto Press.

Creswell, J. W. (2009). Research design: Qualitative, quantitative, and mixed methods approaches. Los Angeles: Sage Publications.

Dei, G. J. S. (2000). African development: The relevance and implications of 'indigenousness'. In G. J. S Dei., B. L. Hall, \& D. G. Rosenberg (Eds.), Indigenous knowledges in global contexts: Multiple readings of our world (pp. 70-86). Toronto: University of Toronto Press.

Duenkel, N., \& Pratt, J. (2013). Ecological education and action research: A transformative blend for formal and nonformal educators. Action Research, 11(2), 125-141.

Ejuu, G. (2012). The status of implementation of the education sector early childhood development policy in Uganda. Kampala: Uganda Government.

Elliott, J. (1991). Action research for educational change. Buckinham: Open University Press.

Engel-Di Mauro, S., \& Carroll, K. K. (2014). An African-centred approach to land education. Environmental Education Research, 20(1), 70-81.

Ezzy, D. (2002). Qualitative analysis: Practice and innovation. New York: Routledge.

Fanon, F. (1963). The wretched of the earth. New York: Grove Press.

Freire, P. (2005). Pedagogy of the oppressed (30th ed.). New York: The Continuum International Publishing Group Inc.

George, J. M. (1999). Indigenous knowledge as a component of the school curriculum. In L. M. Semali \& J. L. Kincheloe (Eds.), What is indigenous Knowledge?: Voices from the Academy (pp. 79-94). New York: Falmer Press. 
Goldschmidt, T., Witte, F., \& Wanink, J. (1993). Cascading effects of the introduced Nile perch on the detritivorous/phytoplanktivorous species in the sublittoral areas of Lake Victoria. Conservation Biology, 7(3), 686-700.

Goodnough, K. (2008). Dealing with messiness and uncertainty in practitioner research: The nature of participatory action research. Canadian Journal of Education, 31(2), 431458.

Grande, S.(2008). Red pedagogy. In N. K. Denzin, Y. S. Lincoln \& L. H. Smith (Eds.), Handbook of critical and Indigenous methodologies (pp. 233-254). London: Sage.

Gruenewald, D. A, \& Smith, G.A. (Eds.). (2014). Place-based education in the global age: Local diversity. New York: Psychology Press.

Gruenewald, D. A. (2003a). The best of both worlds: A critical pedagogy of place. Educational Researcher, 32(4), 3-12.

Gruenewald, D. A. (2003b). Foundations of place: A multidisciplinary framework for placeconscious education. American Educational Research Journal, 40(3), 619-654.

Gruenewald, D. A. (2008). Place-based education: Grounding culturally responsive teaching in geographical diversity. In D.A. Gruenewald \& G.A. Smith (Eds.), Place-based education in the global age: Local diversity (pp. 137-154). New York: Psychology Press.

Habermas, J. (1996). Between facts and norms: Contributions to a discourse theory of law and democracy. Cambridge: Mit Press.

Hall, B. L. (2000). Breaking the educational silence: For seven generations, an information legacy of the Royal Commission on Aboriginal peoples. In G. J. S Dei., B. L. Hall, \& D. G. Rosenberg (Eds.), Indigenous knowledges in global contexts: Multiple readings of our world (pp. 202-212). Toronto: University of Toronto Press.

Hall, B. L., Dei, G. J. S., \& Rosenberg, D. G. (Eds.). (2000). Indigenous knowledges in global contexts: Multiple readings of our world. Toronto: University of Toronto Press.

Holmes, L. (2000). Heart knowledge, blood memory, and the voice of the land: Implications of research among Hawaiian elders. In G. J. S Dei., B. L. Hall, \& D. G. Rosenberg (Eds.), Indigenous knowledges in global contexts: Multiple readings of our world (pp. 37-53). Toronto: University of Toronto Press.

Johns, T. (2008). Learning to love our black selves: Healing from internalized oppressions. In P. Reason, \& H. Bradbury (Eds.), The sage handbook of action research: Participative inquiry and practice (pp. 473-486). London: Sage.

Kagolo, F. (2014). Uganda starts Ebola surveillance after outbreak in Guinea. New Vision. Retrieved from http://www.newvision.co.ug/news/653899-uganda-starts-ebolasurveillance-after-outbreak-in-guinea.html 
Kahn, R., \& Kahn, R. V. (2010). Critical pedagogy, ecoliteracy, and planetary crisis: The ecopedagogy movement. New York: Peter Lang.

Kayira, J. (2015). (Re) creating spaces for uMunthu: Postcolonial theory and environmental education in southern Africa. Environmental Education Research, 21(1), 106-128.

Kemmis, S.(2008). Critical theory and participatory action research. In P. Reason, \& H. Bradbury (Eds.), The sage handbook of action research: Participative inquiry and practice (pp. 121-138). London: Sage.

Kemmis, S., \& McTaggart, R. (2005). Participatory action research: Communicative action and the public sphere. In N. K. Denzin \& Y. S. Linkoln (Eds.), The sage handbook of qualitative research (pp. 559-603). London: Sage.

Kemmis, S., McTaggart, R., \& Nixon, R. (2014). The action research planner: Doing critical participatory action research (iBooks edition). Springer Science \& Business Media.

Kincheloe, J. L. (2003). Teachers as researchers: Qualitative inquiry as a path to empowerment (iBooks edition). Taylor and Francis e-Library.

Kincheloe, J. L., \& Steinberg, S. R. (2008). Indigenous knowledges in education: Complexities, dangers, and profound benefits. In N. K. Denzin, Y. S. Lincoln \& L. H. Smith (Eds.), Handbook of critical and Indigenous methodologies (pp. 135-156). London: Sage.

Kindon, S., Pain, R., \& Kesby, M. (2007). Participatory action research approaches and methods: Connecting people, participation and place (iBooks edition). Taylor and Francis e-Library.

Klein, S. (Ed.). (2012). Action research methods: Plain and simple. New York: Palgrave.

Knijnik, G. (1999). Indigenous knowledge and ethnomathematics approach in the Brazilian landless people education. New York: Falmer Press.

Kyeyune, R. (2003). Challenges of using English as a medium of instruction in multilingual contexts: A view from Ugandan classrooms. Language, Culture and Curriculum, 16(2), 173-184.

Labé, O., Dembélé, M., Sirois, G., Motivans, A., \& Bruneforth, M. (2013). Half a century of education progress in Sub-Saharan Africa (1960-2010). African \& Asian Studies, 12(1), 30-63.

Lubuulwa, K. K. (2012). Rites of passage in Kiganda orature and literature. Deutschland: Lambert.

Marshall, J., \& Maclntosh, R. (2007). Quality in research as "taking an attitude of inquiry". Management Research News, 30(5), 368-380.

Maurial, M. (1999). Indigenous knowledge and schooling: A continuum between conflict and dialogue. In L. M. Semali \& J. L. Kincheloe (Eds.), What is indigenous knowledge?: Voices from the academy (pp. 59-77.). New York: Falmer Press. 
McArdle, K. L., \& Reason, P. (2008). Action research and organization development. In T.G. Cummings (Ed.), Handbook of organization development (pp.123-136). London: Sage Publications.

McClay, W., \& McAllister, T. (2014). Why place matters: Geography, identity, and civic life in modern America (iBooks edition). Encounter Books.

McNiff, J. (1993). Teaching as learning : An action research approach. London: Routledge.

Memmi, A. (2013). The colonizer and the colonized. London: Routledge.

Michalopoulos, S., \& Papaioannou, E. (2016). The long-run effects of the scramble for Africa. The American Economic Review, 106(7), 1802-1848.

Mills, G. E. (2007). Action research : A guide for the teacher researcher. New Jersey: Prentice Hall.

Mills, S. (2009). Gender and colonial space (iBooks Edition). Manchester United Press.

Moore-Gilbert, B. J. (1997). Postcolonial theory: Contexts, practices, politics. London: Verso.

Mosha, S. R. (1999). The inseparable link between intellectual and spiritual formation in indigenous knowledge and education: A case study of Tanzania. In L.M. Semali \& J.L. Kincheloe (Eds.), What is indigenous knowledge?: Voices from the academy (pp. 209-225.). New York: Falmer Press

Musinguzi, G. (2012). Marburg virus claims another victim; death toll at 5. New Vision. Retrieved from http://www.newvision.co.ug/news/636762-marburg-virus-claimsanother-victim-death-toll-at-6.html

Mutesa, I. (1967). Desecration of my kingdom. London: Constable.

Nakagawa, Y., \& Payne, P. G. (2015). Critical place as a fluid margin in post-critical environmental education. Environmental Education Research, 21(2), 149-172.

Namubiru, E. (2012). What you need to know about ebola. New Vision. Retrieved from http://www.newvision.co.ug/news/633571-what-you-need-to-know-aboutebola.html

Natukunda, C. (2013). Uganda population at record 37 million. New Vision, Sunday Vision. Retrieved from New Vision: Uganda's Leading Daily website: http://www.newvision.co.ug/news/644270-uganda-population-at-record-37million.html

NEMA. (2004). State of environment report for Uganda 2004/05. Retrieved from Kampala: http://www.nemaug.org/national s o reports.php 
NEMA. (2010). State of the environment report for Uganda 2010. Retrieved from Kampala: http://www.nemaug.org/national s o reports.php

Ministry of Water, Lands and Environment. (2001). The Uganda forestry policy. Policy Document. Kampala: Retrieved from http://library.health.go.ug/download/file/fid/872

Ministry of Water, Lands and Environment. (2002). The national forest plan. Kampala: Republic of Uganda. Retrieved from: http://extwprlegs1.fao.org/docs/pdf/uga144366.pdf

Noffke, S. E., \& Stevenson, R. B. (1995). Educational action research : Becoming practically critical. New York: Teachers College Press.

Ntuli, P. P. (2002). Indigenous knowledge systems and the African renaissance. In C. A. O Hoppers (Ed.), Indigenous knowledge and the integration of knowledge systems: Towards a philosophy of articulation (pp. 53-66). Claremont: New Africa Books.

Nyerere, J. K. (1967). Education for self-reliance. The Ecumenical Review, 19(4), 382-403.

Nyerere, J. (1964). Freedom and unity. Transition, (14), 40-45. doi:10.2307/2934587 Retrieved from: http://www.jstor.org/stable/2934587

Ogutu-Ohwayo, R. (1990). The decline of the native fishes of lakes Victoria and Kyoga (East Africa) and the impact of introduced species, especially the Nile perch, Lates niloticus, and the Nile tilapia, Oreochromis niloticus. Environmental biology of fishes, 27(2), 8196.

Omotoso, S. A. (2010). Education and emancipation: An African philosophical perspective. Journal of Pan African Studies, 3(9), 222-231.

Orr, D. W. (1992). Ecological literacy : Education and the transition to a postmodern world. New York : State University of New York Press.

Orr, D. W. (2004). Earth in mind: On education, environment, and the human prospect (iBooks Edition). Island Press.

Owor, M. (2012). PLE best schools named. New Vision. Retrieved from http://www.newvision.co.ug/news/628466-ple-best-schools-named.html

Prakash, M. S. (1999). Indigenous knowledge systems: Ecological literacy through initiation into people's science. In L. M. Semali \& J. L. Kincheloe (Eds.), What is indigenous knowledge?: Voices from the academy (pp. 157-178.). New York: Falmer Press.

Pringle, R. M. (2005). The origins of the Nile perch in Lake Victoria. BioScience, 55(9), 780787.

Rahman, M. A. (2008). Some trends in the praxis of participatory action research. In P. Reason, \& H. Bradbury (Eds.), The sage handbook of action research: Participative inquiry and practice (pp. 49-62). London: Sage 
Randle, D. (1989). Teaching green : A parent's guide to education for life on Earth. London: Green Print.

Reason, P. (1996). Cooperative inquiry. Curriculum Inquiry, 26(1), 81-87.

Reason, P. (1998). Political, epistemological, ecological and spiritual dimensions of participation. Studies in cultures, organizations and societies, 4(2), 147-167.

Rieckmann, M. (2017). Education for sustainable development goals: Learning objectives (pp. 67). Paris: UNESCO. Retrieved from http://unesdoc.unesco.org/ulis/cgibin/ulis.pl?catno $=247444 \&$ set $=005$ AADF75F_2_16\&gp $=1 \& l i n=1 \& l l=1$

Rodney, W. (1974). How Europe underdeveloped Africa. Washington : Howard University Press.

Rubadiri, D. (2004). An African thunderstorm (Electronic Version). Retrieved from: https://www.poemhunter.com/poem/an-africa-thunderstorm/.

Scotland, J. (2012). Exploring the philosophical underpinnings of research: Relating ontology and epistemology to the methodology and methods of the scientific, interpretive, and critical research paradigms. English Language Teaching, 5(9), 9-16.

Semali, L. (1999). Community as classroom:(Re) valuing indigenous literacy. In L. M. Semali \& J. L. Kincheloe (Eds.), What is indigenous knowledge?: Voices from the academy (pp. 95-118). New York: Falmer Press.

Semali, L., \& Kincheloe, J. (1999). What is indigenous knwledge and why should we study it? What is indigenous knowledge? In L.M. Semali \& J. L. Kincheloe (Eds.), What is indigenous knowledge?: Voices from the academy (pp. 3-57). New York: Falmer Press.

Shizha, E. (2005). Reclaiming our memories: The education dilemma in postcolonial African school curricula. In A. A. Abdi \& A. Cleghorn (Eds.), Issues of African Education: Sociological Perspectives (pp. 65-83). New York: Palgrave.

Smith, G. A. (2013). Place-based education: Practice and impacts. In R. B. Stevenson, M. Brody, J. Dillon \& A. E. J. Wals (Eds.), International handbook of research on environmental education (pp. 213-220). New York: Routledge.

Smith, G. A, \& Sobel, D. (2010). Place-and community-based education in schools (iBooks Edition). Taylor and Francis.

Smith, L. T. (2013). Decolonizing methodologies: Research and indigenous peoples London: Zed Books

Spivak, G. C. (1988). Can the subaltern speak? In R. C. Morris (Ed.), Can the subaltern speak? Reflections on the history of an idea (pp. 21-78). New York: Columbia University Press. 
Ssempogo, H. (2009). Museveni forces forestry boss on leave. New Vision. Retrieved from http://www.newvision.co.ug/D/8/12/698587

Stern, T., Townsend, A., Rauch, F., \& Schuster, A. (Eds.). (2014). Action research, innovation and change (iBooks Edition). Routledge

Stevenson, R. B., \& Robottom, I. (2013). Critical action research and environmental education: Conceptual congruencies and imperatives in practice. In R. B. Stevenson, M. Brody., J. Dillon \& A. E. J. Wals (Eds.), International handbook of research on environmental education (pp. 469-479). New York: Routledge.

Stringer, E. T. (2014). Action research (4th ed.). New Delhi: Sage Publications.

Swadener, B., \& Mutua, K. (2008). Decolonizing performances: Deconstructing the global postcolonial. In N.K. Denzin; Y. S. Lincoln \& L. H. Smith (Eds.), Handbook of critical and Indigenous methodologies (pp. 31-43). London: Sage.

Tenywa, G. (2012). Unknown people cut down part of Mabira forest. New Vision. Retrieved from http://www.new vision.co.ug/news/628099-unknown-people-cut-down-part-of$\underline{\text { mabira-forest.html }}$

Thiele, L. P. (2013). Sustainability (iBooks Edition). Polity Press.

Tilbury, D. (1995). Environmental education for sustainability: Defining the new focus of environmental education in the 1990s. Environmenatal Education Research, 1(2), 195212.

Titchen, A. (2015). Action research: genesis, evolution and orientations. International Practice Development Journal, 5(1), 1-16.

Tuan, Y. (2013). Topophilia: A study of environmental perceptions, attitudes, and values. New York: Columbia University Press.

Tuck, E., \& McKenzie, M. (2015). Place in research: Theory, methodology, and methods. New York: Routledge.

UNESCO. (1992). Rio Declaration on environment and development. Retrieved from: http://www.unesco.org/education/pdf/RIO_E.PDF.

UNESCO, (2010). Uganda: Education for sustainable development implementation strategy. Kampala.

Vartiainen, H., \& Enkenberg, J. (2013). Reflections of design-oriented pedagogy for sustainable learning: An international perspective. Journal of Teacher Education for Sustainability, 15(1), 57-72.

Wa Thiong'o, N. (1994). Decolonising the mind: The politics of language in African literature. Nairobi: East African Publishers. 
Wane, N. N. (2000). Indigenous knowledge: Lessons from the elders-A Kenyan case study. Indigenous knowledges in global contexts: In G. J .S Dei., B. L. Hall, \& D. G. Rosenberg (Eds.), Indigenous knowledges in global contexts: Multiple readings of our world (pp. 54-69). Toronto: University of Toronto Press.

Wangoola, P. (2000). Mpambo, the African multiversity: A philosophy to rekindle the African spirit. In G.J.S Dei, B. L. Hall, \& D. G. Rosenberg (Eds.), Indigenous knowledges in global contexts: Multiple readings of our world (pp. 265-277). Toronto: University of Toronto Press.

Wattchow, B., \& Brown, M. (2011). A pedagogy of place : Outdoor education for a changing world. Victoria: Monash University Publishing.

Welcomme, R. L. (Ed.). (1988). International introductions of inland aquatic species (No. 294). Rome: Food \& Agriculture Org.

Ziltener, P., \& Künzler, D. (2013). Impacts of colonialism : A research survey. Journal of World-Systems Research, 19(2), 290-311. 


\section{APPENDICES}

\section{Appendix A: Ethics approval}

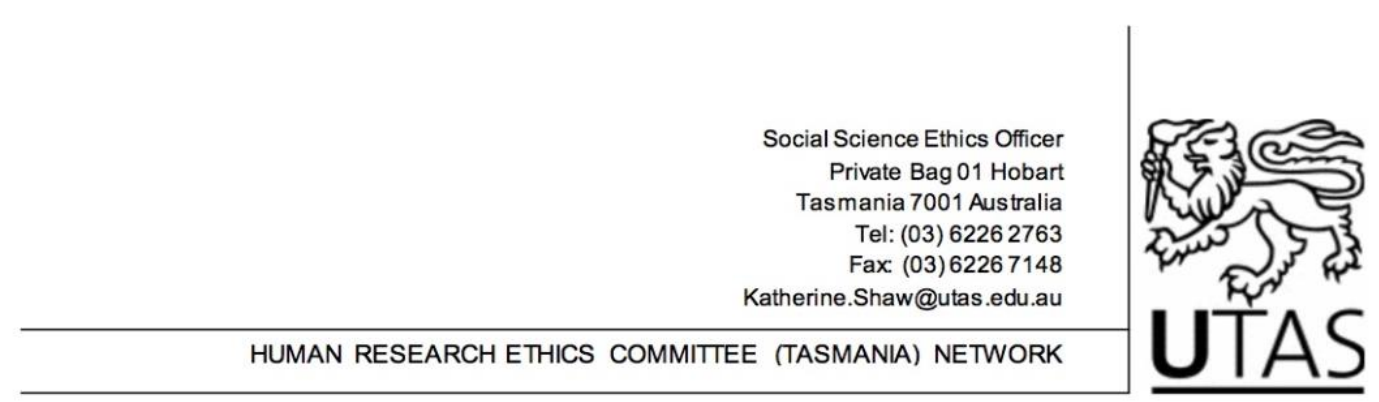

4 March 2015

Dr Allen Hill

Faculty of Education

Locked Bag 1307

Student Researcher: Kevin Kezabu

Sent via email

Dear Dr Hil

Re: FULL ETHICS APPLICATION APPROVAL

Ethics Ref: H0014612 - Intersection of Indigenous Knowledge and Place Based

Education: Possibilities for New Visions of Sustainability Education in Uganda

We are pleased to advise that the Tasmania Social Sciences Human Research Ethics Committee approved the above project on 2 March 2015.

This approval constitutes ethical clearance by the Tasmania Social Sciences Human Research Ethics Committee. The decision and authority to commence the associated research may be dependent on factors beyond the remit of the ethics review process. For example, your research may need ethics clearance from other organisations or review by your research governance coordinator or Head of Department. It is your responsibility to find out if the approval of other bodies or authorities is required. It is recommended that the proposed research should not commence until you have satisfied these requirements.

Please note that this approval is for four years and is conditional upon receipt of an annual Progress Report. Ethics approval for this project will lapse if a Progress Report is not submitted.

The following conditions apply to this approval. Failure to abide by these conditions may result in suspension or discontinuation of approval.

1. It is the responsibility of the Chief Investigator to ensure that all investigators are aware of the terms of approval, to ensure the project is conducted as approved by the Ethics Committee, and to notify the Committee if any investigators are added to, or cease involvement with, the project. 
2. Complaints: If any complaints are received or ethical issues arise during the course of the project, investigators should advise the Executive Officer of the Ethics Committee on 0362267479 or human.ethics@utas.edu.au.

3. Incidents or adverse effects: Investigators should notify the Ethics Committee immediately of any serious or unexpected adverse effects on participants or unforeseen events affecting the ethical acceptability of the project.

4. Amendments to Project: Modifications to the project must not proceed until approval is obtained from the Ethics Committee. Please submit an Amendment Form (available on our website) to notify the Ethics Committee of the proposed modifications.

5. Annual Report: Continued approval for this project is dependent on the submission of a Progress Report by the anniversary date of your approval. You will be sent a courtesy reminder closer to this date. Failure to submit a Progress Report will mean that ethics approval for this project will lapse.

6. Final Report: A Final Report and a copy of any published material arising from the project, either in full or abstract, must be provided at the end of the project.

Yours sincerely

Katherine Shaw

Executive Officer

Tasmania Social Sciences HREC

A PARTNERSHIP PROGRAM IN CONUUNCTION WITH THE DEPARTMENT OF HEALTH AND HUMAN SERVICES 
Appendix B: Information letter for headteachers

\title{
INTERSECTION OF INDIGENOUS KNOWLEDGE AND PLACE-BASED EDUCATION: POSSIBILITIES FOR NEW VISIONS OF SUSTAINABILITY EDUCATION IN UGANDA
}

\author{
INFORMATION LETTER FOR THE HEADTEACHERS
}

Dear Headteacher,

\section{Invitation:}

Your school is invited to participate in a study about the intersection of Indigenous Knowledge and place-based education as a possibility for new ways of sustainability education in Ugandan secondary schools. This study is being conducted in partial fulfilment of the requirements for the award of a Doctor of Philosophy in Education degree for Kevin Lubuulwa Kezabu under the supervision of Dr Jennifer McMahon, Dr Allen Hill and Professor David Kember of the University of Tasmania in Australia.

\section{The purpose of this study:}

The purpose of this study is to explore the use of Indigenous Knowledge as part of placebased education pedagogy to influence learners to reconnect with their communities, cultures and places. It will also investigate how community elders can contribute to place-based education in their communities.

\section{Why your School has been invited:}

Your school is hereby invited to take part in this study because you have Luganda and Oral Literature on the school curriculum. The Head of Department of Languages and Literature in your school expressed interest to join the research project which will run for the academic year 2015. The choice of your school taking part in this study is entirely voluntary. In case you decline, you will not be affected by the decision.

\section{What you will do:}

If you consent to have your school participate, the researcher will then seek the consent of the two teachers from the department of Languages and literature to work with. One will be a teacher of Oral Literature and the other will be for Luganda.

The two teachers will work alongside other teachers of Oral Literature and Luganda in five schools in other sub-counties of Mukono district. Because of their expertise, they will be co- 
participants and work as a part of a research team on this project. The teachers will attend Professional Learning Development (PLD) workshops where, through focus group discussions, all will plan how to implement place-based education in their respective schools. They will attend one workshop a term for the three terms to reflect, amend and decide on the next course of action in the implementation of place-based in the classroom. The participants will agree on the convenient day to schedule the workshop.

\section{Possible benefits for the participants:}

The main benefit in taking part in this study is that your school will be working towards exploring new and empowering pedagogies which can help teachers and students reconnect with their cultures and Buganda. Your teachers will be joining other teachers in other schools in the district to work on a project that aims to bring about positive change in your community. Secondly, the teachers will gain Participatory Action Research skills which have been shown to improve teaching practice.

\section{Possible risks:}

The researchers do not foresee any potential risks to the participants. However, in the course of the study, if the teachers feel stressed and wish to quit the study, they will be free to do so.

\section{Change of mind:}

If for any reason you think it best for your school to withdraw from this study, you do not have to give any explanation to anyone and no one will blame you for anything. However, it may not be possible to remove any data or a part of the data of your teachers' contribution from the net or from the storage bank until after a period of five years from the publication of the thesis.

\section{What will happen to the information:}

Hard copies of the field notes, audio files will be stored on the Launceston campus of the University of Tasmania in a locked cabinet accessible only by the researchers. Your teachers' names and other identifying information will be removed from these data files and replaced with codes. Computer files will be password protected and stored on a secure server at the School of Education, Launceston campus. After a period of five years from the publication of the thesis, all transcriptions and field notes will be shredded and raw audio recordings will be deleted as well. All information will be treated with utmost confidentiality.

In Uganda, electronic data will be stored on both the hard drive of the student researcher's laptop (password protected) and backed up to UTAS HDR student cloud storage. As a further back-up, the student researcher will email data to the Chief investigator/supervisor for storage on the secure UTAS network. 


\section{How the results of the study will be published:}

After the completion of the data collection at the end of 2015, the student researcher will produce a summary report of the data. The participants will be given opportunity to comment on draft versions of the same. Your school will be provided with a copy of the summary report.

Participants will be anonymous in all publications of results. Pseudonyms will be used when referring to quotes from interviews, discussions or audio recordings.

\section{Any questions about this study:}

If you have any questions relating to this study, please do not hesitate to contact any of the following researchers:

Dr Jennifer McMahon

Email: Jennifer.McMahon@utas.edu.au

Dr Allen Hill

Email: Allen.Hill@utas.edu.au

Professor David Kember

Email: David.Kember@utas.edu.au

Kevin Lubuulwa Kezabu

Email: Kevin.Kezabu@utas.edu.au

Tel: +256 778972599

Thank you for taking the time to consider this research. There is a consent form attached for you to complete should you choose to participate in the study. When you have completed the consent form, please place it in the envelope provided and seal it. The researcher will come for it at your office. This information letter is for you to keep. 


\section{Appendix C: Consent form for headteachers}

\section{INTERSECTION OF INDIGENOUS KNOWLEDGE AND PLACE-BASED EDUCATION: POSSIBILITIES FOR NEW VISIONS OF SUSTAINABILITY EDUCATION IN UGANDA}

\section{CONSENT FORM FOR HEADTEACHERS}

1. I agree that my school takes part in the research study named above.

2. I have read and understood the Information Sheet for this study.

3. The nature and possible effects of the study have been explained to me.

4. I understand that the study involves two teachers of Oral Literature and Luganda working alongside other teachers of the same subjects, and community elders in five other sub-counties in Mukono district as a co-participant. They will be attending Professional Learning Development (PLD) workshops where, through focus group discussions, they will plan how to implement place-based education in their respective schools. The study will take three terms of academic year 2015. I understand that the PLD workshops will not interfere with the teacher's duties.

5. I understand that my school's participation involves no foreseeable risk(s).

6. I understand that all research data will be securely stored on the Launceston Campus of the University of Tasmania premises for five years from the publication of the study results and will then be destroyed. In Uganda, electronic data will be stored on both the hard drive of the student researcher's laptop (password protected) and backed up to UTAS HDR student cloud storage. As a further back-up, the student researcher will email data to the Chief investigator/supervisor for storage on the secure UTAS network. Hard copies of data will be kept in a locked filing draw in the home of the student researcher and/or at the office of the Education Faculty of Uganda Christian University.

7. Any questions that I have asked have been answered to my satisfaction.

8. I understand that the researcher(s) will maintain confidentiality and that any information about the school will be used only for purposes of research. I understand that the researcher(s) will remind participants of the importance of confidentiality but cannot guarantee that other participants who will also be co-participants will maintain confidentiality such as when all participants are involved in a focus group during the Professional Learning Development workshops.

9. I understand that the results of the study will be published so that our school cannot be identified as a participant. 
10. I understand that my school participation is voluntary and that we may withdraw at any time without any effect. I also understand that it is not possible to withdraw data in case we choose to withdraw from the project.

Head Teacher's name:

Head Teacher's signature:

Date:

\section{Statement by Investigator}

I have explained the project and the implications of participation in it to this volunteer and I believe that the consent is informed and that he/she understands the implications of participation.

If the Investigator has not had an opportunity to talk to participants prior to them participating, the following must be ticked.

The participant has received the Information Sheet where my details have been provided. The participants have had the opportunity to contact me prior to consenting to participate in this project.

Investigator's name:

Investigator's signature:

Date: 


\section{Appendix D: Information letter for teachers}

UNIVERSITY of

T A S M A N I A
FACULTY OF EDUCATION

\section{INTERSECTION OF INDIGENOUS KNOWLEDGE AND PLACE-BASED EDUCATION: POSSIBILITIES FOR NEW VISIONS OF SUSTAINABILITY EDUCATION IN UGANDA INFORMATION LETTER FOR TEACHERS}

Dear Teacher,

\section{Invitation:}

You are invited to participate in a study about the intersection of Indigenous Knowledge and place-based education as a possibility for new ways of sustainability education in Ugandan secondary schools. This study is being conducted in partial fulfilment of the requirements for the ward of a Doctor of Philosophy in Education degree for Kevin Lubuulwa Kezabu under the supervision of Dr Jennifer McMahon, Dr Allen Hill and Professor David Kember of the University of Tasmania in Australia.

\section{The purpose of this study:}

The purpose of this study is to explore how teachers use Indigenous Knowledge as placebased education to influence their learners to reconnect with their communities, cultures and places. It will also investigate how community elders can contribute to place-based education in their communities.

\section{Why you have been invited:}

You have been invited to this study because of your expertise as a teacher of Oral Literature or Luganda in your secondary school. Your Head of Department expressed interest of your department to join the research project which will run for the academic year 2015. Your taking part in this study is entirely voluntary. In case you decline to take part, you or your position will not in any way be affected by the decision.

\section{What you will do:}

In this study, you will work alongside other teachers of Oral Literature and Luganda; and community elders in five other sub-counties in Mukono district. In this study, you will be a part of a research team; you will be a co-participant. You will attend Professional Learning Development (PLD) workshops where, through focus group discussions, we will plan how to implement place-based education in our respective schools. You will attend one workshop a term for the three terms to reflect, amend and decide on the next course of action in the implementation of place-based education in the classroom. Since it will be a collaborative study, the direction of the next step will be decided upon by the entire team. 
Our group discussions in the PLD workshops will be audio recorded and we will also use documents like the lesson plans and schemes of work that you may have prepared for the implementation of the plan to enhance our reflection and replanning. However, all this will only be done with your consent. All participants will be free to review and correct the transcripts. Participants will not be able to withdraw data after completing the focus group discussions.

\section{Possible benefits for the participants:}

The main benefit in taking part in this study is that you will be working towards exploring new and empowering pedagogies which can help teachers and students reconnect with their cultures and with Buganda. You will also be working as part of the team to combat a community problem and bring about positive change in your community. Secondly you will gain Participatory Action Research skills which have been shown to improve teaching practice.

\section{Possible risks:}

The researchers do not foresee any potential risks to the participants. However, in the course of the study, if you feel stressed and wish to quit the study, you are free to do so.

\section{Change of mind:}

This research project would really be complemented by your expert participation but for any reason if you deem it best to withdraw, you do not have to give any explanation to anyone and no one will blame you for anything. However, it may not be possible to remove your data or a part of the data with your contribution from the storage bank until after a period of five years from the publication of the thesis.

\section{What will happen to the information:}

Hard copies of the field notes, audio files will be stored on the Launceston campus of the University of Tasmania in a locked cabinet accessible only by the researchers. Your name and other identifying information will be removed from these data files and replaced with a code. Computer files will be password protected and stored on a secure server at the School of Education, Launceston campus. After a period of five years from the publication of the thesis, all transcriptions and field notes will be shredded and raw audio recordings will be deleted as well. All information will be treated with utmost confidentiality.

In Uganda, electronic data will be stored on both the hard drive of the student researcher's laptop (password protected) and backed up to UTAS HDR student cloud storage. As a further back-up, the student researcher will email data to the Chief investigator/supervisor for storage on the secure UTAS network.

\section{How the results of the study will be published:}

After the completion of the data collection at the end of 2016, the student researcher will produce a summary report of the data. The participants will be given opportunity to comment on draft versions of the same. You will be provided with a copy of the summary report. 
Participants will be anonymous in all publications of results. Pseudonyms will be used when referring to quotes from interviews, discussions or audio recordings. However, you can choose to have your first name if that is preferable to you.

\section{Any questions about this study:}

If you have any questions relating to this study, please do not hesitate to contact any of the following researchers:

Dr Jennifer McMahon

Email: Jennifer.McMahon@utas.edu.au

Dr Allen Hill

Email: Allen.Hill@utas.edu.au

Professor David Kember

Email: David.Kember@utas.edu.au

Kevin Lubuulwa Kezabu

Email: Kevin.Kezabu@utas.edu.au

Tel: +256 778972599

Thank you for taking the time to consider this research. There is a consent form attached for you to complete should you choose to participate in the study. When you have completed the consent form, please place it in the envelope provided, seal it and hand it to your Head of Department for the researcher to collect. This information letter is for you to keep. 


\section{Appendix E: Consent for teachers}

UNIVERSITY of

TAS MAN I A
FACULTY OF EDUCATION

\section{INTERSECTION OF INDIGENOUS KNOWLEDGE AND PLACE-BASED EDUCATION: POSSIBILITIES FOR NEW VISIONS OF SUSTAINABILITY EDUCATION IN UGANDA}

\section{CONSENT FORM FOR TEACHERS}

1. I agree to take part in the research study named above.

2. I have read and understood the Information Sheet for this study.

3. The nature and possible effects of the study have been explained to me.

4. I understand that the study involves working alongside other teachers of Oral Literature and Luganda; and community elders in five other sub-counties in Mukono district as a co-participant. I will attend Professional Learning Development (PLD) workshops where, through focus group discussions, we will plan how to implement place-based education in our respective schools. The study will take three terms of the academic year 2015. I understand that our group discussions in the PLD workshops will be audio recorded and we will also use documents like the lesson plans and schemes of work that will be prepared for the implementation of the plan to enhance our reflection and re-planning. I will be free to review and correct the transcripts.

5. I understand that participation involves no foreseeable risk(s).

6. I understand that all research data will be securely stored on the Launceston Campus of the University of Tasmania premises for five years from the publication of the study results and will then be destroyed. In Uganda, electronic data will be stored on both the hard drive of the student researcher's laptop (password protected) and backed up to UTAS HDR student cloud storage. As a further back-up, the student researcher will email data to the Chief investigator/supervisor for storage on the secure UTAS network. Hard copies of data will be kept in a locked filing drawer in the home of the student researcher and/or at the office of the Education Faculty of Uganda Christian University.

7. Any questions that I have asked have been answered to my satisfaction.

8. I understand that the researcher(s) will maintain confidentiality and that any information I supply to the researcher(s) will be used only for purposes of research. I understand that the researchers will remind participants of the importance of confidentiality but cannot guarantee that other participants who will also be coparticipants will maintain confidentiality such as when all participants are involved in a focus group during the Professional Learning Development workshops.

9. I understand that the results of the study will be published so that I cannot be identified as a participant. A Pseudonym will be used when referring to quotes from 
interviews, discussions or audio recordings. I also understand that I can choose to have my first name to be used if I so wish.

10. I understand that my participation is voluntary and that I may withdraw at any time without any effect. I understand that I will not be able to withdraw my data after completing the focus group discussions and interviews.

Teacher's name:

Teacher's signature:

Date:

\section{Statement by Investigator}

I have explained the project and the implications of participation in it to this volunteer and I believe that the consent is informed and that he/she understands the implications of participation.

If the Investigator has not had an opportunity to talk to participants prior to them participating, the following must be ticked.

The participant has received the Information Sheet where my details have been provided so participants have had the opportunity to contact me prior to consenting to participate in this project.

Investigator's name:

Investigator's signature:

Date: 


\section{Appendix F: Information letter for community elders in Luganda}

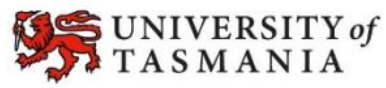

FACULTY OF EDUCATION

\section{ENKWATAGANYA Y'ENJIGIRIZA YEKINANSI NE BY'ENNONO: EMPENDA EZOKUSOMESA OKUKUUMA EMBEERA Y'ENSI ENNUNGI OKUYITIBWA OKWETABA MUKUNONYEREZA}

Ssebo / Nyabo,

Oyanirizibwa okwetaba mukunonoonyereza okukwata kunkwataganya y'enjigiriza yekinansi ne by'enonno okugezaako okufuna engeri empya ez'okukuuma embeera y'ensi enungi nga tutandikira mu masomero gaffe. Okunoonyereza kuno kutegekedwa ng'ekimu kubyetaago by'omusomo gwadiguli eyawaggulu eya mukyala Kevin Lubuulwa Kezabu nga ayambibwako abakugu bano; Dr Jennifer McMahon, Dr Allen Hill ne Professor David Kember aba Ssetendekero lye Tasmania mu Australia.

Kinajukirwa nti omulembe guno abaana baffe bawukanye nnyo n'ensi yabwe. Bulikintu ne bakissa mu katale okukitunda nga mwemuli nobutaka bwabwe.

Okunoonyereza kuno kugezaako kutangaaza engeri abasomesa gyebasobola okukozesa amagezi ag' ebyobuwaangwa ng'emu kunjigiriza ey' ebyekinansi okugezaako okugatta abayizi kumawanga gaabwe era ne kunsi yabwe. Era okunoonyereza kuno kugezaako okuzuula engeri abataka mukitundu gyebasobola okuyambamu kubyenjigiriza ye kinansi mu Buganda.

Osabiddwa okwetaba mukunoonyereza kuno olwokuba oli mutaka mu kitundu nga n'olwekyo olina obumanyirivu bungi kunnono z'abaganda era namagezi geby' obuwangwa bwa Buganda. Abasomesa mu masomero wano bebakulonze ngabakwesiga nti ojjakusobola okutuyamba mukunoonyereza kuno kulw'obumanyirivubwo. Okunoonyereza kuno kusuubirwa okumala etaamu ssatu ez'omwaka gwa bbiri kumi netaano.

Mukunoonyereza kuno, ogenda kwetaba wamu n'abataka abalala era n'abasomesa b'olulimi Oluganda mu magombolola ataano mu Mukono district. Mukunoonyereza kuno, ojakuba omu ku bakugu. Osuubirwa okwetaba mu kukubaganya ebirowoozo n'abataka abalala bataano enfunda bbiri. Era ojja kwetaba mu misomo gy'abasomesa b'olulimi Oluganda enfunda ssatu mukubaganye ebirowoozo engeri gye mu nasobola okukolera awamu okukwataganya eby'enjigiriza y'ekinansi ne by'obuwangwa mu masomero gaffe. Tujja kuba nga tukwata amaloboozi mu nsisinkano zino naye ojja kumala kusabibwa ekyo okukolebwa. Olina eddembe obutamalaako nsoma zonna. Tewali ajja ku kukaka.

Nsuubira nti ojja kuganyulwa nyo mukunoonyereza kuno kulwensonga nti ojja kuba ng'oli omu kwabo abakubye ekkubo erijja mu byenjigiriza eyekinansi ng'ate oyambye okulaga omugaso ogwokukozesa abantu abukulu/abataka mu Buganda okukolera awamu n'abasomesa abatendeke mubyengiriza mumasomero gaffe. Oluvanyumma lw'okunoonyereza kuno, ojja 
kukwasibwa akatabo ek'ebivuddemu era ojja kuba omu kwabo abayambye ennyo mu kunonyereza kuno.

Bwoba nga osiimye okwetaba mu kunoonyereza kuno, soma era teeka omukono gwo ku kiwandiko ekirala ekikuweereddwa okulaga nti tokakiddwa era nti kubadde kwagalakwo. Teeka ekiwandiiko ekyo mubaasa ekuweereddwa. Tujja kugikima okuva ewuwo.

Bw'oba ng'olina ekibuuzo kyonna ekikwatagana kukunoonyereza kuno tuukirira abakugu bano wammanga:

Dr Jennifer McMahon

Email: Jennifer.McMahon@utas.edu.au

Dr Allen Hill

Email: Allen.Hill@utas.edu.au

Professor David Kember

Email: David.Kember@utas.edu.au

Kevina Lubuulwa Kezabu

Email: Kevin.Kezabu@utas.edu.au

Tel: +256 778972599 


\section{Appendix G: Information letter for community elders in English}

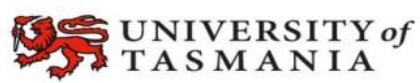

TAS M A N I A
FACULTY OF EDUCATION
INTERSECTION OF INDIGENOUS KNOWLEDGE AND PLACE-BASED EDUCATION: POSSIBILITIES FOR NEW VISIONS OF SUSTAINABILITY EDUCATION IN UGANDA

Dear Community Elder,

\section{Invitation:}

You are invited to participate in a study about the intersection of Indigenous Knowledge and place-based education as a possibility for new ways of sustainability education in Ugandan secondary schools. This study is being conducted in partial fulfilment of the requirements for the award of the Doctor of Philosophy in Education for Kevin Lubuulwa Kezabu under the supervision of Dr Jennifer McMahon, Dr Allen Hill and Professor David Kember of the University of Tasmania in Australia.

\section{The purpose of this study:}

The purpose of this study is to explore how teachers use Indigenous Knowledge as placebased pedagogy to influence their learners to reconnect with their communities, cultures and places. It will also investigate how community elders can contribute to place-based education in their communities.

\section{Why you have been invited:}

You have been invited to this study because of your role as an elder and your deep knowledge of the Kiganda cultural norms and values. The teachers in your community have confidence in your wisdom and knowledge and they specifically suggested that you could work with us on this project. It will run for the three school terms of year 2015. Your taking part in this study is entirely voluntary. In case you decline to take part, you or your relationship with the teachers will not in any way be affected by the decision.

\section{What you will do:}

In this study, you will work alongside other community elders and teachers of Oral Literature and Luganda in five other sub-counties in Mukono district. In this study, you will be a part of a research team; you will be a co-participant. You will attend focus group interviews with other community elders and be invited to Professional Learning Development (PLD) workshops where, through focus group discussions, we will all plan how to implement place-based education in our respective schools. You will attend one workshop a term for the three terms 
to reflect, amend and decide on the next course of action in the implementation of place-based education in the classroom. Since it will be a collaborative study, the direction of the next step will be decided upon by the entire team.

The focus group interviews with the other elders and group discussions in the PLD workshops will be audio recorded so that it may be easy for us to recall what we planned and therefore reflect and replan. However, all this will only be done with your consent. You will be free to review and correct the transcripts.

\section{Possible benefits for the participants:}

The main benefit in taking part in this study is that you will be exploring how you can use Indigenous Knowledge to help the teachers and the learners in your sub-county to reconnect with their communities, cultures and places so that they may develop a care for their environment. This will also be an opportunity for you to contribute to place-based education in your community.

\section{Possible risks:}

The researchers do not foresee any potential risks to you or the other participants. However, in the course of the study, if you feel stressed and wish to quit the study, you are free to do so.

\section{Change of mind:}

This research project would really be complemented by your expert participation but for any reason if you deem it best to withdraw, you do not have to give any explanation to anyone and no one will blame you for anything. However, it may not be possible to remove your data or a part of the data with your contribution from the storage bank until after a period of five years from the publication of the thesis.

\section{What will happen to the information:}

Hard copies of the field notes, audio files will be stored on the Launceston campus of the University of Tasmania in a locked cabinet accessible only by the researchers. Your name and other identifying information will be removed from these data files and replaced with a code. Computer files will be password protected and stored on a secure server at the School of Education, Launceston campus. After a period of five years from the publication of the thesis, all transcriptions and field notes will be shredded and raw audio recordings will be deleted as well. All information will be treated with utmost confidentiality.

In Uganda, electronic data will be stored on both the hard drive of the student researcher's laptop (password protected) and backed up to UTAS HDR student cloud storage. As a further back-up, the student researcher will email data to the Chief investigator/supervisor for storage on the secure UTAS network. 


\section{How the results of the study will be published:}

After the completion of the data collection at the end of 2016, the student researcher will produce a summary report of the data. The participants will be given opportunity to comment on draft versions of the same. You will be provided with a copy of the summary report.

Participants will be anonymous in all publications of results. Pseudonyms will be used when referring to quotes from interviews, discussions or audio recordings.

\section{Any questions about this study:}

If you have any questions relating to this study, please do not hesitate to contact any of the following researchers:

Dr Jennifer McMahon

Email: Jennifer.McMahon@utas.edu.au

Dr Allen Hill

Email: Allen.Hill@utas.edu.au

Professor David Kember

Email:David.Kember@utas.edu.au

Kevin Lubuulwa Kezabu

Email: Kevin.Kezabu@utas.edu.au

Tel: +256712849453 


\section{Appendix H: Consent form for community elders in Luganda}

UNIVERSITY of

TAS MAN I A
FACULTY OF EDUCATION

\section{ENKWATAGANYA Y'ENJIGIRIZA YEKINANSI NE BY'ENNONO: EMPENDA EZOKUSOMESA OKUKUUMA EMBEERA Y'ENSI ENNUNGI OKUKKIRIZA KW'OMUTAKA}

1. Nzikiriza okwetaba mukonoonyereza kuno waggulu.

2. Nsomye ebbaluwa ekwata kukunoonyereza kuno era nengitegeera.

3. Ebikwata kukunoonyereza kuno n'omugaso gw'okunoonyereza kuno binnyinyoddwa era mbitegedde.

4. Nkitegedde nti mukonoonyereza kuno, ynenda kwetaba wamu n'abataka abalala era n'abasomesa b'olulimi Oluganda mu magombolola ataano mu Mukono district. Mukunoonyereza kuno, njakuba omu kubakugu. Nsuubirwa okwetaba mu kukubaganya ebirowoozo n'abataka abalala bataano enfunda bbiri. Era njja kwetaba mu misomo gy'abasomesa b'olulimi Oluganda enfunda ssatu tukubaganye ebirowoozo engeri gyetunasobola okukolera awamu okukwataganya eby'enjigiriza y'ekinansi ne by'obuwangwa mu masomero gaffe. Nkitegedde nti amaloboozi gajja kuba nga gakwatibwa kulutambi munsisinkana zino naye njja kumala kusabibwa ekyo okukolebwa.

5. Nyinyonyoddwa nti ebinaava mukunoonyereza kuno bijja kuterekebwa ku Ssettendekero ly'eTasmania mu Australia emyaka etaano okuva akatabo lwe kanakubibwa mukyapa n'oluvannyuma bisanyizibwewo.

6. Ebibuuzo byonna byembuzizza babinzizeemu mungeri ematiza.

7. Nkitegedde nti abakugu bonna mukonoonyereza kuno bajja kwegendereza nyo obwekusifu bwebirowozo bya buli muntu yenna era ebinavaamu byonna bijja kukozesebwa mukonoonyereza kuno kwokka.

8. Nkitegedde nti ebinaava mukonoonyereza kuno bijja kukubibwa mu katabo era ebigambo byange ddala bijja kulagibwa nti byange.

9. Nkitegedde nti ennetaba yange mukonoonyereza kuno yakyeyagalire era nsobola okukyusa ebirowoozo byange nenkuvaamu wonna wenjagalira. Era nkitegedde nti bwemba nkyusizza mundowooza yange, kiyinza obutasoboka kugyayo birowoozo byange ebinaaba bikwatiddwa kulutambi.

Erinnya:

Omukono:

Olunaku: 


\section{Appendix I: Consent form for community elders in English}

\section{INTERSECTION OF INDIGENOUS KNOWLEDGE AND PLACE-BASED EDUCATION: POSSIBILITIES FOR NEW VISIONS OF SUSTAINABILITY EDUCATION IN UGANDA}

\section{CONSENT FORM FOR COMMUNITY ELDERS}

1. I agree to take part in the research study named above.

2. I have read and understood the information sheet for this study.

3. The nature and possible effects of the study have been explained to me.

4. I understand that the study involves working alongside other community elders and teachers of Oral Literature and Luganda in five other sub-counties in Mukono district. I will attend focus group interviews with other community elders and be invited to Professional Learning Development (PLD) workshops where, through focus group discussions, we will all plan how to implement place-based education in the respective schools. I will attend one workshop a term for the three terms to reflect, amend and decide on the next course of action in the implementation of place-based education in the classroom. The focus group interviews with the other elders and group discussions in the PLD workshops will be audio recorded so that it may be easy for us to recall what we planned and therefore reflect and replan. I will be free to review and correct the transcripts.

5. I understand that participation involves no foreseeable risk(s).

6. I understand that all research data will be securely stored on the Launceston campus of the University of Tasmania premises for five years from the publication of the study results, and will then be destroyed. In Uganda, during the study, electronic data will be stored on both the hard drive of the student researcher's laptop (password protected) and backed up to UTAS HDR student cloud storage. As a further back-up, the student researcher will email data to the Chief investigator/supervisor for storage on the secure UTAS network. Hard copies of data will be kept in a locked filing draw in the home of the student researcher and/or at the office of the Education Faculty of Uganda Christian University

7. Any questions that I have asked have been answered to my satisfaction.

8. I understand that the researcher(s) will maintain confidentiality and that any information I supply to the researcher(s) will be used only for purposes of research. I understand that the researchers will remind participants of the importance of confidentiality but cannot guarantee that other participants who will also be coparticipants will maintain confidentiality such as when all participants are involved in a focus group during the Professional Learning Development workshops. 
9. I understand that the results of the study will be published so that I cannot be identified as a participant. A Pseudonym will be used when referring to quotes from interviews, discussions or audio recordings. I also understand that I can choose to have my first name to be used if I so wish.

10. I understand that my participation is voluntary and that I may withdraw at any time without any effect. I understand that I will not be able to withdraw my data after completing the focus group discussions.

Community Elder's name:

Community Elder's signature:

Date:

\section{Statement by Investigator}

I have explained the project and the implications of participation in it to this volunteer and I believe that the consent is informed and that he/she understands the implications of participation.

If the Investigator has not had an opportunity to talk to participants prior to them participating, the following must be ticked.

The participant has received the Information Sheet where my details have been provided so participants have had the opportunity to contact me prior to consenting to participate in this project.

Investigator's name:

Investigator's signature:

Date: 


\section{Appendix J : Evaluation survey for the first PLD workshop}

This survey was administered to all the teachers at the end of the first PLD workshop. Although initially intended to select participants for the study, this anonymous survey helped in showing me the teachers' general attitude towards the workshop and the project. I also used this survey to find out the teachers' willingness to work with the elders and IK in their schools.

Dear teacher,

Thank you for coming to this workshop. Please take a few minutes to let us know what you think of this Professional Learning Development (PLD) workshop and about place-based education and participatory action research. Your opinion will be valued and will be used to improve future PLD workshops of this nature.

Please tick $\sqrt{ }$ in the opinion box of your choice.

\begin{tabular}{|l|l|l|l|l|}
\hline $\begin{array}{l}\text { How successful has the PLD workshop been } \\
\text { in stimulating your thinking about } \\
\text { environmental issues in Uganda? }\end{array}$ & Excellent & Good & Fair & Poor \\
\hline $\begin{array}{l}\text { How successful has the PLD workshop been } \\
\text { in stimulating your thinking about place- } \\
\text { based education? }\end{array}$ & Excellent & Good & Fair & Poor \\
\hline $\begin{array}{l}\text { How would you rate the relevance of place- } \\
\text { based education to Ugandan educators? }\end{array}$ & Excellent & Good & Fair & Poor \\
\hline $\begin{array}{l}\text { How would you rate the relevance of } \\
\text { participatory action research to your } \\
\text { professional life? }\end{array}$ & Excellent & Good & Fair & Poor \\
\hline $\begin{array}{l}\text { Would you recommend your school to take } \\
\text { part in the research study on place-based } \\
\text { education? }\end{array}$ & Yes & No & Not sure & \\
\hline
\end{tabular}

Please explain the kind of presenter that impacted on your professional development

What worked well for you in the workshop? Why do you say so?

Please advise on any shortcomings that you feel need to be improved in the next workshop.

Thank you so much for working with us 


\section{Appendix K: Observation guide for teachers' lessons}

This observation guide was used by the student researcher plus all the co-participant teachers for the various class observations that we all were involved in for this project. Often, this guide helped to show the teachers what to look for while during the class observations and the teachers referred to the same in the weekly discussions.

Names of Participants:

1.

2 .

Date of Observation:

School:

Class of Observation:

What IK activity is observed taking place?

What is the procedure of this event?

In what way does it call on the participants' reconnection to their community and culture?

How do the elders/ teachers involve the learners in the activity?

What students' responses are observed during this lesson?

What other participants' responses are observed during this activity?

Any additional comments about this event? 


\section{Appendix L: Interview guide for discussions/reflections after IK lessons}

I used this interview guide for the group discussions/interviews that were held after every IK lessons at the participating schools. Even though originally prepared for only the participant teachers, elders also attended and contributed richly to the discussions.

Place of group interview:

Date of group interview:

1. Tell us what you did in your class today.

2. Basing on the previous PLD plan, what went well in these lessons?

3. What challenges have you encountered in implementing place-based pedagogy in your class?

4. How best can you overcome them?

5. Do you feel that the PLD workshop discussions and planning helped you in the implementation of the place- based pedagogy in your lessons?

6. How are your students reacting to place-based pedagogy? What changes in your students' learning have you noticed?

7. Are there instances when you feel students' prior knowledge of their Indigenous Knowledge and experiences are supported by place-based education?

8. How well do you think place-based education meets your students' needs?

9. How do you find working with the community elders?

10. How has place-based education been received by others?

11. How do you feel about this research project in general?

Thanks for your time 


\section{Appendix M: Interview guide for the weekly Nyama Kyoma teachers' meetings}

I used this interview guide during the co-participant teachers' weekly meetings/discussions. These discussions mainly helped the teachers to reflect on how to integrate the IK that they had gained during the IK lessons into their teaching.

Place of Discussion:

Date of Place of discussion:

1. What IK activity are we discussing tonight?

2. Please describe the things that stood out for you during the elder's IK lesson (i.e. about the river, the plants, the historical narratives). Does anyone want to share their diary entries on any of this?

3. What went well in these lessons? Does anyone want to share any of their students' work with us?

4. How are your students reacting to place-based pedagogy? What changes in your students' learning have you noticed due to this IK activity? Does anyone want to share any documents (i.e lesson plans or schemes of work), diary entries or students' work with us?

5. What challenges have you encountered in implementing place-based pedagogy in your teaching?

6. How best can we overcome the challenges?

7. Can we now discuss how we can bring this activity into the curriculum?

8. Can we now discuss about next week's class observation arrangements?

9. Does anyone want to suggest anything else regarding our progress or the project?

Thanks for coming today 


\section{Appendix N: Interview guide for first group interview with community elders}

I used this interview guide during the first group interview/discussion with the community elders prior to the first PLD with the teachers. During this group interview/discussion, the elders also chose the areas of IK preference that they would facilitate in the schools for this research.

Community elders present:

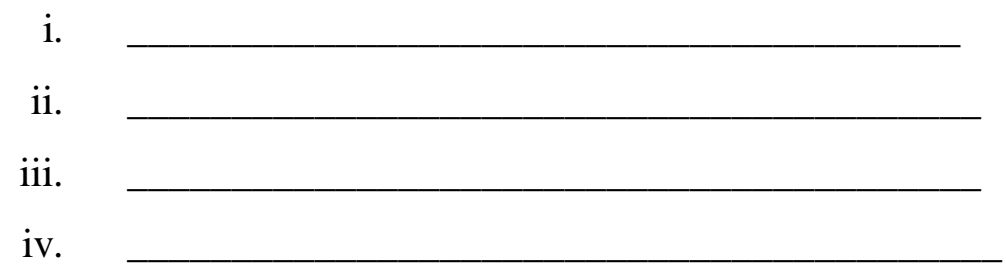

Place of Interview:

Date of Interview:

Thank you for coming for this focus group interview.

1. As elders in Buganda, can each one please tell us a little about themselves?

2. Please explain about your role in your clan at present.

3. How does your role today differ from the role of the elders during your father's time?

4. What do you think is the cause of this difference?

5. What do you think about formal education today in relation to people's attachment to their cultures?

6. What can you say about young people's attachment to their land or to Buganda?

7. Do you think it is for better or for worse? Why is that so?

8. What do you think are some of the norms in Buganda that have greatly been neglected and why?

9. Now that you have the chance to work with formal educators, what strategies can you use to reclaim the hearts of today's young generation towards Buganda and the Kiganda norms?

Thank you for your time 


\section{Appendix O: Interview guide for the last group interview with community elders}

This interview guide was used for my last group interview/discussion with the participant community elders at Bulange Mmengo. The interview/discussion was intended for the participant community elders to reflect, and discuss their views on their contribution to the study and whether they thought their traditional role of passing on knowledge was redefined by working with the teachers in educating the young about their cultures and places.

Community elders present:

i.

ii.

iii.

iv.

Place of Interview:

Date of Interview:

Thank you for coming for our final focus group interview.

1. Please explain what your role has been in this research project?

2. Can you describe the activities you have carried out with the teachers and students during this project?

3. Do you think in this project you have made a difference in the young people's knowledge and attachment to Buganda? Why do you say so?

4. What part of your contribution do you think the students and teachers enjoyed best? Why do you say so?

5. How do you find working with teachers and students? Do you think you will be able to continue this partnership?

6. What part of the project did you enjoy best and why?

7. What challenges have you encountered in this project?

8. How best can we address these challenges?

9. Is there something else anyone wants to share with us to improve this kind of education?

Thank you so much for your time 
Appendices 